UNIVERSIDADE DE SÃO PAULO

INSTITUTO DE ASTRONOMIA, GEOFÍSICA E CIÊNCIAS ATMOSFÉRICAS

JÔNATAN DUPONT TATSCH

Uma ANÁlise dos Fluxos de Superfície E do Microclima SOBRE CERRADO, CANA-DE-AÇÚCAR E EUCALIPTO, COM IMPLICAÇÕES PARA MUdANÇAS ClimÁTICAS REgIONAIS 
JÔNATAN DUPONT TATSCH

\section{UMA ANÁlise dos FluXos de Superfície E do MiCROClima SOBRE CERRADO, CANA-DE-AÇÚCAR E EUCALIPTO, COM IMPLICAÇÕES PARA MUdANÇAS ClimáticAS REGIONAIS}

Dissertação apresentada ao Instituto de Astronomia, Geofísica e Ciências Atmosféricas, para obtenção do título de Mestre em Ciências.

Área de Concentração: Meteorologia

Orientador: Prof. Dr. Humberto Ribeiro da Rocha

v. 2

SÃO PAULO

2006 
A minha mãe Astéria Dupont Tatsch com admiração, amor e gratidão. 


\section{AGRADECIMENTOS}

Aos meus pais pela formação moral, incentivo e pelo exemplo de vida; a minha irmã "Dadá" por estar sempre ao meu lado me apoiando.

Ao tio Turíbio Soares que me incentivou a continuar estudando e me apoiou desde o primeiro momento em São Paulo. A tia Alice Dupont Soares que me ajudou sempre que precisei com muita disposição e agilidade, principalmente com os artigos.

Meu especial agradecimento à minha "Paixão" Nathalie T. Boiaski, por sua compreensão, companheirismo, carinho e apoio que foi fundamental nesta etapa de minha vida.

Ao meu grande amigo e companheiro Ricardo Acosta por compartilhar seus conhecimentos através de nossas discussões e descontrações, dia a pós dia ou noite após noite. Sua presença foi valiosa durante todo o mestrado.

Minha gratidão ao Professor Dr. Humberto Ribeiro da Rocha pela confiança em mim depositada. Sua orientação didática, compreensão, serenidade e visão científica permitiram o desenvolvimento desta dissertação e das idéias contidas nestas páginas.

Ao Dr. Osvaldo Cabral pela ajuda essencial e constante ao longo do trabalho, principalmente na familiarização com os dados experimentais utilizados. As discussões durante as viagens de campo foram preciosas e me ajudaram a compreender um pouco mais das dificuldades inerentes de medidas micrometeorológicas.

A Pr. Dra Leila M. Vespoli de Carvalho por sua disposição e boa vontade em discutir alguns resultados na etapa final deste trabalho, o que me estimulou muito e me levou a novas direções.

A todos meus colegas de curso de mestrado, em especial a: Igor Cerqueira, Mariana Palagano e Maria Cristina Lemos pelo companheirismo e pelos momentos que compartilhamos durante o curso.

Aos meus amigos Paulistas Hélber C. de Freitas e Eduardo G. Lopes pela dinâmica no dia-a-dia do LCB e pelo exemplo de profissionalismo. Ao esforço da equipe de Campo (Helber+Eduardo+Osvaldo Cabral+Marco Ligo) que está por trás de toda estrutura de coleta de dados, manutenção, testes de instrumentos, construção e logística das torres.

Ao Prof. Dr. Edmilson Dias de Freitas que já me ensinava muito antes de ser professor. Também por revisar grande parte desta dissertação no último relatório do departamento, compensando os anteriores; e pela ajuda em vários momentos. 
Ao Msc. Éder Vendrasco pela nova amizade e por sua paciência e boa vontade em me ensinar a utilizar algumas linguagens de programação.

A Pra. Dra. Maria Elisa Siqueira Silva (FFLCH) pela amizade e ajuda no tratamento de dados de precipitação do estado de SP.

Aos colegas de laboratório (Rogério, Leuda, Tannus e Marta), e aos amigos Ricardo Hallak, Michel Muza e Vagner Anabor pela colaboração e ajuda em vários momentos.

Ao Departamento de Ciências Atmosféricas da USP pela oportunidade de realização do curso de mestrado e a todos os professores com os quais muito aprendi.

À FAPESP pelo suporte financeiro desta pesquisa através do auxílio 03/10004-1.

Aos técnicos e analistas de informática do Departamento de Ciências Atmosféricas: Sebastião, Fagner, Luciana e Samuel, pelo suporte essencial e as funcionárias (os) das secretarias e da Biblioteca pela presteza.

A minha querida amiga Michele Reboita, sempre disposta a me ajudar.

A meus sogros pelo apoio e amizade.

Agradeço aos professores do Laboratório de Micrometeorologia - UFSM, em especial ao Pr. Dr. Otávio Costa Acevedo, quem me introduziu nesta linha de pesquisa, pelo estímulo e impulso para realização do mestrado no IAG/USP.

Aos vigias da portaria pelos cafés durante as pernoitadas no IAG, em especial a: Valdomiro e Tiago.

À Deus.

A todos os amigos que de alguma maneira sempre estiveram presentes e ajudaram direta ou indiretamente no desenvolvimento desta dissertação. 


\section{RESUMO}

Este trabalho investiga as potenciais mudanças de temperatura e precipitação em escala regional no estado de São Paulo, decorrentes das mudanças do uso da terra. Realizou-se a análise de um conjunto de observações micrometeorológicas no período de fevereiro de 2005 a fevereiro de 2006, sobre áreas de cerrado, cana-de-açúcar e eucalipto. O balanço de energia no cerrado indicou que o saldo de radiação foi maior que sobre a cana-de-açúcar, devido principalmente ao maior albedo e perda de radiação de onda longa na cana. No eucalipto o saldo de radiação foi semelhante ao do cerrado. A partição de energia no cerrado e na cana-de-açúcar diferiu marcadamente nos quatro meses após a colheita, quando a razão de Bowen e o fluxo de calor no solo foram maiores na cana-de-açúcar. No período úmido o eucalipto destacou-se com maior evapotranspiração $\left(5,2 \mathrm{~mm} \mathrm{dia}^{-1}\right)$ do que no cerrado e na cana-de-açúcar $\left(3,1\right.$ e 2,5 $\mathrm{mm} \mathrm{dia}^{-1}$, respectivamente). Apesar disso, o eucalipto foi a área mais sensível à condição de estresse hídrico, reduzindo a evapotranspiração em maior proporção no final de agosto. A temperatura máxima diária (Tmax) sobre o cerrado foi menor que sobre cana-de-açúcar (de 1,3 a $2{ }^{\circ} \mathrm{C}$ ) e maior do que sobre o eucalipto (de 0,5 a $1,3{ }^{\circ} \mathrm{C}$ ), consistente com a comparação da partição de energia na maior parte do ano. A temperatura mínima diária (Tmin) sobre o cerrado foi maior que sobre a cana de-açúcar (por até $3{ }^{\circ} \mathrm{C}$ ) e maior do que sobre o eucalipto (por até $1{ }^{\circ} \mathrm{C}$ ).

Também foram analisadas as séries históricas de precipitação e temperatura do ar (Tmax e Tmin) em Ribeirão Preto e Campinas no período de 1943 a 2000, sugerindo em ambas uma oscilação decadal marcada por uma fase quente (da Tmax) e seca (da chuva), entre 1943-1965, seguida de uma fase úmida e Tmax levemente fria, até 2000. Este padrão mostrou-se semelhante a variabilidade da Oscilação decadal do Pacífico, portanto um controle de variabilidade natural de grande escala. A Tmin média anual mostrou um aumento significativo nos últimos 58 anos, apesar de alguns anos relativamente frios na década de 1980, particularmente em Ribeirão Preto. Nas últimas duas décadas a persistência de anomalias quentes da Tmin foi marcante, consistente com as tendências globais, possivelmente devido a intensificação do efeito estufa. Entretanto, há evidências de que a crescente urbanização pode ter influenciado o sinal das estações, baseado na comparação com a variabilidade das reanálises do NCEP/DOE. O efeito da urbanização é mais provável em Campinas devido a três fatores: localização em relação a mancha urbana, regime local dos ventos e grande aumento populacional entre 1950 e 2000. Considerando que a cana substituiu o cerrado no último século e baseado na comparação do microclima em cada ecossistema, sugere-se que as mudanças de uso da terra associadas à expansão da cana-de-açúcar não explicam a variabilidade de longo prazo da temperatura. Apesar desta falta de evidência, verificou-se uma tendência de resfriamento da Tmax, significativa somente no inverno, que poderia ser resultante das queimadas de cana-de-açúcar. 


\begin{abstract}
This work investigates potential regional scale temperature and precipitation changes in the São Paulo state, caused by land use changes. We analised micrometeorological measurements, in the period February 2005 to February 2006, over three different ecosystems (cerrado, sugar cane and eucalyptus plantation). The surface energy balances showed that over the cerrado the net radiation was larger than for sucar cane, mostly due to a larger albedo and long wave radiation loss. The net radiation was similar between the cerrado and eucalyptus. The energy partition over the cerrado and sugar cane differed markedly during the first four months after sugar cane's harvest, when the Bowen ratio and soil heat flux were both higher over the latter area. During the wet period, was evapotranspiration over eucalyptus appeared remarkably larger $\left(5,2 \mathrm{~mm}\right.$ day $\left.^{-1}\right)$, compared to the cerrado and sugar cane $\left(3,1\right.$ e $2,5 \mathrm{~mm}^{-1}{ }^{-1}$, respectively). Despite that, the eucalyptus area was the most sensitive to soil water stress conditions, where the largest reduction in evapotranspiration was observed at the end of August. The daily maximum temperature (Tmax) over the cerrado was lower than over the sugar cane (from 1,3 to $2{ }^{\circ} \mathrm{C}$ ) and larger than over eucalyptus (from 0,5 to $1,3{ }^{\circ} \mathrm{C}$ ), concurrent with the comparisons of energy partitioning during most of the year. The daily minimum temperature (Tmin) over cerrado site was larger than over the sugar cane (up to $3{ }^{\circ} \mathrm{C}$ ) and over eucalyptus (up to $1{ }^{\circ} \mathrm{C}$ ).

Time series of precipitation and air temperature (Tmax and Tmin), in Ribeirão Preto and Campinas cities, were further analyzed, in the 1943 to 2000 period, and suggested over both stations a decadal oscillation marked by warm phasis (in Tmax) and dry phase (in precip), in the sub-period 1943-1965, followed by an wet phase (in precip) and slightly cold phase (of Tmax) up to 2000. This pattern appeared to be similar to the Pacific Decadal Oscillation variability, thus likely to be controlled by a large scale natural variability. The annual mean Tmin showed a significant increasing trend in the last 58 years, despite of some cold years during 1980's, particularly in Ribeirão Preto city. In the last two decades $(1980$ - 2000) the persistence of warm Tmin anomalies was more clearly noticed, concurrent with global mean temperature trends, likely arising from the enhancement of the greenhouse effect. However, we found evidences that increasing urbanization could have affected the measurements over the meteorological weather stations, based on comparisons with NCEP/DOE reanalysis data variability. The urbanization effect is most likely in the Campinas city, partly to three factors: station is localized close to the urban spot area, local wind regimes, and substantial population growth between 1950 to 2000 . Hypothesizing that the sugar cane plantations replaced, in the last 30 years, the primitive cerrado areas that existed in the early 20th century, and comparing the microclimate over both ecosystems, it is suggested that the land use changes associated to sugar cane plantation does not
\end{abstract}


explain the long term temperature variability observed in the weather stations. However, the seasonal trends of Tmax appeared to decrease in the last 30 years, during the winter season, what could be caused by the increasing sugar cane burning emission. 


\section{LISTA DE FIGURAS}

Figura 1.1. Mapa da área ocupada por cana-de-ácucar no estado de SP. Parte superior: regiões pontilhadas identificam o avanço dos canaviais em áreas antes dominadas pela laranja e pecuária. A região de Ribeirão Preto é destacada em vermelho. Parte inferior: em 1988 a mancha das lavouras de cana-de-açúcar ocupava $8616 \mathrm{~km}^{2}$ (23\% da área agrícola da região), enquanto que em 2003 atingiu $18297 \mathrm{~km}^{2}$ (50\% da área agrícola da região). Fonte: Centro de Tecnologia Canavieira, Embrapa - Monitoramento por Satélite e Associação Brasileira de Agrobusines (ABAG).

Figura 1.2. Valores de Evapotranspiração $\left(\mathrm{mm} \mathrm{dia}^{-1}\right)$ reportados para várias espécies de eucalipto e épocas do ano. Os valores são médias sazonais (pontos) ou a amplitude de variação (hastes). As abreviações para os métodos utilizados são: EC - Eddy Covariance, PM Equação de Penman-Monteith, L -lisímetros, PC - Pulso de calor, SF - Sap Flow, FG Fluxo gradiente, BE - Balanço de energia.

Figura 1.3. Série temporal de anomalias de temperatura em relação ao período de 1961-90 (barras) para uma temperatura média anual global de $14^{\circ} \mathrm{C}$ e para uma concentração média de $\mathrm{CO}_{2}$ de 334 ppmv (curva sólida) durante o período base, usando dados de amostras de ar contido em núcleos de gelo (antes de 1958) e de Mauna Loa a partir de 1958 (Adaptado de Karl \& Trenberth 2003).

Figura 2.1.1 (a) Localização dos sítios experimentais, estações meteorológicas mais próximas e topografia da região com resolução de $90 \mathrm{~m}$ (dados do USGS). A variação de altitude (m) é indicada à direita pela escala de cinza. (b) imagem realçada do satélite LANDSAT-5 da cobertura vegetal da região. Fonte: Projeto CANASAT, imagem referente à safra 2005/06 (disponível em http://www.dsr.inpe.br/mapdsr/)............................................................12

Figura 2.1.2.Crescimento da cana-de-açúcar (cortada em 14/04/2005) durante o ciclo 2005/2006 em Luiz Antônio, SP.Com dados de Cabral et al. (2006).A escala superior indica o número de dias após o corte da cana (DAC).

Figura 2.4.1. Número de estações pluviométricas do DAEE, no estado de SP, ao norte de $22^{\circ} \mathrm{S}$, no setor Oeste do estado, entre 49 e $52^{\circ} \mathrm{W}$, e no setor Leste do estado, entre $46^{\circ}$ e $49^{\circ} \mathrm{W}$.

Figura 2.4.2. Série da temperatura máxima (superior) e mínima (inferior) média anual das estações meteorológicas do IAC de (a) Campinas e (b) Ribeirão Preto. A linha vermelha representa a reta de regressão ajustada para os diferentes segmentos das séries. Anos com mais de $10 \%$ de dados faltantes não são plotados. As setas em azul localizam os pontos onde as mudanças abruptas foram estatisticamente significativas (N.S. $<5 \%$ ).

Figura 3.1.1. Precipitação acumulada em cinco dias (mm pentada $\left.{ }^{-1}\right)$ no (a) cerrado, (b) eucalipto e (c) cana. Barras negativas indicam ausência de dados. Período de 1/01/2005 a 6/02/2006. 
Figura 3.1.2. Variação das médias diárias da (a) pressão atmosférica (Patm), em hPa, e (b) da velocidade do vento $(\mathrm{U}) \mathrm{em} \mathrm{m} \mathrm{s}^{-1}$ no cerrado, eucalipto e na cana. A precipitação em $\mathrm{mm}$ dia $^{-1}$ (Prec) é mostrada na escala a direita de (a). Os dados são mostrados para o período de $7 / 02 / 2005$ a 6/02/2006 para a cana e o cerrado, e de 22/07/2005 a 06/02/2006 para o eucalipto. 30

Figura 3.1.3. Idem Fig. 3.1.2, porém para (a) temperatura média diária (Tmed) em ${ }^{\circ} \mathrm{C}$, (b) amplitude térmica diária (ATD) em ${ }^{\circ} \mathrm{C} \mathrm{e} \mathrm{(c)} \mathrm{umidade} \mathrm{específica} \mathrm{(q)} \mathrm{em} \mathrm{g} \mathrm{Kg}^{-1}$. As linhas sólidas representam uma média móvel de 21 dias. .32

Figura 3.1.4. Variação sazonal dos totais diários de (a) irradiância solar global incidente (Ki), em $\mathrm{MJ} \mathrm{m} \mathrm{m}^{-2} \mathrm{dia}^{-1}$, e precipitação (Prec) em $\mathrm{mm} \mathrm{dia}^{-1}$ (escala a direita); (b) saldo de radiação (Rn) em $\mathrm{MJ} \mathrm{m}^{-2} \mathrm{dia}^{-1}$, no cerrado, eucalipto e na cana. As linhas sólidas representam uma média móvel de 21 dias. Os dados são mostrados para o período de 7/02/2005 a 6/02/2006 para cana e o cerrado, e de 22/07/2005 a 06/02/2006 para o eucalipto.

Figura 3.1.5. Variação das médias diárias de (a) albedo solar, (b) albedo RFA (ambos em \%) no cerrado e eucalipto, (c) albedo solar e (d) albedo RFA, ambos na cana. Os dados são mostrados para o período de 7/02/2005 a 6/02/2006 para a cana e o cerrado, e de $22 / 07 / 2005$ a 06/02/2006 para o eucalipto. A linha pontilhada indica a data da colheita. A precipitação em $\mathrm{mm} \mathrm{dia}^{-1}$ (Prec) é mostrada na escala inferior a direita de (a) e (c). A variação da altura da cana (m) é mostrada na escala a direita em (d), dados de Cabral et al (2006)

Figura 3.1.6. Fotografias do cerrado para diferentes épocas do período de estudo. As datas são especificadas abaixo de cada imagem. Fonte: Laboratório de Clima e Biosfera, IAG/USP.

Figura 3.1.7. Variação sazonal dos totais diários de evapotranspiração (LE), fluxo de calor sensível $(\mathrm{H})$ e do fluxo de calor no solo $(\mathrm{G})$, ambos em MJ m${ }^{-2}$ dia $^{-1}$, no cerrado (a,e), cana $(b, f)$ e eucalipto $(c, g)$. Os círculos em cinza representam G. (d) Temperatura máxima e (h) mínima nas três áreas experimentais. Rn e LE também são representados por uma média móvel de 21 dias, linha em laranja e destacada em verde, respectivamente, para cada sítio experimental. $\mathrm{O}$ mesmo procedimento foi aplicado aos dados de temperatura. Os dados são mostrados para o período de 7/02/2005 a 6/02/2006 para a cana e o cerrado, e a partir de $22 / 07 / 2005$ até $06 / 02 / 2006$ para o eucalipto. .41

Figura 3.1.8. Variação sazonal da Razão de Bowen $(\beta)$ média diurna (6 - 18 h), no cerrado, cana e eucalipto. As linhas destacadas em vermelho (cerrado), preto (cana) e azul (eucalipto), representam uma média móvel de 21 dias. Os dados são mostrados para o período de 7/02/2005 a 6/02/2006 para a cana e o cerrado, e a partir de 22/07/2005 até 06/02/2006 para o eucalipto. .42

Figura 3.1.9 Ciclos diurnos obtidos a partir dos valores médios de 30 minutos das variáveis 
climáticas: (a) déficit da pressão de vapor (DPV) em $\mathrm{kPa}$, (b) temperatura do ar (T) em ${ }^{\circ} \mathrm{C}$, (c) umidade específica (q, eixo a esquerda) em $\mathrm{g} \mathrm{Kg}^{-1}$ e umidade relativa (UR, eixo a direita) em \%, (d) velocidade do vento (U) $\mathrm{em} \mathrm{m} \mathrm{s}^{-1}$, (e) velocidade de atrito (u*) $\mathrm{em} \mathrm{m} \mathrm{s}^{-1}$, para o período úmido (Fev) de 2005, transição úmido-seco (Mar - Mai), período seco (Jun - Ago), transição seco-úmido (Set - Nov) e período úmido (Dez - Fev) de 2006. O eixo x corresponde à hora local.

Figura 3.1.10. Condições típicas (a) noturnas e (b) diurnas, na estação seca sobre a cana e o cerrado. Os valores médios apresentados são referentes ao período noturno $(21-4 \mathrm{hs}) \mathrm{e}$ diurno $(9-16 \mathrm{hs})$. A irradiância de onda longa incidente (Li) foi estimada através da equação $\mathrm{Li}=\sigma \mathrm{T}^{4}\left(0,51+0,066 e^{1 / 2}\right)$ (Brunt, 1932), onde $e$ é a pressão de vapor d'água. A irradiância de onda longa emergente (Le) foi estimada como resíduo do balanço de radiação $(\mathrm{Rn}=\mathrm{Ki}+\mathrm{Kr}+\mathrm{Li}+\mathrm{Le})$. As unidades dos fluxos radiativos estão em $\mathrm{Wm}^{-2}$.....49

Figura 3.1.11. Idem a Fig. 3.1.10, porém para o período úmido.

Figura 3.1.12. (a) Histograma da velocidade do vento noturna ( $19-6$ h) na cana e no cerrado.(b) Influência da velocidade do vento sobre as medidas de temperatura na cana e no cerrado à noite. Os pontos em azul (vermelho) referem-se aos dados de 30 minutos de temperatura em todo período (outubro de 2005 a fevereiro de 2006). Foram selecionados somente os casos em que não ocorreu precipitação. As classes de velocidade do vento foram definidas na forma de tercentis: ventos relativamente calmos, moderados e fortes, representados pelas letras $\mathrm{C}, \mathrm{M}$ e $\mathrm{F}$, respectivamente (maiúsculas para a cana e minúsculas para $\mathrm{o}$ cerrado).

Figura 3.2.1. (a) Climatologia anual da precipitação para SP. (b) Campo de altitude para SP com resolução de $1 \mathrm{~km}$ (Dados do USGS). A escala de cores está em metros...

Figura 3.2.2. Pluviograma médio mensal (em mm), calculado em 320 estações do DAEE/SP, no setor Oeste (preto) e no setor Leste (azul) do centro-norte de SP (latitude acima de $22^{\circ} \mathrm{S}$ ), no período de 1940-2000. 53.

Figura 3.2.3. Séries das anomalias absolutas anuais de precipitação em relação ao período de 1940-1999, no eixo y a direita (ou total anual no eixo a esquerda) nos setores (a) Oeste e (b) Leste de SP. As linhas sólidas em cinza representam a série suavizada pela função loess (regressão polinomial ponderada localmente, Cleveland 1979). 55

Figura 3.2.4. Séries das anomalias absolutas anuais de Precipitação em relação ao período de 1943-2000, no eixo y à esquerda (ou total anual no eixo à direita) em (a) Campinas e (b) Ribeirão Preto. As linhas sólidas em cinza representam a série suavizada pela função loess. 
Figura 3.2.5. (a) Totais anuais de precipitação em Campinas no período de 1890-2000 e nos setores Leste e Oeste de SP, a partir de 1940. (b) Série temporal do índice da Oscilação Decadal do Pacífico no período de 1900-2000 (com dados de Mantua et al. 1997, disponíveis em http://www.atmos.washington.edu/ mantua/abst.PDO.html). (c) Anomalias absolutas da precipitação anual de Campinas em relação ao período de 1890-2000 (eixo y a esquerda). A escala a direita no eixo y corresponde à série desta anomalia acumulada no tempo (linha vermelha). As outras linhas sólidas representam as séries suavizadas pela função loess. .59

Figura 3.2.6. Séries das anomalias anuais absolutas de temperatura (eixo y à direita) em relação ao período de 1943-2000 (ou média anual no eixo à esquerda). (a) Tmax, (b) Tmin e (c) ATD em Ribeirão Preto. (d) Tmax, (e) Tmin e (f) ATD em Campinas. As linhas sólidas em cinza representam a série suavizada pela função loess. 61

Figura 3.2.7. Séries das anomalias absolutas trimestrais de temperatura máxima (eixo y à direita) em relação ao período de 1943-2000 (ou média trimestral no eixo à esquerda). (a-d) Ribeirão Preto, (e-h) Campinas. As linhas sólidas em cinza representam a série suavizada pela função loess. Em cada gráfico o trimestre correspondente é indicado na parte superior a direita.

Figura 3.2.8. Séries das anomalias absolutas trimestrais de temperatura mínima (eixo y à direita) em relação ao período de 1943-2000 (ou média trimestral no eixo à esquerda). (a-d) Ribeirão Preto, (e-h) Campinas. As linhas sólidas em cinza representam a série suavizada pela função loess. Em cada gráfico o trimestre correspondente é indicado na parte superior a direita. .65

Figura 3.2.9. Séries das anomalias absolutas trimestrais da Amplitude térmica diária (eixo y à direita) em relação ao período de 1943-2000 (ou média trimestral no eixo à esquerda). (ad) Ribeirão Preto, (e-h) Campinas. As linhas sólidas em cinza representam a série suavizada pela função loess. Em cada gráfico o trimestre correspondente é indicado na parte superior a direita.

Figura 3.2.10. Localização das cidades de (a) Ribeirão Preto e (b) Campinas em relação a área ocupada com cana-de-açúcar atualmente. O perímetro urbanizado das cidades é destacado em vermelho e a posição das estações em azul.

Figura 3.2.11. (a)Anemograma diurno e (b) noturno da estação meteorológica de Campinas com dados no período 2000-2003. (c) Anemograma diurno e (d) noturno observado em Sertãozinho no período 1997-1998 (Fonte: Rocha, 1998).

Figura 3.2.12. (a) Evolução populacional do município de Campinas (linha sólida) e variação da ATD média por década (linha pontilhada) no período de 1950 a 2000. (b) Mesmo que em (a) porém para Ribeirão Preto. A escala a direita está invertida, ou seja a ATD decresce. Dados populacionais do IBGE, censos demográficos de 1940 a 2000, disponível em http://www.ibge.gov.br/cidadesat/. .68

Figura 3.2.13. Anomalias mensais de temperatura (em relação ao período de 1979-2000) dos 
dados observados e R-2 em Ribeirão Preto. (a) Temperatura máxima, (b) temperatura mínima e (c) amplitude térmica diária. Uma média móvel de 3 meses é aplicada para suavização das curvas. O coeficiente de correlação entre os dois conjuntos de dados (sem suavização) é mostrado. A tendência para os dados observados (R-2) é representada pela

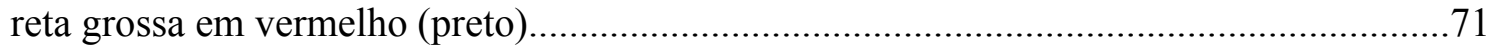

Figura 3.2.14. Idem a Fig. 3.2.13, porém para Campinas..........................................................

Figura 3.2.15. Séries de RW de (a) precipitação, (b) ATD, (c) Tmax e (d) Tmin. As linhas em vermelho (preto) referem-se aos dados de Ribeirão Preto (Campinas). 


\section{LISTA DE TABELAS}

Tabela 2.1.1. Datas da colheita e de outros eventos notáveis para o sítio da cana durante o período de observação.

Tabela 2.2.1. Descrição das variáveis medidas (nome e símbolo utilizado no texto), instrumentação e geometria de instalação, nos sítios experimentais de Cerrado, Cana e Eucalipto.

Tabela 3.1.1. Totais mensais de precipitação $(\mathrm{mm})$ observados nas 3 áreas e normais climatológicas da região no período de 1961-1990. Os valores acima da normal estão em negrito. Os cinco períodos definidos foram: úmido ( $\mathrm{Fev}$ de 2005), transição do período úmido para seco (Mar - Mai 2005), seco (Jun - Ago 2005), transição do período seco para úmido (Set - Nov 2005) e úmido (Dez 2005 - Fev 2006).

Tabela 3.1.2. Valores médios da umidade específica (q) em $\mathrm{g} \mathrm{Kg}^{-1}$, umidade relativa (UR) em \% e velocidade do vento (U) em $\mathrm{m} \mathrm{s}^{-1}$, na cana (Can), cerrado (Cer) e eucalipto (Euc). ND indica a ausência de dados. Os valores sombreados do teste t-student indicam se as médias comparadas são estatisticamente diferentes para o nível de significância (N.S.) $<5 \%$.

Tabela 3.1.3. Totais diários da irradiância solar incidente (Ki), saldo de radiação $(\mathrm{Rn})$ e fluxo de calor no solo $(\mathrm{G})$, todos em $\mathrm{MJ} \mathrm{m}^{-2} \mathrm{dia}^{-1}$; albedo solar $(\alpha)$ em \%, na cana (Can), cerrado (Cer) e eucalipto (Euc). ND significa ausência de dados. Os valores sombreados do teste tstudent indicam se as médias comparadas são estatisticamente diferentes para o N.S $<5 \%$.

Tabela 3.1.4. Idem a tabela 3.1.3 porém para: fluxo de calor sensível (H), calor latente (LE), fluxo de calor no solo $(\mathrm{G})$, ambos em $\mathrm{MJ} \mathrm{m}^{-2} \mathrm{dia}^{-1}$; e para razão de Bowen $(\beta)$, na cana (Can), cerrado (Cer) e eucalipto (Euc).

Tabela 3.1.5. Valores médios de temperatura máxima (Tmax), temperatura mínima (Tmin) e da temperatura média diária (Tmed), todas em ${ }^{\circ} \mathrm{C}$, na cana (Can), cerrado (Cer) e eucalipto (Euc). ND significa ausência de dados. Os valores sombreados do teste t-student indicam se as médias comparadas são estatisticamente diferentes para o N.S. $<5 \%$.

Tabela 3.2.1. Valores médios de precipitação para cada mês do ano nos setores Leste e Oeste do Norte de SP, nos períodos climatológicos de 1940-1969 (P1) e 1970-1999 (P2). Os valores sombreados do teste t-student indicam se as médias comparadas são estatisticamente diferentes para o nível de significância de 5\%. As médias com diferenças significativas estatisticamente (baseadas no teste-t), para N.S. $<1 \%$ ou N.S. $<5 \%$, entre os dois períodos estão destacadas em cinza ou negrito, respectivamente. 
Tabela 3.2.2. Valores médios de precipitação para cada mês do ano nas estações de Campinas e Ribeirão Preto, nos períodos de 1943-1971 (P1) e 1972-2000 (P2). As médias com diferenças significativas estatisticamente (baseadas no teste-t), para N.S. $<1 \%$ ou N.S. $<5 \%$, entre os dois períodos estão destacadas em cinza ou negrito, respectivamente. .58

Tabela 3.2.3. Tendências de temperatura máxima, mínima e da amplitude térmica diária $\left({ }^{\circ} \mathrm{C}\right.$ em 58 anos) para cada trimestre do ano nas estações de Ribeirão Preto e Campinas. As tendências significativas para N.S. $<5 \%$, baseadas no teste-t, são destacadas em negrito...62

Tabela 3.2.4. Correlação entre as temperaturas máxima e mínima observada e R-2 em Campinas e Ribeirão de 1979 - 2000 para os quatro trimestres do ano. .69

Tabela 3.2.5. Tendências da temperatura média anual $\left({ }^{\circ} \mathrm{C}\right.$ em 22 anos) para as observações, R-2 e suas diferenças durante o período de 1979-2000 em Campinas e Ribeirão Preto.

Tabela 4.1. Faixas de probabilidade de influência na variabilidade de longo prazo da temperatura do ar (máxima e mínima) e precipitação, nas estações de Campinas e Ribeirão Preto .80 


\section{LISTA DE SIGLAS, SÍMBOLOS E ABREVIATURAS}

SIGLA/SÍMBOLO/

ABREVIATURA

ABAG

AGC

AGRISHOW

AMIP

ATD

c

Can

Cer

CLD

CLN

$\mathrm{CO}_{2}$

$c_{p}$

$c_{p d}$

DAC

DAEE

Dir

DJF

DOE

DPV

DSR

e

EC

EMBRAPA

ERA-40

es

Euc

Fc

$\mathrm{F}_{\mathrm{c}}$

$F_{\text {correção }}$

G

$\mathrm{H}$

$\mathrm{H}_{2} \mathrm{O}$

IAC

INPE

IPCC

IRGA

IVP

JJA

$\mathrm{Ki}$

$\mathrm{Kr}$

\author{
DEFINIÇÃO
}

Associação Brasileira de Agrobusines

Automatic Gain Control

Feira internacional de Tecnologia agrícola em ação - Ribeirão Preto

Atmospheric Model Intercomparison Project

Amplitude térmica diária $\left({ }^{\circ} \mathrm{C}\right)$

Uma grandeza escalar da atmosfera

Cana-de-açúcar

Cerrado

Camada limite diurna

Camada limite noturna

Dióxido de carbono

Calor específico do ar a pressão constante $\left(\mathrm{J} \mathrm{Kg}^{-1} \mathrm{~K}^{-1}\right)$

Calor específico ar seco a pressão constante $\left(\mathrm{J} \mathrm{Kg}^{-1} \mathrm{~K}^{-1}\right)$

Dias após o corte

Departamento de Águas e Energia Elétrica do estado de São Paulo

Direção do vento $\left({ }^{\circ}\right)$

Trimestre do ano referente a dezembro, janeiro e fevereiro

Department of Energy

Déficit da pressão de vapor d'água $(\mathrm{k} \mathrm{Pa})$

Divisão de Sensoriamento Remoto

Pressão parcial de vapor d'água $(\mathrm{k} \mathrm{Pa})$

Eddy Covariance

Empresa Brasileira de Pesquisa Agropecuária

European Centre for Medium-Range Weather Forecasts Reanalysis

Pressão de saturação de vapor d'água $(\mathrm{k} \mathrm{Pa})$

Eucalipto

Fluxo turbulento de $\mathrm{CO}_{2}\left(\mu \mathrm{mol}\right.$ de $\mathrm{CO}_{2} \mathrm{~m}^{-2} \mathrm{~s}^{-1}$ )

Fluxo vertical total médio de uma grandeza escalar $c$

Fluxo associado aos efeitos de mudança na densidade do ar causados pelas flutuações da temperatura e vapor d'água $\left(\mathrm{W} \mathrm{m}^{-2}\right)$

Fluxo de calor no solo $\left(\mathrm{Wm}^{-2}\right)$

Fluxo de calor sensível $\left(\mathrm{Wm}^{-2}\right)$

Vapor d'água

Instituto Agronômico de Campinas

Instituto Nacional de Pesquisas Espaciais

Intergovernmental Panel on Climate Change

Infrared gas analyser (Analisador de gás no infra-vermelho)

Faixa espectral do infravermelho próximo

Trimestre do ano referente a junho, julho e agosto

Irradiância solar incidente $\left(\mathrm{Wm}^{-2}\right)$

Irradiância solar refletida $\left(\mathrm{Wm}^{-2}\right)$ 
LBA

LE

Le

$\mathrm{Li}$

MAM

$\mathrm{m}_{\mathrm{d}}$

$\mathrm{m}_{\mathrm{w}}$

NCAR

NCEP

ND

NDVI

N.S.

ODP

OMR

Patm

P1

P2

Prec

q

R-1

R-2

RClimDex

RFA

RFAi

RFAr

$\mathrm{Rn}$

RW

SBS

SON

$\mathrm{T}$

Tmax

Tmed

Tmin

U

UR

USGS

$\mathrm{u}^{*}$

$\alpha$

$\alpha_{\mathrm{v}}$

$\beta$

$\bar{w}$

$w^{\prime}$

$\rho$

$\bar{\rho}_{c}$
Large Scale Biosphere-Atmosphere Experiment in Amazônia

(Experimento de Grande Escala da Biosfera-Atmosfera na Amazônia)

Fluxo de calor latente $\left(\mathrm{Wm}^{-2}\right)$

Irradiância de onda longa emergente da superfície $\left(\mathrm{Wm}^{-2}\right)$

Irradiância de onda longa incidente $\left(\mathrm{Wm}^{-2}\right)$

Trimestre do ano referente a março, abril e maio

Peso molecular do ar seco

Peso molecular de vapor d'água

National Center for Atmospheric Research

National Centers for Environmental Prediction

Dado não disponível

Normalized Difference Vegetation Index

Nível de significância estatística

Oscilação Decadal do Pacífico

Método Observação menos Reanálises

Pressão atmosférica $(\mathrm{hPa})$

Período climatológico definido de 1940-1969

Período climatológico definido de 1970-1999

Precipitação (mm)

Umidade específica $\left(\mathrm{g} \mathrm{Kg}^{-1}\right)$

Reanálises 1

Reanálises 2

software packages for indices calculation in $R$

Radiação fotossinteticamente ativa

Radiação fotossinteticamente ativa incidente $\left(\mathrm{Wm}^{-2}\right)$

Radiação fotossinteticamente ativa refletida $\left(\mathrm{Wm}^{-2}\right)$

Saldo de Radiação $\left(\mathrm{Wm}^{-2}\right)$

Random-Walk

Sociedade Brasileira de Solos

Trimestre do ano referente a setembro, outubro e novembro

Temperatuta do ar $\left({ }^{\circ} \mathrm{C}\right)$

Temperatura maxima diária $\left({ }^{\circ} \mathrm{C}\right)$

Temperatura media diária $\left({ }^{\circ} \mathrm{C}\right)$

Temperatura minima diária $\left({ }^{\circ} \mathrm{C}\right)$

Velocidade do vento horizontal $\left(\mathrm{m} \mathrm{s}^{-1}\right)$

Umidade Relativa (\%)

United States Geological Survey

Velocidade de fricção $\left(\mathrm{m} \mathrm{s}^{-1}\right)$

Albedo solar global (\%)

Albedo da radiação fotossinteticamente ativa (\%)

Razão de Bowen

Velocidade média vertical do vento $\left(\mathrm{m} \mathrm{s}^{-1}\right)$

Flutuação instantânea da velocidade vertical em torno da velocidade média vertical do vento $\left(\mathrm{m} \mathrm{s}^{-1}\right)$

Densidade do ar $\left(\mathrm{Kg} \mathrm{m}^{-3}\right)$

Densidade média de um escalar $\mathrm{c}\left(\mathrm{Kg} \mathrm{m}^{-3}\right)$ 
$\rho_{c}{ }^{\prime}$

$\rho_{\mathrm{d}}$

$\rho_{\mathrm{w}}$

$\tau$

$\lambda$

Flutuação instantânea do escalar em torno da densidade média do escalar c $\left(\mathrm{Kg} \mathrm{m}^{-3}\right)$

Densidade do ar seco $\left(\mathrm{Kg} \mathrm{m}^{-3}\right)$

Densidade de $\mathrm{H}_{2} \mathrm{O}\left(\mathrm{Kg} \mathrm{m}^{-3}\right)$

Fluxo de momentum $\left(\mathrm{N} \mathrm{m}^{-2}\right)$

Calor latente de evaporação da água $\left(\mathrm{J} \mathrm{Kg}^{-1}\right)$ 


\section{SUMÁRIO}

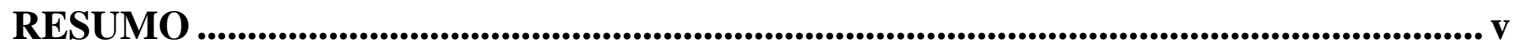

ABSTRACT .............................................................................................................................................. vi

LISTA DE FIGURAS...........................................................................................................

LISTA DE TABELAS ....................................................................................................................... xiii

LISTA DE SIGLAS, SÍMBOLOS E ABREVIATURAS................................................ xv

1. INTRODUÇÃO ................................................................................................................................... 1

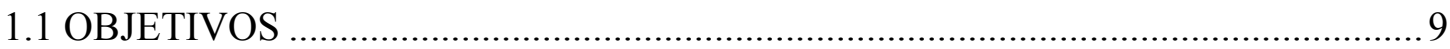

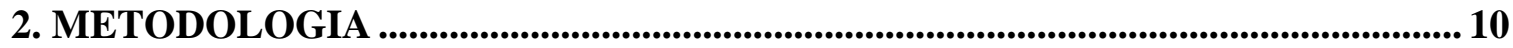

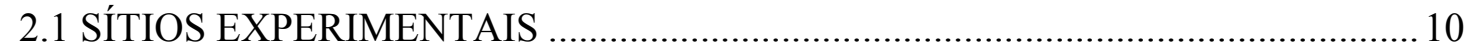

2.2 MEDIDAS MICROMETEOROLÓGICAS _............................................................ 14

2.3 ESTIMATIVAS DOS FLUXOS TURBULENTOS ................................................. 16

2.4 TENDÊNCIAS CLIMÁTICAS REGIONAIS.........................................................2 20

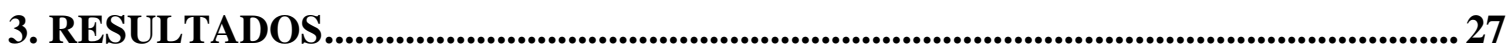

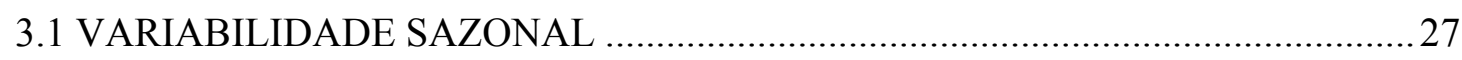

3.2. TENDÊNCIAS REGIONAIS DE PRECIPITAÇÃO E TEMPERATURA ..............52

4. CONCLUSÕES E SUGESTÕES PARA TRABALHOS FUTUROS ........................... 76

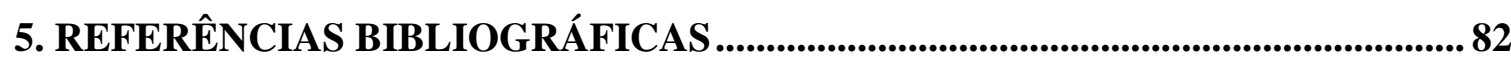

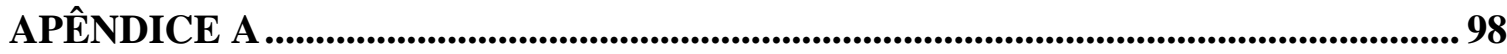

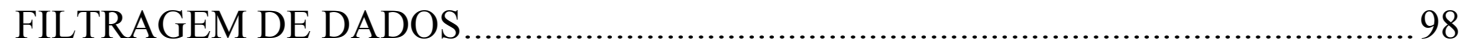

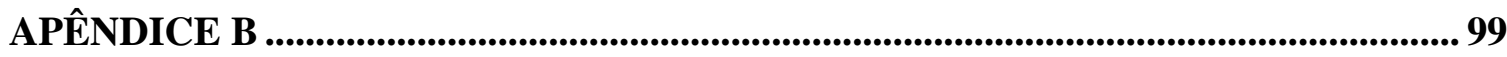

CLIMATOLOGIA DA REGIÃO DE SANTA RITA DO PASSA QUATRO .................99

CLIMATOLOGIA SAZONAL DA PRECIPITAÇÃO DE SP ....................................... 100

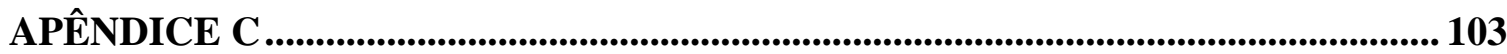

FOTOGRAFIAS DAS ESTAÇOES DE RIBEIRÃO PRETO E CAMPINAS …........... 103

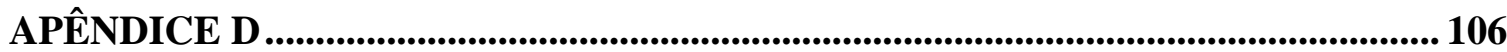

COMPARAÇÃO DOS TOTAIS DIÁRIOS DA IRRADIÂNCIA SOLAR INCIDENTE .

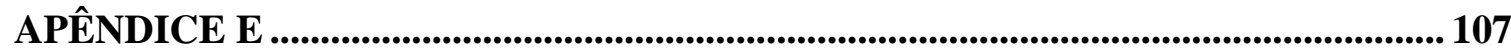

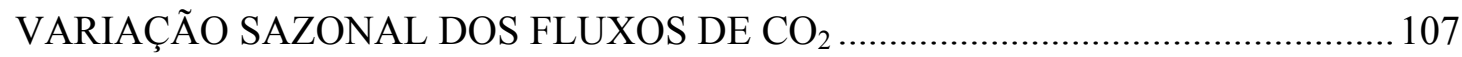

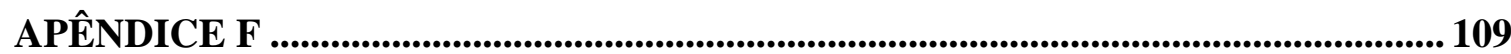

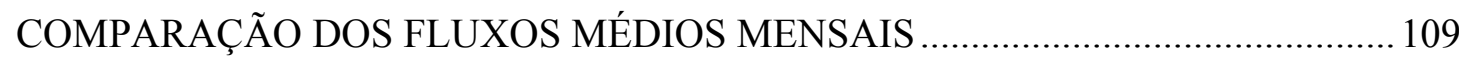




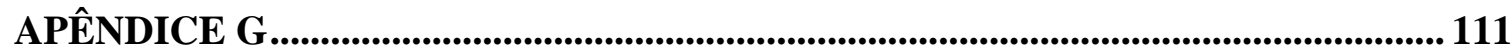

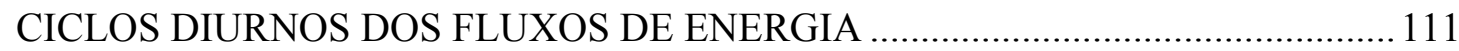




\section{INTRODUÇÃO}

O tempo e o clima influenciam o estado da vegetação terrestre, a qual se adapta evolutivamente ao ambiente, e limitam sua funcionalidade principalmente por meio da oferta de energia, água, e das variações de temperatura. Em sentido oposto, os diferentes padrões do balanço de energia à superfície, manifestantes sobre cada ecossistema terrestre que se expressam no microclima local, podem em tese controlar o clima regional e os processos hidrológicos (Rocha, 2004). Os padrões de balanços à superfície sobre diferentes tipos de vegetação são controlados por características da superfície, como albedo, área foliar, rugosidade, capacidade fotossintética, entre outros, que conseqüentemente controlam a temperatura e umidade do ar, a velocidade do vento, a evapotranspiração, e até mesmo a precipitação (Pielke et al. 1991). Um exemplo desta relação de controle da superfície no clima é a conversão de áreas com culturas anuais por reflorestamento nos Estados Unidos, que levaria a uma significativa redução do albedo, aumento da evapotranspiração e consequentemente a uma significativa redução da temperatura máxima (Jackson et al. 2005). No Brasil, outro exemplo, em sentido oposto, são as mudanças climáticas regionais na Amazônia, como o aumento da temperatura e redução da precipitação, que se manifestariam como decorrência do desmatamento regional (Nobre et al. 1991, Duriex et al.2003). A interação entre a biosfera e a atmosfera é um tema explorado na Amazônia (LBA, 1996), mas ainda pouco entendido nas demais regiões brasileiras. Outras formas de variabilidade climática, como por exemplo as mudanças climáticas globais provocadas pelo aumento dos gases de efeito estufa, também podem influenciar o estado da vegetação em proporções comparáveis (Stohlgren et al. 1998). De forma ilustrada, a urbanização, o desflorestamento, o monocultivo intensivo, ou de forma resumida, as práticas de uso da terra e a agricultura, podem controlar o clima local e potencialmente o clima regional. Estas atividades antropogênicas provêem os bens e insumos necessários ao homem, mas ainda se questiona como a exploração contínua dos recursos naturais, que se tornou prioridade para o crescimento econômico do Brasil e países em geral, pode ser conciliada com o conceito de sustentabilidade no longo prazo. Com o aumento da população e expansão dos centros urbanos, estas ações provavelmente se intensificarão no futuro. Este trabalho contempla esta linha de pesquisa, investigando as questões das conseqüências das mudanças no uso da terra na escala regional no clima, que são temas priorizados pelo Intergovernmental Panel on Climate Change (IPCC, 2001b). 


\section{O CERRADO E AS MUDANCCAS DE USO DA TERRA}

No Brasil as mudanças de uso da terra manifestaram-se pela substituição da vegetação primária por agroecossistemas, como as culturas anuais e perenes, pastagens, e florestas de rápido crescimento (pinus e eucalipto). Em conseqüência da ocupação da região Sudeste nos últimos séculos e do avanço da fronteira de áreas agrícolas na região Centro-oeste nas últimas décadas, resta apenas $20 \%$ da área original do Cerrado (Myers et al. 2000), hoje considerado um dos biomas globais mais ameaçados (Silva \& Bates, 2002). O cerrado foi a maior região de savana na América do Sul e o segundo maior bioma natural do Brasil (Ribeiro \& Walter, 1998), ocorrendo desde o sul de São Paulo e Paraná à borda da Amazônia, abrangendo uma ampla faixa latitudinal e uma variação de altitude do nível do mar até 1800 m (Oliveira-Filho \& Ratter, 2002). O domínio do cerrado ocorre sob regime de chuvas marcadamente sazonal, precipitação anual entre 800 e $2250 \mathrm{~mm}$, com aproximadamente 90\% desta concentrada no período de setembro a abril (estação chuvosa); a temperatura média anual varia de 18 a $28^{\circ} \mathrm{C}$ (Oliveira-Filho \& Ratter, 2002). Uma característica do Cerrado é a coexistência de estratos arbóreo, arbustivo e herbáceo. A heterogeneidade espacial no domínio do Cerrado ocorre conforme a densidade destes estratos, definindo fisionomias que variam do cerradão, a forma de predominância arbórea, até o campo limpo, onde prevalecem as gramíneas, passando por cerrado sensu stricto, campo cerrado e campo sujo. O controle destas diferentes formas varia como resposta da precipitação, características do solo (quantidade de nutrientes, capacidade de retenção de água e toxicidade), disponibilidade de água e ocorrência de fogo (Eiten, 1972; Tannus, 2004), entre outros. Durante a estação chuvosa ocorre uma grande produção de biomassa, principalmente nas gramíneas, enquanto no período de estiagem, grande parte da vegetação rasteira torna-se inativa e a biomassa aérea seca (Klink \& Solbrig, 1996), favorecendo a ocorrência de fogo. Esta heterogeneidade na estrutura e funcionamento do cerrado adiciona complexidade à medição e a modelagem dos fluxos de massa e energia sobre tais paisagens .

Os estudos do balanço de energia sobre o Cerrado brasileiro foram reportados por Miranda et al. $(1996,1997)$ em Brasília-DF, Vourlitis et al. $(2001,2004)$, Priante-Filho et al. (2003), sobre Cerradão no Mato Grosso, e por Rocha et al. (2002, 2005, 2006), Tannus (2004), Bruno (2004), Negrón-Juarez (2004), em cerrado sensu stricto no norte de SP.

Originalmente o cerrado cobria 14\% de SP (SMA, 2003). Em 1993 a área de ocupação agrícola no estado foi $\sim 71 \%$ da área total (Camargo et al. 1995), e $\sim 33.307 \mathrm{~km}^{2}$ de Mata Nativa, 
ou $\sim 13 \%$ do território (Machado et al. 2004). Kronka (1993) estimou entre 1962 e 1992 uma redução de $57 \%$ da cobertura vegetal natural do estado (incluindo todas as fisionomias do cerrado). Atualmente existem pequenos fragmentos do cerrado, ocupando $2100 \mathrm{~km}^{2}$, ou menos de $1 \%$ de sua área original. As formas de campo limpo, campo cerrado e cerrado sensu stricto, que ocupam os solos mais pobres, foi substituída pela agricultura e plantações de eucalipto e pinus, pastagens e citrus (Durigan et al. 2003). De forma mais abrangente, a cana-de-açúcar ocupou os solos mais férteis, onde predominava o Cerradão e a floresta estacional, embora atualmente a cana seja plantada também nos solos mais arenosos. Com o advento do carro a álcool, a cana-deaçúcar tornou-se um monocultivo intensivamente explorado a partir da década de $1970 . \mathrm{Na}$ região de Ribeirão Preto a área de cana-de-açúcar aumentou em 23\% desde 1988, quando houve uma estagnação da produção de carros a álcool, atingindo $18.297 \mathrm{~km}^{2}$, que corresponde a $50 \%$ da área agrícola em 2003 (Brito 2005, Fig. 1.1), quando houve uma retomada com a introdução do motor bi-combustível. Atualmente, o maior pólo canavieiro do Brasil, concentrado no centronorte de SP, ocupa $~ 3$ milhões ha (DSR-INPE 2006) (Fig. 1.1), sendo responsável por 64\% da produção total de cana-de-açúcar do Brasil.

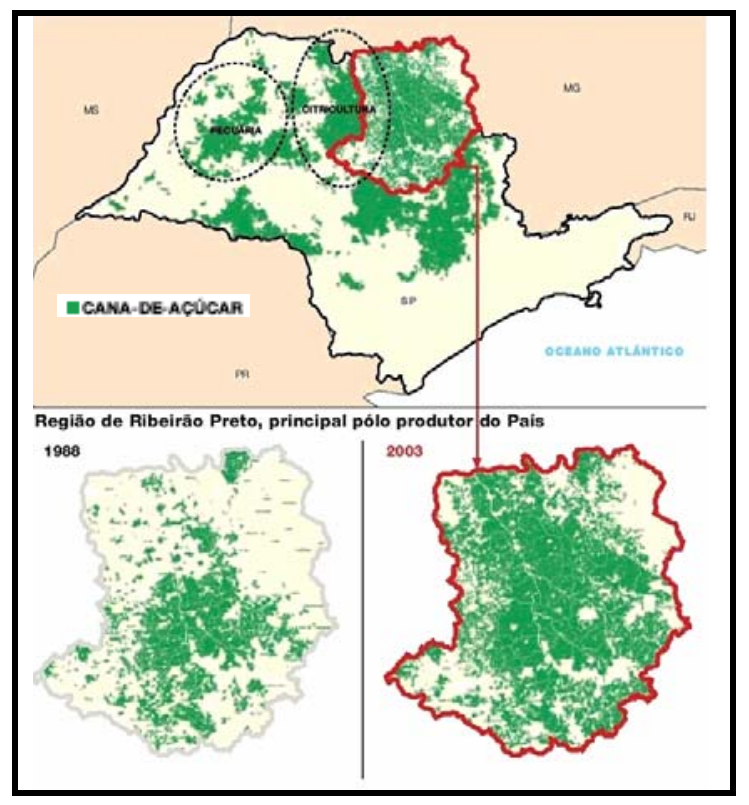

Figura 1.1. Mapa da área ocupada por cana-de-ácucar no estado de SP. Parte superior: regiões pontilhadas identificam o avanço dos canaviais em áreas antes dominadas pela laranja e pecuária. A região de Ribeirão Preto é destacada em vermelho. Parte inferior: em 1988 a mancha das lavouras de cana-deaçúcar ocupava $8616 \mathrm{~km}^{2}$ (23\% da área agrícola da região), enquanto que em 2003 atingiu $18297 \mathrm{~km}^{2}$ (50\% da área agrícola da região). Fonte: Centro de Tecnologia Canavieira, Embrapa - Monitoramento por Satélite e Associação Brasileira de Agrobusines (ABAG).

O monocultivo de cana-de-açúcar em escala regional poderia influenciar no clima regional de duas formas: através do balanço de energia local e do efeito dos aerossóis provenientes das queimadas, que regionalmente ocorre no período da safra da cana-de-açúcar 
(Abril a Novembro, com pico nos meses mais secos). Na Amazônia atribuiu-se uma redução de $15 \%$ da radiação solar incidente à superfície devido às queimadas (Koren et al. 2004), o que poderia contribuir para a redução da temperatura máxima diária.

Os estudos do balanço de energia em cana-de-açúcar (Rocha, 1998; Cabral, 2001; Cabral et al. 2003; Negrón-Juarez, 2004) mostraram que ocorre uma pequena redução no saldo de radiação e na evapotranspiração média anual, e o aumento na temperatura do ar sobre o dossel da plantação, em comparação ao cerrado. A conversão da vegetação primitiva do Sudeste pela cana-de-açúcar pode ser um controle da variação da temperatura do ar e do regime de precipitação na escala regional, segundo experimentos numéricos reportados por Negrón-Juarez (2004).

As plantações de eucalipto no Brasil têm aumentado nos últimos 20 anos, ocupando uma área de 3,6 milhões ha em 2000 (SBS, 2001), distribuída no sul da Bahia, Espírito Santo, Minas Gerais, Rio Grande do Sul, Paraná e São Paulo (neste último 6110 km², Kronka et al. 2002), para a produção de celulose, papel e produtos madeireiros. As plantações de eucalipto comumente são questionadas pela alta demanda de água, devido à sua alta produtividade e evapotranspiração (Calder 1992,1999), o que reduziria a vazão dos rios e nascentes. Entretanto, a variedade de espécies e ambientes estudados não permitiu uma conclusão consensual sobre esta polêmica. Estudos na Austrália reportaram taxas de evapotranspiração superiores a $8 \mathrm{~mm} \mathrm{dia}^{-1}$ quando a água não foi limitada (Landsberg, 1999, Fig. 1.2), por outro lado, em plantações no Brasil durante o período seco foram observados valores próximos a $1 \mathrm{~mm} \mathrm{dia}{ }^{-1}$ (Soares \& Almeida, 2001, Fig. 1.2). As estimativas de perdas por interceptação em plantações de eucalipto são de $\sim 10 \%$ da precipitação anual (eucalipto de 3 a 6 anos) (Lima, 1996). A Figura 1.2 apresenta as estimativas de evapotranspiração para diferentes espécies de Eucalyptus nos países com expressivo plantio. Lima (1996) faz uma ampla revisão sobre o impacto ambiental das plantações de eucalipto, principalmente quanto à hidrologia de microbacias e a produtividade, relatando que o consumo de água por espécies de eucalipto, normalmente utilizadas em plantações intensivas de curta rotação, não é diferente das plantações de outras espécies florestais, tanto em relação ao controle estomático da transpiração quanto às taxas de interceptação. Entretanto o autor sugere estudos de comparação do balanço hídrico de bacias hidrográficas para períodos de longo prazo para uma avaliação mais profunda. 


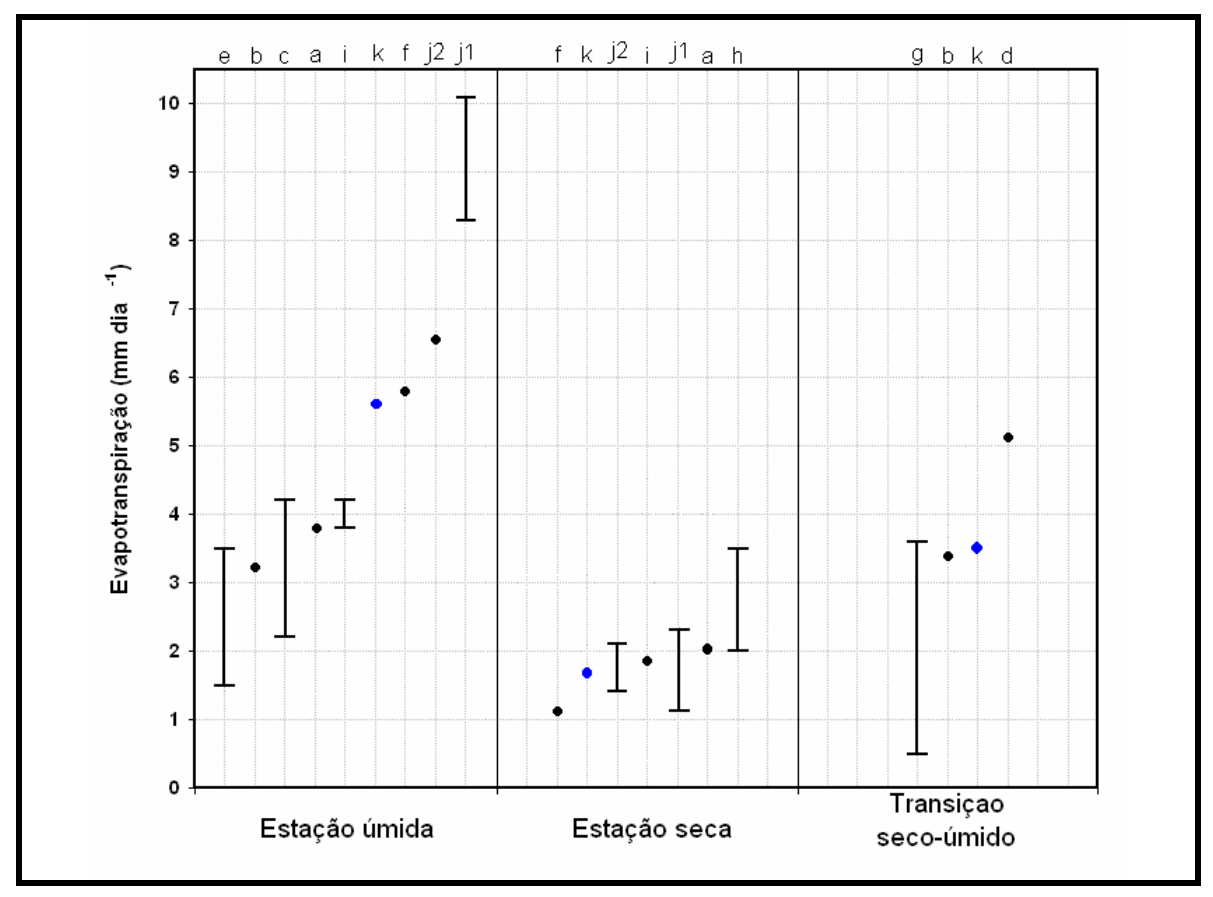

Figura 1.2. Valores de Evapotranspiração $\left(\mathrm{mm} \mathrm{dia}^{-1}\right)$ reportados para várias espécies de eucalipto e épocas do ano. Os valores são médias sazonais (pontos) ou a amplitude de variação (hastes). As abreviações para os métodos utilizados são: EC - Eddy Covariance, PM - Equação de Penman-Monteith, L -lisímetros, PC - Pulso de calor, SF - Sap Flow, FG - Fluxo gradiente, BE - Balanço de energia. Segue abaixo a legenda do gráfico.

\begin{tabular}{|c|c|c|c|}
\hline Legenda & Espécie (idade em anos) & Método & Referência e localização \\
\hline $\mathrm{a}$ & E. miniata, E. tetradonta (8) & $\mathrm{EC}$ & Cook et al. 1998, Norte da Austrália) \\
\hline $\mathrm{b}$ & E. marginata & $\mathrm{BE}$ & Silberstein et al. 2001, Oeste da Austrália \\
\hline $\begin{array}{c}\mathrm{c} \\
\mathrm{d}\end{array}$ & E. maculata (11) & $\mathrm{FG}$ & $\begin{array}{c}\text { Denmead } \text { et al. 1993 } \\
\text { Dunin \& Greenwood (1986), } \\
\text { Nordeste da Austrália }\end{array}$ \\
\hline $\mathrm{e}$ & E. camaldulensis (1) & $\mathrm{PM}$ & Roberts et al. 1992, Sul da Índia \\
\hline $\mathrm{f}$ & E. grandis (9) & $\mathrm{PM}$ & Soares \& Almeida (2001), Brasil \\
\hline $\mathrm{g}$ & E. globulus (8) & $\mathrm{SF}, \mathrm{PM}$ & David et al. 1997, Portugal \\
\hline $\mathrm{h}$ & E. tereticornis (4) & $\mathrm{PM}$ & Kallarackal \& Somen (1997a,b), Sul da Índia \\
\hline $\mathrm{i}$ & E. urophylla (3) & L, PC & Lane et al. 2004, China \\
\hline $\mathrm{j} 1$ & $\begin{array}{c}\text { Eucalyptus } * \\
\text { Fertilizados e } \\
\text { Não fertilizados }\end{array}$ & PM & Landsberg (1999), Austrália \\
\hline $\mathrm{K}$ & E. grandis e urophylla (2) & EC & este estudo \\
\hline
\end{tabular}

*Resumo dos resultados de cinco áreas experimentais, localizadas na bacia Murray-Darling em New South Wales, Austrália 


\section{MUDANÇAS CLIMÁTICAS: EXISTEM? QUAIS AS CAUSAS?}

O clima terrestre teve grandes mudanças ao longo de sua história (IPCC 2001a), mas entretanto são as mudanças recentes do clima que tem despertado maior interesse, em decorrência da alta probabilidade de sua origem antropogênica. Os dados da temperatura média global mostram um maior aquecimento a partir de 1980 (Fig. 1.3) que é inexplicável pelas forçantes naturais conhecidas (IPCC, 2001a). O aumento dos gases estufa na atmosfera, como o $\mathrm{CO}_{2}$, fornece uma explicação plausível para aquele fato, diante da forte correlação entre ambos (Figura 1.3, Karl \& Trenberth 2003). As estimativas do aquecimento global ocorrido no século 20 são de 0,6 \pm 0,2 ${ }^{\circ} \mathrm{C}$ (Hansen \& Lebedeff, 1987; Jones, 1988; IPCC, 1990; Vinnikov et al., 1990; Jones, 1994b; IPCC, 1996; IPCC, 2001a). Um aspecto mais interessante nos dados globais de temperatura são taxas diferenciais de aquecimento entre a temperatura mínima e máxima (Karl et al. 1993). O aumento da temperatura mínima e máxima observado entre 1950 e 2004 foi de 0,2 e $0,14{ }^{\circ} \mathrm{C}$ por década, respectivamente, e a tendência da amplitude térmica diária foi de $-0,07{ }^{\circ} \mathrm{C}$ por década (Vose et al. 2005).

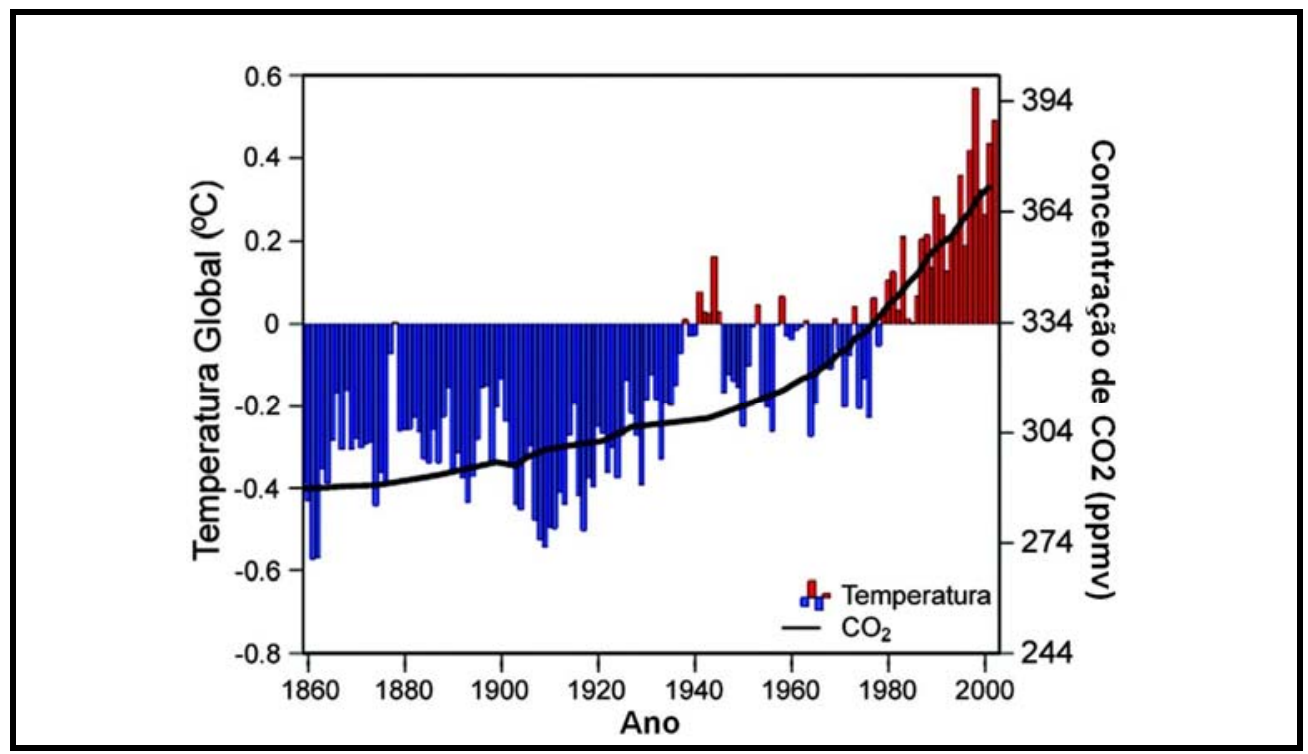

Figura 1.3. Série temporal de anomalias de temperatura em relação ao período de 1961-90 (barras) para uma temperatura média anual global de $14^{\circ} \mathrm{C}$ e para uma concentração média de $\mathrm{CO}_{2}$ de 334 ppmv (curva sólida) durante o período base, usando dados de amostras de ar contido em núcleos de gelo (antes de 1958) e de Mauna Loa a partir de 1958 (Adaptado de Karl \& Trenberth 2003). 
Existem vários fatores climáticos que podem ter efeito sobre a amplitude térmica diária. Análises de simulações de diversos modelos climáticos globais incluindo o aumento observado nos gases estufas e nos aerossóis de sulfato, revelam uma tendência da amplitude térmica diária de mesmo sinal mas com menor magnitude que a observada (Stone \& Weaver, 2003; Braganza et al. 2004). Os autores atribuíram esta diferença a outros efeitos climáticos de grande escala que não são considerados nas simulações, como o aumento da nebulosidade observado em várias regiões do mundo (Henderson-Sellers, 1986, 1989, 1990,1992; Jones \& Henderson-Sellers, 1992, Dai et al. 1997), durante o período simulado. As nuvens têm um grande impacto sobre a amplitude térmica diária (Dai et. al., 1999) pela redução do aquecimento diurno devido a reflexão da luz solar e aumento da temperatura noturna pelo aumento da radiação de onda longa incidente. Solos úmidos também reduzem a amplitude térmica diária através do aumento do resfriamento evaporativo diurno.

Entre os efeitos locais mais importantes que influenciam a amplitude térmica diária estão: a urbanização (Arnfield, 2003), irrigação (Mahmood et al. 2004) e desertificação (Nasrallah \& Balling, 1995). Destes três somente os dois primeiros reduzem a amplitude térmica. A urbanização é o exemplo mais conhecido de como as mudanças na cobertura superficial podem modificar o clima regional através do conhecido efeito "ilha de calor urbana" (Arya, 1988). A forma e intensidade deste fenômeno variam no espaço e tempo de acordo com as características meteorológicas e urbanas do local (Oke, 1987). Para caracterizar o grau de urbanização é frequentemente usado como parâmetro a população da cidade. Geralmente um limiar de 50000 habitantes é utilizado para diferenciar estações urbanas de rurais (Karl et al. 1993; Easterling et. al. 1997; Gallo et al. 1999, Hansen et al. 2001).

Em grandes centros urbanos o efeito urbano sobre a temperatura máxima diária não é óbvio. As partículas suspensas na atmosfera (poluição) reduzem a radiação solar absorvida e portanto a temperatura diurna, o que é também favorecido pelo alto albedo das áreas urbanizadas. Em oposição, o fluxo de calor sensível predomina no balanço de energia sobre as áreas urbanas, tendendo a aumentar a temperatura máxima diurna. Por outro lado, na temperatura mínima o efeito é mais definido, pois à noite os prédios e as ruas liberam a energia solar absorvida durante o dia, aumentando a temperatura mínima.

Gallo et al. (1999) mostrou que sobre uma ampla rede de estações na área metropolitana de Washington DC (EUA), ocorreram tendências de negativas da amplitude térmica diária, 
aumento da temperatura mínima, enquanto a temperatura máxima não teve mudanças significativas. A área de influência da ilha de calor urbana sobre amplitude térmica diária pode se estender até $10 \mathrm{~km}$ de distância, segundo Gallo et al. 1996, e tende a aumentar com o aumento da população (Karl \& Jones, 1989; Bonan, 2002; Oke 1987, p.292). No Brasil, reportaram-se evidências de aumento da temperatura média em várias capitais brasileiras (Lombardo, 1985; Sansigolo et al. 1992; Marengo, 2001) que foi associado à urbanização, mas também a causas naturais como o aquecimento sistemático das águas superficiais do Oceano Atlântico Sul desde 1950 (Venegas et al. 1997).

Estudos sobre a variabilidade sazonal e interanual climática, ou das mudanças de longo prazo decorrentes das atividades humanas são tópicos de grande importância, mas não se pode considerar o clima adequadamente sem levar em consideração a sua variabilidade na escala de décadas a séculos. Em particular, destaca-se a mudança ocorrida a partir de meados da década de 1970, quando eventos quentes do fenômeno El Nino - Oscilação Sul (ENOS) tornaram-se relativamente mais freqüentes, persistentes e intensos (IPCC, 2001a). Esta mudança é refletida em variações na precipitação e temperatura sobre grande parte dos trópicos, sub trópicos e algumas regiões de latitudes médias (IPCC, 2001a). Mantua et al. (1997) mostraram a existência de uma variabilidade de baixa frequência na configuração da temperatura da superfície do mar do Oceano Pacífico semelhante ao ENOS, que foi denominada Oscilação Decadal do Pacífico (ODP). Enquanto os eventos ENOS persistem por cerca de 6 a 18 meses, as fases da ODP persistem por 20 ou 30 anos. O padrão de variabilidade da ODP provavelmente tem forte influencia sobre a variabilidade climática relacionada ao ENOS (p. ex. Newman et al. 2003).

Carvalho et al. (2006), utilizando dados de reanálises do NCEP/NCAR, reportaram a ocorrência de uma gangorra inter-hemisférica de extremos da temperatura do ar, sob um padrão de fases opostas (quente e fria), da América do Sul tropical e áreas extensas do Hemisfério Norte, com as áreas oceânicas do Hemisfério Sul. Os autores reportam um regime bipolar, por meio de uma mudança de fase nos últimos 52 anos, quando no Sudeste do Brasil houve uma fase quente entre 1948 a 1975, seguida de uma fase fria no período seguinte, de 1976 a 2000.

Portanto, a variabilidade de longo prazo da temperatura e da precipitação em escala secular no Sudeste do Brasil pode decorrer de várias causas: a variabilidade natural do clima, as mudanças de uso da terra, a urbanização e do aquecimento global. Este estudo irá em uma primeira etapa, reportar as medidas observacionais dos balanços de energia, discutindo-se como 
ocorre essa comparabilidade, com ênfase na temperatura do ar sobre estes tipos de cobertura de superfície. A segunda componente irá testar a probabilidade de tendências das séries temporais de temperatura e precipitação no centro-norte de SP, e havendo significância, serão discutidas as possíveis causas, dentre elas as mudanças de uso da terra.

\subsection{OBJETIVOS}

O objetivo do trabalho é a análise do clima e dos fluxos de energia à superfície sobre áreas de Cerrado, Eucalipto e Cana-de-açúcar, por meio de observações de campo. Em uma segunda etapa, é feita uma análise das tendências de longo prazo do clima regional, discutindo-se como as mudanças de uso da terra podem compor esta forma de variabilidade.

As metas específicas para o desenvolvimento do trabalho foram:

(a) Descrição do microclima local e dos fluxos radiativos, por meio de medidas automáticas de temperatura e umidade do ar, pressão atmosférica, precipitação, irradiância solar global e radiação solar fotossinteticamente ativa (incidente e refletida), saldo de radiação, velocidade e direção do vento, e dos fluxos turbulentos de energia à superfície (pelo método de eddy covariance) sobre três áreas experimentais com cobertura de Cerrado, Cana-de-açúcar e Eucalipto, durante o período de fevereiro de 2005 até fevereiro de 2006;

(b) Análise da variação climática e dos fluxos de superfície na escala do ciclo diurno e na escala sazonal, comparando-se os três ecossistemas;

(c) Discutir as tendências de longo prazo da temperatura nas séries históricas de Campinas e Ribeirão Preto e a variabilidade da precipitação no centro-norte de SP, interpretando-se a possível influência das mudanças de uso da terra, e/ou de outros controles como a urbanização e as mudanças globais. 


\section{METODOLOGIA}

Este projeto dá continuidade à análise de dados micrometeorológicos medidos sobre sítios experimentais com torre de fluxos no norte do estado de SP, um no ecossistema de cerrado sensu stricto (aqui referenciado como cerrado) (Rocha et al. 2002, Bruno 2004, Tannus 2004, Rocha et al. 2005, 2006), e o outro em uma área de cultivo de cana-de-açúcar (aqui referenciado como cana), inicialmente em Sertãozinho, SP (Rocha, 1998; Rocha et al. 2001; Cabral 2001, Cabral et al. 2003; Negrón-Juarez, 2004), posteriormente deslocado para uma área mais próxima do cerrado (Fig. 2.1.1). A terceira torre micrometeorológica foi implementada sobre uma plantação de Eucalipto (aqui referenciada como eucalipto), próxima ao cerrado (Fig. 2.1.1). A estratégia observacional de localização dos sítios experimentais em áreas próximas, no mesmo clima regional e com certas semelhanças de solos, foi com o propósito de reduzir as incertezas na análise de comparação do microclima e dos fluxos de superfície.

\subsection{SÍTIOS EXPERIMENTAIS}

A área de estudo encontra-se na micro-região de Ribeirão Preto, noroeste do estado de São Paulo. Três torres micrometeorológicas monitoraram os fluxos de superfície e o clima no período de 7 de fevereiro de 2005 a 6 de fevereiro de 2006. A Fig. 2.1.1 mostra a topografia, cobertura vegetal, posição dos sítios experimentais e de estações meteorológicas convencionais na região. A descrição das áreas experimentais é feita a seguir.

Ecossistema de cerrado: localizado na Gleba Pé de Gigante, município de Santa Rita do Passa Quatro, na área do Parque Estadual Vassununga (administrada pelo Instituto Florestal, SP), onde fica a nascente do córrego Paulicéia, que é afluente da margem direita do rio MogiGuaçú. A torre micrometeorológica, de $22 \mathrm{~m}$ de altura, foi implementada em Janeiro de 2000 (Rocha et al. 2002), nas coordenadas $21^{\circ} 37^{\prime} \mathrm{S}, 47^{\circ} 38^{\prime} \mathrm{W}$, a $710 \mathrm{~m}$ de altitude, e é circundada por plantações de eucalipto, citrus e cana-de-açúcar (Fig. 2.1.1.b). A reserva tem área de 1225 ha, e é o maior fragmento de cerrado em área contígua do estado. A fisionomia predominante é de cerrado sensu stricto e a altura média do dossel é de $10 \mathrm{~m}$. Para esta fisionomia a densidade de indivíduos é de 15000 ind ha ${ }^{-1}$ (estrato arbóreo) e 159000 ind ha ${ }^{-1}$ (estrato herbáceo) (Batalha et 
al. 2001). O solo é formado predominantemente por Neossolo quartzarênico, previamente chamado de Areia Quartzosa.

Agroecossistema de eucalipto: localizado sobre uma plantação de eucalipto, no talhão de reflorestamento $\mathrm{n}^{\mathrm{o}} 18 \mathrm{com} 45$ ha, da Fazenda Cara Preta (Votorantin Celulose e Papel S.A.), a nordeste da área do cerrado. A densidade de indivíduos é de 1410 ind ha ${ }^{-1}$ (Marcos Aidar, Instituto de Botânica/USP, comunicação pessoal). A torre micrometeorológica $\left(21^{\circ} 35^{\prime} \mathrm{S}\right.$, $47^{\circ} 36^{\text {'W }} 761 \mathrm{~m}$ ) foi implementada em julho de 2003, após a colheita do eucalipto. Desde então, a torre foi vandalizada em agosto de 2004, e o sistema de medição retornou a operar em julho de 2005. O sítio experimental foi montado com uma torre portando o sistema de alimentação (painéis e baterias), e uma segunda torre a $60 \mathrm{~m}$ de distância, com o sistema de eddy covariance e estação automática. As variedades plantadas foram clones híbridos de Eucalyptus grandis e urophylla, com ciclo de 7 anos, em agosto de 2003. Em janeiro de 2004 houve uma tempestade de granizo, o que forçou um replantio em fevereiro de 2004. O manejo adotado foi um espaçamento de $3 \times 3 \mathrm{~m}$ (entre as árvores e entre as linhas). A altura média das árvores em agosto de 2005 era de $11 \mathrm{~m}$ enquanto que em fevereiro de 2006, aproximadamente $13 \mathrm{~m}$.

Agroecossistema de cana-de-açúcar: localizado sobre uma plantação de cana-deaçúcar (Saccharum spp.) de 351 ha, na Fazenda São José do Pulador (Fazenda 27) da Usina Santa Rita $\left(21^{\circ} 38^{\prime} \mathrm{S}, 47^{\circ} 47^{\prime} \mathrm{W}, 552 \mathrm{~m}\right)$ no município de Luiz Antônio, SP (Fig. 2.1.1). O solo predominante é do tipo Latossolo Vermelho-Amarelo, textura arenosa. A torre foi instalada no início de fevereiro de 2005 no talhão $n^{\circ}$ 20, contendo a soca de cana-de-açúcar, variedade SP832847 , plantada com espaçamento entre linhas de $1,5 \mathrm{~m}$ e com altura média de $\sim 3,5 \mathrm{~m}$ na época de colheita, realizada nos dias 14 de abril de 2005 e 10 de maio de 2006 (segundo e terceiro corte, respectivamente). A produtividade medida pela usina em 2005 foi de $102,4 \mathrm{t} \mathrm{ha}^{-1} \mathrm{e}$ a produtividade estimada pela amostragem de biomassa em 2006 foi de $118 \pm 23 \mathrm{tha}^{-1}$ (Cabral et al 2006). O manejo da área está resumido na Tabela 2.1.1. Uma estimativa do crescimento da cana para o ciclo 2005/06 é mostrada na Fig. 2.1.2, com dados de Cabral et al. (2006). A metodologia usada para determinação da altura da vegetação é baseada em relações empíricas entre a altura e o peso seco dos colmos (Cabral, 2001). Estes últimos dados foram obtidos por amostras periódicas da biomassa aérea, ao longo do ciclo na área experimental. 


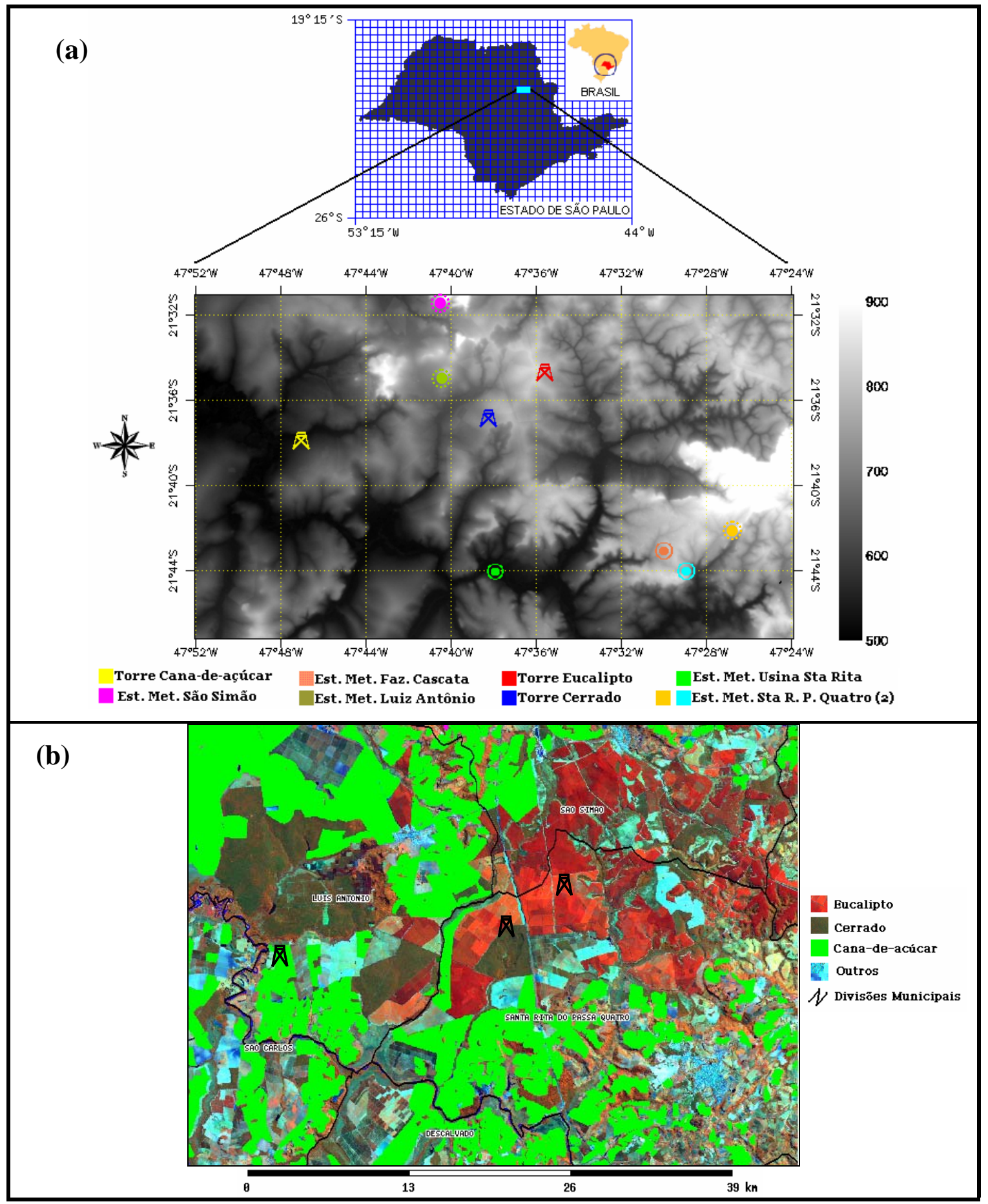

Figura 2.1.1 (a) Localização dos sítios experimentais, estações meteorológicas mais próximas e topografia da região com resolução de $90 \mathrm{~m}$ (dados do USGS). A variação de altitude (m) é indicada à direita pela escala de cinza. (b) imagem realçada do satélite LANDSAT-5 da cobertura vegetal da região. Fonte: Projeto CANASAT, imagem referente à safra 2005/06 (disponível em http://www.dsr.inpe.br/mapdsr/). 
Tabela 2.1.1. Datas da colheita e de outros eventos notáveis para o sítio da cana durante o período de observação.

\begin{tabular}{cc}
\hline DATA & DESCRIÇÃo \\
\hline 6 de Fevereiro de 2005 & Instalação da plataforma instrumental \\
\hline 23 de Fevereiro de 2005 & \begin{tabular}{c} 
Aplicação do maturador \\
\hline 14 de Abril de 2005
\end{tabular} \\
\hline 12 a 20 de Maio de 2005 & $\begin{array}{c}\text { Colheita: a cana foi queimada dias antes e cortada a seguir; } \\
\text { as folhas foram deixadas sobre o solo. }\end{array}$ \\
\hline Início de Junho de 2005 & Aplicação de herbicidas \\
\hline 10 de maio de2006 & Colheita \\
\hline
\end{tabular}

A evolução do crescimento da cana foi lenta no início, com um aumento de $\sim 50 \mathrm{~cm}$ entre 30 e 160 dias após o corte (DAC), depois rápida (de $75 \mathrm{~cm}$ para 2,5 $\mathrm{m}$ entre 160 e $260 \mathrm{DAC}$ ) e novamente lenta, se aproximando de 3,5m de altura no auge de seu desenvolvimento (Fig. 2.1.2).

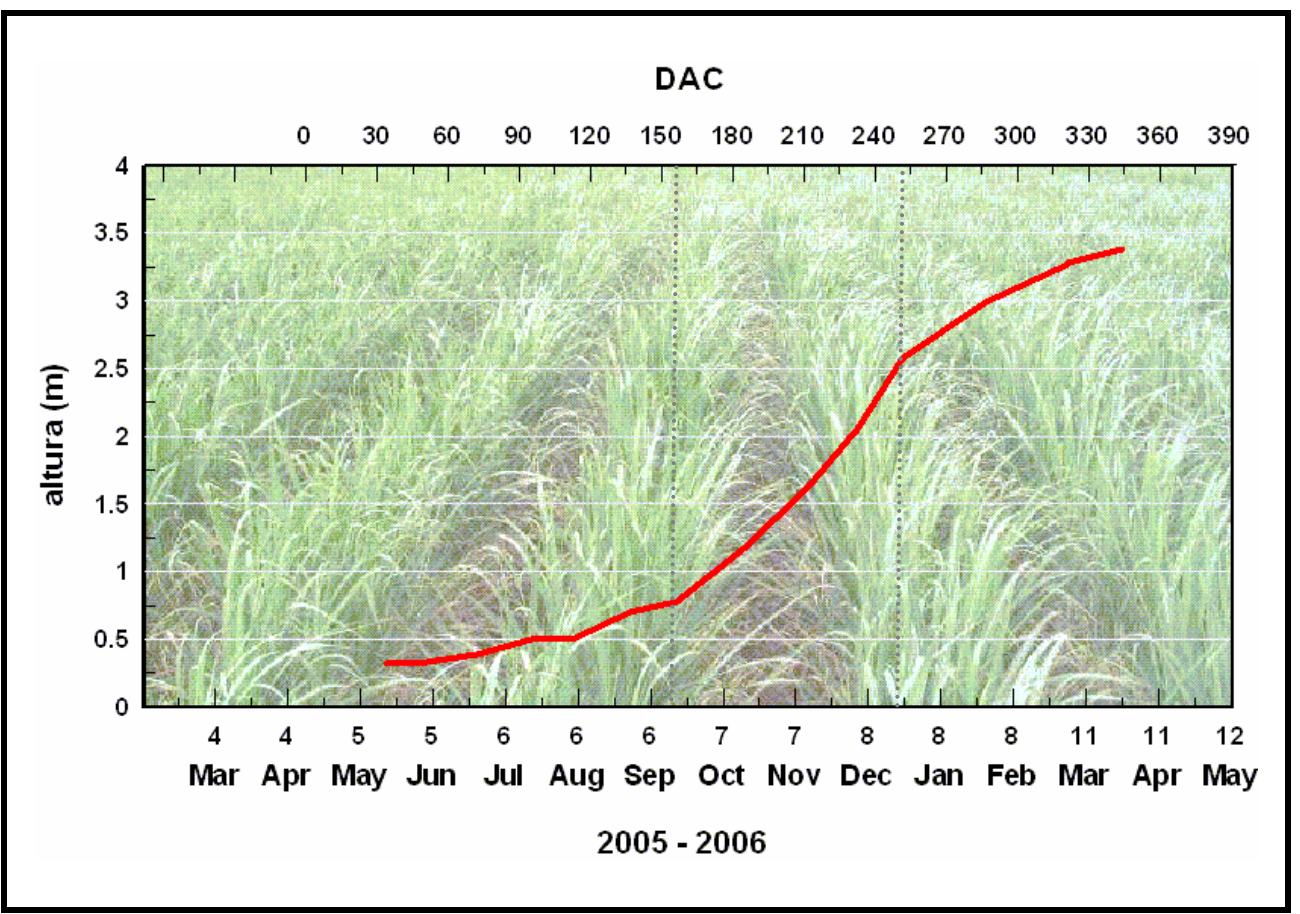

Figura 2.1.2.Crescimento da cana-de-açúcar (cortada em 14/04/2005) durante o ciclo 2005/2006 em Luiz Antônio, SP.Com dados de Cabral et al. (2006).A escala superior indica o número de dias após o corte da cana (DAC). 


\subsection{MEDIDAS MICROMETEOROLÓGICAS}

A instrumentação utilizada em cada sítio incluiu medições automáticas das variáveis climáticas, com estações meteorológicas, e dos fluxos de energia entre superfície e a atmosfera, conforme descrito na Tabela 2.2.1. Os sítios foram visitados quinzenalmente para a coleta de dados e manutenção. As estimativas dos fluxos de energia foram realizadas acima do dossel da vegetação, sobre uma torre micrometeorológica com um sistema de eddy covariance (EC). O sistema é composto por um analisador de gás infravermelho (IRGA), do qual se obtém a medida das concentrações de $\mathrm{CO}_{2}$ e $\mathrm{H}_{2} \mathrm{O}$, um anemômetro sônico tridimensional (medida das componentes tridimensionais do vento, e da temperatura do ar), um gabinete com datalogger CR5000 (Campbell Systems), ou computador portátil, e software para aquisição dos dados de alta freqüência $(10 \mathrm{~Hz})$. Nos analisadores de caminho fechado utiliza-se uma bomba de sucção de ar a vácuo $\left(91 \mathrm{~min}^{-1}\right)$ e um rotâmetro de controle de fluxo. No sistema de caminho aberto o analisador realiza as medidas pela absorção no caminho ótico, instalado próximo ao anemômetro sônico. Uma combinação dos dados do IRGA e do anemômetro sônico em $10 \mathrm{~Hz}$ é enviada a uma saída serial do datalogger, onde são armazenados. As variáveis climáticas foram amostradas a cada 15 s e gravadas como médias de 10min em um datalogger (CR10X ou CR5000, Campbell Systems).

O período de coleta de dados foi de 1 ano (7/02/2005 a 6/02/2006), na cana e no cerrado, e 6 meses e meio (22/07/2005 a 06/02/2006) no eucalipto. Durante estes períodos houve falhas nos dados, cujas principais razões foram relacionadas às falhas de instrumentação, manutenção e calibração de instrumentos, transferência de dados, condições atmosféricas adversas (chuvas intensas, descargas elétricas), rejeição de dados (controle de qualidade) e vandalismo. Para a discussão, foram removidos os dados que não passaram por um controle de qualidade que consistiu na filtragem dos dados médios de $30 \mathrm{~min}$ de acordo com limites inferiores e superiores aceitáveis para cada variável, conforme descrito na Tabela A.1 do Apêndice A. Isto removeu efetivamente os dados com erros grosseiros. Adicionalmente, as estimativas duvidosas de LE foram removidas em casos suspeitos de mau funcionamento do analisador de $\mathrm{CO}_{2}$ e $\mathrm{H}_{2} \mathrm{O}$ (a deposição de gotículas de umidade e precipitação obstrui a janela do IRGA de caminho aberto, comprometendo a medida da concentração de $\mathrm{H}_{2} \mathrm{O}$ e consequentemente a de LE): as estimativas foram removidas nos eventos de precipitação em que ocorreram picos (outliers) na concentração de vapor d'água e mudanças na variável AGC (Automatic Gain Control). 
Tabela 2.2.1. Descrição das variáveis medidas (nome e símbolo utilizado no texto), instrumentação e geometria de instalação, nos sítios experimentais de Cerrado, Cana e Eucalipto.

\begin{tabular}{|c|c|c|c|c|c|c|c|}
\hline \multirow{2}{*}{ VARIÁVEL } & \multirow{2}{*}{ SÍMBOLO } & \multicolumn{3}{|c|}{ SENSOR } & \multicolumn{3}{|c|}{ POSIÇÃO (m) } \\
\hline & & CERRADO & CANA & EUCALIPTO & CERRADO & CANA & EUCALIPTO \\
\hline $\begin{array}{c}\text { Temperatura } \\
\text { do ar }\end{array}$ & $\mathrm{T}\left({ }^{\circ} \mathrm{C}\right)$ & $\begin{array}{l}\text { Psicrômetro } \\
\text { CSI HMP45C }\end{array}$ & $\begin{array}{l}\text { Psicrômetro } \\
\text { CSI HMP45C }\end{array}$ & $\begin{array}{l}\text { Psicrômetro } \\
\text { CSI HMP45C }\end{array}$ & 21 & 8,5 & 16 \\
\hline $\begin{array}{l}\text { Umidade } \\
\text { Relativa }\end{array}$ & UR (\%) & $\begin{array}{l}\text { Psicrômetro } \\
\text { CSI HMP45C }\end{array}$ & $\begin{array}{l}\text { Psicrômetro } \\
\text { CSI HMP45C }\end{array}$ & $\begin{array}{l}\text { Psicrômetro } \\
\text { CSI HMP45C }\end{array}$ & 21 & 8,5 & 16 \\
\hline Precipitação & Prec (mm) & $\begin{array}{c}\text { Pluviômetro } \\
\text { Hydrological } \\
\text { Services }\end{array}$ & $\begin{array}{c}\text { Pluviômetro } \\
\text { Hydrological } \\
\text { Services }\end{array}$ & - & 21 & 8,5 & 16 \\
\hline $\begin{array}{l}\text { Velocidade } \\
\text { do vento }\end{array}$ & $\mathrm{U}\left(\mathrm{ms}^{-1}\right)$ & $\begin{array}{l}\text { Anemômetro } \\
\text { RM Young }\end{array}$ & $\begin{array}{l}\text { Anemômetro } \\
\text { RM Young }\end{array}$ & $\begin{array}{l}\text { Anemômetro } \\
\text { MET ONE }\end{array}$ & 21 & 8,5 & 16 \\
\hline $\begin{array}{l}\text { Direção } \\
\text { do vento }\end{array}$ & $\operatorname{Dir}\left({ }^{\circ}\right)$ & $\begin{array}{l}\text { Anemômetro } \\
\text { RM Young }\end{array}$ & $\begin{array}{l}\text { Anemômetro } \\
\text { RM Young }\end{array}$ & $\begin{array}{l}\text { Anemômetro } \\
\text { MET ONE }\end{array}$ & 21 & 8,5 & 16 \\
\hline $\begin{array}{c}\text { Pressão } \\
\text { Atmosférica }\end{array}$ & Patm (hPa) & $\begin{array}{l}\text { Barômetro } \\
\text { Vaisala } \\
\text { PTB101B }\end{array}$ & $\begin{array}{c}\text { Barômetro } \\
\text { Vaisala } \\
\text { PTB101B }\end{array}$ & LI 7500 & 21 & 1 & 18 \\
\hline $\begin{array}{c}\text { Irradiância } \\
\text { solar global } \\
\text { incidente e } \\
\text { refletida }\end{array}$ & $\begin{array}{l}\mathrm{Ki} \text { e } \mathrm{Kr} \\
\left(\mathrm{Wm}^{-2}\right)\end{array}$ & $\begin{array}{l}\text { Piranômetro } \\
\text { Licor } 200 \mathrm{X}\end{array}$ & $\begin{array}{l}\text { Piranômetro } \\
\text { Licor } 200 X\end{array}$ & $\begin{array}{c}\text { Piranômetro } \\
\text { CMP } 3 \\
\text { Kipp \& Zonen }\end{array}$ & 21 & 8,5 & 16 \\
\hline $\begin{array}{l}\text { RFA } \\
\text { incidente e } \\
\text { refletida }\end{array}$ & $\begin{array}{l}\text { RFAi e } \\
\text { RFAr } \\
\left(\mathrm{Wm}^{-2}\right)\end{array}$ & $\begin{array}{l}\text { Licor Quantum } \\
\text { LI } 190\end{array}$ & $\begin{array}{c}\text { PAR LITE } \\
\text { Kipp \& Zonen }\end{array}$ & $\begin{array}{c}\text { PAR LITE } \\
\text { Kipp \& Zonen }\end{array}$ & 21 & 8,5 & 16 \\
\hline Saldo de radiaçao & $\begin{array}{c}\mathrm{Rn} \\
\left(\mathrm{Wm}^{-2}\right)\end{array}$ & $\begin{array}{l}\text { Saldo- } \\
\text { Radiômetro } \\
\text { REBS }\end{array}$ & $\begin{array}{l}\text { Saldo- } \\
\text { Radiômetro } \\
\text { REBS }\end{array}$ & $\begin{array}{c}\text { Saldo- } \\
\text { Radiômetro } \\
\text { NRLITE } \\
\text { Kipp \& Zonen }\end{array}$ & 21 & 8,5 & 16 \\
\hline $\begin{array}{l}\text { Fluxo de calor } \\
\text { no solo }\end{array}$ & $\begin{array}{c}\mathrm{G} \\
\left(\mathrm{Wm}^{-2}\right)\end{array}$ & REBS HFT3 & REBS HFT3 & REBS HFT3 & $(0,02)$ & $(0,02)$ & $(0,02)$ \\
\hline $\begin{array}{c}\text { Fluxo de calor } \\
\text { Latente } \\
\mathrm{e} \\
\mathrm{CO}_{2}\end{array}$ & $\begin{array}{c}\mathrm{LE} \\
\left(\mathrm{Wm}^{-2}\right) \\
\mathrm{Fc} \\
(\mu \mathrm{mol} \mathrm{de} \\
\left.\mathrm{CO}_{2} \mathrm{~m}^{-2} \mathrm{~s}^{-1}\right)\end{array}$ & $\begin{array}{l}\text { Anemômetro } \\
\text { sônico } \\
\text { Gill R2-A e } \\
\text { LI } 7500 *\end{array}$ & $\begin{array}{l}\text { Anemômetro } \\
\text { sônico } \\
\text { Gill R2-A e } \\
\text { LI } 6262 * *\end{array}$ & $\begin{array}{c}\text { Anemômetro } \\
\text { sônico } \\
\text { CSAT3 e } \\
\text { LI 7500* }\end{array}$ & 21 & 10,5 & 18 \\
\hline $\begin{array}{l}\text { Fluxo de calor } \\
\text { sensível }\end{array}$ & $\begin{array}{c}\mathrm{H} \\
\left(\mathrm{Wm}^{-2}\right)\end{array}$ & $\begin{array}{c}\text { Anemômetro } \\
\text { sônico } \\
\text { Gill R2-A }\end{array}$ & $\begin{array}{c}\text { Anemômetro } \\
\text { sônico } \\
\text { Gill R2-A }\end{array}$ & $\begin{array}{c}\text { Anemômetro } \\
\text { sônico } \\
\text { CSAT3 }\end{array}$ & 21 & 10,5 & 18 \\
\hline
\end{tabular}

* Analisador de Gás por Infravermelho (IRGA) do tipo caminho aberto.

** IRGA do tipo caminho fechado. 
Uma pequena parte de falhas nos dados de temperatura, umidade do ar, direção e intensidade do vento da estação meteorológica foram preenchidas por meio de regressão com as variáveis similares do sistema de EC. Algumas falhas nos dados diários de precipitação da cana foram preenchidas com dados coletados em um pluviômetro na Fazenda São José do Pulador, a $\sim 2 \mathrm{~km}$ da torre.

Exclusivamente no caso de falhas nas médias diárias de Patm e Ki, respectivamente, o preenchimento foi feito por meio de regressão linear entre dois sítios experimentais. Posteriormente foram preenchidas as falhas de Rn e RFAi, pelas relações lineares de dependência destas variáveis com Ki. Neste procedimento particular, geralmente utilizaram-se períodos adjacentes às falhas (pelo menos 3 vezes a janela da falha), dependendo da localização das mesmas.

Os totais diários dos fluxos de superfície foram calculados pela somatória das médias de 30 min. As falhas nos dados de 30 min dos fluxos turbulentos LE e H não foram preenchidas. Para a análise da variação sazonal daqueles fluxos, utilizou-se uma série histórica dos totais diários, cujas falhas foram preenchidas com funções de dependência linear de LE, ou H, com Rn (ou Rn-G, no caso da cana), que totalizaram 12\%,15\% e 7\% dos dados, na cana, cerrado e eucalipto, respectivamente.

As médias diárias do albedo solar $(\alpha)$ e do albedo da radiação fotossintéticamente ativa $\left(\alpha_{\mathrm{v}}\right)$ foram calculados como $\alpha=\Sigma \mathrm{Ki} / \Sigma \mathrm{Kr}$, e $\alpha_{\mathrm{v}}=\Sigma \mathrm{RAFr} / \Sigma \mathrm{RAFi}$, respectivamente, com dados de 30 min para a somatória das $24 \mathrm{~h}$.

Para fins de discussão dos dados, definiram-se médias para cinco períodos de tempo ao longo do ano, sobre os quais se testou a diferença estatística das médias, respectivamente: período úmido de 2005 (Fevereiro, 2005), transição do período úmido para o seco (Março a Maio, 2005), seco (Junho a Agosto, 2005), transição do período seco para o úmido (Setembro a Novembro, 2005) e úmido de 2006 (Dezembro, 2005 - Fevereiro, 2006).

\subsection{ESTIMATIVAS DOS FLUXOS TURBULENTOS}

O escoamento do ar próximo à superfície está associado aos vórtices turbulentos (ou “eddies”), através dos quais as parcelas de ar deslocam-se carregando consigo propriedades tais como calor, umidade, momento ou poluição. Estes mecanismos descrevem os chamados fluxos 
turbulentos: fluxo de calor sensível $(H)$, fluxo de calor latente $(L E)$, fluxo de momento $(\tau)$, fluxo de um escalar ou poluente $\left(F_{\chi}\right)$. De uma forma geral os fluxos de superfície representam o principal mecanismo de interação entre a biosfera e a atmosfera.

A técnica de eddy covariance ou eddy correlation (EC) é um tipo de abordagem observacional micrometeorológica que fornece amostras destes vórtices turbulentos para quantificar os fluxos verticais $(H, L E, F c)$ na interface superfície-atmosfera. Embora a medida seja feita em um único ponto na área amostrada, chamada de footprint, podem-se amostrar dimensões que variam de centenas de $\mathrm{m}$ a km (Schimid 1994). A aplicação da EC é fundamentada na suposição de que os vórtices turbulentos, enquanto advectados através do sensor, por um escoamento estacionário e homogêneo, mantêm suas propriedades inalteradas (Hipótese de Taylor, ver p. ex. Stull 1988, p. 5-7).

Segundo a teoria de EC o fluxo vertical total médio de uma grandeza escalar $c$ é dado por:

$$
F_{c}=\overline{w \cdot \rho_{c}}
$$

onde, $w$ é a velocidade vertical do vento, $\rho_{c}$ é a densidade (ou a concentração atmosférica) do escalar $c$ e a barra representa a média temporal em um intervalo de tempo apropriado.

Usando as formulações de Reynolds para cálculo da média as variáveis à direita da equação (2.3.1) podem ser decompostas da seguinte forma:

$$
w=\bar{w}+w^{\prime} \quad \text { e } \rho_{c}=\bar{\rho}_{c}+\rho_{c}^{\prime}
$$

onde $\bar{w}$ e $\bar{\rho}_{c}$ são as componentes médias e $w^{\prime}$ e $\rho_{c}$ ' as flutuações instantâneas em torno da média da velocidade vertical do vento e da densidade da grandeza escalar c, respectivamente. Substituindo estas duas expressões em (2.3.1) e aplicando as propriedades da média de Reynolds, obtém-se:

$$
F_{c}=\bar{w} \cdot \overline{\rho_{c}}+\overline{w^{\prime} \cdot \rho_{c}^{\prime}}
$$

(I) (II)

A razão principal desta decomposição é justamente o fato do campo turbulento (') ser responsável pelo transporte efetivo das quantidades, na forma dos fluxos turbulentos. Estes são, 
assim, definidos como o transporte da componente turbulenta da propriedade pelo campo turbulento do vento (II). O transporte da componente média da propriedade pelo campo de vento médio é chamado de transporte advectivo (I). Por hipótese, considera-se um intervalo de tempo tal que quantidade total de ar ascendente seja aproximadamente igual à quantidade de ar descendente, isto é, $\bar{w}=0$. Desta forma, o fluxo turbulento de uma grandeza escalar $c$ pode ser expressa como:

$$
F_{c}=\overline{w^{\prime} \cdot \rho_{c}^{\prime}}+F_{\text {correção }}
$$

Portanto, na prática esta técnica consiste em fazer observações em alta freqüência tanto da propriedade que se quer estimar o fluxo quanto da componente do vento na direção em que o fluxo ocorre. A partir de um grande número de amostras de ambas variáveis calcula-se a covariância estatística entre as duas variáveis (a média do produto dos desvios de cada uma dessas variáveis em relação a sua média). Fluxos positivos representam transferência de massa ou energia da superfície para a atmosfera e valores negativos o oposto.

O termo $F_{\text {correção }}$ está associado aos efeitos de mudança na densidade do ar causados pelas flutuações da temperatura e vapor d'água (Webb et al., 1980). Esta correção freqüentemente chamada de correção de Webb é aplicada somente no caso das medidas de concentração de $\mathrm{H}_{2} \mathrm{O}$ e $\mathrm{CO}_{2}$ por analisadores de gás infravermelho do tipo aberto. Os fluxos de calor sensível também foram corrigidos levando em consideração a variação do calor específico com a umidade específica (Stull 1988, p. 428). Os efeitos destas correções nos fluxos podem variar de 3 a $10 \%$.

Os fluxos de superfície foram calculados sobre o intervalo de tempo de $30 \mathrm{~min}$ usando as seguintes formulações:

$$
\begin{aligned}
& \tau=-\rho \overline{w^{\prime} U^{\prime}}=-\rho u_{*}^{2} \\
& L E=\bar{\lambda} \overline{w^{\prime} \rho_{w}^{\prime}}=\lambda\left(1+\frac{\bar{\rho}_{w} m_{d}}{\rho_{d} m_{w}}\right)\left(\overline{w^{\prime} \rho_{w}^{\prime}}+\overline{\rho_{w}} \frac{\overline{w^{\prime} T^{\prime}}}{\bar{T}}\right) \\
& H=\bar{\rho} \overline{c_{p}} \overline{w^{\prime} T^{\prime}}=\bar{\rho} c_{p d}\left(\overline{w^{\prime} T^{\prime}}+0,84 \bar{T} \overline{w^{\prime} q^{\prime}}\right)
\end{aligned}
$$


onde $\tau$ é o fluxo de momentum, $u *$ é a velocidade de atrito, $U$ é a velocidade horizontal do vento, $w$ é a velocidade vertical do vento, $T$ é a temperatura do ar, $\mathrm{m}_{\mathrm{d}} / \mathrm{m}_{\mathrm{w}}$ é a razão entre o peso molecular do ar seco e o do vapor d'água, $\lambda$ é o calor latente de evaporação da água, $c_{p}$ e $c_{p d}$ são os calores específicos do ar e ar seco a pressão constante, respectivamente, e $\rho, \rho_{d}$ e $\rho_{w}$, são as densidades do ar, ar seco e $\mathrm{H}_{2} \mathrm{O}$, respectivamente. 


\subsection{TENDÊNCIAS CLIMÁTICAS REGIONAIS}

Nesta segunda componente do estudo será feita uma análise climatológica para SP, com ênfase na variação da precipitação e da temperatura do ar no centro-norte do estado. Apresenta-se inicialmente uma climatologia da precipitação em SP, calculada utilizando-se 40 anos de dados diários de precipitação (no período de 1961-2000), coletados em 1080 estações meteorológicas do DAEE/SP. Alguns detalhes da metodologia, juntamente com a climatologia da precipitação sazonal, são encontrados no Apêndice B.

Também será feita uma análise da variabilidade da precipitação em escala regional no centro-norte de SP, utilizando-se a média de aproximadamente 200 estações do DAEE/SP, todas ao norte de $22^{\circ} \mathrm{S}$. As estações foram separadas por dois setores de localização: as estações no Oeste do estado, entre 49 e $52^{\circ} \mathrm{W}$, e no Leste do estado, entre $46^{\circ}$ e $49^{\circ} \mathrm{W}$ (vide Fig. B. 1 do Apêndice B). No setor Leste houve desde 1940 um aumento substancial de estações $(\sim 120)$, enquanto no setor Leste houve crescimento do número de estações com o tempo, desde 1940 até 1970, quando se estabilizou em $\sim 100$ estações (Fig. 2.4.1).

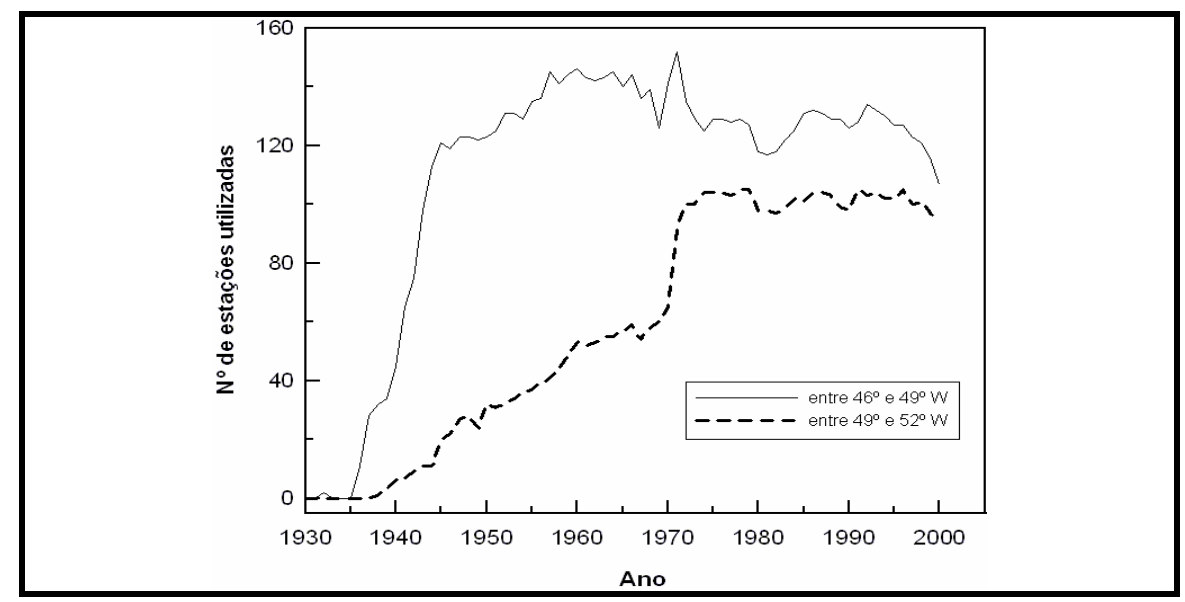

Figura 2.4.1. Número de estações pluviométricas do DAEE, no estado de $\mathrm{SP}$, ao norte de $22^{\circ} \mathrm{S}$, no setor Oeste do estado, entre 49 e $52^{\circ} \mathrm{W}$, e no setor Leste do estado, entre $46^{\circ}$ e $49^{\circ} \mathrm{W}$.

Na seqüência, serão estimadas as tendências de longo prazo de temperatura do ar e da precipitação, a partir de séries históricas de temperatura (máxima e mínima) e precipitação diária, observadas nas estações de Campinas ( $\left.22^{\circ} 54^{\prime} \mathrm{S}, 47^{\circ} 05^{\prime} \mathrm{W}, 674 \mathrm{~m}\right)$ e Ribeirão Preto $\left(22^{\circ} 11^{\prime} \mathrm{S}, 47^{\circ}\right.$ 
48' W, $621 \mathrm{~m}$ ). Estas estações meteorológicas foram escolhidas devido à disponibilidade de dados suficientes para uma análise de longo prazo, com dados no período de 1890-2000 (Campinas) e 1943-2000 (Ribeirão Preto). Estes dados foram submetidos a um controle de qualidade e testes de homogeneidade (veja abaixo). Adicionalmente dados de direção de vento da estação de Campinas no período de 2000 a 2003 também foram usados para se avaliar a representatividade das medidas de temperatura. Apesar de um curto período de dados os resultados encontrados concordaram plenamente com os encontrados por Barbano et. al 2003, que determinaram a climatologia da freqüência da direção do vento para estação de Campinas. Infelizmente, para Ribeirão Preto estas informações não foram disponibilizadas. Alternativamente, utilizaram-se dados observados em Sertãozinho (município localizado $15 \mathrm{~km} \mathrm{a}$ noroeste da estação de Ribeirão Preto), durante o período de 1997-1998 (Rocha, 1998).

$\mathrm{Na}$ análise das tendências de temperatura nas últimas duas décadas, analisou-se conjuntamente a temperatura do ar à superfície das reanálises de modelos de circulação geral. Este procedimento decorre de Kalnay e Cai (2003), que recentemente introduziram um método para estimar o impacto das mudanças de uso da terra e da urbanização, pela comparação das tendências de temperatura observadas em estações meteorológicas com aquelas de reanálises do NCEP/NCAR (R-1, Kalnay et al. 1996). Este método foi posteriormente denominado “observação menos reanálises” (OMR) (Kalnay et al. 2006). Nos dados R-1 as observações de superfície, com exceção da pressão atmosférica, não são usadas sobre o continente, somente sobre o oceano. As temperaturas à superfície são estimadas a partir de dados de sondagens verticais da atmosfera combinadas com as parametrizações dos processos de superfície do modelo (Kalnay et al. 1996). Por isso, os dados R-1 são considerados insensíveis às alterações das propriedades de superfície e consequentemente aos controles regionais e locais na variabilidade da temperatura.

A essência do OMR é identificar, pelo menos parcialmente, o impacto das mudanças do uso da terra e de outras forçantes próximas à superfície, através da diferença entre as tendências das observações (que refletem o efeito de todas forçantes climáticas, inclusive as de superfície) e as de R-1 (que somente contém o efeito das forçantes que influenciam as tendências de temperatura atmosféricas assimiladas). Assim, este procedimento permite cancelar as tendências devido à variabilidade natural do clima (presentes em ambas as observações e R-1, Kalnay et al. 2006) e atribuir a diferença entre os conjuntos de dados, principalmente aos efeitos de mudança 
na cobertura de superfície. Entretanto, uma parte desta diferença pode também ser devido a efeitos não climáticos e erros de interpolação dos dados R-1 para a altura do instrumento.

\section{Qualidade dos dados de Reanálises}

O método OMR assume que a temperatura do ar a superfície de R-1 é satisfatória. Entretanto, os dados R-1 contém vários erros bem documentados (Kistler et al. 2001) relacionados à descrição da nebulosidade e da umidade do solo que foram corrigidos nas reanálises do National Center for Environmental Prediction /Department of Energy (NCEP/DOE), Atmospheric Model Intercomparison Project (AMIP)-II Reanalysis (aqui referenciados como R-

2). Consequentemente, os dados de R-2 devem caracterizar melhor a temperatura próxima à superfície sobre o continente (Kanamitsu et al. 2002).

Uma segunda questão a ser considerada sobre os dados R-1, é a dificuldade de usá-los para estimativas de tendências climáticas de longo prazo por duas razões: i) mudanças nos sistemas de observação, como por exemplo na década 1950 (quando houve mudanças na densidade e horários das radiossondagens) e em 1978 (quando dados de satélites foram incluídos); estas mudanças são associadas a "saltos" na série climatológica de R-1, podendo gerar tendências artificiais (Kistler et al. 2001); ii) as reanálises não são explicitamente alteradas para refletir as mudanças na composição atmosférica, tais como os gases estufa e também outras mudanças na atmosfera, tais como os aerossóis (ambos de origem natural e antropogênica) (Trenberth, 2004). Em relação a esta última deficiência, Cai e Kalnay (2005) mostraram analiticamente que as reanálises reproduzem essencialmente a intensidade das tendências antropogênicas presentes nas observações que são usadas no sistema de assimilação de dados.

Neste trabalho o método OMR foi adotado levando em consideração os problemas acima mencionados. Optou-se por utilizar os dados diários de temperatura a $2 \mathrm{~m}$ de R-2, com uma grade gaussiana de resolução espacial de $\sim 1,9^{\circ}$ (Kanamitsu et. al. 2002), no período de 1979 a 2000. Para melhor representar as localidades de Ribeirão Preto e Campinas, a temperatura do ar estimada nos dados R-2 foi interpolada linearmente dos pontos adjacentes para cada estação. A partir das médias mensais da temperatura máxima e da temperatura mínima, calculou-se a amplitude térmica mensal subtraindo-se a primeira da segunda, respectivamente, para ambos os conjuntos de dados. Então, as anomalias mensais foram calculadas pela remoção do ciclo anual 
médio de 22 anos. Este procedimento tem a vantagem de eliminar efetivamente os erros sistemáticos dos dados de reanálises (Cai e Kalnay, 2005). O período selecionado é menor do que as séries históricas das estações devido à menor disponibilidade de dados R-2.

\section{Qualidade e Homogeneidade das séries climáticas de Campinas e Ribeirão Preto}

Os dados de temperatura e precipitação observados nas estações de Campinas e Ribeirão Preto, antes das análises de tendências, foram submetidos a um controle de qualidade e em seguida a um teste de homogeneidade, particularmente no caso das séries de temperatura. Estes procedimentos foram realizados com o pacote Rclimdex, escrito na linguagem $\mathrm{R}$ e desenvolvido pelo Serviço Meteorológico do Canadá (com software e documentação disponível para download em http://cccma.seos.uvic.ca/ETCCDMI). A primeira etapa do controle de qualidade consistiu em testes lógicos como: temperatura máxima menor ou igual à temperatura mínima e valores de precipitação negativos. Os erros mais freqüentes foram os identificados pelo primeiro teste, onde os valores da coluna de Tmax e Tmin ou estavam trocados, ou repetidos, sendo o valor inconsistente rejeitado. $\mathrm{Na}$ segunda etapa, foram listados os dados potencialmente errôneos, definidos como valores que excedessem um determinado limiar. O limiar escolhido para definição de um outlier para os dados diários de temperatura (Tmax e Tmin) foi de 4 vezes o desvio padrão (calculado individualmente para cada dia do ano em relação ao período de referência, 1961-1990). Estes limiares foram escolhidos (após tentativas com vários limiares) com compromisso de resguardar que erros severos fossem selecionados sem incluir também muitos valores corretos nas listas. Para os dados diários de precipitação não foi aplicado este teste, os casos de precipitação maior que $100 \mathrm{~mm} \mathrm{dia}^{-1}$ foram identificados por inspeção visual da série diária (através de gráficos) e verificados para se assegurar que os dias adjacentes não eram faltantes, ou seja, para certificar-se que altos valores não foram resultantes de precipitação acumulada em vários dias.

$\mathrm{Na}$ seqüência analisou-se a homogeneidade das séries temporais. Uma série temporal homogênea é definida quando as suas variações são causadas somente por variações do tempo e do clima (Conrad \& Pollak, 1950). Entretanto, séries climatológicas de longo prazo frequentemente contêm inomogeneidades causadas por fatores não climáticos, tornando os dados não representativos da variação climática real que ocorreu no tempo. Estes fatores incluem 
mudanças em: práticas de observação, instrumentos , localização da estação, ambiente da estação, método usado no cálculo da média diária, entre outros. Estas mudanças podem ser súbitas ou graduais. Portanto, é essencial considerar estes fatores para a remoção das inomogeneidades de séries climáticas, ou pelo menos alertar sobre os possíveis erros que eles podem causar. Diversos métodos foram desenvolvidos para detectar inomogeneidades e ajustar os dados para compensar os desvios por elas produzidos (ver Peterson et al. 1998, para uma revisão detalhada). Contudo, o ajuste de homogeneidade de uma série pode ser muito complexo (Aguilar et. al 2003) e exigir frequentemente dados de estações vizinhas, informações detalhadas sobre o histórico da estação e uma grande quantidade de tempo. A estação de Ribeirão Preto foi visitada em Abril de 2006, segundo o responsável local (Antônio Carlos Machado de Vasconcelos, IAC/Ribeirão Preto, comunicação pessoal) as informações históricas da estação assim como os dados registrados são enviados diretamente para sede principal do IAC em Campinas. Adicionalmente, ele alertou que a partir de 1993 a área ao redor da estação é ocupada para realização do evento Agropecuário Agrishow, que ocorre anualmente no mês de maio, reunindo cerca de 130000 pessoas. Em maio de 2006, o Centro de Ecofisiologia, Biofísica e Climatologia Agrícola, localizado em Campinas (responsável pela rede de estações meteorológicas do IAC), foi consultado na tentativa de um levantamento histórico das duas estações, mas infelizmente nenhuma informação sobre a estação de Ribeirão Preto foi disponibilizada, e sobre a estação de Campinas foi apenas informado que houve uma mudança na localização da estação, por volta da década de 60 , para um ponto a $~ 3$ $\mathrm{km}$ de distância da sua posição original e com uma diferença de altitude de $\sim 10 \mathrm{~m}$. Durante as visitas, as estações foram fotografadas; estas informações são encontradas no Apêndice C. Desta forma, o objetivo deste trabalho foi identificar somente os problemas mais graves nas séries temporais, tendo em vista a precariedade de informações históricas das estações.

Para cada estação as séries temporais da Tmax e Tmin média anual foram testadas separadamente usando o método de regressão de duas fases, proposto por Easterling \& Peterson (1995) e posteriormente revisado por Lund \& Reeves (2002) e Wang (2003). Um guia prático para utilização deste método é encontrado em Wang \& Feng (2004).

A Fig. 2.4.2 apresenta os resultados do teste de homogeneidade para as duas estações. A estação de Campinas com período de dados disponível maior (1890-2000) mostrou 3 descontinuidades (Fig 2.4.2.a) enquanto a de Ribeirão Preto mostrou 2 descontinuidades (tanto para Tmax quanto para Tmin) (Fig 2.4.2.b). Das 3 descontinuidades na Tmax em Campinas, 2 
foram estatisticamente significativas (N.S. < 5\%): em 1903 (ou seja, entre 1903-1904) com um grande "degrau" de $-2,17^{\circ} \mathrm{C}$, e outra em 1963 com um "degrau" de $-1,23{ }^{\circ} \mathrm{C}$. Em Ribeirão Preto apenas uma descontinuidade na Tmax foi identificada com significância estatística: em 1963, com um degrau de $-1^{\circ} \mathrm{C}$. Para a Tmin de Campinas assim como na Tmax, uma descontinuidade significativa foi detectada em 1903, porém com menor intensidade (degrau de $-0,9{ }^{\circ} \mathrm{C}$ ) que naquela. No caso de Ribeirão Preto a Tmin não mostrou descontinuidades significativas. Entretanto, deve-se destacar que a decisão sobre ajustar ou rejeitar uma série, dependerá do histórico da estação, ou seja, se houver alguma causa documentada para aquela (s) descontinuidade(s) (mesmo que ela não indique significância estatística para um determinado nível).

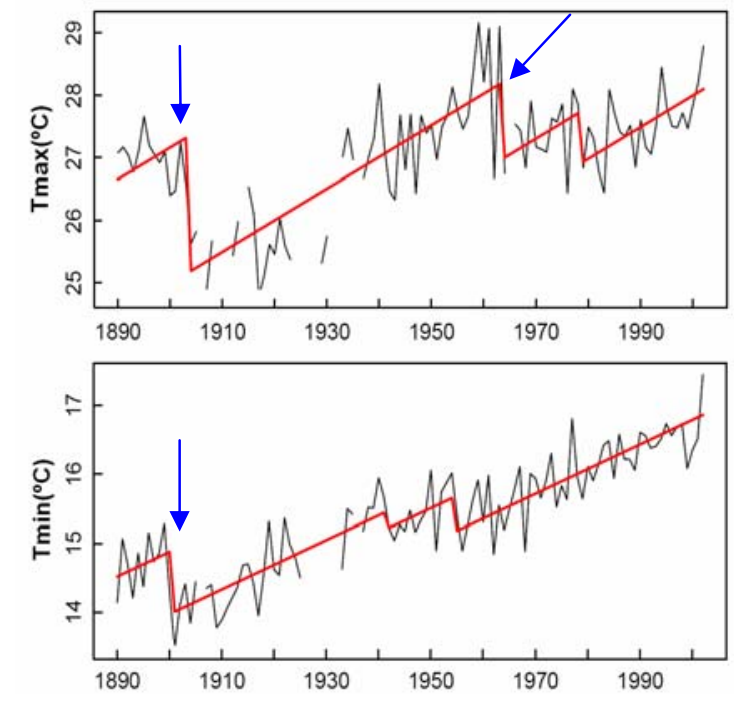

(a)
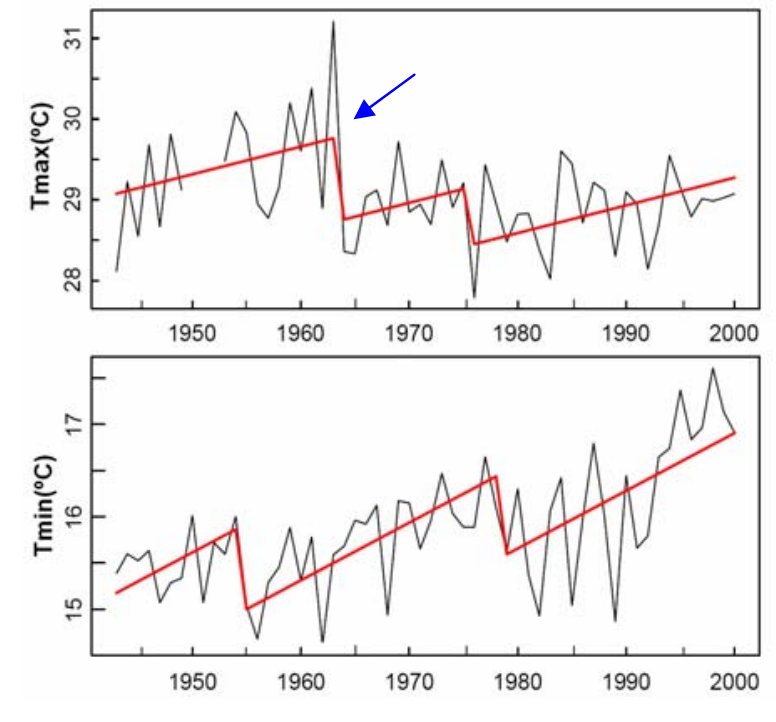

(b)

Figura 2.4.2. Série da temperatura máxima (superior) e mínima (inferior) média anual das estações meteorológicas do IAC de (a) Campinas e (b) Ribeirão Preto. A linha vermelha representa a reta de regressão ajustada para os diferentes segmentos das séries. Anos com mais de 10\% de dados faltantes não são plotados. As setas em azul localizam os pontos onde as mudanças abruptas foram estatisticamente significativas (N.S. $<5 \%$ ).

Devido à grande magnitude da descontinuidade encontrada na Tmax média anual de Campinas em 1903 (-2,17 ${ }^{\circ} \mathrm{C}$, Fig. 2.4.2.a, superior) e por também revelar-se na Tmin, optou-se por descartar os dados de Tmax e Tmin do período entre 1890 e 1942. Nota-se que a 
descontinuidade de 1963 na Tmax foi detectada nas séries das duas estações meteorológicas, o que leva a supor que um evento climático de impacto regional afetou a Tmax, já que a estação de Ribeirão Preto fica a 200 km da estação de Campinas. O ano de 1963 foi caracterizado por um episódio de El Niño fraco, sendo seguido de um La Niña moderado em 1964, esta transição pode ter colaborado para aquela mudança verificada nas séries. Outro aspecto interessante é que os máximos da série de Tmax anual ocorreram no início da década de 1960, nas duas localidades. Como a temperatura média anual é derivada da Tmax e Tmin, então o aumento da temperatura média anual nos últimos 50 anos não é conseqüência de um aumento generalizado de Tmax e Tmin, mas devido ao maior aumento da Tmin em comparação a Tmax anual.

Levando em consideração a discussão acima, o período efetivamente selecionado foi de 1943-2000, o qual inclui 58 anos de dados comuns às duas estações. 


\section{RESULTADOS}

\subsection{VARIABILIDADE SAZONAL}

Para entender como o clima, a fenologia e as formas de manejo alteram o balanço de energia de cada tipo de vegetação, inicialmente examinou-se o padrão sazonal das variáveis climáticas (precipitação, pressão, vento, temperatura, umidade, irradiância solar, albedo) observadas nas áreas experimentais. Na seqüência, os fluxos de calor sensível e latente são analisados e as temperaturas observadas sobre cada tipo de vegetação são comparadas.

\section{CLIMA}

Antes de analisar os dados climáticos das torres micrometeorológicas, primeiramente foram examinadas as características gerais do clima da região de Santa Rita do Passa Quatro, no período de 1961-1990. Os resultados e as informações detalhadas sobre os dados utilizados são encontrados no Apêndice B.

A precipitação acumulada nas áreas experimentais no período de estudo (7/02/2005 6/02/2006) foi de $941 \mathrm{~mm}$ (cerrado), $997 \mathrm{~mm}$ (cana) e $955 \mathrm{~mm}$ (eucalipto) (Tabela 3.1.1). A medida no eucalipto pode ter sido levemente subestimada devido a algumas falhas de dados. Estes valores mostraram-se muito próximos entre si, e foram de 33 a 37\% abaixo da média anual climatológica (igual a $1498 \mathrm{~mm}$ ). Destaca-se uma substancial estiagem de meados de Fevereiro a meados de Março de 2005 (Fig. 3.1.1), quando o mês de fevereiro de 2005 ficou $120 \mathrm{~mm}$ abaixo da normal. O mês de janeiro de 2006 ficou $~ 140 \mathrm{~mm}$ abaixo da normal, destacando-se também como um desvio negativo (Tabela 3.1.1). De forma oposta, no mês de maio de 2005 houve um evento extremo no final do mês (acima de $90 \mathrm{~mm}_{\text {pentada }}{ }^{-1}$, nas três áreas, Fig. 3.1.1), que proporcionou um total mensal duas vezes maior que a normal. Com relação ao início da estação chuvosa, as primeiras chuvas começaram em setembro, mas recuperaram-se apenas no final do mês de outubro (Fig. 3.1.1.a,b).

A pressão atmosférica média diária mostrou mínimos na estação chuvosa ( $930 \mathrm{hPa}$ no cerrado, $\sim 950 \mathrm{hPa}$ na cana e $925 \mathrm{hPa}$ no eucalipto), e máximos na estação seca ( $\sim 940 \mathrm{hPa}$ no cerrado e $\sim 960 \mathrm{hPa}$ na cana) (Fig. 3.1.2.a), com amplitude anual de $\sim 8 \mathrm{hPa}$. A diferença da pressão entre a cana e o eucalipto (cerrado) foi sistemática, de $\sim 26 \mathrm{hPa}$ (20 hPa), simplesmente devido às diferenças de altitude. 
Tabela 3.1.1. Totais mensais de precipitação $(\mathrm{mm})$ observados nas 3 áreas e normais climatológicas da região no período de 1961-1990. Os valores acima da normal estão em negrito. Os cinco períodos definidos foram: úmido (Fev de 2005), transição do período úmido para seco (Mar - Mai 2005), seco (Jun - Ago 2005), transição do período seco para úmido (Set - Nov 2005) e úmido (Dez 2005 - Fev 2006).

\begin{tabular}{|c|c|c|c|c|}
\hline \multirow[b]{2}{*}{ Mês/Ano } & \multicolumn{3}{|c|}{ Sítios experimentais } & \multirow{2}{*}{$\frac{\text { Normal }}{1960-90}$} \\
\hline & Cerrado & Eucalipto & Cana & \\
\hline Fevereiro/2005 & 97 & 79,2 & 83,6 & 217 \\
\hline Março/2005 & 156,7 & 178,6 & 151,8 & 170 \\
\hline Abril/2005 & 39,4 & 29,1 & 64 & 81 \\
\hline Maio/2005 & 87,7 & 120,4 & 101,9 & 54 \\
\hline Junho/2005 & 18,7 & 21,1 & 8,13 & 32 \\
\hline Julho/2005 & 30,6 & 26,4 & 29,2 & 24 \\
\hline Agosto/2005 & 0,7 & 0,7 & 2,25 & 24 \\
\hline Setembro/2005 & 84 & 88,6 & 88,5 & 66 \\
\hline Outubro/2005 & 113,3 & 97,9 & 44,5 & 134 \\
\hline Novembro/2005 & 85,4 & 87,9 & 100 & 174 \\
\hline Dezembro/2005 & 122 & 189,6 & 251 & 256 \\
\hline Janeiro/2006 & 132,3 & $53,5^{*}$ & 119,6 & 266 \\
\hline Período úmido/2005 & 97 & 79,2 & 83,6 & 217 \\
\hline Transição úmido-seco & 283,7 & 328,1 & 317,8 & 305 \\
\hline Período seco & 50,7 & 48,2 & 40 & 80 \\
\hline Transição seco-úmido & 282,6 & 274,4 & 233 & 374 \\
\hline Período úmido/2006 & 254,3 & $243,1^{*}$ & 370,6 & 522 \\
\hline Total & 967,5 & $973^{*}$ & 1044,6 & 1498 \\
\hline $7 / 02 / 2005$ a $6 / 02 / 2006$ & 941 & $955^{*}$ & 997 & - \\
\hline
\end{tabular}

"Valores provavelmente subestimados devido às falhas dos dados

A velocidade média diária do vento mostrou uma razoável variação sazonal, sendo maior na transição do período seco para úmido, nas três áreas: $2,2 \mathrm{~m} \mathrm{~s}^{-1}$ na cana, $3,4 \mathrm{~m} \mathrm{~s}^{-1}$ no cerrado e 2,4 $\mathrm{m} \mathrm{s}^{-1}$ no eucalipto (Tabela 3.1.2, Fig. 3.1.2.b). No evento do corte da cana surge o aumento da velocidade de 1 para $2 \mathrm{~m} \mathrm{~s}^{-1}$, que deve ter decorrido da diminuição da rugosidade de superfície, ao mesmo tempo em que houve uma redução da velocidade do vento no cerrado. De forma geral, observam-se picos acima de $5 \mathrm{~m} \mathrm{~s}^{-1}$ na cana e no cerrado, em eventos isolados de precipitação. 


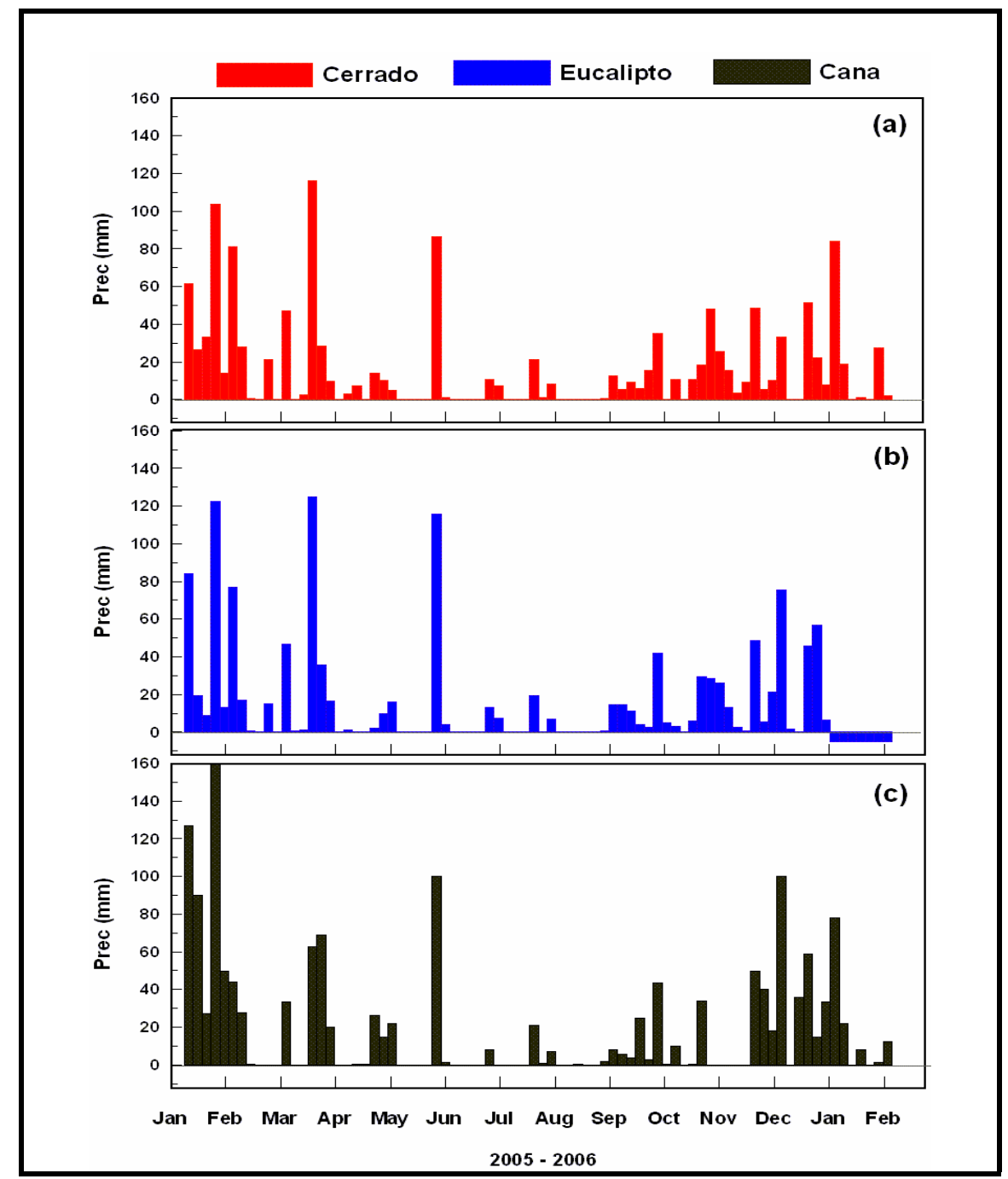

Figura 3.1.1. Precipitação acumulada em cinco dias ( $\mathrm{mm} \mathrm{pentada}^{-1}$ ) no (a) cerrado, (b) eucalipto e (c) cana. Barras negativas indicam ausência de dados. Período de 1/01/2005 a 6/02/2006.

No eucalipto a intensidade do vento foi levemente maior que na cana (Fig. 3.1.2.b), mas menor que no cerrado, por todo período de observação (Tabela 3.1.2). A razão destas diferenças não foi totalmente analisada, sendo possíveis os seguintes elementos para uma discussão: diferenças nos parâmetros aerodinâmicos, como o comprimento de rugosidade e o deslocamento do plano zero; efeito da turbulência no sensor do cerrado devido ao setor com rebaixamento topográfico à montante do escoamento; efeito de aumento da turbulência na subcamada de rugosidade do eucalipto, devido ao fato do sensor estar a $2 \mathrm{~m}$ acima do nível da copa; e circulações de efeito topográfico devido à diferença de altitude entre as áreas. 


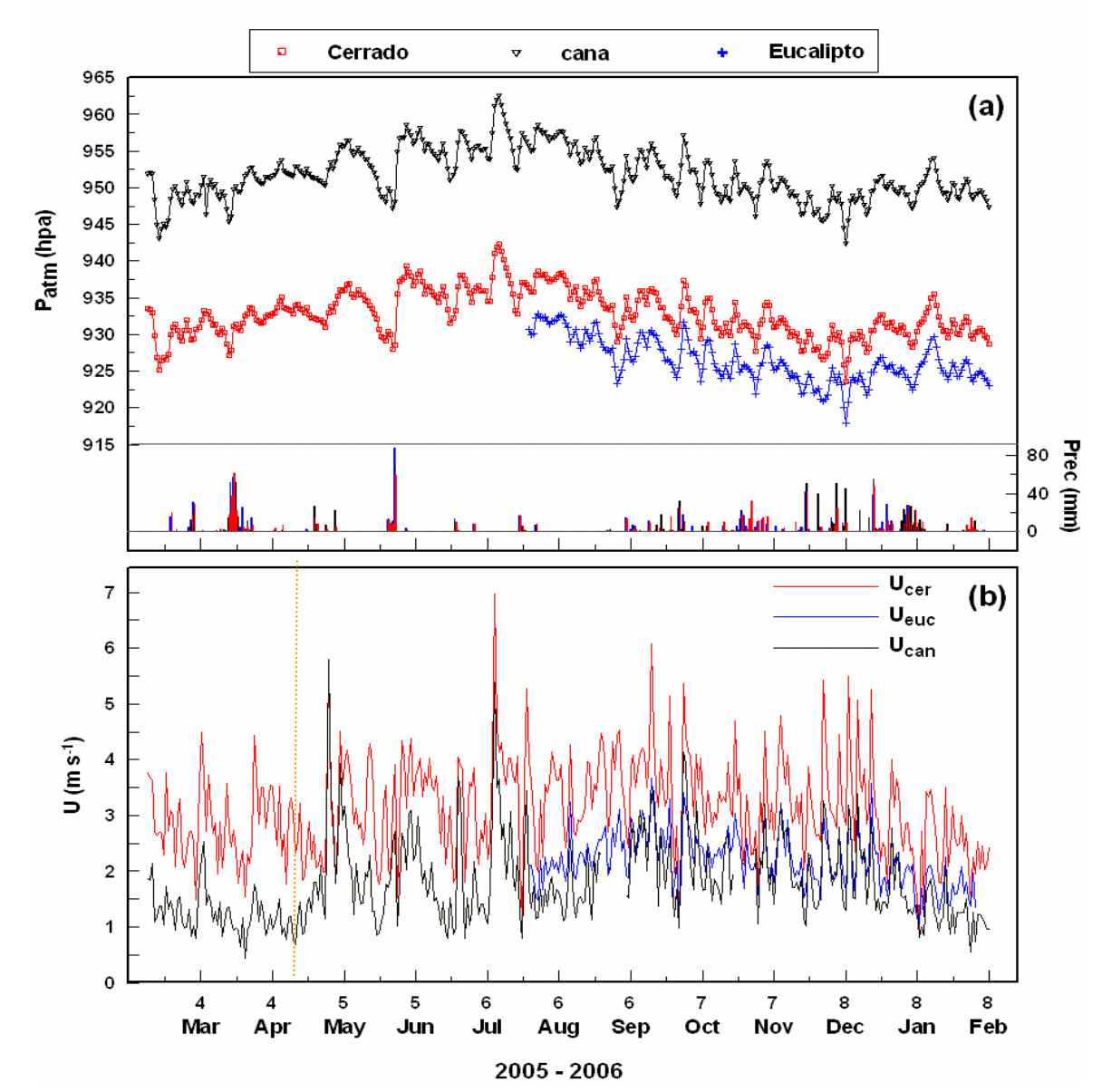

Figura 3.1.2. Variação das médias diárias da (a) pressão atmosférica (Patm), em $\mathrm{hPa}, \mathrm{e}(\mathrm{b})$ da velocidade do vento (U) em $\mathrm{m} \mathrm{s}^{-1}$ no cerrado, eucalipto e na cana. A precipitação em $\mathrm{mm} \mathrm{dia}^{-1}$ (Prec) é mostrada na escala a direita de (a). Os dados são mostrados para o período de 7/02/2005 a 6/02/2006 para a cana e o cerrado, e de 22/07/2005 a 06/02/2006 para o eucalipto.

A média diária da temperatura do ar acima da copa (Fig. 3.1.3.a) situou-se entre $28^{\circ} \mathrm{C} \mathrm{e}$ $11^{\circ} \mathrm{C}$ nas três áreas, o que se mostrou de acordo com a variabilidade sazonal climatológica regional (vide Apêndice B). As temperaturas médias anuais no cerrado $\left(22,3^{\circ} \mathrm{C}\right)$ e na cana $\left(22^{\circ} \mathrm{C}\right)$ ficaram dentro do desvio padrão médio interanual da média climatológica da região $(22,1 \pm 0,5$ $\left.{ }^{\circ} \mathrm{C}\right)$. A passagem de frentes frias e as estiagens intermitentes causaram variações substanciais na amplitude térmica diária (ATD), as quais foram mais acentuadas na cana (Fig. 3.1.3.b). A ATD 
na cana foi sempre superior às demais áreas, o que decorreu de sua maior temperatura máxima e menor temperatura mínima. Estas diferenças na ATD, assim como as implicações da maior velocidade do vento no cerrado serão discutidas detalhadamente no final desta seção.

Tabela 3.1.2. Valores médios da umidade específica (q) em $\mathrm{g} \mathrm{Kg}^{-1}$, umidade relativa (UR) em $\%$ e velocidade do vento (U) em $\mathrm{m} \mathrm{s}^{-1}$, na cana (Can), cerrado (Cer) e eucalipto (Euc). ND indica a ausência de dados. Os valores sombreados do teste t-student indicam se as médias comparadas são estatisticamente diferentes para o nível de significância (N.S.) $<5 \%$.

\begin{tabular}{|c|c|c|c|c|c|c|c|c|c|c|}
\hline & Can & Cer & Euc & $\begin{array}{c}\text { teste-t } \\
(\mathrm{Can} / \mathrm{Cer}) \\
\end{array}$ & $\begin{array}{c}\text { teste-t } \\
(\mathrm{Euc} / \mathrm{Cer}) \\
\end{array}$ & Can & Cer & Euc & $\begin{array}{c}\text { teste-t } \\
\text { (Can/Cer) } \\
\end{array}$ & $\begin{array}{c}\text { teste-t } \\
\text { (Euc/Cer) } \\
\end{array}$ \\
\hline \multicolumn{5}{|c|}{ Período úmido 2005} & \multicolumn{6}{|c|}{ Transição (úmido - seco) } \\
\hline $\mathrm{q}$ & 13,3 & 12,2 & ND & 1,68 & ND & 13,3 & 12,6 & ND & 2,6 & ND \\
\hline UR & 72,6 & 62,1 & ND & 3,61 & ND & 76,7 & 69,9 & ND & 5,10 & ND \\
\hline $\mathrm{U}$ & 1,30 & 2,78 & ND & $-9,99$ & ND & 1,60 & 2,91 & ND & $-11,10$ & ND \\
\hline \multicolumn{5}{|c|}{ Período seco } & \multicolumn{6}{|c|}{ Transição (seco - úmido) } \\
\hline $\mathrm{q}$ & 9,5 & 9,1 & 9 & 1,66 & $\begin{array}{ll}-0,67 \\
\end{array}$ & 12,8 & 12,2 & 12 & 2,48 & $\begin{array}{c}-0,84 \\
\end{array}$ \\
\hline UR & 71,0 & 60,6 & 59,6 & 6,54 & $-0,45$ & 71,3 & 69,0 & 70,2 & 1,60 & 0,93 \\
\hline $\mathrm{U}$ & 1,84 & 3,41 & 2,23 & $-12,13$ & $-8,50$ & 2,19 & 3,37 & 2,36 & $-10,16$ & $-10,15$ \\
\hline \multicolumn{5}{|c|}{ Período úmido 2006} & \multicolumn{6}{|c|}{ Anual } \\
\hline $\mathrm{q}$ & 14,2 & 13,5 & 13,2 & 4,73 & $-1,26$ & $\begin{array}{c}12,4 \\
(12,6)\end{array}$ & $\begin{array}{c}11,8 \\
(11,84)\end{array}$ & $(11,8)$ & \multirow{3}{*}{$\begin{array}{r}8,78 \\
-22,16\end{array}$} & $-0,28$ \\
\hline UR & 76,4 & 71,0 & 73,5 & 3,4 & 1,51 & $\begin{array}{c}73,8 \\
(72,2)\end{array}$ & $\begin{array}{c}67,1 \\
(66,6)\end{array}$ & (69) & & 2,09 \\
\hline $\mathrm{U}$ & 1,55 & 2,80 & 1,93 & $-9,79$ & $-7,07$ & $\begin{array}{l}1,76 \\
(1,9) \\
\end{array}$ & $\begin{array}{c}3,12 \\
(3,19)\end{array}$ & $(2,19)$ & & $-14,57$ \\
\hline
\end{tabular}

Os dados são médias calculadas para cada período sazonal. Os valores entre parênteses são as médias calculadas sobre o período de 22/07/2005 a 06/02/2006.

${ }^{\circ}$ Dados do eucalipto somente a partir de 22/07/2005.

A umidade específica do ar média diária (q) mostrou uma pronunciada variabilidade sazonal de16 $\mathrm{g} \mathrm{kg}^{-1} \mathrm{em}$ março, durante a transição para o período seco, para um mínimo de $7 \mathrm{~g} \mathrm{~kg}$ ${ }^{1}$ em agosto (Fig. 3.1.3.c), o que também se mostrou de acordo com a variabilidade sazonal climatológica regional. Nota-se que o padrão de q foi fortemente relacionado com a distribuição da precipitação (Fig. 3.1.3.c,b), como esperado. Comparando-se as áreas, q mostrou-se significativamente maior na cana em relação às demais, tendo sido a média anual de $12,4 \mathrm{~g} \mathrm{~kg}^{-1}$ na cana e $11,8 \mathrm{~g} \mathrm{~kg}^{-1}$ no cerrado (valor próximo ao do eucalipto) (Tabela 3.1.2). 

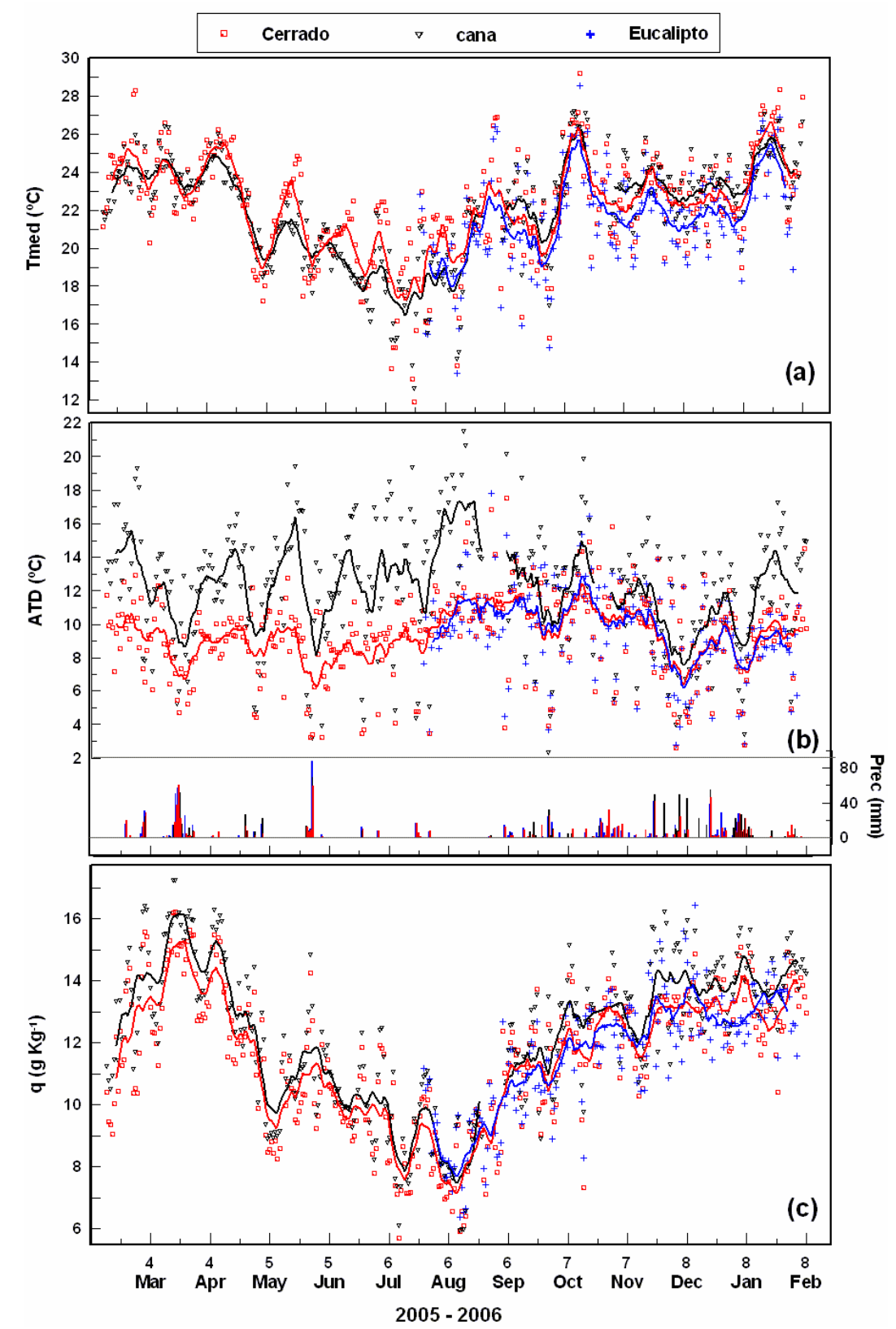

Figura 3.1.3. Idem Fig. 3.1.2, porém para (a) temperatura média diária (Tmed) em ${ }^{\circ} \mathrm{C}$, (b) amplitude térmica diária (ATD) em ${ }^{\circ} \mathrm{C}$ e (c) umidade específica (q) em $\mathrm{g} \mathrm{Kg}^{-1}$. As linhas sólidas representam uma média móvel de 21 dias. 


\section{FLUXOS RADIATIVOS}

O padrão sazonal dos totais diários da irradiância solar global incidente (Ki) e do saldo de radiação (Rn) nas três áreas (Fig. 3.1.4) mostra uma oscilação seguindo a variabilidade da irradiância no topo da atmosfera (Fig. 3.1.4.a). Em média Ki no inverno é reduzida de $\sim 35 \%$ comparada ao verão. Os eventos de precipitação (Fig. 3.1.4.a) causam valores mínimos inferiores a $5 \mathrm{MJ} \mathrm{m}^{-2} \mathrm{dia}^{-1}$. Embora se observem diferenças de Ki entre as áreas no decorrer do tempo (Fig. 3.1.4.a), as médias sazonais não indicaram diferenças estatisticamente significativas (Tabela 3.1.3), assim como os totais diários (vide Apêndice D).

O saldo de radiação $(\mathrm{Rn})$ reportado é aproximadamente a radiação disponível que é utilizada pelo sistema solo-vegetação para os processos de aquecimento do ar e do solo, fotossíntese e evapotranspiração. Nota-se que Rn é fortemente controlado pelo padrão de Ki na variação sazonal (Fig. 3.1.4.b). Os máximos sazonais de Rn nas três áreas alcançaram $\sim 20 \mathrm{MJ} \mathrm{m}^{-}$ ${ }^{2}$ dia $^{-1}$ durante o verão e $7 \mathrm{MJ} \mathrm{m}^{-2}$ dia $^{-1}$ no inverno. Nos eventos de precipitação as médias foram levemente negativas. O termo Rn é menor na cana do que no cerrado em todo o período, mas principalmente na estação seca (Fig. 3.1.4.b), com médias anuais estatisticamente diferentes: 10,9 $\mathrm{MJ} \mathrm{m}^{-2}$ dia $^{-1}$ no cerrado e $10,2 \mathrm{MJ} \mathrm{m}^{-2}$ dia $^{-1}$ na cana (Tabela 3.1.3). O saldo de radiação médio no cerrado é muito semelhante ao reportado por Priante-Filho et al. (2003), igual a 10,8 $\mathrm{MJ} \mathrm{m}^{-2} \mathrm{dia}^{-1}$, sobre área de Cerradão em Sinop, MT (latitude $11^{\circ} 25^{\prime} \mathrm{S}$ ).

Quanto ao eucalipto o termo $\mathrm{Rn}$ mostrou-se menor em relação ao cerrado apenas no período seco (Fig. 3.1.4.b), com valores de 6,8 e 7,6 $\mathrm{MJ} \mathrm{m}^{-2} \mathrm{dia}^{-1}$, respectivamente (Tabela 3.1.3). Essa diferença ocorre principalmente pelo maior albedo do eucalipto (17\%) em relação ao cerrado $(13,4 \%)$ na estação seca. Para todo o período de observação, que no eucalipto completou 6 meses, o termo Rn foi significativamente diferente apenas comparando-se a cana e o cerrado, e não o eucalipto com cerrado (Tabela 3.1.3).

O albedo RFA no cerrado (termo $\alpha_{\mathrm{v}}$ ) mostra um máximo no final da estação seca, quando tem uma queda abrupta (Fig. 3.1.5.b), de 4\% para 2,7\%, coincidente com as primeiras chuvas em setembro, e a produção de folhas novas, portanto, aumento da capacidade fotossintética (Fig. E.1.a do Apêndice E) e absorção da RFA. Após atingir o mínimo em fevereiro $(\sim 2,2 \%)$, o termo $\alpha_{v}$ começa a aumentar novamente, provavelmente decorrente do envelhecimento das folhas verdes, que vai se acentuando progressivamente até a estação seca, 
quando atinge $\sim 4 \%$. De forma geral, no cerrado durante a estação seca a componente arbórea reduz a capacidade fotossintética (Fig. E.1.a do Apêndice E) devido à senescência, e a componente herbácea entra em fase de dormência, secando as folhas, o que é ilustrado por fotografias na (Fig. 3.1.6).

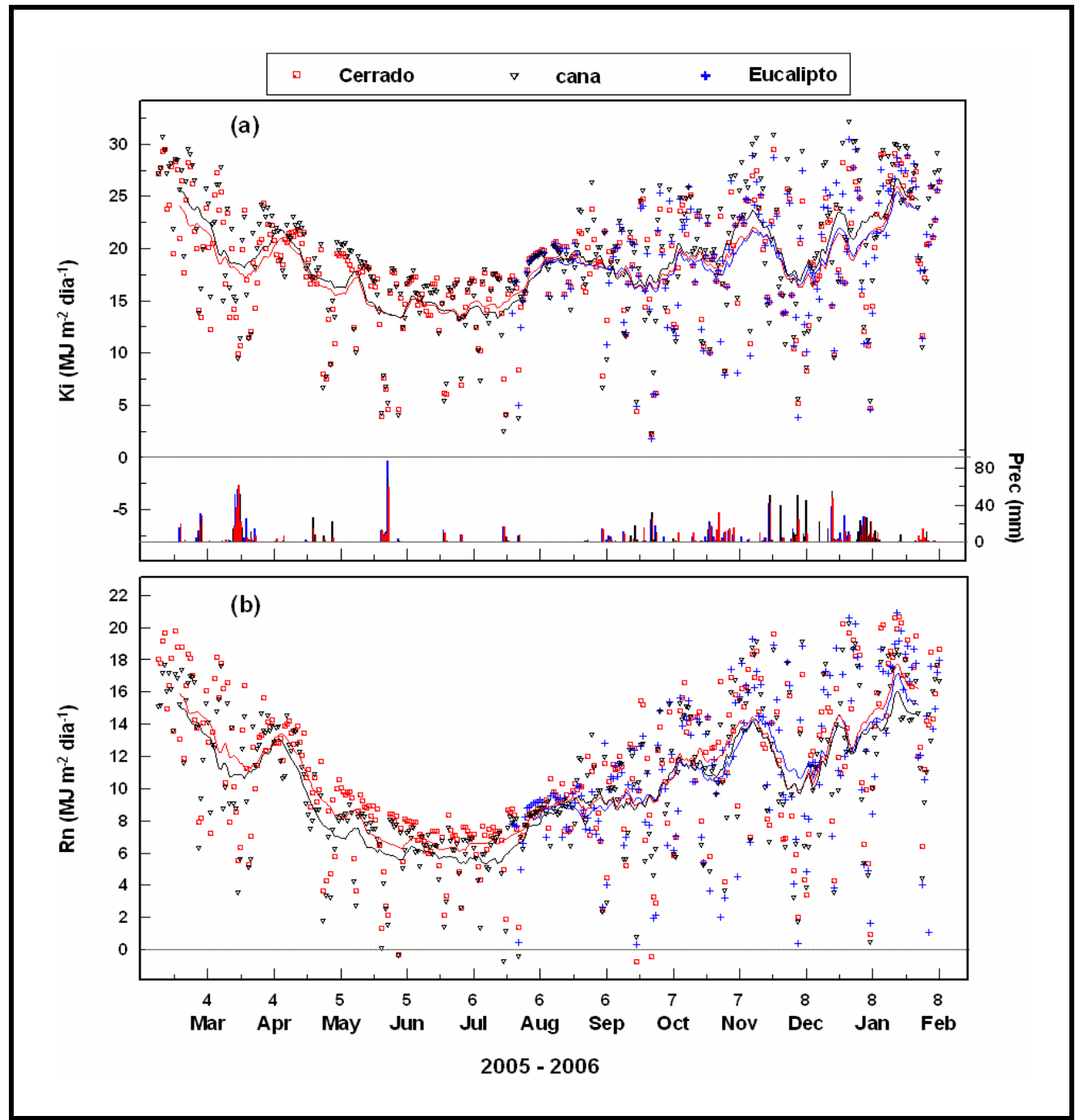

Figura 3.1.4. Variação sazonal dos totais diários de (a) irradiância solar global incidente (Ki), em MJ m${ }^{-2}$ dia $^{-1}$, e precipitação (Prec) em $\mathrm{mm} \mathrm{dia}^{-1}$ (escala a direita);

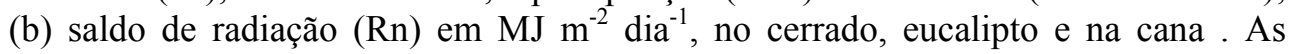
linhas sólidas representam uma média móvel de 21 dias. Os dados são mostrados para o período de 7/02/2005 a 6/02/2006 para cana e o cerrado, e de 22/07/2005 a 06/02/2006 para o eucalipto. 
O albedo solar global $(\alpha)$ no cerrado foi estacionário em torno de 13 a 14\% de Fevereiro a Maio de 2005, reduzindo-se levemente para 12,4\% até meados de agosto (Fig. 3.1.5.a), coincidente com o máximo do termo $\alpha_{\mathrm{v}}$. Com o início das chuvas, o termo $\alpha$ aumenta abruptamente para $17 \%$, permanecendo em um patamar superior durante $\sim 2$ meses, e diminuindo com o decorrer da estação chuvosa (Fig. 3.1.5.a). A diferença de fase entre $\alpha$ e $\alpha_{v}$ está relacionada com as características de absorção e reflexão nas faixas do infravermelho próximo (IVP) e da RFA pela vegetação e seu substrato ao longo do ano. No período seco (Junho-Agosto) Ki pode penetrar mais facilmente no interior do dossel, e assim o solo coberto por serrapilheira escura pode controlar o albedo solar absorvendo mais radiação na faixa do IVP. Por outro lado, na estação chuvosa o controle de $\alpha$ resulta principalmente da influência da copa das árvores, que sombreia o solo, e controla a absorção de RFA e do IVP. Ainda comentando-se sobre controles de $\alpha$ no cerrado, Tannus (2004) reporta que o número de eventos frios (quedas na temperatura mínima) e anos mais secos (baixa umidade do solo) afetam estes patamares de $\alpha$ na escala interanual.

Tabela 3.1.3. Totais diários da irradiância solar incidente (Ki), saldo de radiação (Rn) e fluxo de calor no solo $(\mathrm{G})$, todos em $\mathrm{MJ} \mathrm{m}^{-2} \mathrm{dia}^{-1}$; albedo solar $(\alpha) \mathrm{em} \%$, na cana (Can), cerrado (Cer) e eucalipto (Euc). ND significa ausência de dados. Os valores sombreados do teste t-student indicam se as médias comparadas são estatisticamente diferentes para o N.S $<5 \%$.

\begin{tabular}{|c|c|c|c|c|c|c|c|c|c|c|}
\hline & Can & Cer & Euc & $\begin{array}{c}\text { teste-t } \\
(\text { Can/Cer })\end{array}$ & $\begin{array}{c}\text { teste-t } \\
\text { (Euc/Cer) }\end{array}$ & Can & Cer & Euc & $\begin{array}{c}\text { teste-t } \\
(\text { Can/Cer })\end{array}$ & $\begin{array}{c}\text { teste-t } \\
\text { (Euc/Cer) }\end{array}$ \\
\hline & \multicolumn{5}{|c|}{ Período úmido 2005} & \multicolumn{5}{|c|}{ Transição (úmido - seco) } \\
\hline $\mathrm{Ki}$ & $25,5 \pm 1,3$ & $24 \pm 1,2$ & ND & 1,08 & ND & $17,9 \pm 1$ & $17,3 \pm 1$ & ND & 0,85 & ND \\
\hline $\mathrm{Rn}$ & $14,9 \pm 0,7$ & $15,8 \pm 0,8$ & ND & $-0,87$ & ND & $9,4 \pm 0,5$ & $10,3 \pm 0,5$ & ND & $-1,56$ & ND \\
\hline$\alpha$ & $19,1 \pm 1,9$ & $13,3 \pm 1,3$ & ND & 66,87 & ND & $17,9 \pm 1,8$ & $13,6 \pm 1,4$ & ND & 20,81 & ND \\
\hline & \multicolumn{5}{|c|}{ Período seco $^{a}$} & \multicolumn{5}{|c|}{ Transição (seco - úmido) } \\
\hline $\mathrm{Ki}$ & $15,5 \pm 0,8$ & $16,2 \pm 0,8$ & $16 \pm 1,6$ & $-0,22$ & $-2,46$ & $19,5 \pm 1$ & $18,7 \pm 1$ & $18,4 \pm 1,8$ & 0,61 & $-0,49$ \\
\hline $\mathrm{Rn}$ & $6,6 \pm 0,3$ & $7,6 \pm 0,4$ & $6,8 \pm 0,7$ & $-1,69$ & $-2,28$ & $11,1 \pm 0,6$ & $11,3 \pm 0,6$ & $11,5 \pm 1,1$ & $-0,53$ & 0,24 \\
\hline$\alpha$ & $17,6 \pm 1,8$ & $13,4 \pm 1,3$ & $17 \pm 3,6$ & 33,19 & $-24,39$ & $16,3 \pm 1,6$ & $16,6 \pm 1,6$ & $14,8 \pm 2,9$ & $-1,61$ & $-11,18$ \\
\hline & \multicolumn{5}{|c|}{ Período úmido 2006} & \multicolumn{5}{|c|}{ Anual } \\
\hline $\mathrm{Ki}$ & $22,3 \pm 1,1$ & $20,9 \pm 1$ & $20,8 \pm 2,1$ & 1,21 & $-0,17$ & $\begin{array}{c}19 \pm 1 \\
(20,2 \pm 1)\end{array}$ & $\begin{array}{l}18,4 \pm 0,9 \\
(19,5 \pm 1)\end{array}$ & $(19,2 \pm 1,9)$ & 1,37 & $-0,51$ \\
\hline $\mathrm{Rn}$ & $13,1 \pm 0,7$ & $14 \pm 0,7$ & $13,5 \pm 1,3$ & $-1,06$ & $-0,44$ & $\begin{array}{l}10,2 \pm 0,5 \\
(11,1 \pm 0,6)\end{array}$ & $\begin{array}{c}10,9 \pm 0,5 \\
(11,7 \pm 0,6)\end{array}$ & $(11,4 \pm 1,2)$ & $-1,97$ & $-0,59$ \\
\hline$\alpha$ & $18,3 \pm 1,8$ & $14,8 \pm 1,5$ & $14,7 \pm 2,9$ & 25,18 & $-0,26$ & $\begin{array}{c}18 \pm 1,8 \\
(17,4 \pm 1,7)\end{array}$ & $\begin{array}{c}14,1 \pm 1,4 \\
(15,2 \pm 1,5)\end{array}$ & $(15,1 \pm 3)$ & 28,81 & $-0,83$ \\
\hline
\end{tabular}

Os dados são valores médios ( \pm erro instrumental) calculados para cada período sazonal. Os valores entre parênteses são as médias calculadas sobre o período de 22/07/2005 a 06/02/2006. ${ }^{\not a}$ Dados do eucalipto somente a partir de 22/07/2005. 


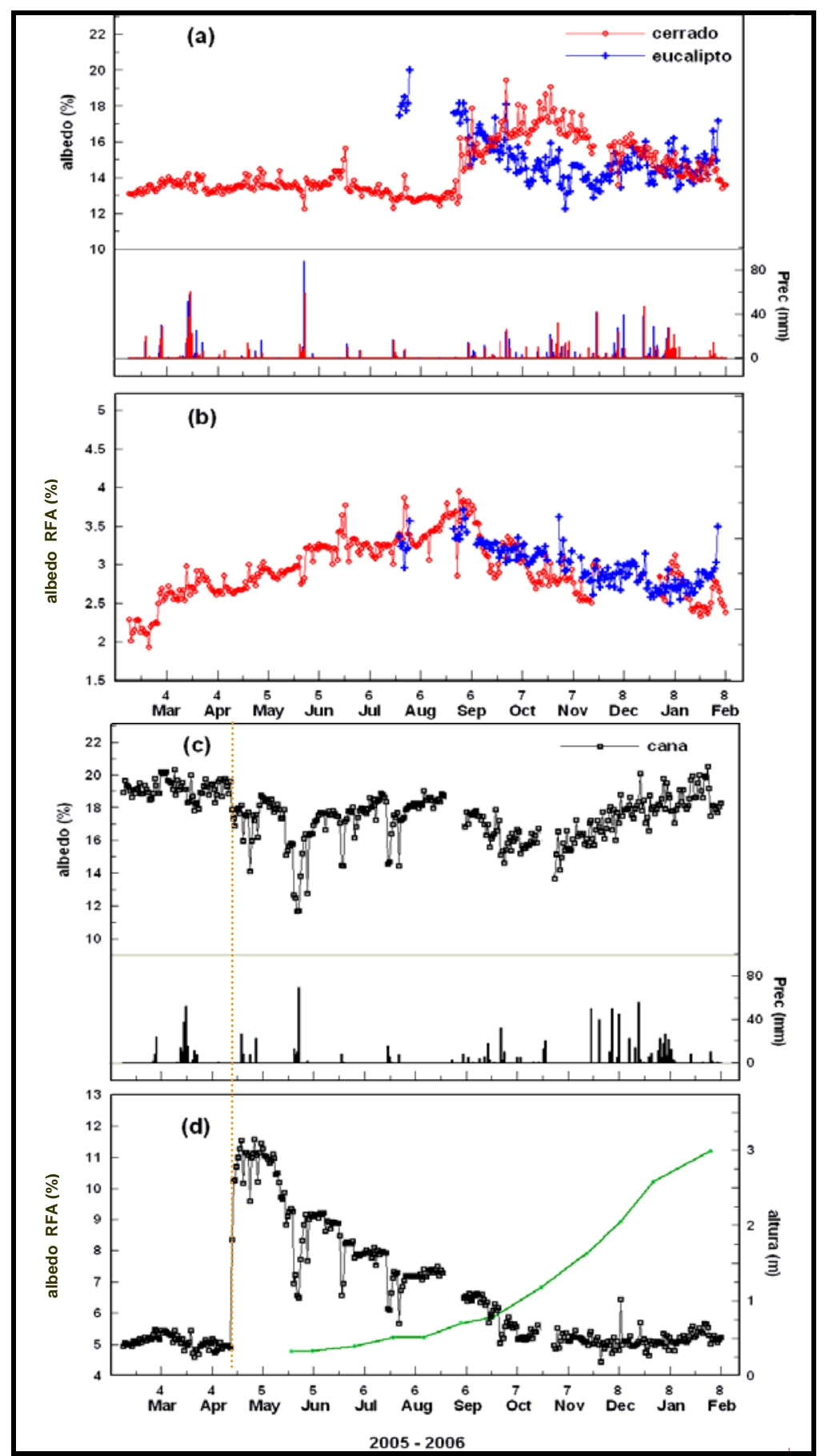

Figura 3.1.5. Variação das médias diárias de (a) albedo solar, (b) albedo RFA (ambos em \%) no cerrado e eucalipto, (c) albedo solar e (d) albedo RFA, ambos na cana. Os dados são mostrados para o período de $7 / 02 / 2005$ a 6/02/2006 para a cana e o cerrado, e de 22/07/2005 a 06/02/2006 para o eucalipto. A linha pontilhada indica a data da colheita. A precipitação em $\mathrm{mm} \mathrm{dia}^{-1}$ (Prec) é mostrada na escala inferior a direita de (a) e (c). A variação da altura da cana (m) é mostrada na escala a direita em (d), dados de Cabral et al (2006). 


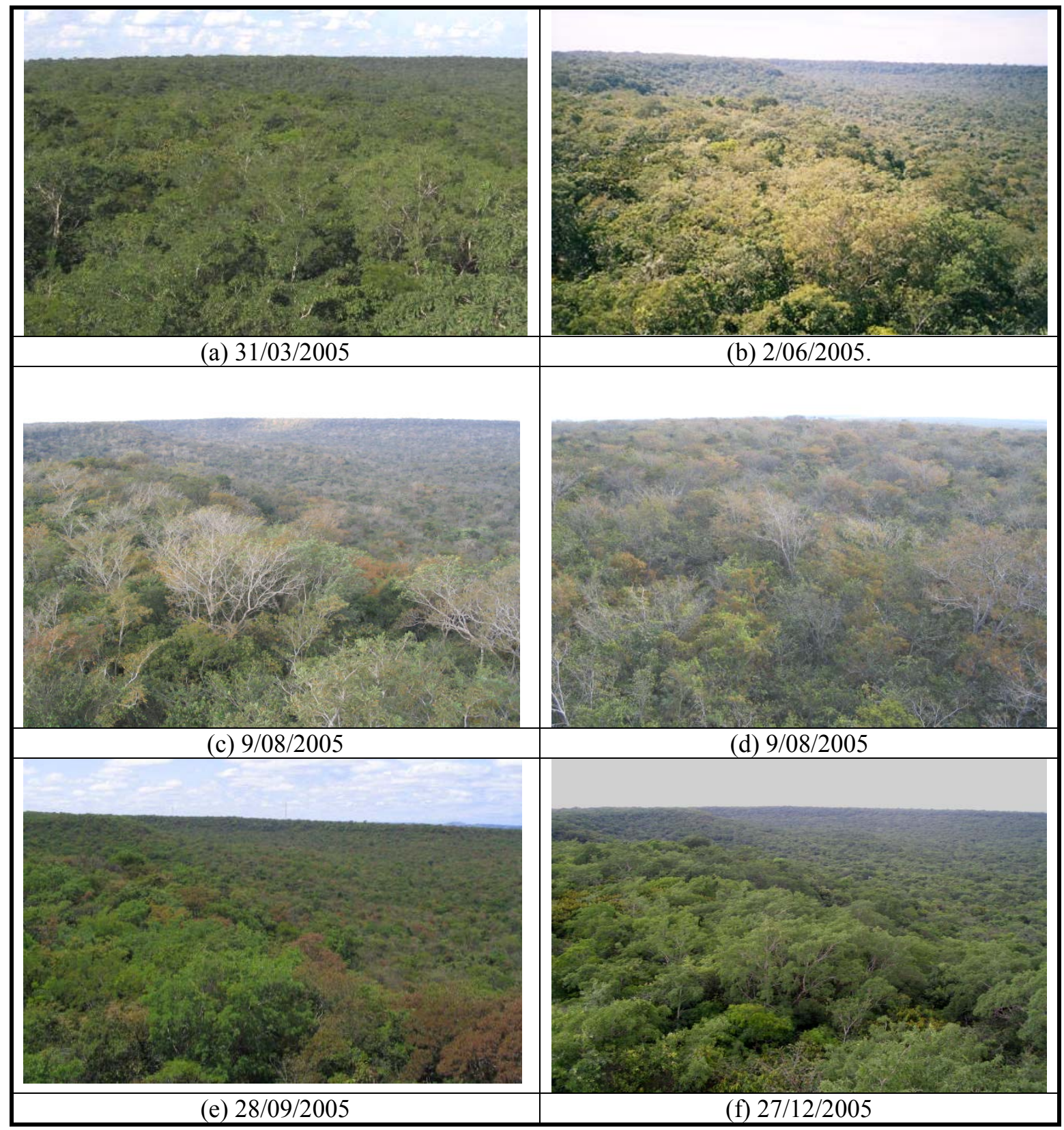

Figura 3.1.6. Fotografias do cerrado para diferentes épocas do período de estudo. As datas são especificadas abaixo de cada imagem. Fonte: Laboratório de Clima e Biosfera, IAG/USP.

Na cana, o padrão mais notável de $\alpha_{\mathrm{v}}$ foi uma contínua redução ao longo do crescimento da cana, sendo a partir da colheita (linha pontilhada na Fig. 3.1.5.d), controlado pela cobertura da vegetação sobre o solo. $\mathrm{O}$ corte da cana foi feito sem queima das folhas secas que foram deixadas sobre o solo. O máximo de $\alpha_{\mathrm{v}}$ foi de $\sim 11 \%$, em meados de abril após a colheita, que decresceu 
até o mínimo de $\sim 5 \%$ em novembro. Portanto, a partir da idade de $\sim 7$ meses de crescimento, o termo $\alpha_{\mathrm{v}}$ estacionou.

Uma característica geral de $\alpha$ foi a semelhança com o padrão de $\alpha_{v}$, mas com menor sensibilidade: $\alpha$ tem máximos antes da colheita, de $\sim 19 \%$, e reduz-se com o corte; depois, com a rebrota da cana, atinge o mínimo ( 15\%) em novembro (Fig. 3.1.5.c). O que ocorre com $\alpha$ da cana é um controle diferente do $\alpha_{\mathrm{v}}$. Os máximos de $\alpha$ ocorrem com a planta no máximo estágio de crescimento. Com o corte, mostra-se uma redução para $17,5 \%$, que se prolonga durante os primeiros 7 meses de crescimento. Como nos primeiros meses há pouca absorção de RFA, é o solo que controla o albedo solar absorvendo mais o IVP. Apesar de ser um solo com tons claros, tal comportamento foi verificado também em solos escuros, onde este efeito é muito pronunciado, como observado em outra plantação de cana sobre latossolo vermelho-escuro em Sertãozinho, SP (Rocha, 1998). Após 7 meses a cobertura da vegetação sombreia o solo, e a partir daí se reduz à absorção do IVP, o que explica o aumento progressivo de $\alpha$. Portanto, nos 7 primeiros meses, a despeito do aumento da absorção da RFA pelo crescimento da vegetação, ainda são as trocas na faixa do IVP pela fração de solo exposto que aparentemente controlam mais o albedo solar.

O efeito da maior umidade superficial do solo sobre a cana observou-se nos mínimos eventuais de $\alpha$ causados por chuvas isoladas, como por exemplo, um mês depois da colheita (final de maio) quando o solo foi arado (Fig. 3.1.5.c). Com o início das chuvas em Setembro verifica-se uma redução mais pronunciada de $\alpha$, de $19 \%$ para $\sim 16 \%$.

Conforme a Fig. 3.1.5.b, o termo $\alpha_{\mathrm{v}}$ no eucalipto acompanhou de forma muito clara a tendência de $\alpha_{v}$ do cerrado, ou seja, diminuindo continuamente da estação seca $(3,3 \%)$ para a chuvosa $(2,5 \%)$, e indicando o aumento da capacidade fotossintética do dossel. Com o termo $\alpha$, aparentemente mostra-se um controle semelhante ao da cana (Fig. 3.1.5.a,c): ocorre uma redução durante o período seco, provavelmente decorrente do estresse da vegetação (redução da evapotranspiração, conforme será discutido a seguir), perda parcial das folhas e exposição do solo, o que aumentaria a absorção do IVP.

A comparação de $\alpha$ médio solar durante o mesmo período de observação (22/07/2005 a 6/02/2006) foi de 15,1\% no eucalipto, 15,2\% (17,4\%) no cerrado (cana) (Tabela 3.1.3). As diferenças entre o termo $\alpha$ do cerrado e da cana são mais pronunciadas quando comparadas na 
média anual: 14 e 18\%, respectivamente (Tabela 3.1.3). Estas diferenças no termo $\alpha$ explicam em grande parte as diferenças de Rn entre as áreas.

\section{FLUXOS DE ENERGIA À SUPERFÍCIE}

As variações temporais das médias diárias da evapotranspiração (ou fluxo de calor latente à superfície, LE) e no fluxo de calor sensível $(\mathrm{H})$ para as três áreas são apresentadas na Fig. 3.1.7. Sobre o cerrado verifica-se uma amplitude sazonal da evapotranspiração do mínimo de $\sim 1,5 \mathrm{~mm} \mathrm{dia}^{-1}$, em junho, até $\sim 4 \mathrm{~mm} \mathrm{dia}^{-1}$, em janeiro (Fig. 3.1.7.a), e de forma clara mostrandose controlado pelo padrão da oferta de energia. A oferta de energia está correlacionada também com a oferta de água (precipitação), que consequentemente determina a umidade disponível do solo.

A variação de H no cerrado mostrou dois máximos: um na estação chuvosa e outro no final da estação seca, ambos com magnitude de $\sim 4 \mathrm{MJ} \mathrm{m}^{-2}$ dia $^{-1}$ (Fig. 3.1.7.e). Os maiores valores de $\mathrm{H}$ no período úmido estão associados há maiores valores de $\mathrm{Rn}$, enquanto que na estação seca foi o estado da vegetação que favoreceu a maior conversão de energia na forma de calor sensível, devido à densidade de área foliar verde relativamente mais baixa (evidenciada pelo aumento de $\alpha_{v}$, Fig. 3.1.5.b) e a diminuição da capacidade fotossintética do dossel (Fig. E.1.a do Apêndice E). Neste último período, a partição de energia representada pelos valores médios diurnos da razão de Bowen (H/LE $=\beta$, Fig. 3.1.8), indicou valores próximos a 1,4. Apesar das condições propícias ao estresse (ausência de chuvas e alta amplitude térmica, Fig. 3.1.1.a e Fig. 3.1.3.b, respectivamente), o cerrado apresentou uma considerável taxa de evapotranspiração $\left(\sim 1,5 \mathrm{~mm} \quad \operatorname{dia}^{-1}\right)$, indicando que parte da vegetação manteve-se fisiologicamente ativa, provavelmente o estrato arbóreo, com raízes profundas. No decorrer da transição para estação chuvosa, o surgimento das folhas provoca um rápido aumento de LE atingindo valores de até $5 \mathrm{~mm} \mathrm{dia}^{-1}$, ao passo que $\mathrm{H}$ diminui e $\beta$ fica em torno de 0,4 na estação chuvosa (Fig. 3.1.8).

A cana-de-açúcar foi colhida em meados de abril, resultando em pequenas taxas de evapotranspiração (inferiores a $1 \mathrm{~mm} \mathrm{dia}^{-1}$ ) e altos valores de $\mathrm{H}$, aproximadamente duas vezes maiores que de LE em maio, devido ao solo descoberto (Fig. 3.1.7.b,f). O impacto sobre os fluxos diurnos é mais significativo, conforme sugerido pela mudança repentina em $\beta$ que em meados de maio, quando o solo foi arado, atingiu seu valor máximo de 4 (Fig. 3.1.8). A razão de 
Bowen (linha suavizada na Fig. 3.1.8) foi predominantemente superior a 1 por cerca de 80 dias (a partir do reinício das observações após o corte da cana), neste período, dos últimos 50 dias houve apenas 3 dias em que choveu (um total de $10 \mathrm{~mm}$ ). Em seguida, logo após alguns eventos de precipitação que ocorreram no final de julho, o termo $\beta$ decaiu abaixo de 1 , como resultado da evaporação da água na camada superficial do solo. No período subseqüente ocorreu outra estiagem e $\beta$ retornou a valores um pouco acima de 1 , somente após dias consecutivos de precipitação em setembro é a que $\beta$ passou a diminuir lentamente até um valor mínimo de $\sim 0,25$ na estação chuvosa de 2005/2006.

A evapotranspiração na cana aumenta gradativamente a partir da colheita, mas notavelmente no período de transição para a estação chuvosa, a partir de meados de setembro até janeiro, quando os máximos foram próximos de $4 \mathrm{~mm} \mathrm{dia}^{-1}$ (Fig. 3.1.7.b), que coincide com o período de máxima taxa de crescimento da cana (vide seção 2.1) e então maior uso da água. Os maiores valores dos totais diários de $\mathrm{H}$ foram observados após a colheita e no período de transição para estação chuvosa, onde máximos em torno de $8 \mathrm{MJ} \mathrm{m}^{-2}$ dia $^{-1}$ ocorreram, concorrente com aumento de Rn (Fig. 3.1.7.f). O contraste sazonal H não foi tão significativo quanto nos valores de LE, por exemplo o valor médio de $\mathrm{H}(\mathrm{LE})$ no período seco foi de 3,2 $(3,4) \mathrm{MJ} \mathrm{m}^{-2} \mathrm{dia}^{-1}$ enquanto no período úmido foi de 4,5 (6,3) $\mathrm{MJ} \mathrm{m}^{-2} \mathrm{dia}^{-1}$ (Tabela 3.1.4).

As componentes do balanço de energia no eucalipto mostraram uma pronunciada variação sazonal (Fig. 3.1.7.c,g). A partir de agosto, houve um aumento progressivo de LE, de 1 $\mathrm{mm} \mathrm{dia}{ }^{-1}$ até o máximo de $8 \mathrm{~mm} \mathrm{dia}^{-1}$ em dezembro. No período úmido o eucalipto destacou-se com maior evapotranspiração (média de $5,2 \mathrm{~mm} \mathrm{dia}^{-1}$ ) do que no cerrado e na cana (médias de 3,1 e $2,5 \mathrm{~mm} \mathrm{dia}^{-1}$, respectivamente). O fluxo de calor sensível reduziu-se de $6 \mathrm{MJ} \mathrm{m}^{-2} \mathrm{dia}^{-1}$ para valores próximos de zero, naquele mesmo período, evoluindo no tempo sob uma proporção inversa à do termo Rn, ao contrário de LE. No mês de agosto houve uma grande redução de LE e aumento de H (Fig. 3.1.7.c,g, Fig. 3.1.8): este fato foi possivelmente resultante da resposta de limitação estomática do eucalipto, o que reduziu também a absorção de $\mathrm{CO}_{2}$ (Fig. E.1.c do Apêndice E), devido as condições de estresse hídrico. No início de setembro, com as primeiras chuvas, notou-se um aumento abrupto de LE, que persistiu durante vários dias, voltando a cair com ocorrência de curtos períodos de estiagem. A média de $\beta$ no eucalipto variou entre 0,09 (no verão) e 0,98 (no período seco) (Tabela 3.1.4), mas picos de até 4 foram observados no período seco (Fig. 3.1.8). 


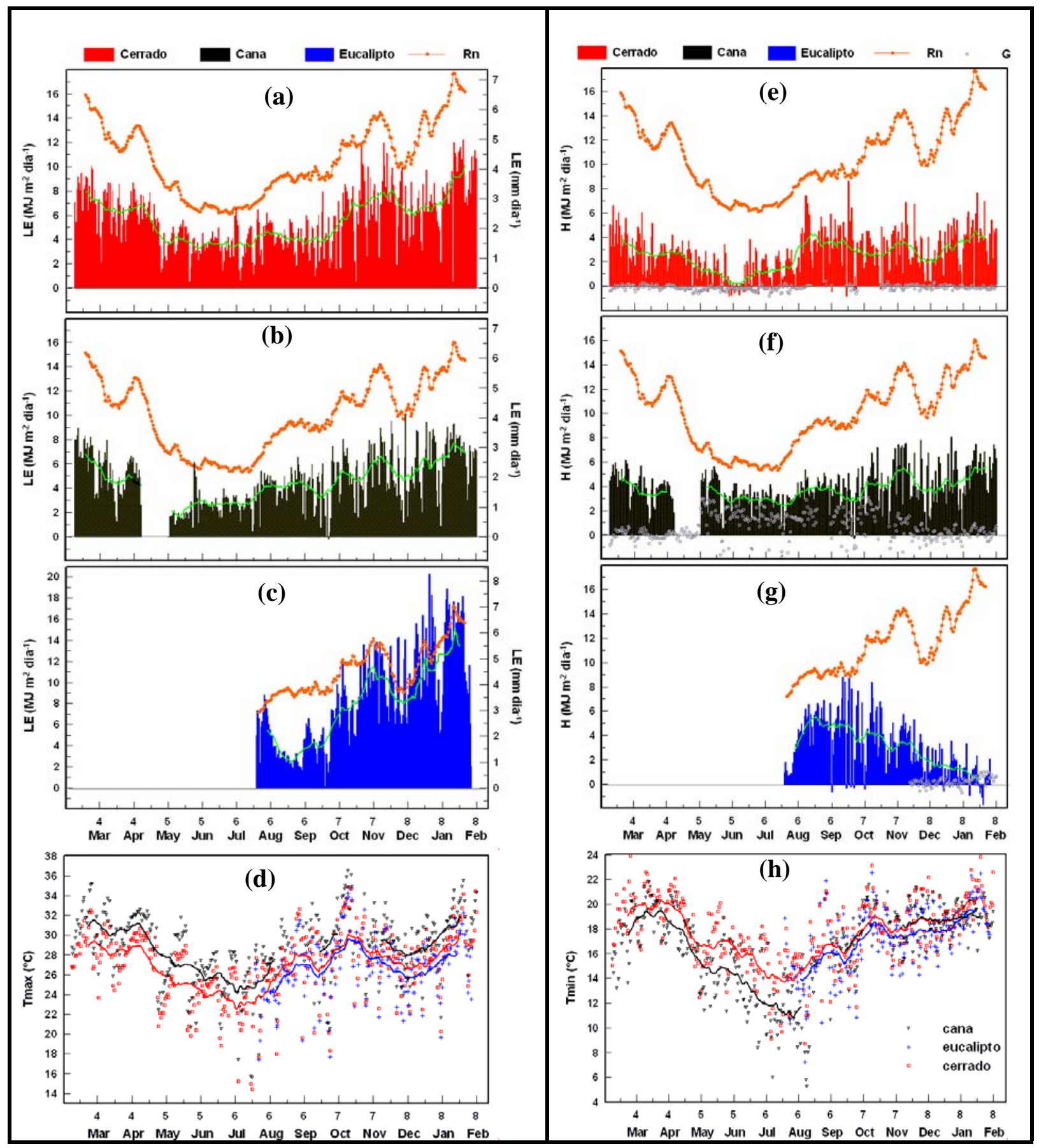

Figura 3.1.7. Variação sazonal dos totais diários de evapotranspiração (LE), fluxo de calor sensível (H) e do fluxo de calor no solo (G), ambos em MJ m${ }^{-2} \mathrm{dia}^{-1}$, no cerrado (a,e), cana (b,f) e eucalipto (c,g). Os círculos em cinza representam G. (d) Temperatura máxima e (h) mínima nas três áreas experimentais. Rn e LE também são representados por uma média móvel de 21 dias, linha em laranja e destacada em verde, respectivamente, para cada sítio experimental. O mesmo procedimento foi aplicado aos dados de temperatura. Os dados são mostrados para o período de 7/02/2005 a 6/02/2006 para a cana e o cerrado, e a partir de 22/07/2005 até 06/02/2006 para o eucalipto. 
A variação dos totais diários do fluxo de calor no solo $(\mathrm{G})$ (Fig.3.1.7.e,g) mostra que, no cerrado e no eucalipto os valores oscilaram em torno de zero. Ressaltou-se na cana os máximos de $\sim 2 \mathrm{MJ} \mathrm{m}^{-2} \mathrm{dia}^{-1}$, após a colheita (solo exposto), e que mostrou-se marcadamente positivo durante $\sim 7$ meses (Fig.3.1.7.f), concorrente com variações de $\alpha$ que acompanharam o crescimento da cana.

Os padrões dos ciclos diurnos médios das componentes do balanço de energia observados sobre as áreas experimentais de cerrado e cana no período de fevereiro a julho de 2005 são reportados por Tatsch et al 2005, adicionalmente, uma análise complementar para as três áreas experimentais incluindo o período de agosto de 2005 a fevereiro de 2006 é descrita no Apêndice G.

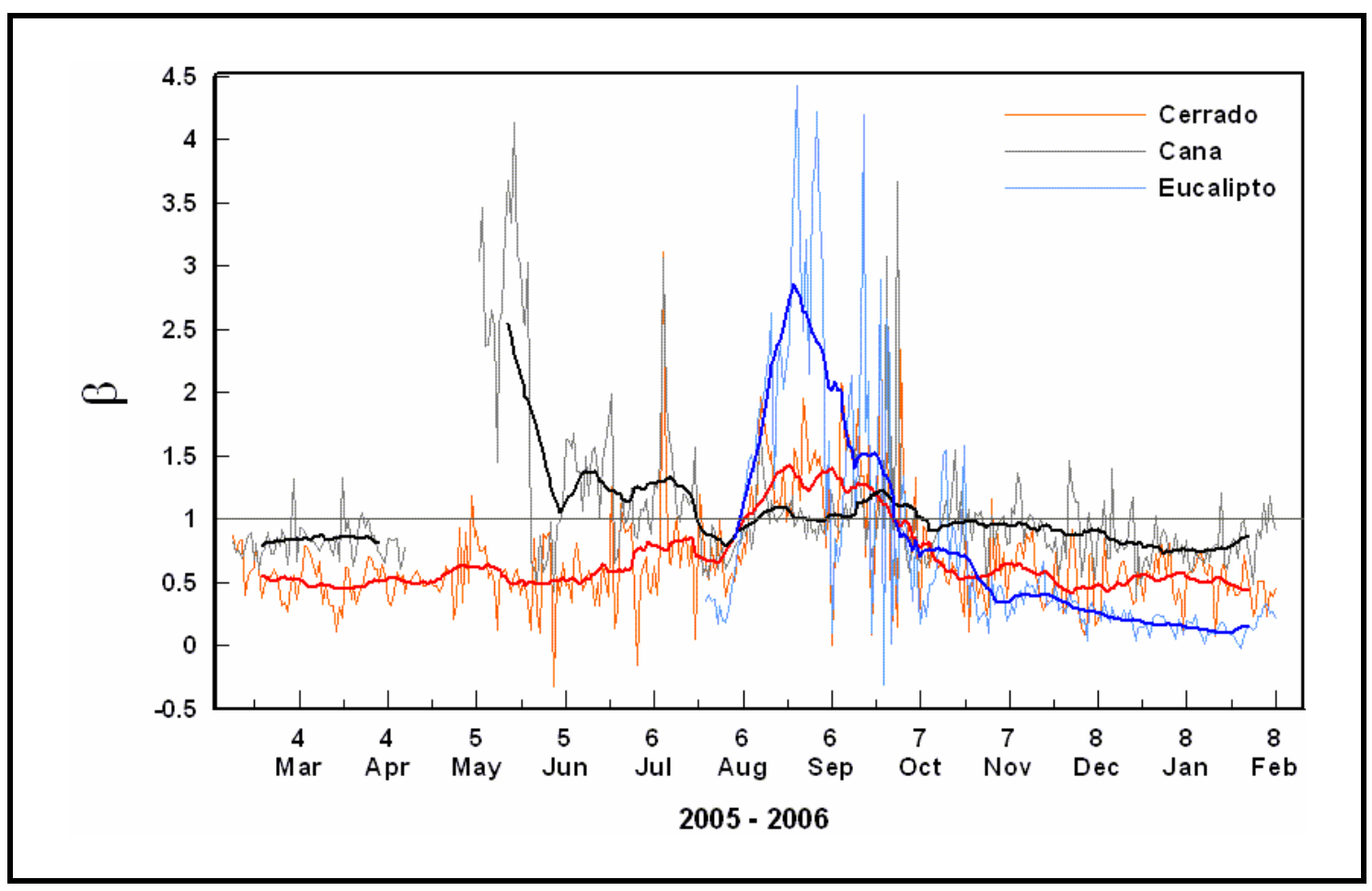

Figura 3.1.8. Variação sazonal da Razão de Bowen $(\beta)$ média diurna $(6-18$ h), no cerrado, cana e eucalipto. As linhas destacadas em vermelho (cerrado), preto (cana) e azul (eucalipto), representam uma média móvel de 21 dias. Os dados são mostrados para o período de 7/02/2005 a 6/02/2006 para a cana e o cerrado, e a partir de 22/07/2005 até 06/02/2006 para o eucalipto. 
Tabela 3.1.4. Idem a tabela 3.1.3 porém para: fluxo de calor sensível (H), calor latente (LE), fluxo de calor no solo $(\mathrm{G})$, ambos em $\mathrm{MJ} \mathrm{m}^{-2}$ dia $^{-1}$; e para razão de Bowen ( $\beta$ ), na cana (Can), cerrado (Cer) e eucalipto (Euc).

\begin{tabular}{|c|c|c|c|c|c|c|c|c|c|c|}
\hline & Can & Cer & Euc & $\begin{array}{c}\text { teste-t } \\
(\mathrm{Can} / \mathrm{Cer}) \\
\end{array}$ & $\begin{array}{c}\text { teste-t } \\
\text { (Euc/Cer) }\end{array}$ & Can & Cer & Euc & $\begin{array}{c}\text { teste-t } \\
(\mathrm{Can} / \mathrm{Cer})\end{array}$ & $\begin{array}{c}\text { teste-t } \\
\text { (Euc/Cer) }\end{array}$ \\
\hline & \multicolumn{5}{|c|}{ Período úmido 2005} & \multicolumn{5}{|c|}{ Transição (úmido - seco) } \\
\hline $\mathrm{H}$ & 4,6 & 3,9 & ND & 1,9 & ND & 3,5 & 2,1 & ND & 6,3 & ND \\
\hline LE & 6,7 & 7,9 & ND & $-2,4$ & ND & 3,7 & 5,3 & ND & $-4,7$ & ND \\
\hline$\beta$ & 0,69 & 0,49 & ND & 4,5 & ND & 0,95 & 0,4 & ND & 7,1 & ND \\
\hline G & 0,11 & $-0,07$ & ND & 1,88 & ND & 0,45 & $-0,16$ & ND & 5,51 & ND \\
\hline \multicolumn{6}{|c|}{ Período seco ${ }^{a}$} & \multicolumn{5}{|c|}{ Transição (seco - úmido) } \\
\hline $\mathrm{H}$ & 3,2 & 1,9 & 4,1 & 5,5 & 5,8 & 4,0 & 3,0 & 3,7 & 3,6 & 2,25 \\
\hline LE & 3,4 & 3,9 & 4,2 & -3 & 0,9 & 4,9 & 6,0 & 8,4 & -3 & 4,9 \\
\hline$\beta$ & 0,94 & 0,48 & 0,98 & 7,2 & 5,9 & 0,82 & 0,5 & 0,44 & 1,15 & $-0,19$ \\
\hline G & 1,28 & $-0,21$ & ND & 13,6 & ND & 0,9 & $-0,07$ & 0,08 & 6,01 & 2,4 \\
\hline & \multicolumn{5}{|c|}{ Período úmido 2006} & \multicolumn{5}{|c|}{ Anual } \\
\hline $\mathrm{H}$ & 4,5 & 3,3 & 1,1 & 3,9 & $-8,3$ & $\begin{array}{c}3,8 \\
(4,1)\end{array}$ & $\begin{array}{c}2,6 \\
(3,2)\end{array}$ & (3) & 9,3 & $-0,97$ \\
\hline LE & 6,2 & 7,6 & 12,7 & $-3,3$ & 10,4 & $\begin{array}{c}4,6 \\
(5,2)\end{array}$ & $\begin{array}{c}5,7 \\
(6,2)\end{array}$ & $(9,2)$ & $-5,9$ & 7,5 \\
\hline$\beta$ & 0,72 & 0,43 & 0,09 & 9,7 & -12 & $\begin{array}{c}0,82 \\
(0,78)\end{array}$ & $\begin{array}{c}0,45 \\
(0,52)\end{array}$ & $(0,33)$ & 4,1 & $-2,1$ \\
\hline G & 0,06 & $-0,1$ & 0,22 & 3,2 & 6,7 & $\begin{array}{c}0,7 \\
(0,63)\end{array}$ & $\begin{array}{l}-0,13^{\dagger} \\
(-0,1)^{\dagger}\end{array}$ & $(0,15)$ & 13,4 & 8,2 \\
\hline
\end{tabular}

Valores médios dos totais diários calculados para cada período sazonal. Os valores entre parênteses são as médias calculadas sobre o período de 22/07/2005 a 06/02/2006.

Dados do eucalipto somente a partir de 22/07/2005.

$\dagger$ Valores provavelmente subestimados devido às falhas nos meses de agosto a outubro, período em que G no cerrado atinge seus máximos (Negron-Juarez, 2004)

\section{COMPARAÇÃO DA TEMPERATURA ENTRE AS ÁREAS EXPERIMENTAIS}

\section{Cana e Cerrado}

As comparações da cana com o cerrado indicaram de forma geral que a temperatura máxima foi sempre maior sobre a cana do que sobre o cerrado, e a temperatura mínima predominantemente menor (Fig. 3.1.7.d, h), o que pode ser visualizado no padrão dos ciclos diurnos (Fig. 3.1.9.b).

A maior temperatura máxima sobre a cana, em relação ao cerrado (de $1,3{ }^{\circ} \mathrm{C}$ a $2{ }^{\circ} \mathrm{C}$, conforme Tabela 3.1.5), decorreu parcialmente do maior H naquela área (Tabela 3.1.4), e também da partição de energia (termo $\beta$ maior), o que promoveu mais aquecimento do ar, apesar de menos energia disponível sobre a cana, devido ao maior albedo e $\mathrm{G}$. 
Considerando as diferenças de altitude, as medidas no cerrado estão $168 \mathrm{~m}$ acima das medidas sobre a cana, portanto uma correção simples pela taxa de variação vertical da temperatura (TVVT, lapse-rate US-Standard de $-0,6^{\circ} \mathrm{C} / 100 \mathrm{~m}$ ) reduziria a diferença de Tmax em $1{ }^{\circ} \mathrm{C}$, ou seja, as comparações das diferenças ocorreriam entre 0,3 e $1{ }^{\circ} \mathrm{C}$. Assim, mesmo com essa correção, ainda se concluiria que a temperatura diurna na cana é maior.

A comparação de Tmin sugeriu que sobre a cana ela é predominantemente mais fria (por até $3{ }^{\circ} \mathrm{C}$ no período seco, conforme Tabela 3.1.5, Fig. 3.1.9.b). Por isso, a amplitude térmica foi maior sobre a cana do que no cerrado, conforme indicam os ciclos diurnos da temperatura do ar (Fig. 3.1.9.b) e as médias mensais (Fig. F.1.c do Apêndice F). Negron-Juarez (2004) comparou a Tmax e Tmin sobre cana e cerrado e também encontrou um aumento da amplitude térmica na cana (Tmax superior sobre a cana, e Tmin inferior, particularmente na estação seca), concordando os resultados deste trabalho. A correção pelo fator de altitude, como feito com Tmax, neste caso levaria à uma diferença mais acentuada, ou seja, Tmin ainda menor sobre a cana em relação ao cerrado. Entretanto, é importante destacar que o ajuste da TVVT não considera efeitos topográficos locais, como o escoamento de drenagem, que podem ter um impacto sobre a Tmin.

$\mathrm{Na}$ cana, o ar foi um pouco mais úmido no período noturno (de 0,2 a $0,8 \mathrm{~g} \mathrm{~kg}^{-1}$, Fig. 3.1.9.c) e a temperatura mais fria do que no cerrado. Isto levou às estimativas sobre a cana de menor perda por onda longa emergente, mas de menor ganho por onda longa incidente (Fig. 3.1.10.a, Fig. 3.1.11.a). A combinação destas duas componentes resultou em menor déficit noturno sobre a cana, onde as comparações de Rn noturno foram de 4 a $9 \mathrm{~W} \mathrm{~m}^{-2}$ superiores às do cerrado (Fig. 3.1.10.a, Fig. 3.1.11.a, Fig. F.1.f do Apêndice F).

Para fins de melhor comparabilidade, os efeitos de variação vertical da temperatura na camada de superfície (como o perfil super-adiabático diurno e perfil de inversão noturno) também precisariam ser levados em conta. Por exemplo, a sensibilidade da temperatura Tmin depende da profundidade da camada limite noturna (CLN), que por sua vez é controlada por diversos parâmetros, como a velocidade do vento, rugosidade de superfície, instabilidade termodinâmica e perfil vertical da umidade específica. Durante a noite, em condições de céu claro e ventos fracos ocorre a formação de uma camada de inversão próxima à superfície, como resultado do resfriamento da superfície. Ao contrário da camada limite diurna (CLD) onde a turbulência tende a reduzir a TVVT, na CLN o resfriamento suprime a turbulência e intensifica a 
TVVT. Dessa forma, dependendo da altura e da intensidade do vento em que a medida de temperatura é realizada, a TVVT pode ter um efeito significativo (p. ex. Pielke \& Matsui, 2005). Este processo remete a uma possível incerteza na comparação entre a Tmin do cerrado e da cana, devido à diferença nas alturas de medida de temperatura naquelas áreas. A altura do sensor no cerrado fica a $21 \mathrm{~m}(11 \mathrm{~m})$ acima da superfície (do dossel), o que levaria a uma superestimativa da Tmin sobre cerrado em comparação a Tmin sobre a cana, onde o sensor está a $8,5 \mathrm{~m}$ da superfície.

Além da influência da TVVT noturna em relação altura da medida, a temperatura pode ser afetada pela velocidade do vento. O máximo da velocidade do vento (U) no cerrado ocorreu frequentemente durante a noite (Fig.3.1.9.d), enquanto na cana, o máximo de $U$ ocorreu no período diurno, por esta razão, em média a $U$ do cerrado foi duas vezes maior que sobre a cana (Fig. F.1.i do Apêndice F). Para analisar o impacto de U sobre as temperaturas no cerrado e na cana, o vento foi dividido em três categorias: ventos relativamente calmos, moderados e fortes, de acordo com a distribuição da intensidade do vento noturno de cada área experimental (Fig. 3.1.12.a). Os histogramas mostraram que as distribuições de $U$ na cana e no cerrado diferem completamente no período noturno (Fig. 3.1.12.a): por exemplo, no cerrado, $1 / 3$ dos dados classificados como ventos calmos ficaram no intervalo $0-2,5 \mathrm{~m} \mathrm{~s}^{-1}$, e na cana esta classe correspondeu ao intervalo $0-0,3 \mathrm{~m} \mathrm{~s}^{-1}$ (Fig. 3.1.12.b). As temperaturas de cada área foram então comparadas considerando estas classes de vento durante todo período de observação e particularmente no período de outubro de 2005 a fevereiro 2006, a partir de quando, o cerrado já recuperou suas folhas e a cana cobria uma porção significativa do solo. Os resultados mostraram que as diferenças de temperatura entre o cerrado e cana podem atingir até $10^{\circ} \mathrm{C}$, em condições de ventos calmos (Fig. 3.1.12.b, C-c). Por outro lado, quando os ventos são intensos a dispersão dos dados diminui consideravelmente e as temperaturas tornam-se muito semelhantes (Fig. 3.1.12.b, F-f), principalmente no período de outubro de 2005 a fevereiro de 2006. Isto sugere que a turbulência mecânica gerada pelo cisalhamento vertical do vento tem um forte controle sobre as diferenças de temperatura entre as áreas. Os ventos fortes favorecem uma mistura turbulenta mais efetiva (transporte calor dos níveis superiores para a superfície) na CLN, aumentando a temperatura na superfície. Este processo é aqui sugerido como responsável, em grande parte, pela maior Tmin no cerrado em comparação cana, diante das evidências observacionais apresentadas. 
Para investigar se a conversão de cerrado por grandes áreas de cana-de-açúcar pode ter influenciado as tendências de temperatura de longo prazo, os resultados encontrados sobre os microclimas da cana e do cerrado devem ser interpretados com cautela. A substituição de uma área de cerrado por cana, não necessariamente garante que se possa extrapolar para a escala regional um resfriamento noturno, conforme discutido. Por outro lado, a CLD tende a ser mais acoplada a atmosfera do que a CLN, reforçando que a comparabilidade de Tmax é provavelmente mais confiável do que a de Tmin para uma extrapolação regional.

Tabela 3.1.5. Valores médios de temperatura máxima (Tmax), temperatura mínima (Tmin) e da temperatura média diária (Tmed), todas em ${ }^{\circ} \mathrm{C}$, na cana (Can), cerrado (Cer) e eucalipto (Euc). ND significa ausência de dados. Os valores sombreados do teste t-student indicam se as médias comparadas são estatisticamente diferentes para o N.S. $<5 \%$.

\begin{tabular}{|c|c|c|c|c|c|c|c|c|c|c|}
\hline & Can & Cer & Euc & $\begin{array}{c}\text { teste-t } \\
\text { (Can/Cer) } \\
\end{array}$ & $\begin{array}{c}\text { teste-t } \\
\text { (Euc/Cer) } \\
\end{array}$ & Can & Cer & Euc & $\begin{array}{c}\text { teste-t } \\
\text { (Can/Cer) } \\
\end{array}$ & $\begin{array}{c}\text { teste-t } \\
\text { (Euc/Cer) }\end{array}$ \\
\hline \multicolumn{5}{|c|}{ Período úmido 2005} & \multicolumn{6}{|c|}{ Transição (úmido - seco) } \\
\hline Tmax & 31,2 & 29,2 & ND & 3,34 & ND & 29,0 & 27 & ND & 4,38 & ND \\
\hline Tmin & 17,1 & 19,3 & ND & $-3,40$ & ND & 17,1 & 18,4 & ND & $-3,37$ & ND \\
\hline Tmed & 23,6 & 24,3 & ND & $-1,54$ & ND & 22,4 & 22,6 & ND & $-0,65$ & ND \\
\hline \multicolumn{5}{|c|}{ Período seco } & \multicolumn{6}{|c|}{ Transição (seco - úmido) } \\
\hline Tmax & 26,0 & 24,7 & 25,2 & 2,51 & 0,78 & 29,7 & 28,1 & 27,5 & 3,19 & $-1,16$ \\
\hline Tmin & 12,2 & 15,2 & 14,8 & $-7,30$ & $-0,79$ & 17,8 & 17,7 & 17,0 & 0,19 & $-1,90$ \\
\hline Tmed & 18,6 & 20,1 & 20,07 & $-3,84$ & 0,04 & 23,1 & 22,6 & 21,8 & 1,50 & $-1,99$ \\
\hline \multicolumn{5}{|c|}{ Período úmido 2006} & \multicolumn{6}{|c|}{ Anual } \\
\hline Tmax & 29,9 & 28,3 & 27,0 & 3,23 & $-2,78$ & $\begin{array}{c}28,8 \\
(28,5)\end{array}$ & $\begin{array}{c}27,1 \\
(27,7)\end{array}$ & $(26,8)$ & 6,51 & $-2,61$ \\
\hline Tmin & 18,9 & 19,5 & 18,6 & $-2,42$ & $-2,99$ & $\begin{array}{c}16,5 \\
(16,3)\end{array}$ & $\begin{array}{c}17,7 \\
(17,8)\end{array}$ & $(17,1)$ & $-5,24$ & $-2,6$ \\
\hline Tmed & 23,7 & 23,6 & 22,5 & 0,46 & -3 & $\begin{array}{c}22,0 \\
(21,8) \\
\end{array}$ & $\begin{array}{c}22,3 \\
(22,5) \\
\end{array}$ & $(21,7)$ & $-1,14$ & $-3,23$ \\
\hline
\end{tabular}

Os dados são médias calculadas para cada período sazonal. Os valores entre parênteses são as médias calculadas sobre o período de 22/07/2005 a 06/02/2006.

${ }^{\circ}$ Dados do eucalipto somente a partir de 22/07/2005. 


\section{Eucalipto e Cerrado}

As comparações do eucalipto com o cerrado indicaram de forma geral que a temperatura sobre o eucalipto foi menor do que sobre o cerrado (Fig. 3.1.3.a, Fig. 3.1.7.d,h). No período úmido, principalmente, a temperatura no eucalipto é mais fria, tanto a máxima quanto a mínima (Fig. 3.1.9.b).

No eucalipto o termo LE mostrou-se maior que no cerrado, principalmente no período úmido, e o termo $\beta$ inferior, indicando menos energia para o aquecimento do ar no eucalipto (Fig. 3.1.7.a,c, Fig. 3.1.8). Sugerem-se dois possíveis controles que explicam a superioridade de LE do eucalipto em relação ao cerrado: maior capacidade fotossintética e maior turbulência mecânica. Observaram-se maiores taxas de absorção de $\mathrm{CO}_{2}$ do eucalipto, principalmente no período úmido (Fig E.1.c do Apêndice E). As altas taxas de evapotranspiração sobre a plantação de eucalipto já eram esperadas, embora o eucalipto seja uma espécie C3, assim como no cerrado predominam as espécies C3 (todas as arbóreas, e parte das gramíneas) e algumas gramíneas C4, os clones de eucalipto são de espécies selecionadas e com melhoramento genético.

Sob outro ponto vista, os controles climáticos do déficit da pressão de vapor d'água (DPV) e do vento (Fig. 3.1.9. a,d) não parecem afetar essa comparação. Aparentemente é a turbulência mecânica, que seria em parte controlada por características da rugosidade local, sugerido pela superioridade da velocidade de atrito $(\mathrm{u} *)$ no eucalipto (Fig. 3.1.9.e), que aumentaria o termo LE. Desta forma, a temperatura média (Tmed) no eucalipto foi $0,8{ }^{\circ} \mathrm{C}$ menor do que no cerrado, atingindo até $1,1^{\circ} \mathrm{C}$ no período úmido (Tabela 3.1.5). A aplicação da correção de altitude reduziria a diferença média de Tmed entre as áreas para $0,5{ }^{\circ} \mathrm{C}$ (as medidas no eucalipto estão 49 m acima das medidas do cerrado), o que pouco altera a qualidade da discussão.

As diferenças da Tmin entre o eucalipto e o cerrado também podem ter decorrido das diferentes alturas dos sensores, além disso, a velocidade do vento no eucalipto, assim como na cana, também foi menor que no cerrado, mas o padrão do ciclo diurno entre as duas áreas foi muito semelhante (Fig. 3.1.9.d). 


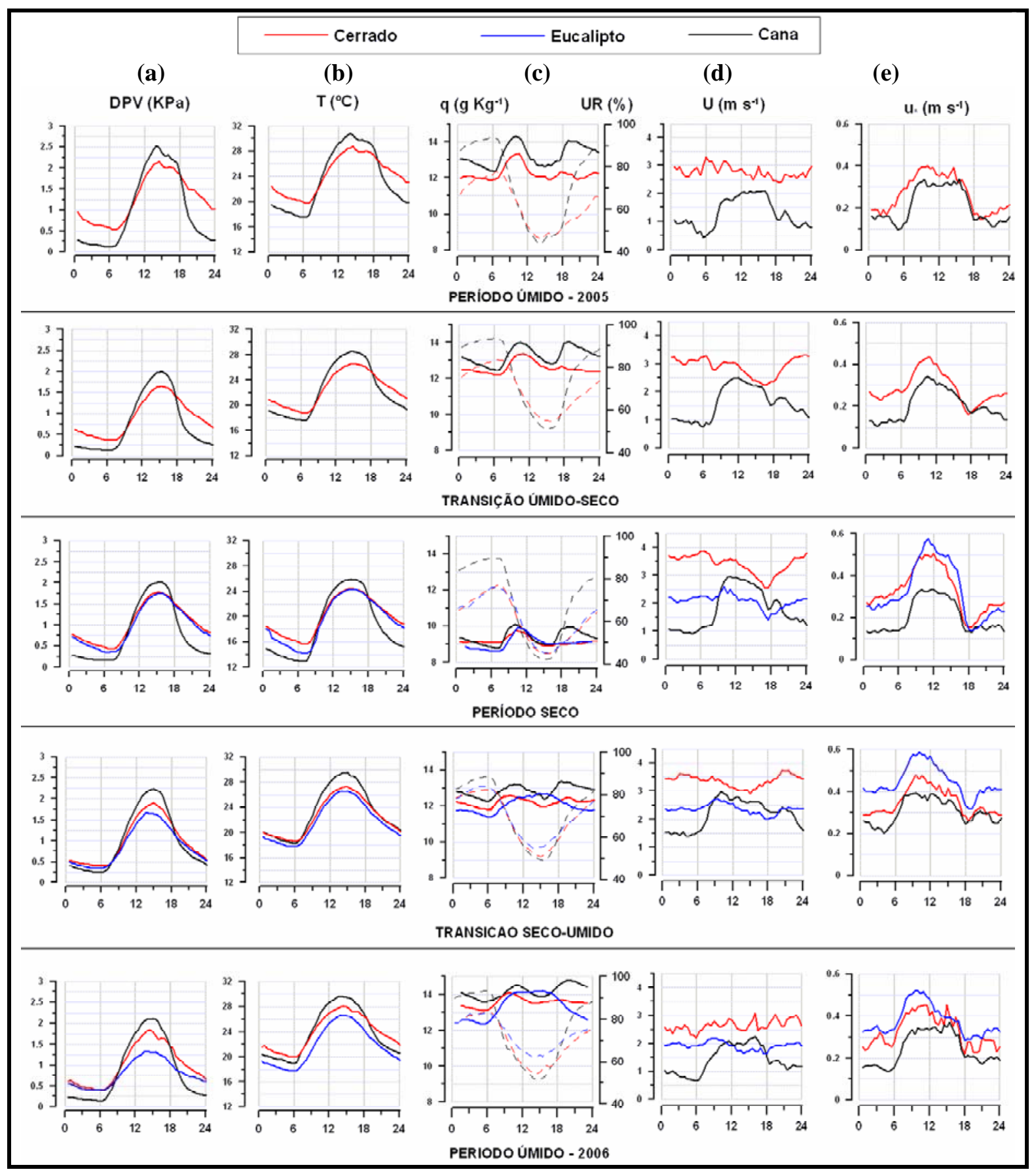

Figura 3.1.9 Ciclos diurnos obtidos a partir dos valores médios de 30 minutos das variáveis climáticas: (a) déficit da pressão de vapor (DPV) em $\mathrm{kPa}$, (b) temperatura do ar (T) em ${ }^{\circ} \mathrm{C}$, (c) umidade específica (q, eixo a esquerda) em $\mathrm{g} \mathrm{Kg}^{-1}$ e umidade relativa (UR, eixo a direita) em \%, (d) velocidade do vento (U) em $\mathrm{m} \mathrm{s}^{-1}$, (e) velocidade de atrito $(\mathrm{u} *) \mathrm{em} \mathrm{m} \mathrm{s}{ }^{-1}$, para o período úmido (Fev) de 2005, transição úmido-seco (Mar - Mai), período seco (Jun - Ago), transição seco-úmido (Set Nov) e período úmido (Dez - Fev) de 2006. O eixo x corresponde à hora local. 


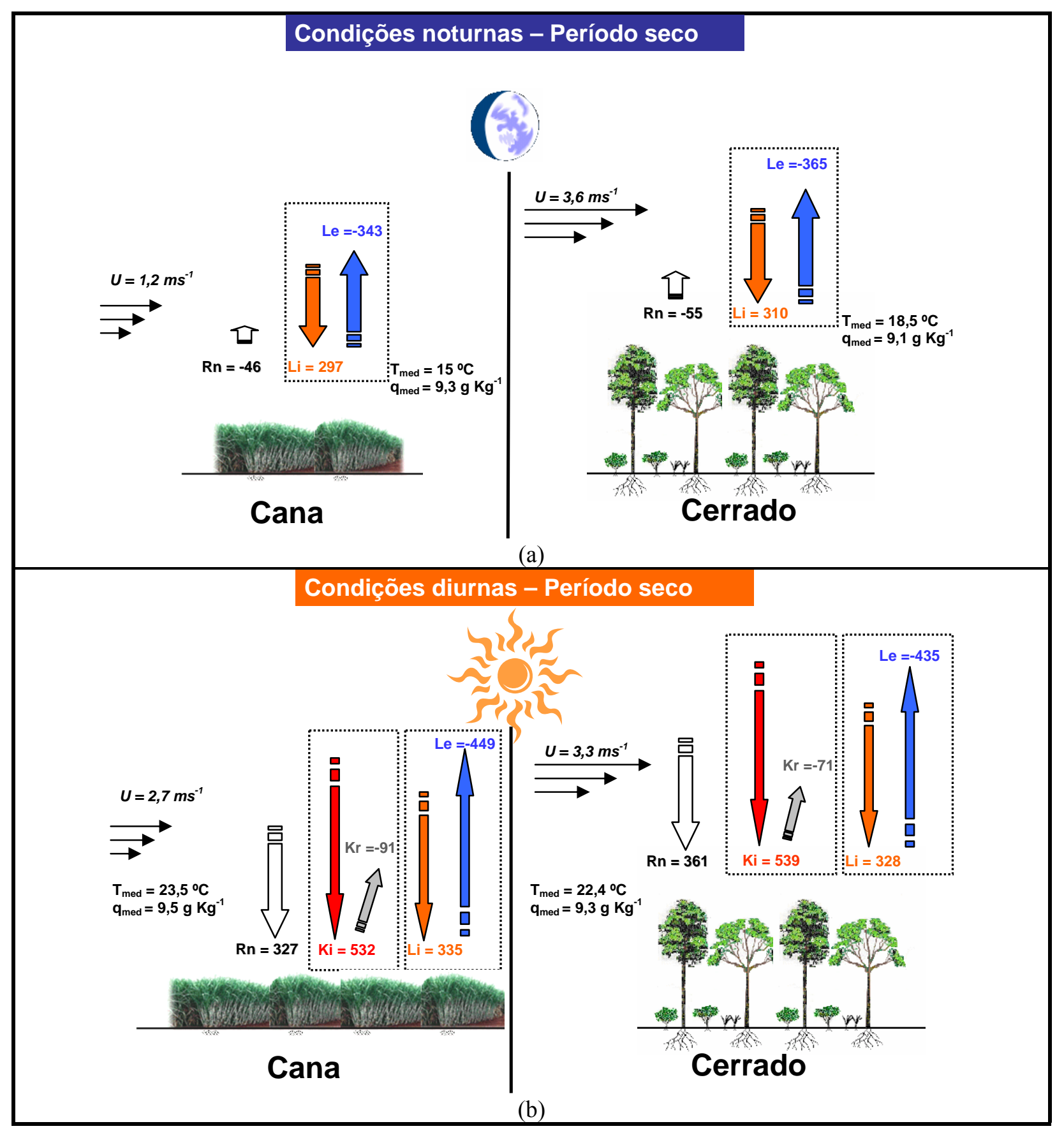

Figura 3.1.10. Condições típicas (a) noturnas e (b) diurnas, na estação seca sobre a cana e o cerrado. Os valores médios apresentados são referentes ao período noturno $(21-4 \mathrm{hs})$ e diurno $(9-16 \mathrm{hs})$. A irradiância de onda longa incidente $(\mathrm{Li})$ foi estimada através da equação $\mathrm{Li}=\sigma \mathrm{T}^{4}\left(0,51+0,066 e^{1 / 2}\right)$ (Brunt, 1932), onde $e$ é a pressão de vapor d'água. A irradiância de onda longa emergente (Le) foi estimada como resíduo do balanço de radiação $(\mathrm{Rn}=\mathrm{Ki}+\mathrm{Kr}+\mathrm{Li}+\mathrm{Le})$. As unidades dos fluxos radiativos estão em $\mathrm{Wm}^{-2}$. 


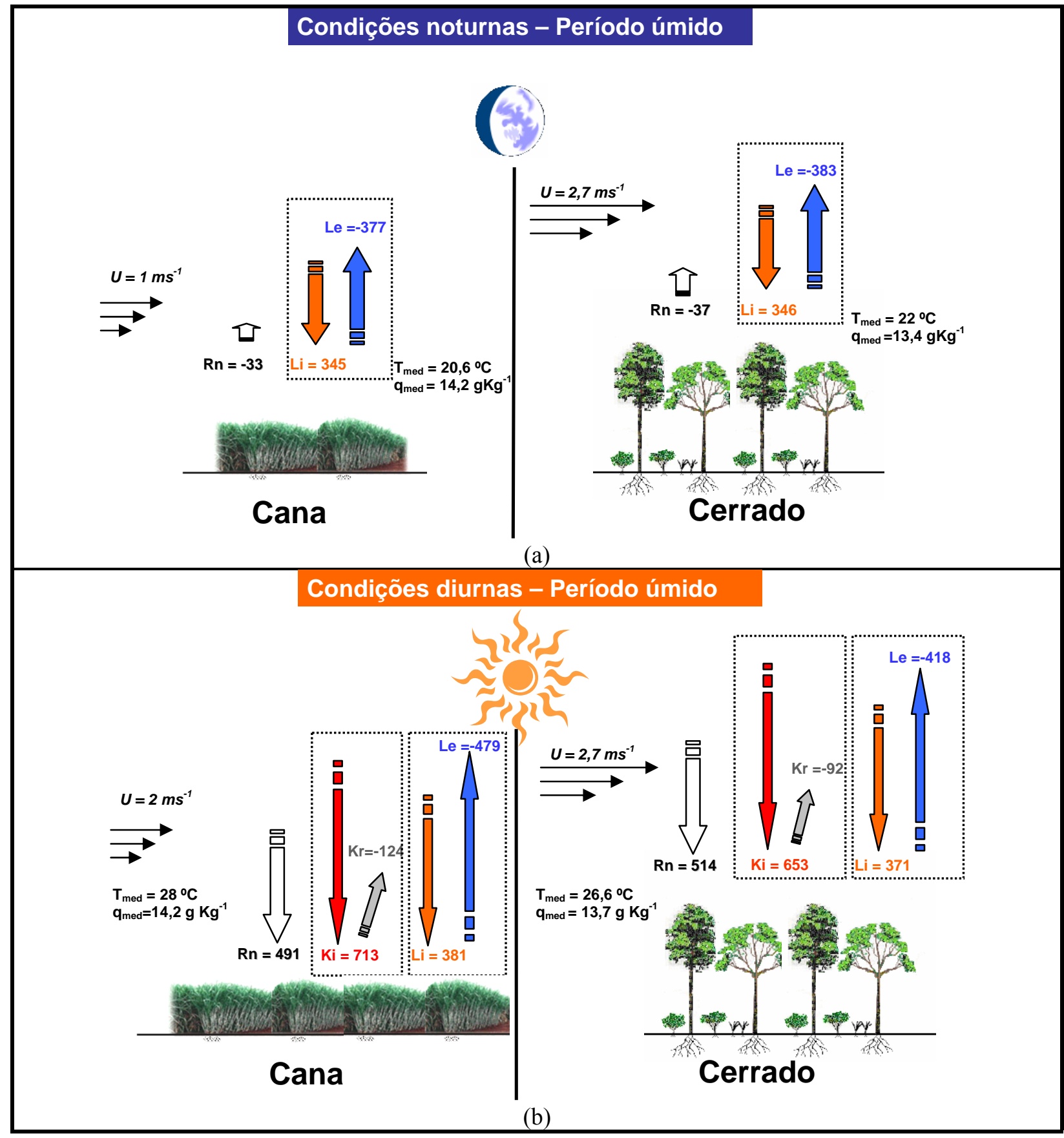

Figura 3.1.11. Idem a Fig. 3.1.10, porém para período úmido. 

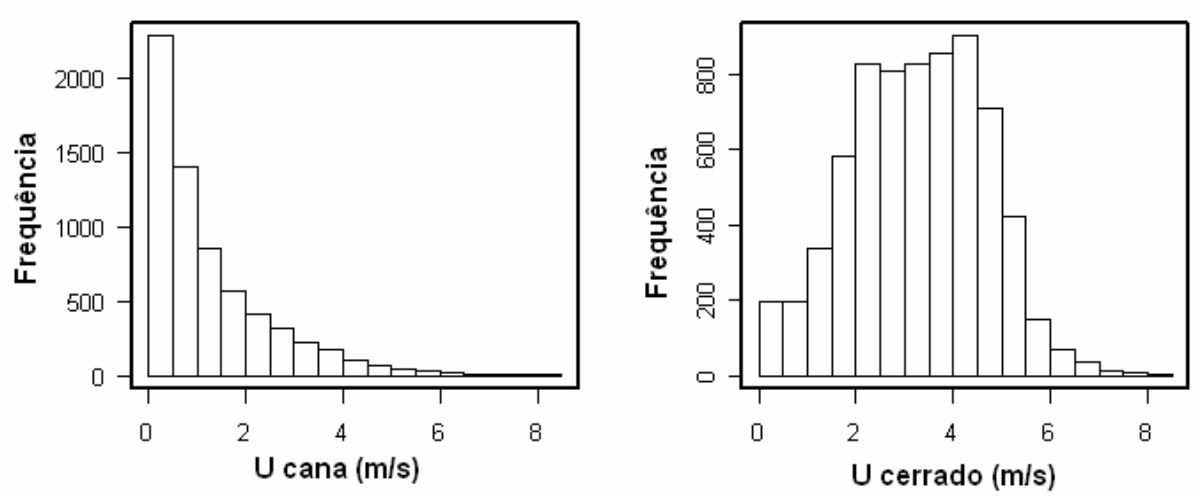

(a)

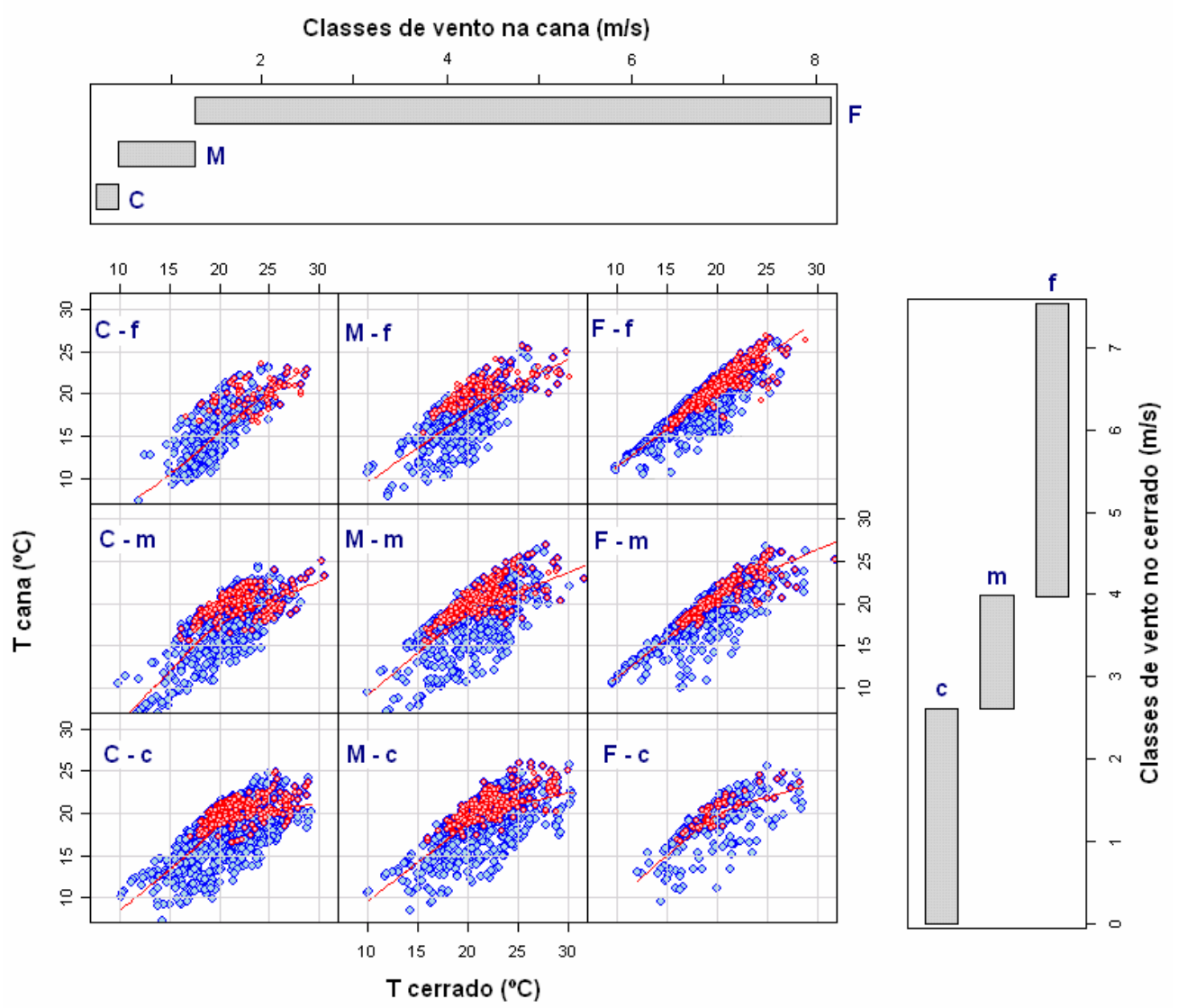

(b)

Figura 3.1.12. (a) Histograma da velocidade do vento noturna $(19-6$ h) na cana e no cerrado.(b) Influência da velocidade do vento sobre as medidas de temperatura na cana e no cerrado à noite. Os pontos em azul (vermelho) referem-se aos dados de 30 minutos de temperatura em todo período (outubro de 2005 a fevereiro de 2006). Foram selecionados somente os casos em que não ocorreu precipitação. As classes de velocidade do vento foram definidas na forma de tercentis: ventos relativamente calmos, moderados e fortes, representados pelas letras $\mathrm{C}, \mathrm{M}$ e $\mathrm{F}$, respectivamente (maiúsculas para a cana e minúsculas para o cerrado). 


\subsection{TENDÊNCIAS REGIONAIS DE PRECIPITAÇÃO E TEMPERATURA}

\section{CLIMATOLOGIA REGIONAL DA PRECIPITAÇ̃̃o}

A climatologia da precipitação média anual de SP é mostrada na Fig. 3.2.1.a e a topografia na Fig 3.2.1.b. Os máximos acompanham o litoral Sul, ao longo da Serra do Mar, com médias acima de $1700 \mathrm{~mm}$. No nordeste do estado, na divisa com MG, e também na Serra da Mantiqueira, surgem máximos secundários com médias entre 1500 e $1700 \mathrm{~mm}$. Na maior parte do estado predominam valores entre 1300 e $1500 \mathrm{~mm}$, abrangendo uma região correspondente a altitudes entre 400 e $800 \mathrm{~m}$ (Fig. 3.2.1.b), que se estende do centro do estado em todas as direções, inclusive o Vale do Paraíba. A região noroeste de SP é caracterizada pelos menores índices pluviométricos (inferiores a $1300 \mathrm{~mm}$ ). Dessa forma, pode-se notar a influência da topografia sobre a distribuição espacial da precipitação, que aumenta de oeste para leste seguindo a tendência de aumento de altitude nesta direção.

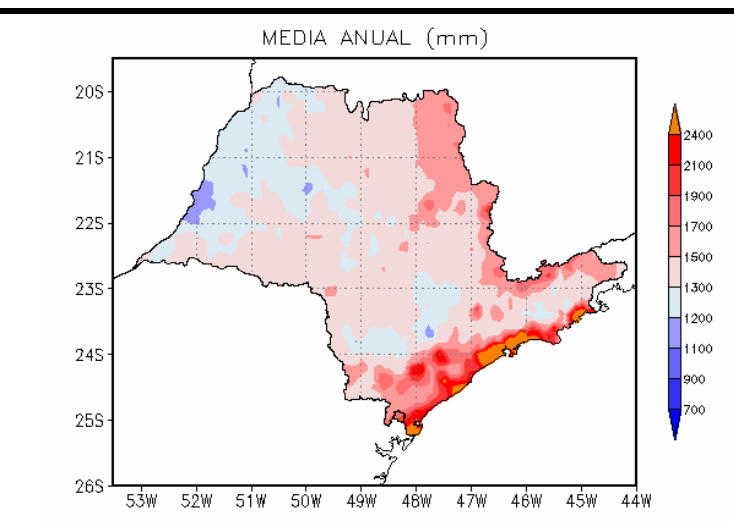

(a)

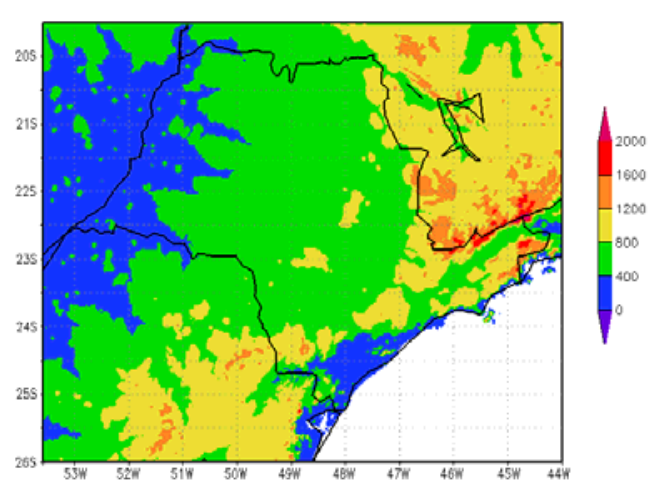

(b)

Figura 3.2.1. (a) Climatologia anual da precipitação para SP. (b) Campo de altitude para SP com resolução de 1 km (Dados do USGS). A escala de cores está em metros.

No norte de SP, a distribuição mensal da precipitação define o período úmido entre outubro e março, e o período seco entre abril e setembro (Fig. 3.2.2). A precipitação anual que é menor no Oeste do estado (Fig. 3.2.1.a) reflete-se principalmente na precipitação mensal do período de dezembro a março (Fig.3.2.2), onde chove um pouco mais no setor Leste. Por exemplo, em dezembro a chuva no setor Leste (Oeste) é de 250 (175) mm, e em Janeiro é de 250 
(210) $\mathrm{mm}$, respectivamente (Fig. 3.2.2). Nos meses secos a diferença de precipitação entre os setores Leste e Oeste do estado não é substancial.

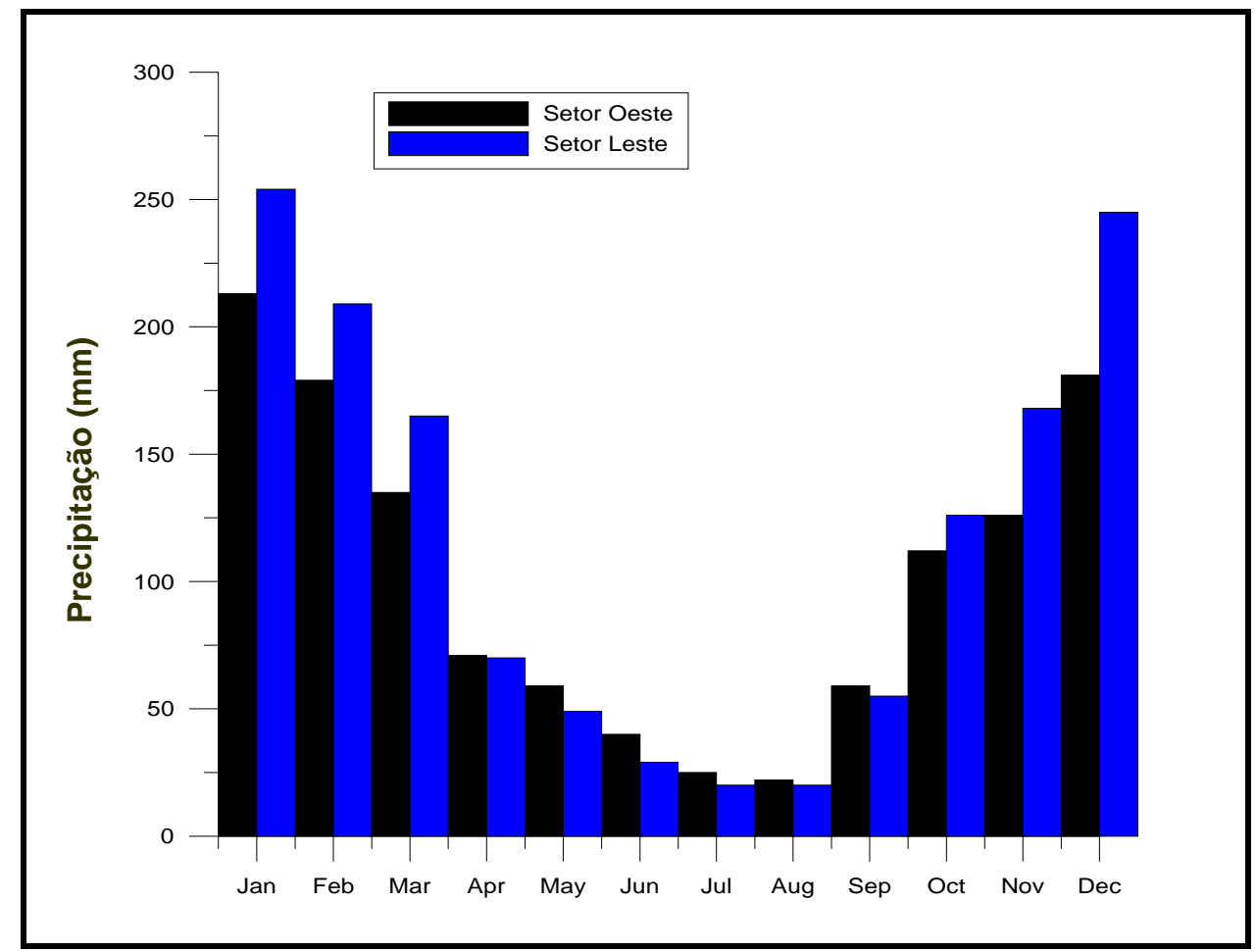

Figura 3.2.2. Pluviograma médio mensal (em mm), calculado em 320 estações do DAEE/SP, no setor Oeste (preto) e no setor Leste (azul) do centro-norte de SP (latitude acima de $22^{\circ} \mathrm{S}$ ), no período de 1940-2000.

\section{VARIAÇÕES CLIMÁTICAS DA PRECIPITAÇÃO}

\section{Escala regional}

Discutem-se aqui os padrões de longo prazo da precipitação em escala regional no setor centro-norte de SP. Com as anomalias absolutas das médias anuais de precipitação, no período de 1940 a 2000, para os setores Leste e Oeste, a norte de $22^{\circ} \mathrm{S}$ em SP, verifica-se uma oscilação com fase seca (predomínio de anomalias negativas da precipitação na primeira metade do período), seguida por uma fase úmida (predomínio de anomalias positivas da precipitação na segunda metade) (Fig. 3.2.3). A fase úmida no setor Leste inicia um pouco mais cedo, por volta 
de 1960, enquanto no setor Oeste a transição de fase é mais definida, por volta de 1970. De forma geral as anomalias absolutas variaram entre $\pm 400 \mathrm{~mm}$ ano ${ }^{-1}$, havendo apenas 5 eventos que excederam este intervalo, particularmente no Leste de SP.

A média da precipitação anual no período 1970-1999 teve um aumento significativo de 16\% em relação à média do período de 1940-1969, coerente nos setores Leste e Oeste, de 208 e $182 \mathrm{~mm}$, respectivamente (Tabela 3.2.1). Comparando-se as médias mensais da precipitação nestes dois períodos (Tabela 3.2.1), também se observa um padrão coerente nos dois setores: o aumento da precipitação foi bem distribuído ao longo do ano, com significância estatística nos meses de transição de estação (abril, maio e setembro) e também no mês de dezembro. Apenas no mês de fevereiro ocorreu redução da precipitação (não significativa) em ambos os setores.

Tabela 3.2.1. Valores médios de precipitação para cada mês do ano nos setores Leste e Oeste do Norte de SP, nos períodos climatológicos de 1940-1969 (P1) e 1970-1999 (P2). As médias com diferenças significativas estatisticamente (baseadas no teste-t), para N.S. $<1 \%$ ou N.S. $<5 \%$, entre os dois períodos estão destacadas em cinza ou negrito, respectivamente.

\begin{tabular}{ccccccc}
\hline & & Oeste & & & Leste & \\
\hline Meses & P1 & P2 & P2-P1 & P1 & P2 & P2-P1 \\
\hline JAN & 207 & 225 & 18 & 249 & 262 & 13 \\
FEV & 186 & 173 & -13 & 214 & 210 & -4 \\
MAR & 124 & 146 & 22 & 161 & 175 & 14 \\
ABR & 62 & 84 & $\mathbf{2 2}$ & 55 & 89 & 34 \\
MAI & 48 & 69 & 21 & 38 & 60 & $\mathbf{2 2}$ \\
JUN & 40 & 40 & 0 & 24 & 33 & 9 \\
JUL & 24 & 26 & 2 & 17 & 24 & 7 \\
AGO & 18 & 27 & 9 & 13 & 26 & 13 \\
SET & 44 & 73 & 29 & 42 & 70 & $\mathbf{2 8}$ \\
OUT & 114 & 113 & -1 & 123 & 134 & 11 \\
NOV & 116 & 134 & 18 & 159 & 172 & 13 \\
DEZ & 153 & 208 & 55 & 219 & 267 & $\mathbf{4 8}$ \\
ANUAL & 1136 & 1318 & 182 & 1314 & 1522 & 208 \\
\hline
\end{tabular}




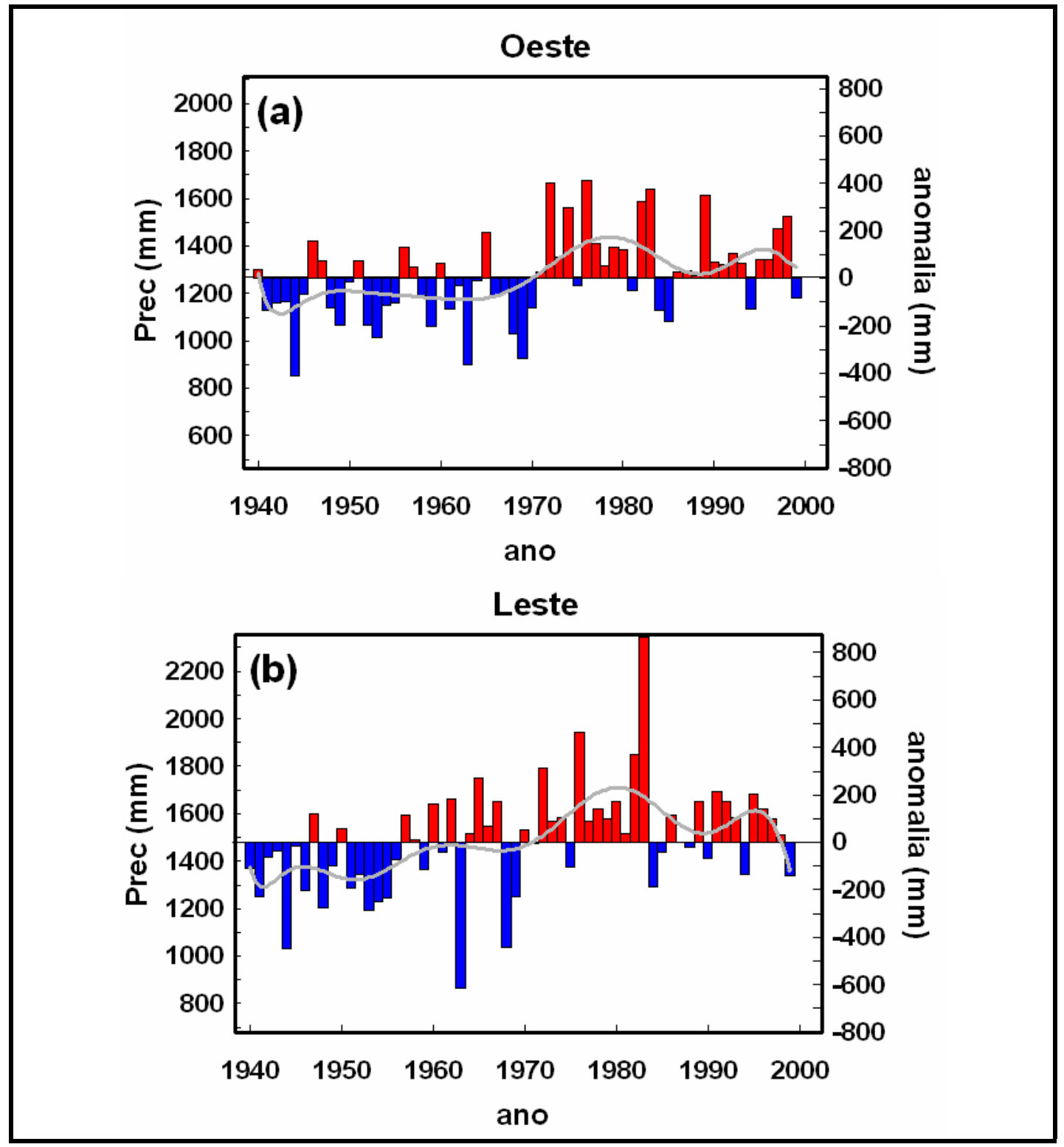

Figura 3.2.3. Séries das anomalias absolutas anuais de precipitação em relação ao período de 1940-1999, no eixo y a direita (ou total anual no eixo a esquerda) nos setores (a) Oeste e (b) Leste de SP. As linhas sólidas em cinza representam a série suavizada pela função loess (regressão polinomial ponderada localmente, Cleveland 1979).

\section{Estações individuais}

A análise anterior foi aplicada nas estações individuais de Campinas e Ribeirão Preto (Fig. 3.2.4). A estação de Campinas (Fig. 3.2.4.a) apresenta um padrão de oscilação comparável 
aos padrões dos setores regionais (mais comparável com o do setor Oeste de SP, conforme a Fig. 3.2.3.a). No entanto a precipitação em Campinas é sistematicamente maior que a precipitação no setor Oeste (Fig. 3.2.5. c), em média por $\sim 195 \mathrm{~mm}$ no período de 1940-2000. A estação de Ribeirão Preto também se compara bem com os padrões regionais de oscilação decadal, identificando-se melhor com o setor Leste (onde a estação faz parte do cálculo da média regional), inclusive em magnitude.

A média da precipitação anual no período 1972-2000 teve um aumento de 8,6\% e 9,5\% em relação à média do período de 1943-1971, em Campinas e Ribeirão Preto, respectivamente, com significância estatística apenas em Ribeirão Preto (Tabela 3.2.2). A comparação das médias mensais da precipitação nestes dois períodos (Tabela 3.2.2) também mostrou um padrão coerente nas duas estações: assim como no centro-norte de SP, houve aumento significativo da precipitação nos meses de transição de estação (abril, maio e setembro); em alguns meses a precipitação diminuiu, como por exemplo no mês de outubro (nas duas estações), em janeiro e março (em Ribeirão Preto), e fevereiro (em Campinas). No entanto, em nenhum caso de diminuição da precipitação, houve significância estatística.

Resulta desta análise que as estações individuais refletem os padrões regionais de variabilidade decadal. Diante deste resultado, pergunta-se quais seriam as causas dessa mudança no padrão da precipitação na escala regional? Dentro deste contexto é importante diferenciar mudança climática de variabilidade climática, o que está intrinsecamente associado à escala de tempo. O que parece uma tendência em algumas décadas, pode se revelar como uma oscilação inserida em um ciclo decadal quando visto na escala secular. Para testar esta hipótese, foi utilizada a série histórica de 111 anos de Campinas (a estação mais antiga de SP, desde 1890, Mello et al 1994) para a análise de sua variabilidade de longo prazo. A Fig 3.2.5.a apresenta a série de longo prazo da precipitação anual de Campinas, e das séries de precipitação dos setores Leste e Oeste, onde se observa que as variações da precipitação entre elas têm forte semelhança. Um aspecto marcante nestas séries é que há forte variabilidade interanual da precipitação, além disso, sugere-se pelas curvas suavizadas (linha preta grossa na Fig. 3.2.5.a) que há também um modo de baixa freqüência com menor amplitude. Este modo de baixa freqüência na estação de Campinas exibe dois mínimos (em 1913 e 1947), intercalados por dois máximos (1930 e 1975), o que sugere um padrão interdecadal de ciclo de $\sim 20$ a 30 anos. As flutuações da precipitação em Campinas sugerem algumas semelhanças com o padrão do índice da ODP (Fig. 3.2.5.b). Por 
exemplo, no período de 1935 a 1963, Campinas passou por uma fase seca (barras na Fig. 3.2.5.c) e no período de 1947 a 1975 a ODP encontrava-se em uma fase fria, indicando uma pequena defasagem entre as duas séries.
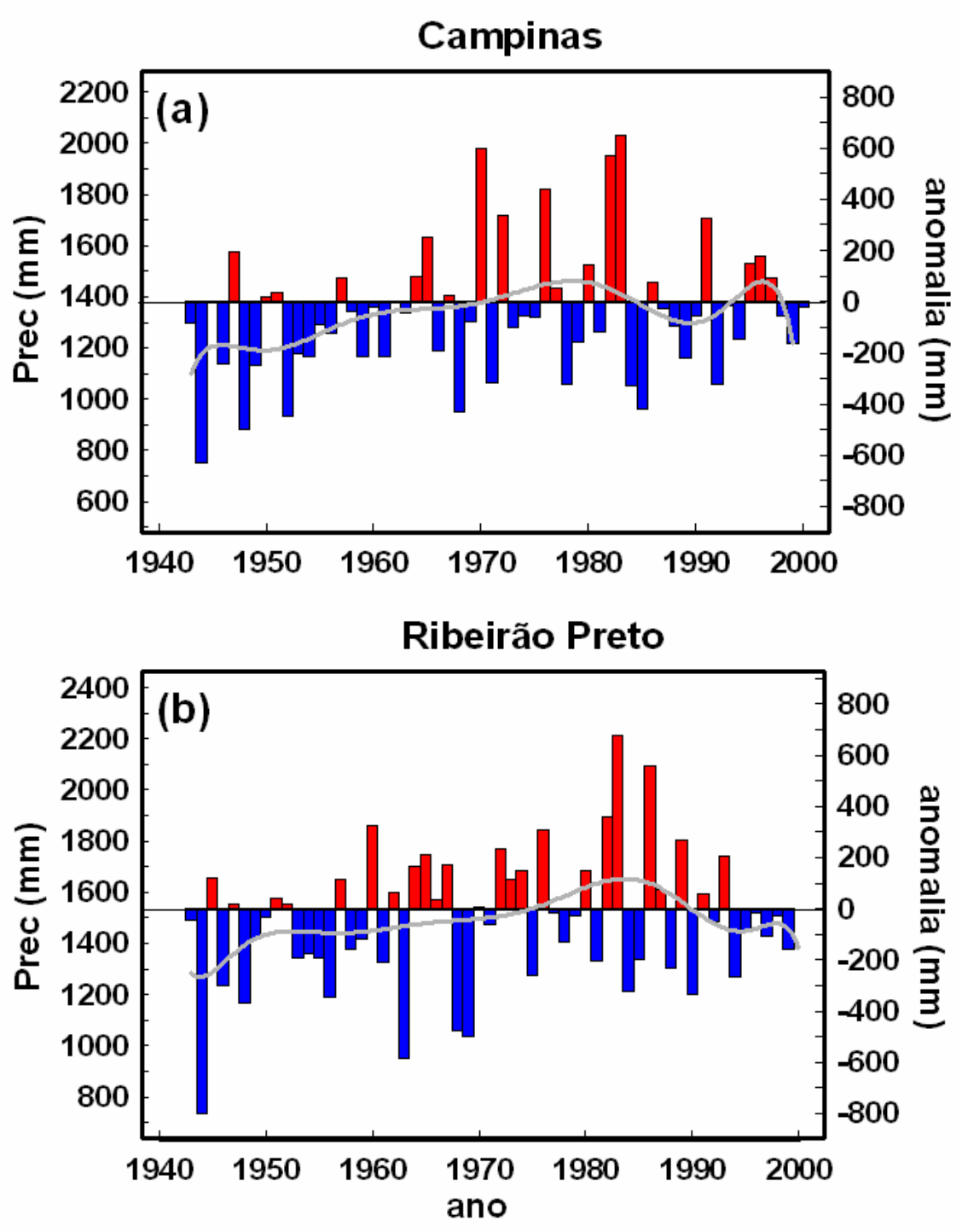

Figura 3.2.4. Séries das anomalias absolutas anuais de Precipitação em relação ao período de 1943-2000, no eixo y à esquerda (ou total anual no eixo à direita) em (a) Campinas e (b) Ribeirão Preto. As linhas sólidas em cinza representam a série suavizada pela função loess.

A anomalia acumulada de precipitação (linha vermelha na Fig. 3.2.5.c) foi calculada com as anomalias absolutas de precipitação (barras coloridas na Fig. 3.2.5.c). O padrão da anomalia acumulada permitiu identificar um caráter de persistência de longo prazo da 
precipitação, de boa comparabilidade com o índice da ODP (Fig. 3.2.5.b). Os regimes de transição da anomalia acumulada são marcados pelos pontos de inflexão (uma mudança de inclinação negativa para positiva, e vice-versa), como por exemplo em 1962. O coeficiente de correlação linear da anomalia acumulada da precipitação normalizada (dividida pelo desvio padrão) e o índice da ODP foi de 0,5 (N.S. $<1 \%$ ), o que é um indício da possível conexão entre a variabilidade da ODP e a chuva em SP na escala interdecadal.

Além da variabilidade climática natural, outros controles da chuva em SP poderiam em hipótese decorrer do aquecimento global, e/ou das mudanças de uso da terra. No entanto há insuficiente informação da literatura que tenha atribuído um sinal claro do efeito destes controles sobre a precipitação nesta região.

Tabela 3.2.2. Valores médios de precipitação para cada mês do ano nas estações de Campinas e Ribeirão Preto, nos períodos de 1943-1971 (P1) e 1972-2000 (P2). As médias com diferenças significativas estatisticamente (baseadas no teste-t), para N.S. $<1 \%$ ou N.S. $<5 \%$, entre os dois períodos estão destacadas em cinza ou negrito, respectivamente.

\begin{tabular}{ccccccc}
\hline & \multicolumn{3}{c}{ Campinas } & \multicolumn{3}{c}{ Ribeirao } \\
\hline Meses & P1 & P2 & P2-P1 & P1 & P2 & P2-P1 \\
\hline JAN & 236 & 262 & 26 & 280 & 264 & -16 \\
FEV & 219 & 190 & -29 & 219 & 222 & 3 \\
MAR & 161 & 165 & 4 & 178 & 166 & -12 \\
ABR & 64 & 79 & 15 & 58 & 90 & $\mathbf{3 2}$ \\
MAI & 45 & 77 & $\mathbf{3 2}$ & 42 & 62 & 20 \\
JUN & 49 & 51 & 2 & 29 & 30 & 1 \\
JUL & 26 & 41 & 15 & 19 & 25 & 6 \\
AGO & 31 & 36 & 5 & 17 & 27 & 10 \\
SET & 50 & 78 & $\mathbf{2 8}$ & 37 & 66 & 29 \\
OUT & 135 & 118 & -17 & 134 & 123 & -11 \\
NOV & 138 & 151 & 13 & 153 & 182 & 29 \\
DEZ & 208 & 231 & 23 & 252 & 296 & 44 \\
ANUAL & 1362 & 1479 & 117 & 1418 & 1553 & $\mathbf{1 3 5}$ \\
\hline
\end{tabular}



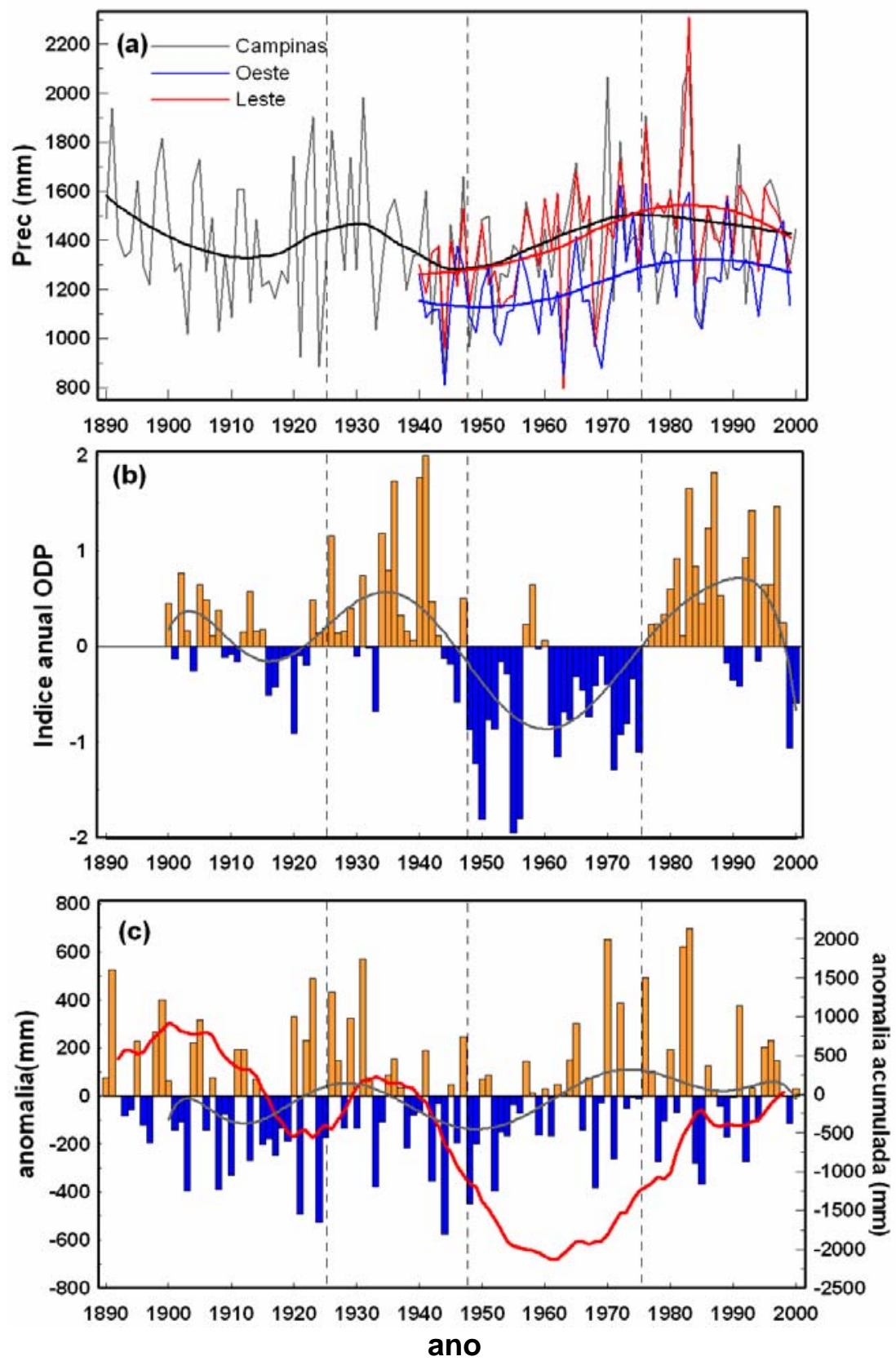

Figura 3.2.5. (a) Totais anuais de precipitação em Campinas no período de 1890-2000 e nos setores Leste e Oeste de SP, a partir de 1940. (b) Série temporal do índice da Oscilação Decadal do Pacífico no período de 1900-2000 (com dados de Mantua et al. 1997, disponíveis em http://www.atmos.washington.edu/ mantua/abst.PDO.html). (c) Anomalias absolutas da precipitação anual de Campinas em relação ao período de 1890-2000 (eixo y a esquerda). A escala a direita no eixo y corresponde à série desta anomalia acumulada no tempo (linha vermelha). As outras linhas sólidas representam as séries suavizadas pela função loess. 


\section{VARIAÇÕES CLIMÁTICAS DE TEMPERATURA}

A Figura 3.2.6 apresenta a variação da temperatura média máxima, mínima e da amplitude térmica diária anual para o período de 1943-2000. A Tmax anual tanto em Ribeirão Preto (Fig. 3.2.6.a) como em Campinas (Fig. 3.2.6.d) foi marcada por uma fase quente, de 1950 até o início da década de 1960 , com anomalias acima de $+0,5^{\circ} \mathrm{C}$. No período posterior, a Tmax oscilou em torno da média, todavia, para todo o período, a tendência linear calculada foi significativa apenas para Ribeirão Preto, sugerindo um pequeno sinal de resfriamento $\left(-0,5^{\circ} \mathrm{C}\right.$ em 58 anos, Tabela 3.2.3). Isto não significa que um processo de diminuição estritamente linear da temperatura esteja em curso na escala decadal, esta estimativa foi uma forma simples de caracterizar a mudança e de quantificar sua magnitude . Mostrou-se que houve um padrão bem definido por uma fase quente intensa, seguida por uma fase sem uma tendência bem definida, o que levou artificialmente à uma estatística significativa, particularmente em Ribeirão preto.

A Tmin anual nas duas estações de 1943 a 2000 (Fig. 3.2.6.b,e) mostra uma tendência crescente marcante $\left(1,4{ }^{\circ} \mathrm{C}\right.$ em 58 anos nas duas estações, com significância estatística, Tabela 3.2.3). No período de 1943-1970 a Tmin foi marcada por anomalias negativas (em torno de $-0,5$ ${ }^{\circ} \mathrm{C}$ ), em ambas as estações. Em Campinas a Tmin aumenta linearmente, desde 1960 até 2000, quando as anomalias se aproximam de $+1{ }^{\circ} \mathrm{C}$ (Fig. 3.2.6.d). Em Ribeirão Preto também se nota uma progressão de Tmin nesta escala de tempo, mas com um aumento abrupto no início da década de 1990 (atingindo anomalias acima de $+1{ }^{\circ} \mathrm{C}$ ). O que difere o padrão de Tmin em Ribeirão Preto e Campinas foi que na década de 1980 houve uma sucessão de eventos frios apenas em Ribeirão Preto, discutida a seguir.

A amplitude térmica diária (ATD) média anual para as duas estações (Fig. 3.2.6.c,f) foi dominada por anomalias positivas (acima de $0,5^{\circ} \mathrm{C}$ ) de 1943 a 1965 e por anomalias negativas no período posterior (em torno de $-0,5^{\circ} \mathrm{C}$ ). A redução da ATD ocorre a uma taxa de $-1,9{ }^{\circ} \mathrm{C}$ e $-1,4{ }^{\circ} \mathrm{C}$ em 58 anos, para Ribeirão Preto e Campinas, respectivamente, em conseqüência das tendências opostas de Tmax e Tmin anual, mas a maior contribuição ao padrão da ATD decorreu do padrão de Tmin.

Na Figura 3.2.7 é mostrada a variação intersazonal da Tmax no período de 1943-2000. De forma geral, nota-se que a variação decadal da Tmax, para as duas estações, é mais marcante nos meses de primavera (SON) e verão (DJF), devido às maiores magnitudes das anomalias (Fig. 3.2.7). Entre os demais trimestres, apenas no inverno (JJA), em Ribeirão Preto, verificou-se uma 
persistência de anomalias de um ano para outro (Fig. 3.2.7.c) e uma tendência negativa significativa de $-0,8^{\circ} \mathrm{C}$ em 58 anos (Tabela 3.2.3).

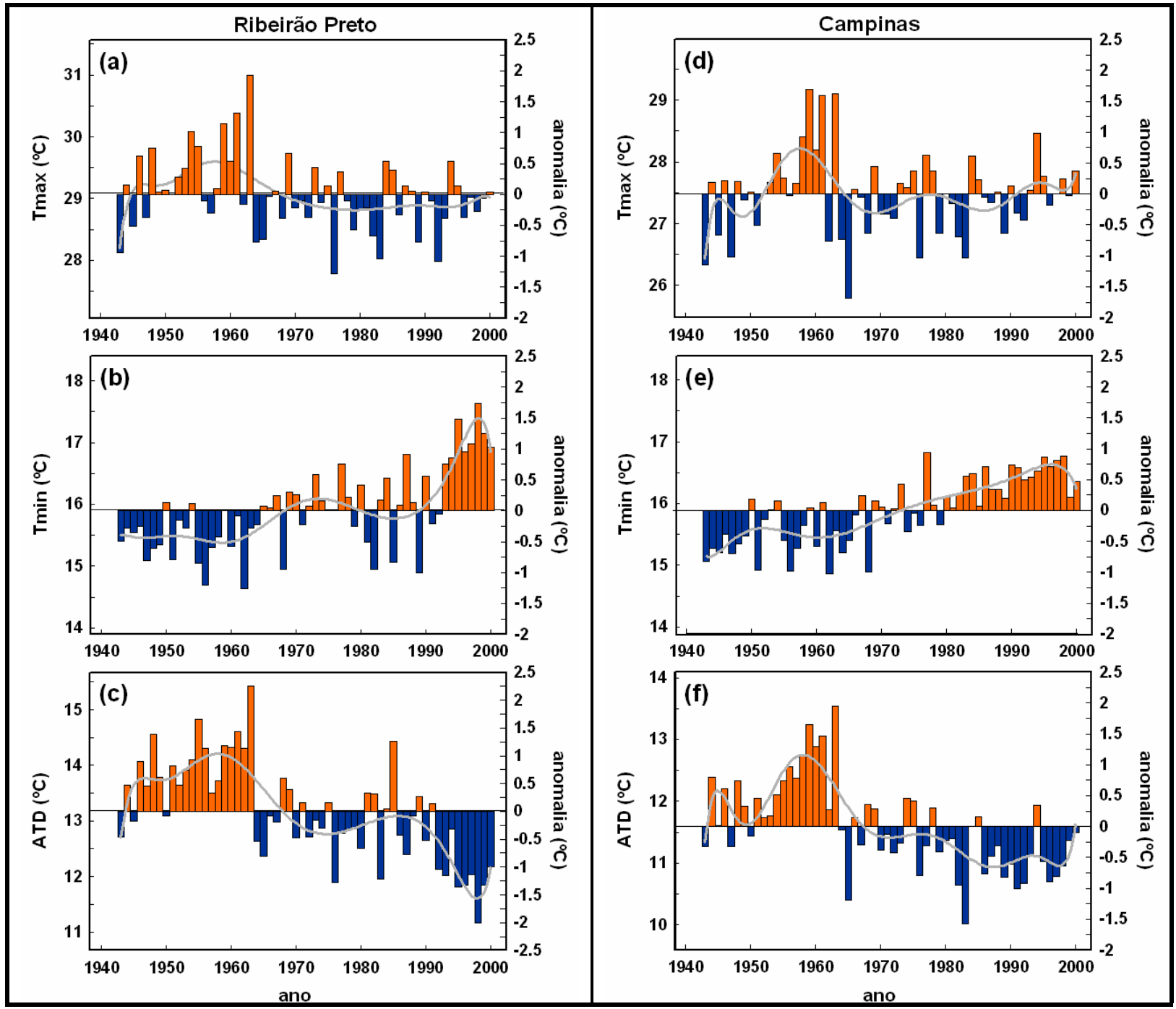

Figura 3.2.6. Séries das anomalias anuais absolutas de temperatura (eixo y à direita) em relação ao período de 1943-2000 (ou média anual no eixo à esquerda). (a) Tmax, (b) Tmin e (c) ATD em Ribeirão Preto. (d) Tmax, (e) Tmin e (f) ATD em Campinas. As linhas sólidas em cinza representam a série suavizada pela função loess.

No caso da Tmin o trimestre de inverno é o de maior variação intersazonal ao longo dos anos, nas duas estações (Fig. 3.2.8.c,g). Os outros trimestres foram mais semelhantes ao padrão da Tmin anual. Entretanto, em Campinas, os trimestres DJF e MAM mostraram uma tendência de aumento da Tmin mais nitidamente (Fig. 3.2.8.e,f) e de maior magnitude $\left(1,4\right.$ e $1,6^{\circ} \mathrm{C}$ em 58 anos, respectivamente, Tabela 3.2.3). 
Tabela 3.2.3. Tendências de temperatura máxima, mínima e da amplitude térmica diária $\left({ }^{\circ} \mathrm{C}\right.$ em 58 anos) para cada trimestre do ano nas estações de Ribeirão Preto e Campinas. As tendências significativas para N.S. $<5 \%$, baseadas no teste-t, são destacadas em negrito.

\begin{tabular}{ccccccc}
\hline & \multicolumn{3}{c}{ Ribeirão Preto } & \multicolumn{3}{c}{ Campinas } \\
\hline Período & Tmax & Tmin & ATD & Tmax & Tmin & ATD \\
\hline DJF & $-0,2$ & $\mathbf{1 , 2}$ & $\mathbf{- 1 , 4}$ & 0,2 & $\mathbf{1 , 5}$ & $\mathbf{- 1 , 2}$ \\
MAM & $-0,4$ & $\mathbf{1 , 9}$ & $\mathbf{- 2 , 3}$ & 0,2 & $\mathbf{1 , 6}$ & $\mathbf{- 1 , 4}$ \\
JJA & $\mathbf{- 0 , 8}$ & $\mathbf{1 , 3}$ & $\mathbf{- 2 , 1}$ & $-0,1$ & $\mathbf{1 , 2}$ & $\mathbf{- 1 , 4}$ \\
SON & $-0,6$ & $\mathbf{1 , 2}$ & $\mathbf{- 1 , 8}$ & $-0,2$ & $\mathbf{1 , 4}$ & $\mathbf{- 1 , 6}$ \\
\hline ANUAL & $\mathbf{- 0 , 5}$ & $\mathbf{1 , 4}$ & $\mathbf{- 1 , 9}$ & 0,0 & $\mathbf{1 , 4}$ & $\mathbf{- 1 , 4}$ \\
\hline
\end{tabular}

Em Ribeirão Preto a tendência crescente da Tmin a partir de 1960 durante o verão foi interrompida por uma seqüência de anos frios na década de 1980 (Fig. 3.2.8.a), o que não ocorreu nitidamente no inverno (Fig. 3.2.8.c). Estes eventos frios coincidiram com anos muito chuvosos, com anomalias superiores a $+400 \mathrm{~mm} \mathrm{ano}^{-1}$ nas duas estações (Fig. 3.2.4). Foram portanto resultantes de uma forma natural de variabilidade climática. De forma interessante, os anos de baixa Tmin naquela década não foram observados em Campinas (Fig. 3.2.8.e), mesmo com a alta precipitação. Como o padrão frio na década de 1980 pode ser de grande escala, o fato de não se observá-lo em Campinas é uma questão que não se explica no escopo deste trabalho.

No que diz respeito às tendências da ATD em cada trimestre (Tabela 3.2.3 e Fig. 3.2.9), observa-se que foram sempre estatisticamente significativas. Da mesma forma que no caso da ATD anual, nas médias trimestrais também houve um domínio do padrão das tendências positivas de Tmin (Fig. 3.2.8). Em Ribeirão Preto a diminuição da ATD (Fig. 3.2.9.a-d) foi mais evidente no outono, nos outros trimestres também se observou à ocorrência de anomalias positivas de ATD na década de 1980, o que produziu uma oscilação na série histórica naquela década.

\section{Possiveis controles dos padrões climáticos}

De acordo com os padrões relatados, questiona-se sobre quais seriam as causas da variação da precipitação e da temperatura nas estações analisadas. Dai et. al. (1999) analisou dados de cobertura de nuvens, precipitação e temperatura em várias partes do mundo no período de 1900-1990, reportando que o efeito do aumento de precipitação e da nebulosidade foi a diminuição da amplitude térmica diária média, por meio do resfriamento evaporativo que atenua o aumento da temperatura máxima. Esta relação inversa entre precipitação e amplitude térmica, 
que é provavelmente resultante da variação natural do clima, é o padrão mais claramente observado neste estudo. A fase quente da Tmax no período de 1943-1965 concorda com a fase mais seca naquela época. Analogamente, o período posterior foi caracterizado por uma fase úmida, observando-se a Tmax estacionária em Campinas, e em Ribeirão com pequena redução, mas significativa (Tabela 3.2.3).

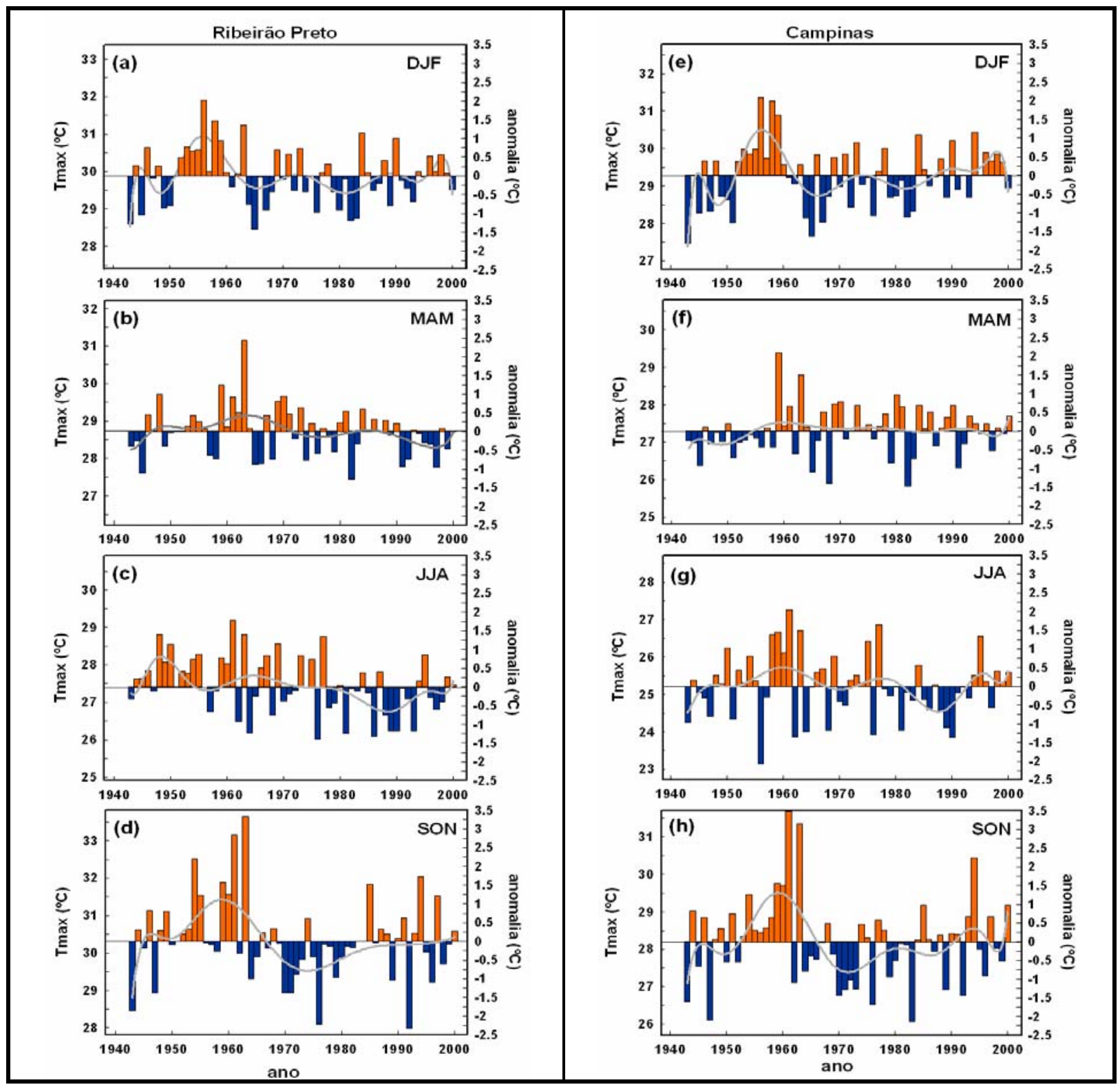

Figura 3.2.7. Séries das anomalias absolutas trimestrais de temperatura máxima (eixo y à direita) em relação ao período de 1943-2000 (ou média trimestral no eixo à esquerda). (a-d) Ribeirão Preto, (e-h) Campinas. As linhas sólidas em cinza representam a série suavizada pela função loess. Em cada gráfico o trimestre correspondente é indicado na parte superior a direita. 
A tendência crescente de Tmin é mais evidente nas duas estações desde o início da década de 1960. Neste período há dois fatores que cresceram concorrentemente: a concentração global dos gases estufa, e a urbanização das cidades. Comentou-se que alguns anos relativamente frios na década de 1980 mas que não comprometeram a definição da tendência de Tmin. Nos últimos 20 anos (10 anos) verifica-se claramente a persistência de anomalias quentes de Tmin em Campinas (Ribeirão Preto). Estes resultados são consistentes com o aumento global da Tmin, que excede, geralmente mas não sempre, o aumento da Tmax, observado em várias regiões do mundo (Karl et al., 1984, 1991, 1993; Horton, 1995; IPCC, 2001b; Easterling et. al. 1997, Alexander et al. 2006), e em várias estações da América do Sul (Rusticucci e Barrucand, 2004; Vincent et al. 2005; Ambrizzi \& Dufek, 2005 ).

Para comentar a possível influência da urbanização nos padrões de Tmax, mostra-se que em Campinas os dados foram coletados em uma área no limite da área urbanizada (Fig. 3.2.10.b). Como a direção predominante do vento durante o dia tem componentes de Sudeste e Norte (Figura 3.2.11.a,b), o efeito da urbanização pode contribuir para o padrão de Tmax. A estação de Ribeirão Preto situa-se 2 km a sudoeste da área mais densamente urbanizada (Fig. 3.2.10.a), em uma posição onde o vento predominante durante o dia (de Leste e Norte, Fig.3.2.11.c,d) pode proporcionar o efeito da ilha de calor. Principalmente após 1970, mostrou-se um padrão estacionário de Tmax, ou de pequena tendência negativa, concordando com a literatura de comparação entre clima urbano e rural (Karl \& Jones, 1989; Bonan, 2002).

É muito sugestivo que haja um efeito da urbanização no padrão de Tmin na estação de Campinas devido a três evidências: pela localização em relação à mancha urbana, direção do vento noturno predominante de Sudeste (Fig. 3.2.11.b), o que contribuiria para o aquecimento observado, e o notável crescimento populacional (Fig.3.2.12.a). Na estação de Ribeirão Preto esta possibilidade é mais incerta: a estação localiza-se na periferia, mas dentro da margem de influência da ilha de calor, mas com um contraponto, devido ao vento noturno (predominante de sudeste, Fig.3.2.11.d) que traz influência de áreas rurais, o que reduziria o controle da urbanização. Não se pode concluir, baseado nos padrões de Tmin no sítio experimental de cana e cerrado (seção 3.1 - Comparação da Temperatura entre áreas experimentais) que haja uma influência conclusiva das áreas rurais nas tendências de temperatura noturna de longo prazo em Ribeirão Preto. 


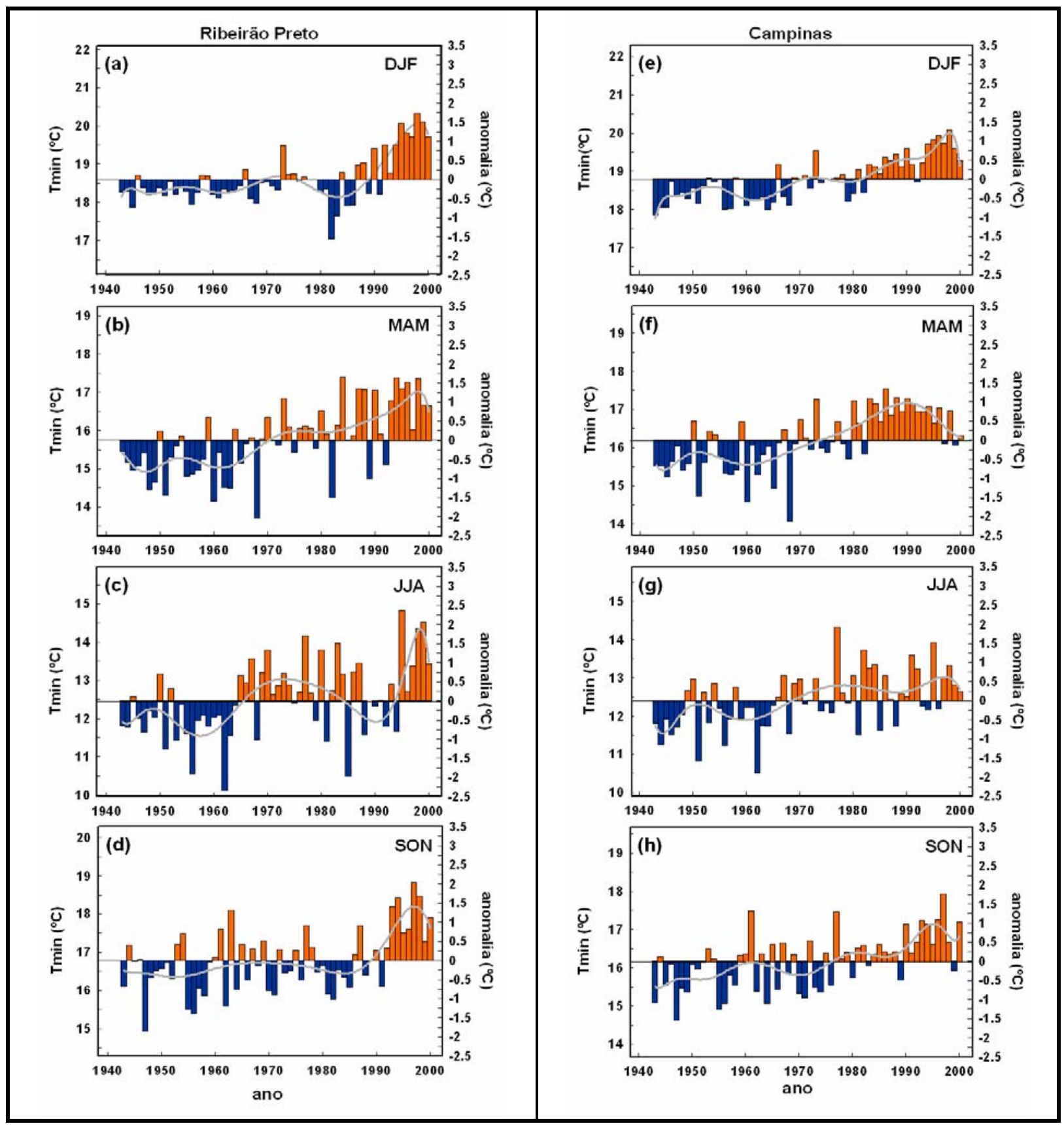

Figura 3.2.8. Séries das anomalias absolutas trimestrais de temperatura mínima (eixo y à direita) em relação ao período de 1943-2000 (ou média trimestral no eixo à esquerda). (a-d) Ribeirão Preto, (e-h) Campinas. As linhas sólidas em cinza representam a série suavizada pela função loess. Em cada gráfico o trimestre correspondente é indicado na parte superior a direita. 


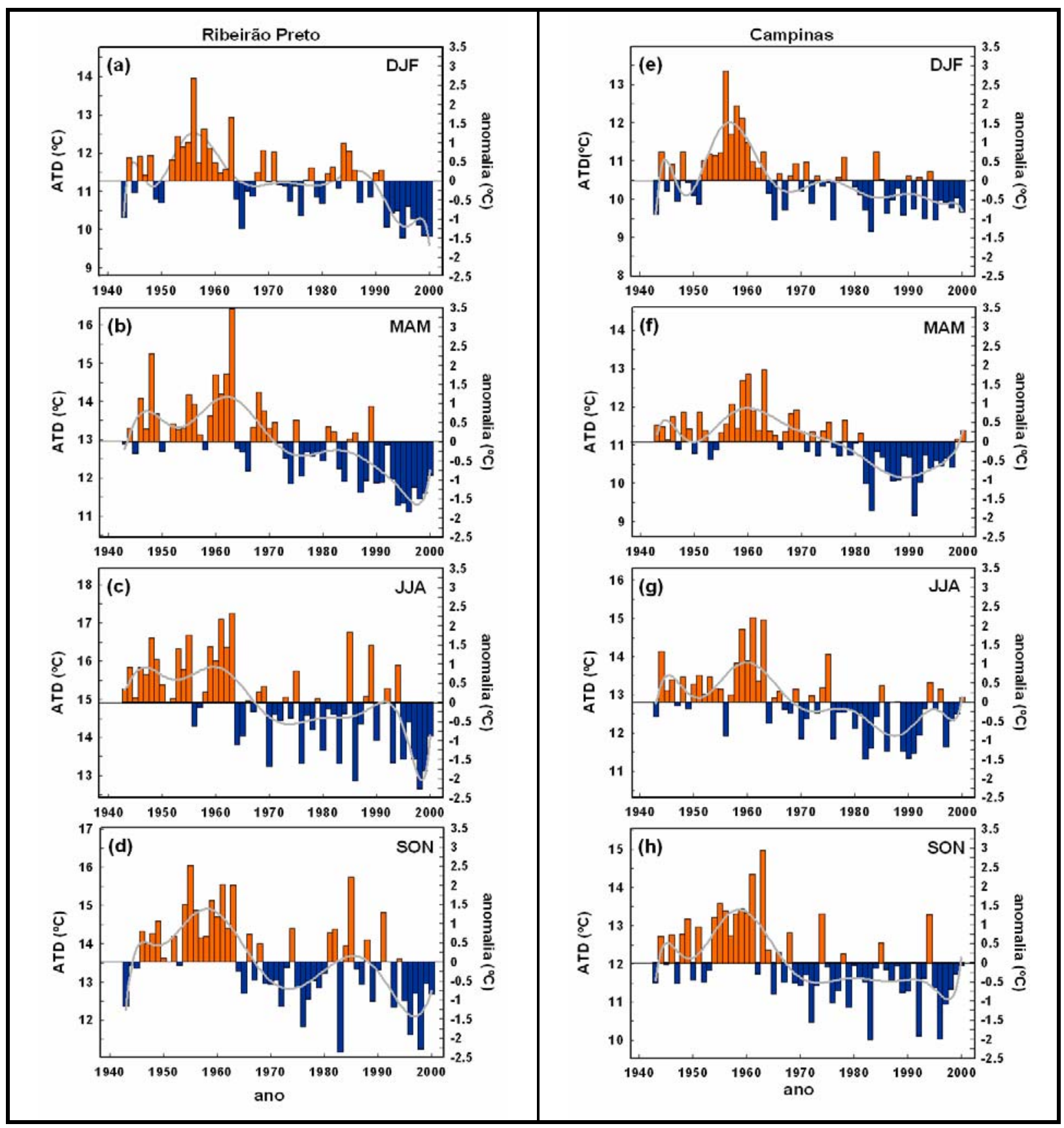

Figura 3.2.9. Séries das anomalias absolutas trimestrais da Amplitude térmica diária (eixo y à direita) em relação ao período de 1943-2000 (ou média trimestral no eixo à esquerda). (a-d) Ribeirão Preto, (e-h) Campinas. As linhas sólidas em cinza representam a série suavizada pela função loess. Em cada gráfico o trimestre correspondente é indicado na parte superior a direita.

Adicionalmente, destaca-se que Campinas é o município mais populoso do interior de SP e Ribeirão Preto é o quarto, ambos com altas taxas de urbanização (superiores a 95\%, IBGE 2000). 
Mostra-se na Figura 3.2.12 o crescimento da população dos municípios de Campinas e Ribeirão Preto entre 1950 e 2000. A população em Campinas quadruplicou de 1960 a 1990 com um aumento gradativo, enquanto a ATD média por década diminuiu linearmente no mesmo período, de 12,4 para 10,9 ${ }^{\circ} \mathrm{C}$. Em Ribeirão Preto, tal relação não é tão bem definida. Em outras palavras, os padrões de tendência da Tmin e da ATD, principalmente em Campinas, parecem melhor corroborados pelas evidências dos estudos de ilha de calor urbana (Oke, 1987; Arnfield, 2003).
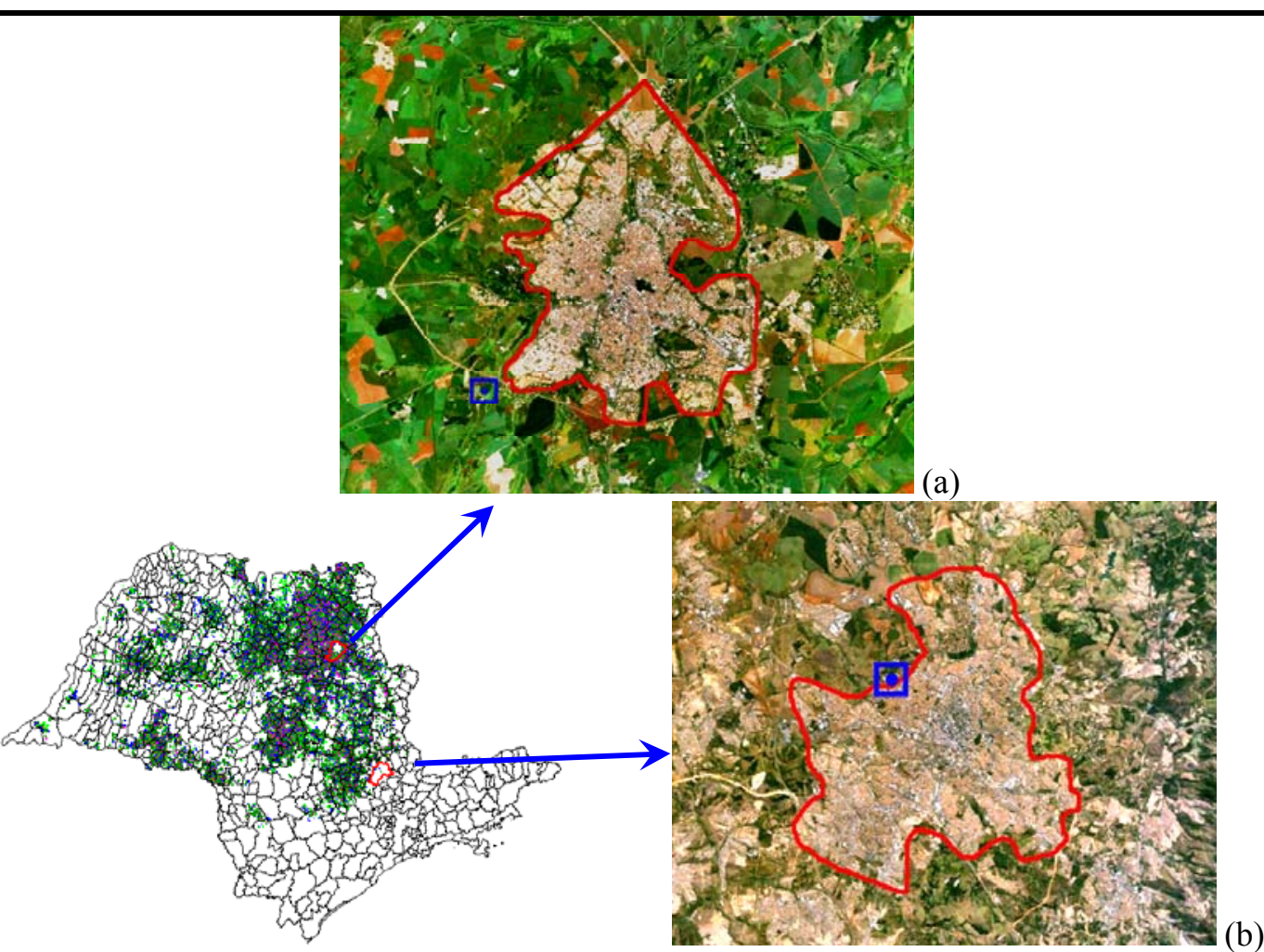

Figura 3.2.10. Localização das cidades de (a) Ribeirão Preto e (b) Campinas em relação a área ocupada com cana-de-açúcar atualmente. O perímetro urbanizado das cidades é destacado em vermelho e a posição das estações em azul.

Mais além, considerando a hipótese de que as queimadas de cana-de-açúcar podem reduzir a Tmax média, de fato verifica-se um resultado apontando nesta direção: os padrões dos meses de inverno (JJA) em Ribeirão Preto (Fig. 3.2.7.c), época de maior ocorrência de queimadas na região, mostraram um notável resfriamento de Tmax. Foi no trimestre seco a única tendência negativa significativa de Tmax (Tabela 3.2.3). A Tmax média em Campinas também mostrou uma tendência negativa nos meses de inverno, embora não significativa estatisticamente (Tabela $3.2 .3)$. 


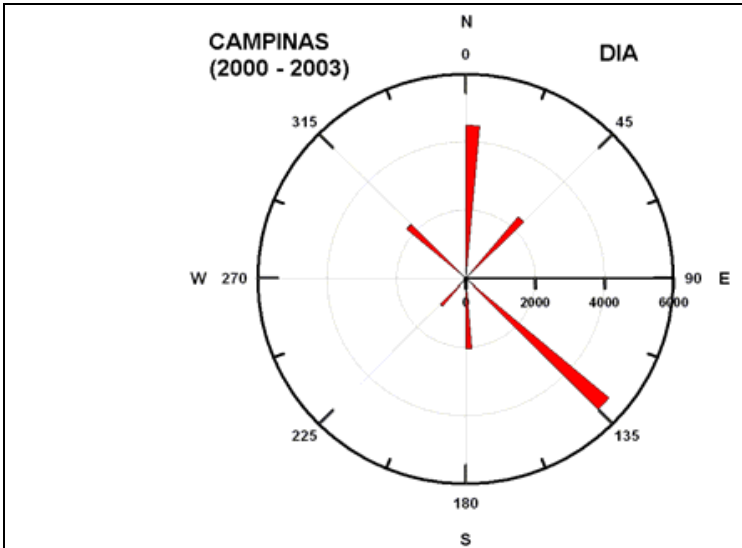

(a)

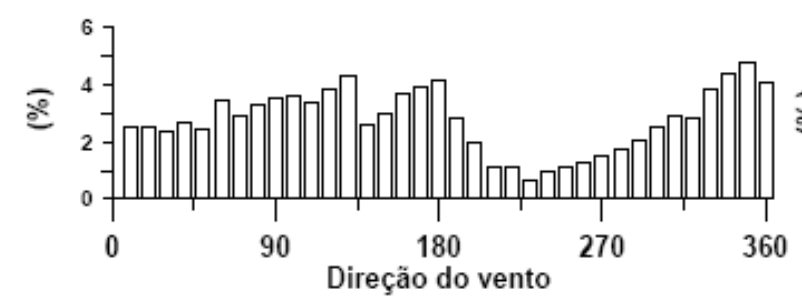

(c)

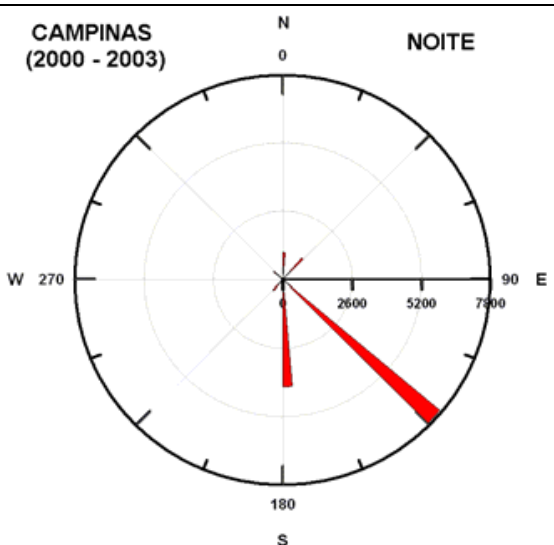

(b)

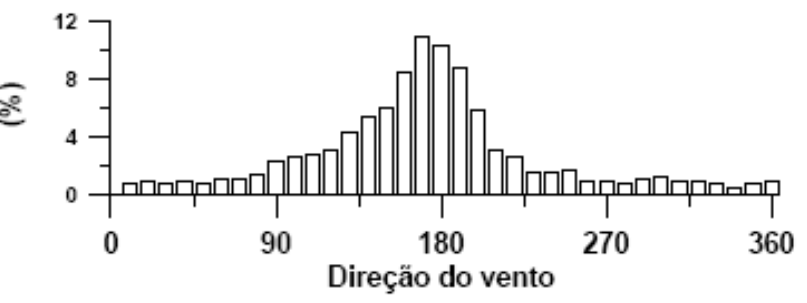

(d)

Figura 3.2.11. (a)Anemograma diurno e (b) noturno da estação meteorológica de Campinas com dados no período 2000-2003. (c) Anemograma diurno e (d) noturno observado em Sertãozinho no período 19971998 (Fonte: Rocha, 1998).

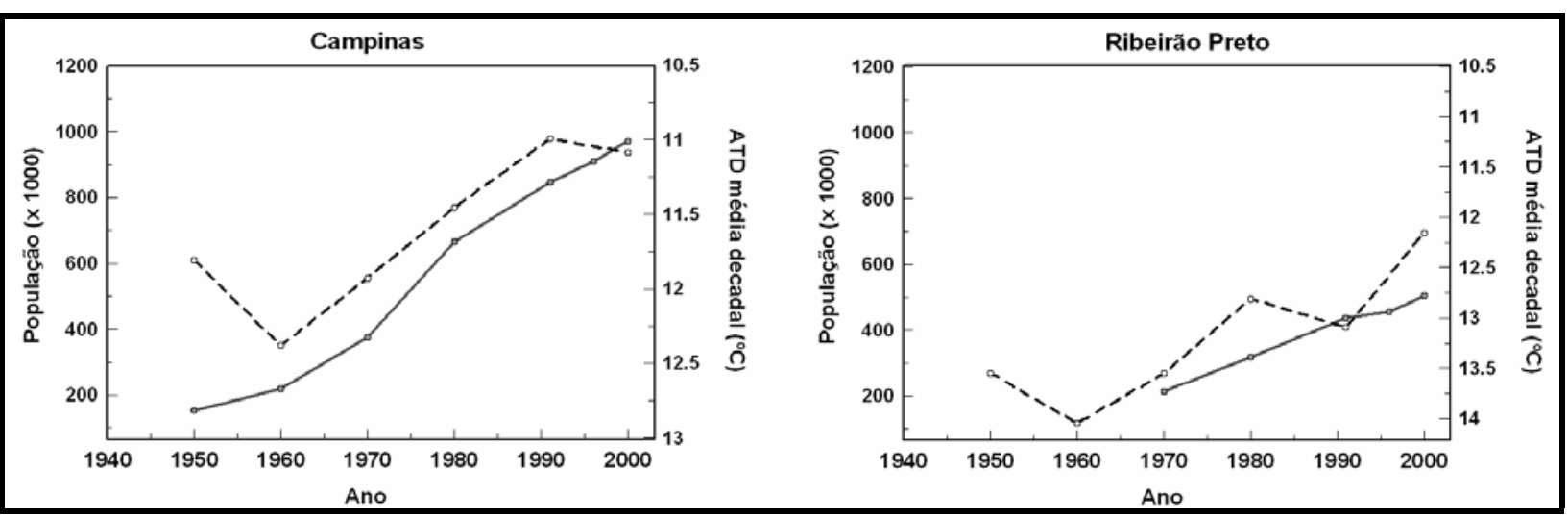

Figura 3.2.12. (a) Evolução populacional do município de Campinas (linha sólida) e variação da ATD média por década (linha pontilhada) no período de 1950 a 2000. (b) Mesmo que em (a) porém para Ribeirão Preto. A escala a direita está invertida, ou seja a ATD decresce. Dados populacionais do IBGE, censos demográficos de 1940 a 2000, disponível em http://www.ibge.gov.br/cidadesat/. 


\section{DIFERENÇA ENTRE OS CONTROLES DE GRANDE E PEQUENA ESCALA}

Nesta seção pretende-se argumentar como os controles de grande escala podem ser discriminados dos controles de pequena escala (local e regional), mostrando-se como exemplo a variabilidade climática da temperatura do ar no período de 1979-2000. Para isso aplicou-se a metodologia de OMR para avaliar se as tendências de temperatura podem ser parcialmente atribuídas aos controles de menor escala (mudanças de uso da terra e/ou urbanização). Primeiramente foi avaliada a qualidade de R-2, por meio da comparação das séries mensais das anomalias da temperatura máxima e mínima com os dados observados. Com base no cálculo do coeficiente de correlação entre R-2 e as observações, mostrou-se que os dados de R-2 foram consistentes com as observações, em termos da variabilidade interanual e intersazonal (Fig. 3.2.13 e 3.2.14), com coeficiente de correlação igual a $0,83(0,78)$ para a temperatura máxima de Ribeirão Preto (Campinas), e de $0,71(0,82)$ para a temperatura mínima de Ribeirão Preto (Campinas), considerando todos os meses do ano (Tabela 3.2.4, Fig. 3.2.13 e 3.2.14).

Nota-se que ocorre uma diferença sistemática entre a Tmin observada e de R-2, em Ribeirão Preto, a partir de 1993. De forma geral, a melhor consistência entre os dados observados e R-2, foi durante o inverno, seguido pela primavera, verão e outono (Tabela 3.2.4).

Tabela 3.2.4. Correlação entre as temperaturas máxima e mínima observada e R-2 em Campinas e Ribeirão de 1979 - 2000 para os quatro trimestres do ano.

\begin{tabular}{ccccc}
\hline & \multicolumn{2}{c}{ Campinas } & \multicolumn{2}{c}{ Ribeirão Preto } \\
\hline Período & Tmax & Tmin & Tmax & Tmin \\
\hline DJF & 0,82 & 0,76 & 0,78 & 0,60 \\
MAM & 0,69 & 0,84 & 0,73 & 0,61 \\
JJA & 0,81 & 0,86 & 0,85 & 0,80 \\
SON & 0,80 & 0,81 & 0,88 & 0,63 \\
ANUAL & 0,78 & 0,82 & 0,83 & 0,71 \\
\hline
\end{tabular}

As observações no período de 1979-2000 em Ribeirão Preto (Fig. 3.2.13), indicaram um aumento da Tmin, até mesmo superior ao aumento da Tmax, $\left(+1,71\right.$ e $+0,33{ }^{\circ} \mathrm{C}$ em 22 anos, respectivamente, Tabela 3.2.5), o que consequentemente diminuiu a ATD das observações significativamente $\left(-1,47^{\circ} \mathrm{C}\right.$ em 22 anos). Isto mostra parte da tendência de longo prazo dos últimos 50 anos, que foi porém mais pronunciada nos últimos 20 anos. Em Campinas a situação é diferente (Fig. 3.2.14): mostrou-se que há um aumento da Tmin $\left(+0,60{ }^{\circ} \mathrm{C}\right.$ em 22 anos), coincidente com o sinal da tendência nos 58 anos; a tendência da Tmax indicou um aumento 
significativo $\left(+0,63{ }^{\circ} \mathrm{C}\right.$ em 22 anos), diferente da tendência de 58 anos (estacionária). Como resultado, a tendência da ATD em 22 anos é aproximadamente estacionária. (Fig. 3.2.14.c).

As tendências de R-2 foram geralmente pequenas, mas com boa concordância com as tendências das observações das últimas décadas (Tabela 3.2.5, Figs. 3.2.13 e 3.2.14). As menores magnitudes das tendências de R-2 em relação às observações já eram esperadas. Por exemplo, em uma escala maior, Simmons et al. (2004) e Lim et al. (2005) reportaram que a média hemisférica nas duas reanálises (ERA40 e R-1) teve uma menor tendência de aquecimento na temperatura média do que a das observações em superfície, devido ao fato das reanálises não reproduzirem adequadamente a tendência climática de longo prazo pela ausência do controle dos processos de menor escala (essência do método OMR).

Em Campinas, tanto a Tmax como a Tmin dos dados de R-2 foram estacionárias, enquanto em Ribeirão Preto ocorreu um aumento em ambas $\left(+0,19\right.$ e $+0,30{ }^{\circ} \mathrm{C}$ em 22 anos, Tabela 3.2.5). É importante destacar que a tendência de R-2 foi consistente em magnitude com a observação: ambos mostraram a tendência de maior aquecimento para a Tmin em Ribeirão Preto $\left(+0,30{ }^{\circ} \mathrm{C}\right.$ e $+1,71{ }^{\circ} \mathrm{C}$ em 22 anos, respectivamente). As tendências de OMR na Tmax de Campinas e Ribeirão Preto foram de $+0,68$ e $+0,14{ }^{\circ} \mathrm{C}$ em 22 anos, respectivamente. Para a ATD a tendência da OMR em Ribeirão Preto foi de redução a uma taxa de $-1,36{ }^{\circ} \mathrm{C}$ em 22 anos, em Campinas houve um pequeno aumento de $+0,15^{\circ} \mathrm{C}$ em 22 anos.

Dessa forma, as tendências da OMR nas últimas duas décadas, para as duas estações (Tabela 3.2.5) podem ser atribuídas aos processos de pequena escala, como as mudanças de uso da terra e urbanização (Kalnay \& Cai 2003).

Tabela 3.2.5. Tendências da temperatura média anual $\left({ }^{\circ} \mathrm{C}\right.$ em 22 anos) para as observações, $\mathrm{R}-2$ e suas diferenças durante o período de 1979-2000 em Campinas e Ribeirão Preto.

\begin{tabular}{cccc}
\hline & & Campinas & Ribeirão Preto \\
\hline \multirow{2}{*}{ Máxima } & Observado & $+0,63$ & $+0,33$ \\
& R-2 & $-0,05$ & $+0,19$ \\
& OMR (diferença) & $+0,68$ & $+0,14$ \\
\hline \multirow{2}{*}{ Mínima } & Observado & $+0,60$ & $+1,71$ \\
& R-2 & $+0,04$ & $+0,30$ \\
& OMR (diferença) & $+0,56$ & $+1,41$ \\
\hline \multirow{2}{*}{ ATD } & Observado & $+0,05$ & $-1,47$ \\
& R-2 & $-0,10$ & $-0,11$ \\
& OMR (diferença) & $+0,15$ & $-1,36$ \\
\hline
\end{tabular}



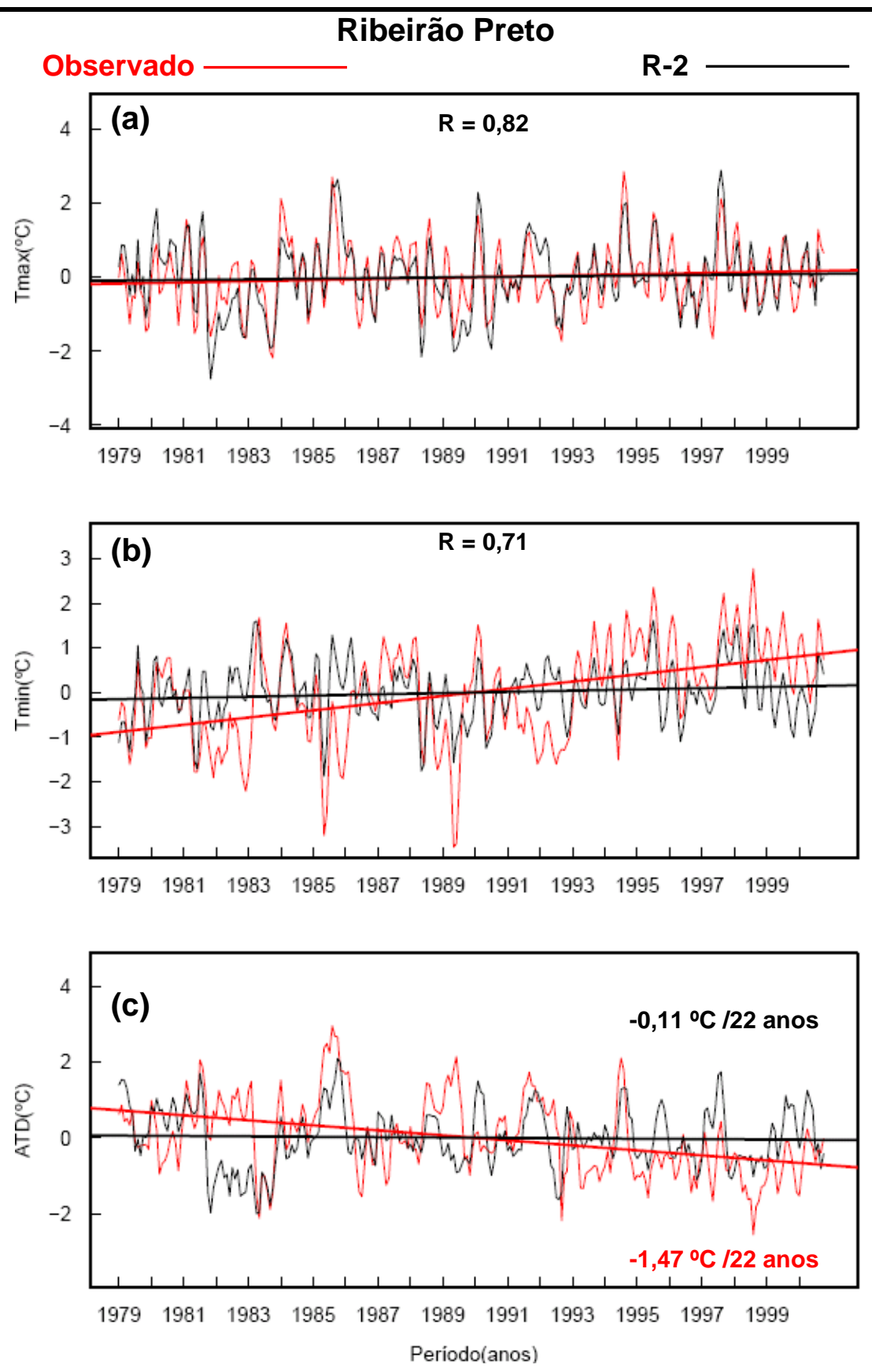

Figura 3.2.13. Anomalias mensais de temperatura (em relação ao período de 1979-2000) dos dados observados e R-2 em Ribeirão Preto. (a) Temperatura máxima, (b) temperatura mínima e (c) amplitude térmica diária. Uma média móvel de 3 meses é aplicada para suavização das curvas. O coeficiente de correlação entre os dois conjuntos de dados (sem suavização) é mostrado. A tendência para os dados observados (R-2) é representada pela reta grossa em vermelho (preto). 


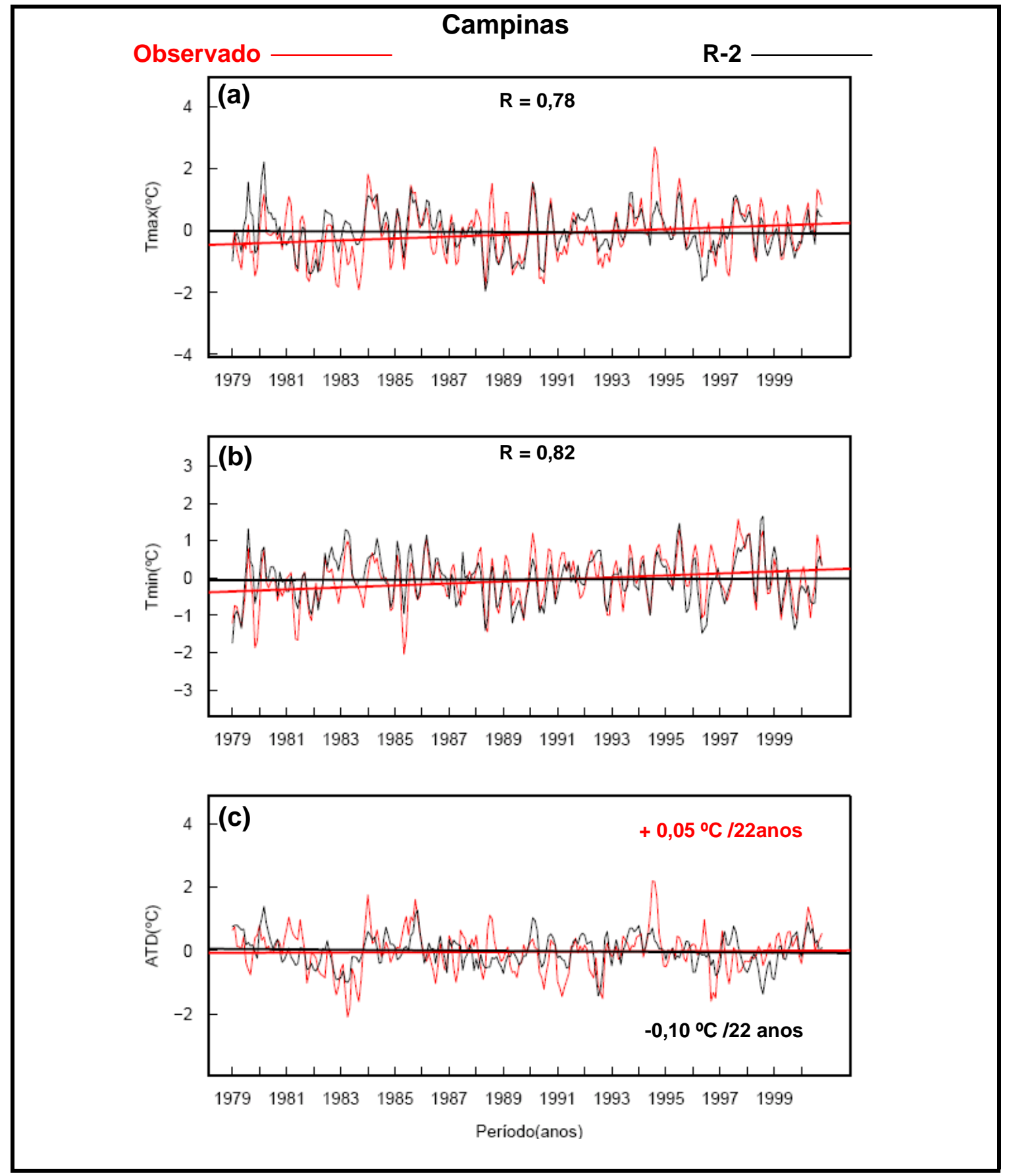

Figura 3.2.14. Idem a Fig. 3.2.13, porém para Campinas. 


\section{VARIABILIDADE COM FILTROS DE CICLO ANUAL E DE TENDÊNCIA}

Com o propósito de discernir mais detalhadamente a variabilidade climática observada nas estações de Campinas e Ribeirão Preto, os dados mensais (como anomalias normalizadas pelo desvio padrão) foram utilizados, e removidos a tendência linear e o ciclo anual das séries de 58 anos. Com este procedimento espera-se que o sinal de processos que promovem mudanças graduais seja potencialmente removido das séries originais, como por exemplo o efeito da urbanização na temperatura mínima. Assim, obteve-se uma série histórica de anomalia acumulada no tempo, também conhecida como Random-Walk (Carvalho et al. 2006) para as variáveis: precipitação, ATD, Tmax e Tmin (Fig. 3.2.15.a-d). A tendência positiva (negativa) do RW durante um determinado intervalo de tempo significa a persistência de anomalias positivas (negativas). A análise do Random-Walk (RW) pode ilustrar o padrão do controle de ciclos naturais do clima na escala interdecadal e o efeito de certos controles de pequena escala muito particulares do local de observação, como por exemplo as modificações locais na cobertura do solo e nas edificações próximas à exposição dos sensores. Rhoades \& Salinger (1993) aplicaram esta metodologia para identificar o efeito de mudanças de origem não meteorológica no sinal das observações, incluindo mudanças na localização da estação e troca de instrumentos.

A variação temporal das séries das anomalias acumuladas de precipitação e da Tmax (Fig. 3.2.15.a,c, RW (Prec) e RW (Tmax), respectivamente) mostram claramente a alta correlação entre as estações notavelmente para a Tmax e a chuva. Além disso, observam-se tendências de aumento da chuva e concorrente resfriamento diurno durante um período de 25 anos (1965 e 1990). Este fato é muito interessante, pois mostra uma associação de controles termodinâmicos consistentes e o fato das estações revelarem igualmente um mesmo controle de grande escala, portanto de variabilidade natural. A Tmax é mais sensível a disponibilidade de água que a Tmin, devido a maior turbulência da camada limite planetária e maior evapotranspiração potencial, durante o dia.

Para o padrão da temperatura mínima em Campinas (linha preta na Fig. 3.2.15.d), a série mostrou uma tendência negativa entre 1960 e início da década de1980, neste mesmo período a tendência foi positiva na série de anomalias de Tmin anual (Fig. 3.2.6.e), o que confirma a hipótese de que o efeito da urbanização seria removido dos dados mensais. No período posterior (1980-2000) verifica-se que tanto a tendência de RW(Tmin) (linha preta na Fig. 3.2.15.d) quanto a de Tmin anual foram positivas. 
Em Ribeirão Preto o padrão da temperatura mínima (linha vermelha na Fig. 3.2.15.d) concorre com o padrão de Campinas até $\sim 1970$, a partir de onde mostra-se bastante discrepante comparativamente. Estas discrepâncias poderiam ter resultado de várias fontes: principalmente a partir de 1993 houve uma tendência positiva da temperatura mínima, que poderia ter resultado da modificação das vizinhanças do local da estação com novas edificações (evento agropecuário AGRISHOW, que ocorre anualmente em Maio). Outras tendências peculiares em Ribeirão Preto, como o resfriamento da temperatura mínima entre 1980 e 1993, não encontram explicação com os dados discutidos neste trabalho. Este resultado levanta uma questão importante com respeito a homogeneidade da série: os testes devem ser realizados sobre os dados mensais ao invés de anuais, ou então conciliar o uso dos dois métodos (análise de RW e do método de regressão de duas fases). Adicionalmente os dados de reanálises também apontaram estas discrepâncias, mostrando-se portanto como outra alternativa. Diante da variação muito semelhante de RW(Tmax) nas duas estações é surpreendente aquelas discrepâncias em RW(Tmin). Ou seja, em Ribeirão Preto existe um controle noturno diferente do de Campinas. A maior sensibilidade da Tmin ocorre porque a CLN é mais rasa que a CLD. Então qualquer mudança nas características da superfície que possa produzir um aquecimento da superfície por radiação no IVP, ou alterar a capacidade térmica, ou a condutividade térmica do solo, o efeito é distribuído através dessa camada. Conforme citado anteriormente, o vento também pode ser um fator importante, a construção de estruturas próximas da estação poderia gerar um ambiente mais protegido e assim descaracterizar a representatividade da medida para a região.

Em relação ao RW(ATD) as séries de Campinas e Ribeirão Preto concordaram até 1985, a partir daí as duas passam a diferir, devido a grande mudança no padrão da Tmin em Ribeirão Preto. A ATD também se mostrou controlada pela precipitação, particularmente no período entre o início da década de 1960 e 1985. 


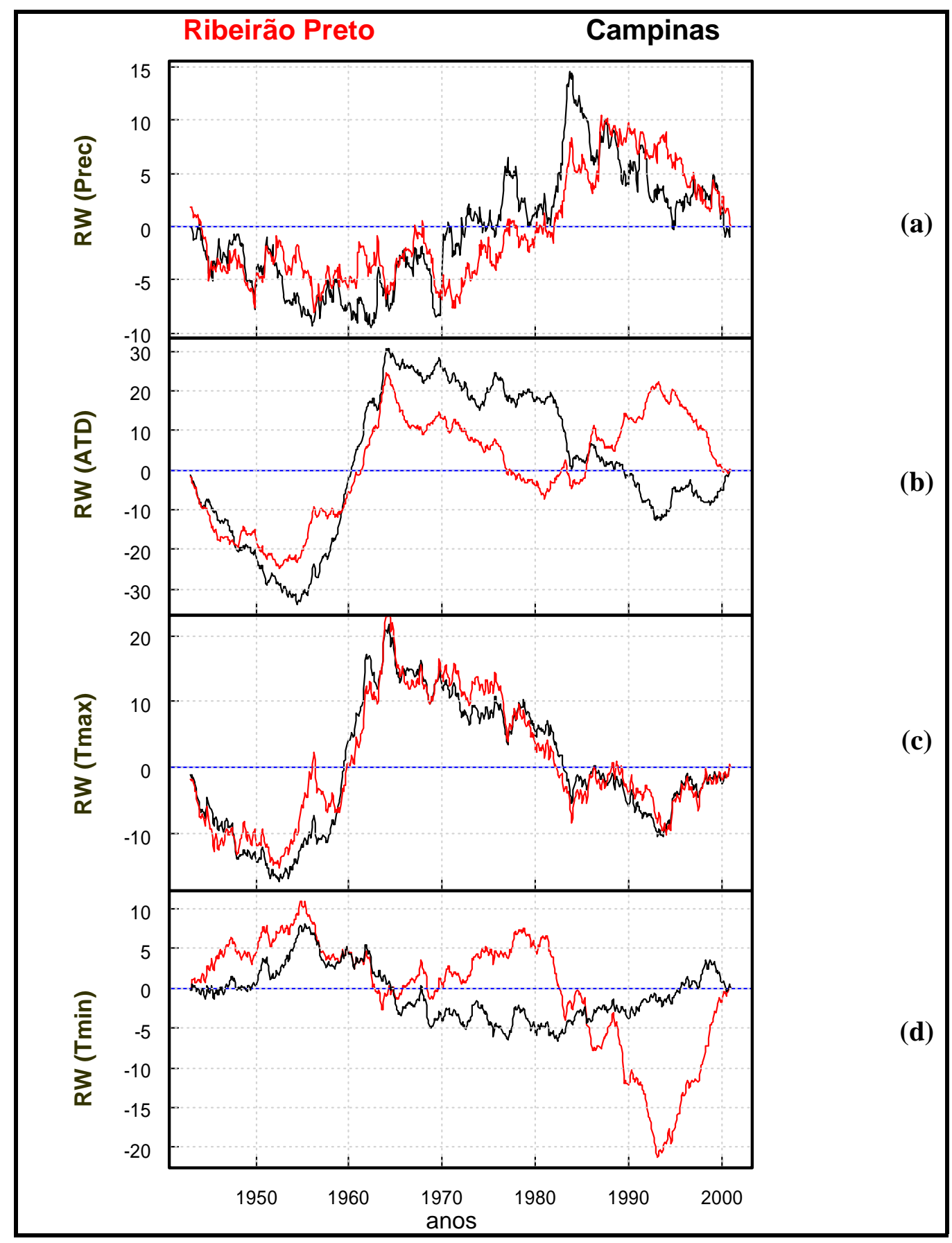

Figura 3.2.15. Séries de RW de (a) precipitação, (b) ATD, (c) Tmax e (d) Tmin. As linhas em vermelho (preto) referem-se aos dados de Ribeirão Preto (Campinas). 


\section{CONCLUSÕES E SUGESTÕES PARA TRABALHOS FUTUROS}

\section{Observações micrometeorológicas}

As variações climáticas observadas nas torres micrometeorológicas sobre as áreas de cerrado, cana-de-açúcar e eucalipto, durante o período de fevereiro de 2005 a fevereiro de 2006, refletiram de forma geral o padrão climatológico marcadamente sazonal da região. A temperatura média diária variou entre 11 e $28{ }^{\circ} \mathrm{C}$ nas três áreas experimentais, enquanto as médias anuais situaram-se dentro do desvio padrão médio interanual da média climatológica da região $(22,1 \pm$ $0,5^{\circ} \mathrm{C}$ ). Os valores da precipitação acumulada mostraram-se próximos entre si, de 33 a $37 \%$ abaixo da média anual climatológica $\left(1498 \mathrm{~mm}\right.$ ano $\left.^{-1}\right)$. Em média, cerca de $70 \%$ da precipitação anual ocorreu de outubro a março e a irradiância solar global incidente no inverno foi reduzida em 35\% comparada ao verão. Estes contrastes na oferta de água e de radiação foram elementos importantes para a variabilidade sazonal das componentes do balanço de energia nas áreas experimentais.

O saldo de radiação no cerrado foi sistematicamente maior que sobre cana (por 7\%) e similar ao do eucalipto, apesar da irradiância solar incidente ter sido semelhante nas áreas. A média anual ( \pm erro instrumental) do albedo no cerrado foi de $14,1( \pm 1,4) \%$, e na cana $18,0( \pm 1,8)$ $\%$, e no caso do eucalipto foi similar ao do cerrado. O menor albedo e a menor temperatura diurna sobre o cerrado foram os principais responsáveis pela diferença do saldo de radiação entre o cerrado e a cana.

No cerrado a variação dos fluxos de superfície foi marcada pela sazonalidade. Esta variação foi fortemente controlada pela oferta de energia e de água, mas também pelos parâmetros biofísicos da vegetação (como albedo solar global e o albedo RFA). No decorrer do ano o albedo RFA aumentou gradativamente até atingir seu valor máximo no final do período seco, com início da estação chuvosa e a produção de novas folhas ocorre uma diminuição abrupta, enquanto o albedo solar global passa a aumentar até atingir seu máximo em meados de outubro. Isto ocorre concorrente a uma rápida recuperação da atividade fotossintética, pequena redução do fluxo de calor sensível e aumento da evapotranspiração.

A cana-de-açúcar é uma cultura anual e por isso variações abruptas dos padrões micrometeorológicos ocorreram no período de transição da colheita. O albedo RFA mostrou um 
contínuo decréscimo ao longo do crescimento da plantação que foi bem correlacionado com o aumento da atividade fotossintética e da evapotranspiração. $\mathrm{O}$ albedo solar global foi maior quando a plantação atingiu seu máximo estágio de crescimento. Após a colheita houve uma mudança abrupta na razão de Bowen que atingiu seu valor máximo, devido ao solo descoberto que proporcionou maior conversão de energia na forma de calor sensível. O fluxo de calor no solo também apresentou uma mudança significativa após a colheita e se manteve positivo até cerca de 7 meses depois.

O albedo RFA no eucalipto diminuiu do período seco para o úmido, seguindo de forma muito clara a tendência do albedo RFA no cerrado. O albedo solar global diminuiu durante o período seco e mostrou um pequeno aumento na transição para o período úmido. Os padrões dos fluxos de energia no eucalipto mostraram uma pronunciada variação sazonal, destacando-se com um aumento substancial das taxas de evapotranspiração e de absorção de $\mathrm{CO}_{2}$ com a transição para o período úmido, enquanto a razão de Bowen teve uma redução progressiva.

O fluxo de calor no solo teve uma contribuição mais significativa para o balanço de energia na cana, que resultou em menos energia disponível em relação às demais áreas. A evapotranspiração foi a principal componente do balanço de energia nas três áreas, com máximos no período úmido. Particularmente, o fluxo de calor sensível foi mais significante, na cana, no período de transição para o período seco, e no período seco, com valores se aproximando aos do fluxo de calor latente. No eucalipto, o fluxo de calor sensível também foi uma componente importante no período seco, particularmente no mês de agosto, inclusive mostrando uma razão de Bowen com maior magnitude dentre as áreas. Em contraste, no período úmido a evapotranspiração do eucalipto destacou-se com valores superiores em relação às demais áreas. Neste período, esta comparação foi marcada por valores médios de evapotranspiração de 5,2 mm dia $^{-1}$ no eucalipto, $3,1 \mathrm{~mm} \mathrm{dia}^{-1}$ no cerrado e $2,5 \mathrm{~mm} \mathrm{dia}^{-1}$ na cana.

As comparações da temperatura do ar entre as áreas apontaram para uma temperatura máxima maior sobre a cana do que sobre o cerrado (em média de 1,3 a $2{ }^{\circ} \mathrm{C}$ ), consistente com a partição de energia naquelas áreas. Já a temperatura mínima foi menor na cana em relação ao cerrado (por $1,2^{\circ} \mathrm{C}$ na média anual), devido em grande parte a maior velocidade do vento à noite sobre o cerrado. Dessa forma a amplitude térmica diária foi maior na cana em comparação ao cerrado. 
A comparação do eucalipto com o cerrado indicou de forma geral que a temperatura (máxima e mínima) sobre o eucalipto foi predominantemente menor do que sobre o cerrado, com grande contraste no período úmido (a diferença na temperatura média foi de $1,1{ }^{\circ} \mathrm{C}$ ), o que também foi consistente com o maior evapotranspiração sobre o eucalipto.

\section{$\underline{\text { Variabilidade climática regional }}$}

A julgar pelo fato de que a cana-de-açúcar substituiu regionalmente o cerrado nos último século, e por concluirmos que a temperatura máxima na cana foi superior à do cerrado, as mudanças do uso da terra pela expansão da cana-de-açúcar não mostram o sinal apropriado para se explicar a variabilidade da série de longo prazo em Campinas (estacionária) e Ribeirão Preto (pequeno decréscimo). Em outras palavras, não se distingue um aumento da temperatura máxima nas últimas décadas. A fraqueza desta hipótese é que as plantações de cana-de-açúcar substituíram em grande parte outras culturas, como o café e o milho, e não necessariamente o cerrado, antes da década de 1970. Dessa forma, como a temperatura mínima sobre a cana foi no mínimo menor que no cerrado, se propõe que as séries de longo prazo possam não ter sido influenciadas em grande proporção pela expansão da cana-de-açúcar.

Quanto ao eucalipto a área de plantio regional ainda é pequena se comparada com a canade-açúcar e sua potencial contribuição para o clima regional não deve ser substancial.

A análise da precipitação em escala regional no setor centro-norte de SP, no período de 1940-2000, mostrou um padrão coerente entre aos setores leste e oeste do estado com uma oscilação marcada por uma fase seca (entre 1940 e 1970) e outra úmida (entre 1971-2000). A comparação da precipitação média anual entre as duas fases evidenciou um aumento significativo de $16 \%$ nos dois setores. Este aumento se manifestou principalmente nos meses de transição de estação (Abril, Maio e Setembro) e também no mês de Dezembro. As estações de Campinas e Ribeirão também refletiram estes padrões regionais de variabilidade decadal da precipitação.

Sobre as causas da variação da precipitação e da temperatura de longo prazo nas estações de Ribeirão Preto e Campinas, mostrou-se uma relação inversa entre precipitação e amplitude térmica, resultante pelo menos em parte da variação natural do clima, com uma fase quente (da temperatura máxima) e seca, no período de 1943-1965, seguida de uma fase úmida, com a temperatura máxima estacionária em Campinas, e com pequena redução em Ribeirão Preto. Este 
padrão mostrou-se semelhante à variabilidade da Oscilação Decadal do Pacífico, o que sugere um controle de variabilidade natural de grande escala sobre a precipitação de SP.

Mostrou-se a existência de uma tendência de aumento significativo da Tmin anual nas duas estações nos últimos 58 anos, e que apesar de alguns anos relativamente frios na década de 1980 (particularmente em Ribeirão Preto), o sinal da tendência não foi descaracterizado. Nas últimas duas décadas a persistência de anomalias quentes da temperatura mínima foi marcante. Este resultado é consistente com o aumento da temperatura mínima em escala global, reportado como conseqüência da intensificação do efeito estufa, e também com a influência da crescente urbanização. A composição de controles de escala regional e local foi bem atestada por meio da comparação das observações da estação com a variabilidade simulada das reanálises. O efeito da urbanização é com mais probabilidade um fator determinante no sinal da estação de Campinas, devido a três fatores: localização em relação à mancha urbana, regime local dos ventos e do grande aumento populacional entre 1950 e 2000.

Apesar da falta de evidências sobre o efeito das mudanças de uso da terra na composição do sinal da temperatura nas duas estações, mostrou-se uma tendência de resfriamento da temperatura máxima, significativa apenas no inverno, que poderia ser resultante das queimadas de cana-de-açúcar.

A Tabela 4.1 apresenta um resumo sobre os principais fatores (dentro do contexto deste estudo) que podem ter influenciado as variáveis climáticas, em termos de faixas qualitativas de probabilidade, baseadas nos resultados encontrados.

Algumas incertezas ainda permanecem nas estimativas de alguns resultados, como discutido previamente sobre os efeitos não climáticos nos dados de temperatura da estação de Ribeirão Preto (últimos 20 anos) e Campinas (mudança abrupta em 1903). Esta questão poderia ser melhor investigada se houvessem informações disponíveis sobre o histórico das estações, como este não foi o caso, uma alternativa seria comparar as séries de temperatura das duas estações com estações vizinhas. Isto permitiria avaliar adequadamente como aqueles efeitos alteraram as características estatísticas das séries de temperatura. Dessa forma, seria possível aplicar testes de homogeneidade as séries e ajustá-las através de técnicas de construção de séries de referência (Peterson \& Easterling, 1994). Para a comparação com a estação de Campinas sugere-se como opção a estação de Piracicaba por duas razões: a localização ( $\sim 50 \mathrm{~km}$ a noroeste de Campinas) e pelo tamanho da série histórica (1917 até o presente). 
Tabela 4.1. Faixas de probabilidade de influência na variabilidade de longo prazo da temperatura do ar (máxima e mínima) e precipitação, nas estações de Campinas e Ribeirão Preto.

\begin{tabular}{|c|c|c|c|}
\hline & Tmax & Tmin & Prec \\
\hline $\begin{array}{c}\text { Variabilidade } \\
\text { Natural }\end{array}$ & Alta & Alta & Alta \\
\hline $\begin{array}{c}\text { Aquecimento } \\
\text { Global }\end{array}$ & Baixa & Alta & - \\
\hline Urbanização & Baixa & Alta & - \\
\hline Queimadas & $\begin{array}{c}\text { Alta } \\
\text { no Inverno }\end{array}$ & - & - \\
\hline $\begin{array}{l}\text { Expansão da } \\
\text { cana-de-açúcar }\end{array}$ & Baixa $^{\dagger}$ & Baixa & - \\
\hline $\begin{array}{c}* \text { Efeitos } \\
\text { Não climáticos }\end{array}$ & Baixa & $\begin{array}{c}\text { Alta } \\
\text { em Ribeirão Preto }\end{array}$ & - \\
\hline
\end{tabular}

* Referem-se a mudanças no ambiente de exposição do intrumento. ${ }^{\dagger}$ Esta probabilidade refere-se a sua influência sobre a variabilidade de baixa freqüência, entretanto, ressalta-se que na alta freqüência a influência é alta.

Associado a elevação da temperatura global é esperado um aumento na intensidade e freqüência de eventos extremos de precipitação (IPCC, 2001a). Este efeito poderia ser analisado utilizando-se a mesma metodologia deste trabalho, com uma série de dados diários regionais, onde os quantis inferior e superior de precipitação sejam levados em conta. Os quantis superiores seriam indicativos dos eventos de chuvas mais intensas, enquanto os quantis inferiores estariam associados aos períodos de estiagem. Neste mesmo sentido, um resultado a ser mais explorado é o relativo às mudanças de precipitação que foram significativas (regional e localmente) nos meses de transição entre estações seca e chuvosa (e vice-versa). Para isso, a aplicação de métodos para estimativa dos parâmetros de início, fim e duração da estação chuvosa, também é sugerida. Os extremos de temperatura também poderiam ser melhor avaliados aplicando-se a análise de Random-Walk sobre a série de dados diários, no entanto, antes disso seria necessário o preenchimento de falhas. Assim, poderia ser feita a comparação com os resultados de Carvalho et al. 2006 encontrados para a mesma região.

A análise de variabilidade de longo prazo das séries de precipitação regional e sua relação com a Oscilação Decadal do Pacífico deve ser mais adequadamente quantificada, o que pode se dar por meio de análise espectral (espectro de Fourier). Os ciclos sugeridos (30-50 anos) devem ser analisados à luz de testes de significância estatística no domínio da freqüência (modos 
de variabilidade significantes). A técnica de ondeletas também se mostra uma ferramenta interessante, complementando a análise espectral.

Uma questão a ser aprofundada é o fato da década de 1980 ter sido marcada por recorrentes anos frios da temperatura mínima no verão, em Ribeirão Preto possivelmente associado ao aumento da precipitação, enquanto em Campinas a temperatura mínima, apesar também da maior chuva, continuou em progressiva ascensão. É possível que o efeito da urbanização possa ter dominado particularmente em Campinas, mas ainda se desconhece a comprovação. Sugere-se então uma estimativa quantitativa para confirmar o efeito da ilha de calor urbana de Campinas. Há duas alternativas que podem ser utilizadas: i) comparação da temperatura de Campinas com a de Piracicaba (diferença entre estação urbana e rural), ii) análise de tendência de índices de vegetação estimados por sensoriamento remoto (p. ex. NDVI), a refletância de superfícies vegetadas e urbanas diferem notavelmente, e então uma diminuição no NDVI no tempo indicaria menos vegetação.

A comparação da temperatura entre as áreas de cerrado, cana e eucalipto, pode ser mais adequadamente julgada se for levado em conta os gradientes verticais de temperatura na camada de superfície ou estimativas das relações de similaridade de Monin-Obukhov, para assim determinar uma altura de medida equivalente entre as áreas experimentais. Para uma análise mais criteriosa, sugere-se ainda a instalação de uma estação meteorológica complementar em uma área de cana mais próxima do cerrado e com altitude semelhante; devido ao impacto dos diferentes regimes locais de vento sobre a temperatura.

Considerando a complexidade dos efeitos das mudanças de uso da terra e da ilha de calor urbana, assim como a de outros impactos envolvidos, como o ajuste incompleto das inomogeneidades dos dados, nebulosidade, aerossóis e mudanças na radiação solar, os resultados deste trabalho podem ser vistos mais como ilustrativos do que definitivos. Adicionalmente há outros fatores não considerados neste estudo que podem também ter uma influência importante sobre o clima de SP, como a temperatura da superfície do mar do Oceano Atlântico Sul (Venegas et. al 1997; Cardoso \& Silva Dias, 2004; Gonçalves et. al 2002). Contudo, chama-se a atenção para uma questão importante que requer mais investigação diante da complexidade de processos envolvidos na descrição dos controles sobre o clima de SP. 


\section{REFERÊNCIAS BIBLIOGRÁFICAS}

Aguilar, E., Auer, I., Brunet, M., Peterson, T.C., Wieringa, J., 2003: Guidelines on Climate Metadata and Homogenization, WCDMP 53, WMO-TD 1186, 55 pp. World Meteorological. Organization, Geneva, Switzerland.

Alexander, L.V., Zhang, X., Peterson, T.C., Caesar, J., Gleason, B., Klein Tank, A.M.G., Haylock, M., Collins, D., Trewin, B., Rahimzadeh, F., Tagipour, A., Rupa Kumar, K., Revadekar, J., Griffiths, G., Vincent, L., Stephenson, D.B., Burn, J., Aguilar, E., Brunet, M., Taylor, M., New, M., Zhai, P., Rusticucci, M., Vazquez-Aguirre, J. L., 2006: Global observed changes in daily climate extremes of temperature and precipitation. Journal of Geophysical Research, 111, D05109, doi:10.1029/2005JD006290.

Ambrizzi, T. \& Dufek, A.S., 2005: Climate Variability of Precipitation and Temperature in São Paulo State, Brazil. In: International Association of Meteorology and Atmospheric Sciences, IAMAS 2005, v.1., Beijing, China.

Arnfield, A.J., 2003: Two decades of urban climate research: a review of turbulence, exchanges of energy and water, and the urban heat island. International Journal of Climatology, 23, 1-26.

Arya, S.P., 1988: Introduction to Micrometeorology. Academic Press, San Diego, 307 p.

Bonan, G.B., 2002: Ecological Climatology: Concepts and Applications. Cambridge University Press, Cambridge. 678 p.

Braganza, K., D.J., Karoly, Arblaster, J. M., 2004: Diurnal temperature range as an index of global climate change during the twentieth century, Geophysical Research Letters, 31, L13217, doi:10.1029/2004GL019998.

Brito, A., 2005: Laranja e gado cedem espaço à cana. O Estado de São Paulo. Caderno Economia \& Negócios. São Paulo, 26 de jun. 2005, p. 12-13. 
Bruno, R. D., 2004: Variabilidade observada da Umidade do solo em Floresta Tropical e Cerrado. Dissertação de Mestrado do Departamento de Ciências Atmosféricas do Instituto de Astronomia e Geofísica da Universidade de São Paulo. 189 p.

Brunt, D., 1932: Notes on radiation in the atmosphere. Quarterly Journal Royal Meteorological Society, 58, 389-420.

Cabral, O.M.R., 2001: O sistema solo-vegetação-atmosfera: Observação e modelagem da canade-açúcar no Estado de São Paulo. Tese de Doutoramento do Departamento de Ciências Atmosféricas do Instituto de Astronomia e Geofísica da Universidade de São Paulo. 96 p.

Cabral, O.M.R., Ligo, M.A.V., Rocha, H.R., Freitas, H.C., Tatsch, J.D., Gomes, E., 2006: Observações micrometeorológicas em plantação de cana-de-açúcar na Usina Santa Rita Fazenda São José do Pulador (27). Relatório de Pesquisa apresentado a Usina Santa Rita.

Cabral, O.M.R., Rocha, H.R., Ligo, M.A.V., Brunini, O., Silva Dias, M.A.F., 2003: Fluxos turbulentos de calor sensível, vapor d'água e $\mathrm{CO}_{2}$ sobre uma plantação de cana-de-açúcar (Saccharum sp.) em Sertãozinho, SP. Revista Brasileira de Meteorologia, 18 (1), 61-70.

Cai, M. \& Kalnay, E., 2005: Can reanalysis have anthropogenic climate trends without model forcing? Journal of Climate, 18, 1844- 1849.

Calder, I.R., 1999: The Blue Revolution: Land Use and Integrated Water Resources Management. Earthscan Publications, London, 192 pp.

Calder, I.R., 1992: Water use of eucalypts - a review. In: Growth and Water Use of Forest Plantations. Calder, I.R., Hall, R.L., Adlard, P.G. (eds.). Wiley, Chichester, p. 167-179. 
Camargo, A.M.M.P., Anefalos, L.C., Coelho, P.J., Olivetti, M.P.A., 1995: Alteração na composição da agropecuária no Estado de São Paulo, 1983-1993. Informações Econômicas, SP, 25(5), 49-81.

Cardoso, A.O. \& Silva Dias, P.L., 2004: Variabilidade da TSM do Atlântico e Pacífico e temperatura na cidade de São Paulo no inverno. Revista Brasileira de Meteorologia, 19 (3), 307-324.

Carvalho, L.V., Anastasios, A.T., Jones, C., Rocha, H.R., Polito, P.S. 2006. Temperature extremes organize in a coherent pattern in space and in a seesaw in time (submetido ao Journal of Geophysical Research).

Cleveland, W.S., 1979: Robust locally weighted regression and smoothing scatterplots. Journal of the American Statistical Association, 74, 829-836.

Conrad, V. \& Pollak, C., 1950: Methods in Climatology. Harvard University Press, Cambridge, MA, 459 pp.

Cook, P.G., Hatton, T.J., Pidsley, D., Herczeg, A.L., Held, A., O’Grady, A., Eamus, D., 1998: Water balance of a tropical woodland ecosystem, Northern Australia: a combination of micrometeorological, soil physical and groundwater chemical approaches. Journal of Hydrology, $210,161-177$.

Dai, A., Del Genio A.D., Fung I.Y., 1997: Clouds, precipitation, and temperature range. Nature, $386,665-666$.

Dai, A., Trenberth, K.E., Karl, T.R, 1999: Effects of clouds, soil moisture, precipitation and water vapor on diurnal temperature range. Journal of Climate, 12, 2451-2473. 
David, T.S., Ferreira, M.I., David, J.S., Pereira, J.S., 1997: Transpiration from a mature Eucalyptus globulus plantation in Portugal during a spring-summer period of progressively higher water deficit. Oecologia,110, 153-159.

Denmead, O.T., Dunin, F.X., Wong, S.C., Greenwood, E.A.N., 1993: Measuring water use efficiency of eucalypt trees with chambers and micrometeorological techniques. Journal of Hydrology, 150, 649-664.

Divisão de Sensoriamento Remoto - Instituto de Pesquisas Espaciais (DSR-INPE), 2006: Mapeamento da Cana via imagens de satélite de observação da terra: CANASAT. Disponível em http://www.dsr.inpe.br/mapdsr/. Acesso em: 18 maio 2006.

Dunin, F.X. \& Greenwood, E.A.N., 1986: Evaluation of the ventilated chamber for measuring evaporation from forest. Hydrological Processes, 1, 47-62.

Duriex, L., Machado, L., Laurent, H., 2003: The impact of deforestation on cloud cover over the Amazon arc of deforestation. Remote Sensing of Environment, 86, 132-140.

Durigan, G., De Siqueira, G.A., Franco, D.C., Bridgewater, S., Ratter, J.A., 2003: Journal of Botany, 60 (2), 217-241.

Easterling, D. R., Horton, B., Jones, P.D., Peterson, T.C., Karl, T.R., Parker, D.E., Salinger, M.J., Razuvayev, V., Plummer, N., Jamason, P., Folland, C.K., 1997: Science, 277 (5324), 364.

Easterling, D.R. \& Peterson, T.C., 1995: A new method for detecting undocumented discontinuities in climatological time series. Internacional Journal of Climatology, 15, 369377.

Eiten, G., 1972: The cerrado vegetation of Brazil. Botanical Review, 38,201-341. 
Gallo, K. P., Easterling, D. R., Peterson, T. C., 1996: The Influence of Land Use/Land Cover on Climatological Values of Diurnal Temperature Range. Journal of Climate, 9 (11), 2941-2944.

Gallo, K.P., Owen, T.W., Easterling, D.R., Jamason, P.F., 1999: Temperature Trends of the U.S. Historical Climatology Network Based on Satellite-Designated Land Use/Land Cover. Journal of Climate, 12, 1344-1348.

Gonçalves, F.L.T., Silva Dias, P.L., Araújo, G.P., 2002: Climatological analysis of wintertime extreme low temperatures in São Paulo City, Brazil: Impact of Sea-Surface Temperature Anomalies. International Journal of Climatology, 22, 1511-1526.

Hansen, J. \& Lebedeff, S., 1987: Global Trends of Measured Surface Air Temperature. Journal of Geophysical Research, 92, 13345-13372.

Hansen, J., Ruedy, R., Sato, M., Imhoff, Mki., Lawrence, W., Easterling, D., Peterson, T., Karl, T., 2001: A closer look at United States and global surface temperature change. Journal Geophysical Research, 106, 23947-23963, doi:10.1029/2001JD000354.

Henderson-Sellers, A., 1986: Cloud changes in a warmer Europe. Climatic Change, 8, 25-52.

Henderson-Sellers, A., 1989: North American total cloud amount variations this century. Global Planetary Change, 1, 175-194.

Henderson-Sellers, A., 1990: Review of our current information about cloudiness changes this century. In: Observed Climate Variations and Change: Contributions in Support of Section 7 of the 1990 IPCC Scientific Assessment. D.E. Parker (ed.). Intergovernmental Panel on Climate Change, Geneva, p. XI.1-XI.12.

Henderson-Sellers, A., 1992: Continental cloudiness changes this century. Geographical Journal $27(3), 255-262$. 
Intergovernmental Panel on Climate Change (IPCC), 1990: Climate Change, The IPCC Scientific Assessment. Cambridge University Press, 365 pp.

IPCC, 1996: Climate Change 1995. The Science of Climate Change. Cambridge University Press, $570 \mathrm{pp}$.

IPCC, 2001a: Third Assessment Report - Climate Change 2001: The Scientific Basis. Houghton, J.T., Ding, Y., Griggs, D.J., Noguer, M., van der Linden, P.J., Dai, X., Maskell, K., Johnson, C.A. (eds.). Cambridge University Press, Cambridge, United Kingdom and New York, NY, USA, $881 \mathrm{pp}$.

IPCC, 2001b: Third Assessment Report - Climate Change 2001: Impacts, Adaptation, and Vulnerability. McCarthy, J.J., Canziani, O.F., Leary, N.A., Dokken, D.J.,White, K.S. (eds.). Cambridge University Press, Cambridge, United Kington and New York, NY, USA, 1031pp.

Jackson, R.B., Jobbágy, E.G., Avissar, R., Roy, S.B., Barrett, D.J., Cook, C.W., Farley, K.A., Le Maitre, D.C., McCarl, B.A., Murray, B.C., 2005: Trading Water for Carbon with Biological Carbon Sequestration. Science, 310 (5756), 1944-1947.

Jones, P.D., 1988: Hemispheric surface air temperature variations: Recent trends and an update to 1987. Journal of Climate, 1, 654-660.

Jones, P.D., 1994b: Hemispheric surface air temperature variations: A reanalysis and an update to 1993. Journal of Climate, 7, 1794-1802.

Jones, P.A \& Henderson-Sellers, A., 1992: Historical records of cloudiness and sunshine in Australia. Journal of Climate, 5, 260-267.

Kallarackal, J. \& Somen, C.K., 1997a: An ecophysiological evaluation of the suitability of Eucalyptus grandis for planting in the tropics. Forest Ecology and Management. 95, 53-61. 
Kallarackal, J. \& Somen, C.K., 1997b: Water use by Eucalyptus tereticornis stands of differing density in southern India. Tree Physiology, 17, 195-203.

Kalnay, E. \& Cai, M., 2003: Impact of urbanization and land-use change on climate. Nature, 423, $528-531$.

Kalnay, E., Cai M., Li, H., Tobin, J., 2006: Estimation of the impact of land-surface forcings on temperature trends in eastern United States, Journal of Geophysical Research, 111, D06106, doi:10.1029/2005JD006555.

Kalnay, E., Kanamitsu, M., Kistler, R., Collins, W., Deaven, D., Gandin, L., Iredell, M., Saha, S., White, G., Woolen, J., Zhu, Y., Chelliah, M., Ebisuzaki, W., Higgins, W., Janowiak, J., Mo, K. C., Ropelewski, C., Wang J., Leetma, A., Reynolds, R., Jenne, R., Joseph, D., 1996: The NCEP/NCAR 40-year reanalysis project. Bulletin of the American Meteorological Society 77, 437-471.

Kanamitsu, M., Ebisuzaki, W., Woollen, J., Yang, S.-K., Hnilo, J.J., Fiorino, M., Potter, G. L., 2002: NCEP-DOE AMIP-II reanalysis (R-2). Bulletin of American Meteorological Society. 83, $1631-1643$.

Karl, T.R. \& Jones, P.D., 1989: Urban Bias in Area Averaged Surface air temperature Trends. Bulletin American Meteorological Society, 70(3), 265-270.

Karl, T.R., Jones, P.D., Knight, R.W., Kukla, G., Plummer, N., Razuvayev, V; Gallo, K.P, Lindseay, J., Charlson, R.J., Peterson, T.C., 1993: A new perspective on recent global warming: asymmetric trends of daily maximum and minimum temperature. Bulletin of American Meteorological Society, 74(6), 1007-1023.

Karl, T.R., Kukla, G., Gavin, J., 1984: Decreasing diurnal temperature range in the United States and Canada from 1941-1980. Journal of Applied Meteorology, 23, 1489-1504. 
Karl, T.R., Kukla, G., Razuvayev, V.N., Changery, M.J., Quayle, R.G., Heim, R.R. Jr, Easterling, D.R., Fu, C.B., 1991: Global warming: Evidence for asymmetric diurnal temperature change. Geophysical Research Letters, 18, 2253-2256

Karl, T. R. \& Trenberth, K. E., 2003: Modern Global Climate Change. Science 302, 1719-1723.

Kistler, R, Kalnay, E, Collins, W, Saha, S, White, G, Woollen, J, Chelliah, M, Ebisuzaki, W, Kanamitsu, M, Kousky, V, van den Dool, H, Jenne, R, Fiorino, M., 2001: The NCEP-NCAR 50-year reanalysis: Monthly means CD-ROM and documentation. Bulletin of the American Meteorological Society, 82: 247-267.

Klink, C.A. \& Solbrig, O.T., 1996: Efeito do fogo na biodiversidade de plantas do Cerrado. In: Biodiversidad y Funcionamento de Pastizales y Sabanas en América Latina. Sarmiento, G., Cabido, M. (eds.). Cyted y Cielat, Venezuela. p.231-244.

Koren, I., Kaufman, Y.J., Remer, L.A., Martins, J.V., 2004: Measurement of the Effect of Amazon Smoke on Inhibition of Cloud Formation. Science, 303 (5662), 1342-1345.

Kousky, V. E., 1988: Pentad outgoing longwave radiation climatology for the South American sector. Revista Brasileira de Meteorologia, 3, 217-231.

Kronka, F.J.N., 1993: Inventário florestal do Estado de São Paulo. Instituto Florestal. São Paulo. $200 \mathrm{pp}$.

Kronka, F.J.N., Marco, A., Matsukuma, C.K. , Pavão, M., Kanashiro, M.M., Ywane, M.S.S., Lima, L.M.P.R., Guillaumon, J.R., Baitello, J.B., Monteiro, C.H.B., 2002: Inventário florestal das áreas reflorestadas do Estado de São Paulo. São Paulo: Pancron, 183 pp.

LBA, 1996: The Large Scale Biosphere-Atmosphere Experiment in Amazonia. Concise Experimental Plan. Elaborated by the LBA Science Planning Group. Disponível em: http://lba.cptec.inpe.br/lba. Acesso em: 23 jan. 2006. 
Landsberg, J., 1999: Tree Water Use and its implications in relation to Agroforestry Systems. In: The Ways Trees Use Water - Water and Salinity Issues in Agroforestry, $n^{\circ} 5$. Rural Industries Research and Development Corporation. Publication $n^{\circ}$ 99/37. Landsberg J (ed), RIRDC, Kingston, Australia. pp. 1-31.

Lane P.N.J., Morris, J., Zhang, N., Guangyi, Z., Guoyi, Z., Daping, X., 2004: Water balance of tropical eucalypt plantations in south-eastern China. Agricultural and Forest Meteorology, 124, $253-267$.

Lim, Y.-K., Cai, M., Kalnay, E., Zhou, L., 2005: Observational evidence of sensitivity of surface climate changes to land types and urbanization, Geophysical Research Letters, 32, L22712, doi:10.1029/2005GL024267.

Lima, W. P., 1996: Impacto Ambiental do Eucalipto. $2^{\circ}$ edição. Editora Edusp. São Paulo, SP. pp 301.

Lombardo, M.A, 1985: Ilha de calor nas metrópoles: o exemplo de S. Paulo. Hucitec.

Lund, R. \& Reeves, J., 2002: Detection of undocumented changepoints: a revision of the two phase regression model. Journal of Climate, 15, 2547-2554.

Machado, R.B., Ramos Neto, M.B., Pereira, P.G.P., Caldas, E.F., Gonçalves, D.A., Santos, N.S., Tabor, K., Steininger, M., 2004: Estimativas de perda da área do Cerrado brasileiro. Relatório técnico, Conservação Internacional, Brasília, DF.

Mahmood, R., Hubbard, K.G., Carlson, C, 2004: Modification of growing-season surface temperature records in the Northern Great Plains due to land-use transformation: verification of modelling results and implication for Global Climate Change. International Journal of Climatology, 24, 311-327. 
Mantua N. J., Hare S. R., Zhang Y., Wallace J. M., Francis R. C. 1997. A Pacific interdecadal climate oscillation with impacts on salmon production. Bulletin of the American Meteorological Society, 78, 1069-1079.

Marengo, J., 2001: Mudanças climáticas globais e regionais: Avaliação do clima atual do Brasil e projeções de cenários climáticos do futuro. Revista Brasileira de Meteorologia, 16, 1-18.

Marengo, J., Alves, L.M., Castro, C.A.C., Mendes, D., 2005: Início da estação chuvosa nas Regiões Sudeste, Centro-Oeste e sul do Nordeste do Brasil, afetadas pela crise de energia. Disponível em http://www.cptec.inpe.br/energia. Acesso em 11 de janeiro de 2005.

Mello, M.H.A, Pedro Jr, M.J, Ortolani, A.A., Alfonsi, R.R., 1994: Chuva e Temperatura: cem anos de observações em Campinas. Boletim Técnico $\mathrm{n}^{\circ}$. 154. Instituto Agronômico de Campinas, SP, 48 pp.

Miranda, A.C., Miranda, H.S., Lloyd, J., Grace, J., McIntyre, J.A., Meir, P., Riggan, P., Lockwood, R., Brass, J., 1996: Carbon dioxide fluxes over a Cerrado Sensu Stricto in central Brazil. In: Amazon Deforestation and Climate. Gash, J.C.H., Nobre, C.A., Roberts, J.M, Victória R. (eds). John Wiley \& Sons, Chichester, UK, p. 353-364.

Miranda, A.C.; Miranda, H.S., Lloyd, J.; Grace, J.; Francey, J.; McIntyre, J.A.; Meir, J.; Riggan, P.; Lockwood, R. , Brass, J., 1997: Fluxes of carbon, water and energy over Brazilian cerrado: an analysis using eddy covariance and stable isotopes. Plant, Cell and Environment, 20, $315-$ 328.

Myers, N., Mittermeier, R.A., Mittermeier, C.G., Fonseca, G.A.B., Kent, J., 2000: Biodiversity hotspots for conservation priorities. Nature, 403, 853-858.

Nasrallah H.A. \& Balling, R.C.,1995: Impact of desertification on temperature trends in the Middle East. Environmental Monitoring and Assessment, 37, 265-271. 
Negrón-Juarez, R.I., 2004: Variabilidade Climática Regional e Controle da Vegetação no Sudeste: Um estudo de Observações sobre cerrado e Cana-de-açúcar e Modelagem Numérica da Atmosfera. Tese de Doutoramento do Departamento de Ciências Atmosféricas do Instituto de Astronomia e Geofísica da Universidade de São Paulo. 159 p.

Newman, M., Compo, G.P., Alexander, M.A., 2003: ENSO-Forced Variability of Pacific Decadal Oscillation. Journal of Climate, 16 (23), 3853-3857.

Nobre, C.A., Sellers P.J., Shukla, J., 1991: Amazonian deforestation and regional climate change. Journal of Climate, 4, 957-987.

Oke, T.R, 1987: Boundary Layer Climates. Second Edition. Routledge Kegan \& Paul.Methuem, London, $435 \mathrm{pp}$.

Oliveira-Filho, A.T.\& Ratter, J.A, 2002: Vegetation Physiognomies and Woody Flora of the Cerrado Biome. In: The Cerrados of Brazil, Ecology and Natural History of a Neotropical Savanna. Oliveira, P. S., Marquis, R. J. (eds). New York: Columbia University Press. p.91121.

Peterson T.C. \& Easterling D.R., 1994: Creation of climatological reference series. International Journal of Climatology, 14, 671-679.

Peterson, T.C., Easterling, D.R., Karl, T.R., Groisman P., Nicholls, N., Plummer, N., Torok, S., Auer, I., Boehm, R., Gullett, D., Vincent, L., Heino, R., Tuomenvirta, H., Mestre, O., Szentimrey, T., Salinger, J., Forland, E., Hansen-Bauer, I., Alexanderson, H., Jones, P., Parker, D. 1998: Homogeneity adjustments of in situ atmospheric climate data: a review. International Journal of Climatology, 18, 1493-1517.

Pielke Sr., R.A. \& Matsui, T., 2005: Should light wind and windy nights have the same temperature trends at individual levels even if the boundary layer averaged heat content change is the same? Geophysical Research Letters, 32, L21813, doi:10.1029/2005GL024407. 
Pielke Sr., R.A., Dalu, G.A., Snook, J.S., Lee, T.J., Kittel, T.G.F, 1991: Non linear influence of mesoescala land use on weather and climate. Journal of Climate, 4, 1053-1069.

Priante-Filho, N., Vourlitis, G.L., Hayashi, M.M.S., Nogueira, J.S.,Campelo Jr, J.H., Nunes, P.C., Souza, L.S., Couto, E. G., Hoeger, W., Raiter, F., Trienweiler, J.L., Miranda, E.J., Priante, P.C., Fritzen, C.L., Lacerda, M., Pereira, L.C., Biudes, M. S., Suli, G.S., Shiraiwa, S., Do Paulo, S.R., Silveira, M, 2003: Comparison of the mass and energy exchange of a pasture and a mature transitional tropical forest of the southern Amazon Basin during a seasonal transition, Global Change Biology 10 (5), 863-876.

Rhoades, A.D. \& Salinger, M.J., 1993: Adjustment of Temperature and Rainfall records for site changes. International Journal of Climatology, 13, 899-913.

Ribeiro, J.F.\& Walter, B.M.T, 1998: Fitofisionomias do bioma cerrado. In: Cerrado: ambiente e flora. Sano, S.M., Almeida, S.M. (eds). Planaltina, EMBRAPA-CPAC. p.89-166.

Roberts, J.M., Rosier, P.T.W., Srinivasa Murthy, K.V., 1992: Physiological studies in young Eucalyptus stands in southern India and their use in estimating forest transpiration. In: Growth and Water Use of Forest Plantations. Calder, I.R., Hall, R.L., Adlard, P.G. (eds.). Wiley, Chichester, p. 226-243.

Rocha, H. R.., 1998: Modelagem e Observações das relações Biosfera-Atmosfera na Região Sudeste. Tese de Doutoramento do Departamento de Ciências Atmosféricas do Instituto de Astronomia e Geofísica da Universidade de São Paulo. 142 p.

, Freitas, H., Rosolem, R., Negron-Juarez, R.I., Tannus, R.N, Ligo, M.V., Cabral, O.M.R.,.Silva Dias, M.A.F, 2002: Measurements of CO2 exchange over a woodland savanna (Cerrado Sensu stricto) in southeast Brasil. Biota Neotropica, 2(1). Disponível em http://www.biotaneotropica.org.br/v2n1/pt/abstract?article+BN01702012002. 
, 2004: Relações Funcionais de Clima e Biosfera no Brasil. Tese de Livre Docência. do Departamento de Ciências Atmosféricas do Instituto de Astronomia e Geofísica da Universidade de São Paulo. 79 p.

, Freitas, H.C., Rosolem, R., Tannus, R.N., Negron-Juarez, R.I.., Ligo, M. V., Cabral, O. M. R., Mesquita, H., Bittencourt, M., 2005: Ciclo hidrológico e microclima. In O Cerrado Pé de Gigante - Ecologia e Conservação, 312 p. Pivello V. R., Varanda E. M. (eds). São Paulo, SMA, Imprensa Oficial do Estado de São Paulo, p. 52-60.

Freitas, H. C., Acosta, R., Tatsch, J. D., Bruno, R. D., Oliveira, L. S., Tannus, R. N., Negron-Juarez, R., Collicchio, E., Borma, L., Zanchi, F. B., Cabral, O. M. R., Ligo, M., Kurzatkowski, D., Ribeiro, R., Goulden, M. L., Miller, S. D., Nobre, A. C., Manzi, A., Wosfy, S. C., Saleska, S. R., Kruijt, B., Von Randow, C., 2006: Patterns of water, heat and CO2 fluxes measured by flux towers across tropical forest, ecotone-floodplain and savanna ecosystems in Brazil. In: Proceedings of $1^{\text {st }}$ ILEAPS Science Conference - Integrated Land Ecosystem-Atmosphere Process Study/IBGBP. Boulder, CO, USA. Helsinki: Finnish Association for Aerosol Research, p. 215-216.

Rusticucci, M.\& Barrucand, M. 2004: Changes in Temperature extremes over Argentina. Journal of Climate, 17 (20), 269-284.

Sansigolo, C.A., Rodrigues, R.C.M., Etchichury, P.C., 1992: Tendências das temperaturas médias no Brasil. In: VII Brazilian Conference of Meteorology, vol. 1, 367-369.

Secretaria de Estado Meio Ambiente do estado de São Paulo - SMA, 2003: Relatório de Qualidade Ambiental do Estado de São Paulo. Disponível em http://www.ambiente.sp.gov.br.

Schmid, H. P., 1994: Source areas for scalars and scalars fluxes. Boundary Layer Meteorology, 67, 293-318. 
Silberstein, R., Held, A.,Hatton, T.,Viney, N., Sivapalan, M., 2001: Energy Balance of a natural jarrah (Eucalyptus marginata) forest in Western Australia: measurements during the spring and summer. Agricultural and Forest Meteorology, 109, 79 - 104.

Silva, J.C. \& Bates, J., 2002: Biogeographic patterns and conservation in South America Cerrado: a Tropical savanna Hotspot. BioScience, 52(3), 225-233.

Simmons, A.J., Jones, P.D., da Costa Bechtold, V., Beljaars, A.C. M., Kallberg, P.W., Saarinen, S., Uppala, S.M., Viterbo, P., Wedi, N., 2004: Comparison of trends and low-frequency variability in CRU, ERA-40 and NCEP/NCAR analyses of surface air temperature. Journal of Geophysical Research, 109, D24115, doi:10.1029/2004JD005306.

Soares, J.V. \& Almeida, A.C., 2001: Modeling the water balance of soil water fluxes in a fast growing Eucalyptus plantation in Brazil. Journal of Hydrology, 253, 130-147.

Sociedade Brasileira de Solos - SBS, 2000: Área plantada com pinus e eucaliptos no Brasil, Disponível em http://www.sbs.org.br/area plantada.htm. Acesso em 20/06/2004.

Stohlgren, T.J., Chase, T.N., Pielke Sr., R.A., Kittel, T.G.F., Baron, J.S, 1998: Evidence that local land use practices influence regional climate, vegetation, and flow patterns in adjacent natural areas. Global Change Biology, 4, 495-504.

Stone, D.A. \& Weaver A.J., 2003: Factors contributing to diurnal temperature range trends in twentieth and twenty-first century simulations of the CCCma coupled model. Climate Dynamics, 20, 435-445.

Stull, R.B. 1988: An introduction to boundary layer meteorology. Kluwer Academic Publishers, Dordrecht, The Netherlands, 665 pp.

Sugahara, S., 1991: Flutuações interanuais, sazonais e intrasazonais da precipitação no estado de São Paulo. Tese de Doutoramento do Departamento de Ciências Atmosféricas do Instituto de Astronomia e Geofísica da Universidade de São Paulo.158p. 
Tannus, R.N., 2004: Funcionalidade e sazonalidade sobre Cerrado e sobre Ecótono FlorestaCerrado: Uma investigação com dados micrometeorológicos de energia e $\mathrm{CO}_{2}$. Tese de Mestrado em Ecologia de Agroecossistemas da Escola Superior de Agricultura Luiz de Queiroz da Universidade de São Paulo. 92p.

Tatsch, J.D.; Rocha, H.R. ; Freitas, H.C.; Cabral, O.M.R.; Tannus, R.N.; Acosta, R., 2005: Variações dos Fluxos de superfície na conversão de Cerrado por Cana-de-açúcar. Ciência e Natura, Volume Especial - Dezembro/2005, p. 111-114.

Trenberth, K.E., 2004: Climatology (communication arising): Impact of landuse change on climate. Nature, 427, 213.

Venegas, S.A., Mysak, L.A., Straub, D.N., 1997: Atmosphere-Ocean coupled variability in the South Atlantic. Journal of Climate, 10, 2904-2920.

Vincent, L. A., Peterson, T. C., Barros, V. R., Marino, M. B., Rusticucci, M., Carrasco, G., Ramirez, E., Alves, L. M., Ambrizzi, T., Berlato, M. A., Grimm, A. M., Marengo, J. A., Molion, L., Moncunill, D. F., Rebello, E., Anunciacao, Y. M. T., Quintana, J., Santos, J. L., Baez, J., Coronel, G., Garcia, J., Trebejo, I., Bidegain, M., Haylock, M. R., Karoly, D., 2005: Observed trends in indices of daily temperature extremes in South America 1960- 2000. Journal of Climate, 18, 5011-5023.

Vinnikov, K.Y., Groisman, P., Lugina, K., 1990: The empirical data on modern global climate changes (temperature and precipitation). Journal of Climate, 3, 662-677.

Vose, R.S., Easterling, D.R., Gleason, B., 2005: Maximum and minimum temperature trends for the globe: An update through 2004. Geophysical Research Letters, 32, L23822, doi:10.1029/2005GL024379.

Vourlitis, G., Priante-Filho, N., Hayashi, M., Nogueira, J., Caseiro, F., Campelo Jr, J., 2001: Seasonal variations in the net ecosystem $\mathrm{CO} 2$ exchange of a mature amazonian transitional tropical forest (Cerradão). Functional ecology, 15, 338-395. 
Vourlitis, G.L., Priante-Filho, N., Hayashi, M.M.S., Nogueira, J.D., Raiter, F., Hoegel, W., Campelo Jr, .H., 2004: Effects of meteorological variations on the $\mathrm{CO} 2$ exchange of a Brazilian transitional tropical forest. Ecological Applications, 14, S89-S100.

Wang, X. L., 2003: Comments on "'Detection of undocumented changepoints: A revision of the two-phase regression model'. Journal of Climate, 16, 3383-3385.

Wang, X.L. \& Fang, Y., 2004: RHTest User Manual. Disponível para download em http://cccma.seos.uvic.ca/ETCCDMI/RHTest/RHTestUserManual.doc.

Webb, E.K., Pearman, G.I., Leuning, R., 1980: Correction of flux measurements for density effects due to heat and water vapor transfer. Quartely Journal Royal Meteorological Society, $106,85-100$. 


\section{APÊNDICE A}

\section{FILTRAGEM DE DADOS}

Tabela A.1. Limites inferiores e superiores aplicados em cada variável para filtragem de dados espúrios.

\begin{tabular}{|c|c|c|}
\hline Variável (símbolo) & Unidades & *Limite inferior/superior \\
\hline Fluxo de calor sensível $(\mathrm{H})$ & $\mathrm{W} \mathrm{m}^{-2}$ & $-200 / 1000$ \\
\hline Fluxo de calor latente (LE) & $\mathrm{W} \mathrm{m}^{-2}$ & $-200 / 1000$ \\
\hline Fluxo de calor no solo $(\mathrm{G})$ & $\mathrm{W} \mathrm{m}^{-2}$ & $-300 / 500$ \\
\hline Saldo de radiação $(\mathrm{Rn})$ & $\mathrm{W} \mathrm{m}^{-2}$ & $-200 / 1200$ \\
\hline Irradiância solar global incidente (Ki) & $\mathrm{W} \mathrm{m}^{-2}$ & $0 / 1300$ \\
\hline Irradiância solar global refletida $(\mathrm{Kr})$ & $\mathrm{W} \mathrm{m}^{-2}$ & $0 / 500$ \\
\hline $\begin{array}{l}\text { Radiação fotossintética ativa incidente } \\
\text { (RFAi) }\end{array}$ & $\mu \mathrm{mol} \mathrm{m} \mathrm{s}^{-2}$ & $0 / 2700$ \\
\hline $\begin{array}{l}\text { Radiação fotossintética ativa refletida } \\
\text { (RFAr) }\end{array}$ & $\mu \mathrm{mol} \mathrm{m} \mathrm{s}^{-2}$ & $0 / 500$ \\
\hline Umidade relativa (UR) & $\%$ & $0 / 100$ \\
\hline Temperatura do ar (T) & ${ }^{\circ} \mathrm{C}$ & $-1 / 40$ \\
\hline Velocidade do vento (U) & $\mathrm{m} \mathrm{s}^{-1}$ & $0 / 20$ \\
\hline Direçao do Vento (dir) & ${ }^{\circ}$ (graus) & $0 / 360$ \\
\hline Precipitação (Prec) & $\mathrm{mm}$ & $0 / 80$ \\
\hline Pressão atmosférica (Patm) & $\mathrm{hPa}$ & $900 / 1000$ \\
\hline Velocidade de friccão $(\mathrm{u} *)$ & $\mathrm{m} \mathrm{s}^{-1}$ & $0 / 5$ \\
\hline
\end{tabular}

*Os limiares foram aplicados nos dados de $30 \mathrm{~min}$ 


\section{APÊNDICE B}

\section{CLIMATOLOGIA DA REGIÃO DE SANTA RITA DO PASSA QUATRO}

Dados de longo prazo de precipitação para as seis estações meteorológicas localizadas nos arredores da área de estudo (ver Fig. 2.1.1.a) foram obtidas no Departamento de Água e Energia Elétrica (DAEE/SP). A partir dos dados mensais determinou-se a média entre as estações para a composição da climatologia da precipitação na região de estudo para o período de 1961 1990. Informações adicionais sobre as estações meteorológicas são fornecidas na Tabela B1. A climatologia da temperatura foi determinada com base nos dados da estação meteorológica C4107 (Tabela B.1) no período de 1982-1998.

Tabela B.1. Estações Meteorológicas utilizadas para determinação da climatologia da região de estudo.

\begin{tabular}{cccccc}
\hline Município & Código DAEE & Altitude & Latitude & Longitude & Período \\
\hline Santa Rita do Passa Quatro & C4-107 & $780 \mathrm{~m}$ & $21^{\circ} 42^{\prime}$ & $47^{\circ} 28^{\prime}$ & $1982-1998$ \\
\hline Luís Antonio & $\mathrm{C} 4-096$ & $670 \mathrm{~m}$ & $21^{\circ} 35^{\prime}$ & $47^{\circ} 42^{\prime}$ & $1970-1990$ \\
\hline Santa Rita do Passa Quatro & $\mathrm{C} 4-095$ & $550 \mathrm{~m}$ & $21^{\circ} 44^{\prime}$ & $47^{\circ} 38^{\prime}$ & $1970-1990$ \\
\hline São Simão & $\mathrm{C} 4-091$ & $610 \mathrm{~m}$ & $21^{\circ} 31^{\prime}$ & $47^{\circ} 36^{\prime}$ & $1965-1990$ \\
\hline Santa Rita do Passa Quatro & $\mathrm{C} 4-024$ & $720 \mathrm{~m}$ & $21^{\circ} 44^{\prime}$ & $47^{\circ} 29^{\prime}$ & $1961-1971$ \\
\hline Santa Rita do Passa Quatro & $\mathrm{C} 4-041$ & $700 \mathrm{~m}$ & $21^{\circ} 43^{\prime}$ & $47^{\circ} 30^{\prime}$ & $1961-1990$ \\
\hline
\end{tabular}

* Estação meteorológica com dados de temperatura disponíveis

O clima na região de Santa Rita do Passa Quatro é marcadamente sazonal: ameno e seco no inverno, e quente e úmido no verão, com temperatura média que varia de $19^{\circ} \mathrm{C}$ no mês mais frio (junho) até $24^{\circ} \mathrm{C}$ no mês mais quente (fevereiro) (Fig. B.1.a). A distribuição da precipitação (Fig. B.1.b) apresenta valores médios mensais superiores a $200 \mathrm{~mm}$ durante os meses de dezembro a fevereiro, enquanto que os meses de junho a agosto os valores são inferiores a $50 \mathrm{~mm}$. A precipitação climatológica anual é de $1498 \pm 312 \mathrm{~mm}^{2} \mathrm{ano}^{-1}$ e a temperatura é de $22,1 \pm 0,5^{\circ} \mathrm{C}$. 


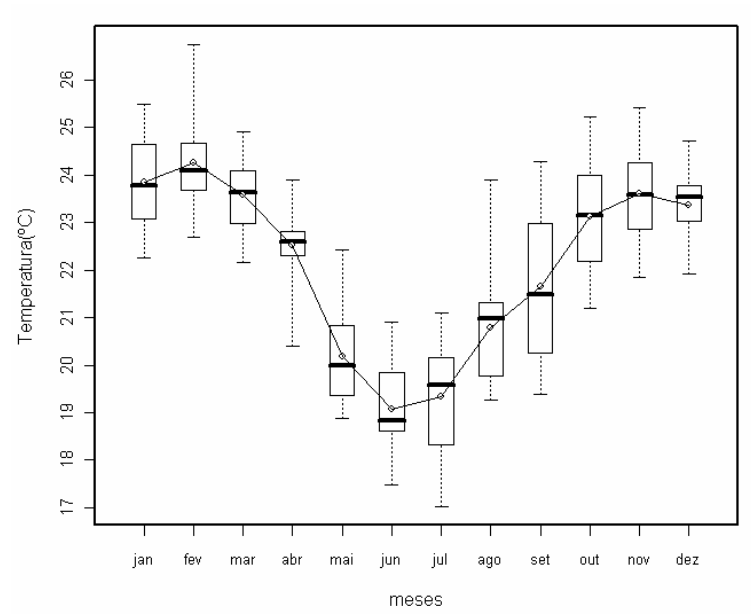

(a)

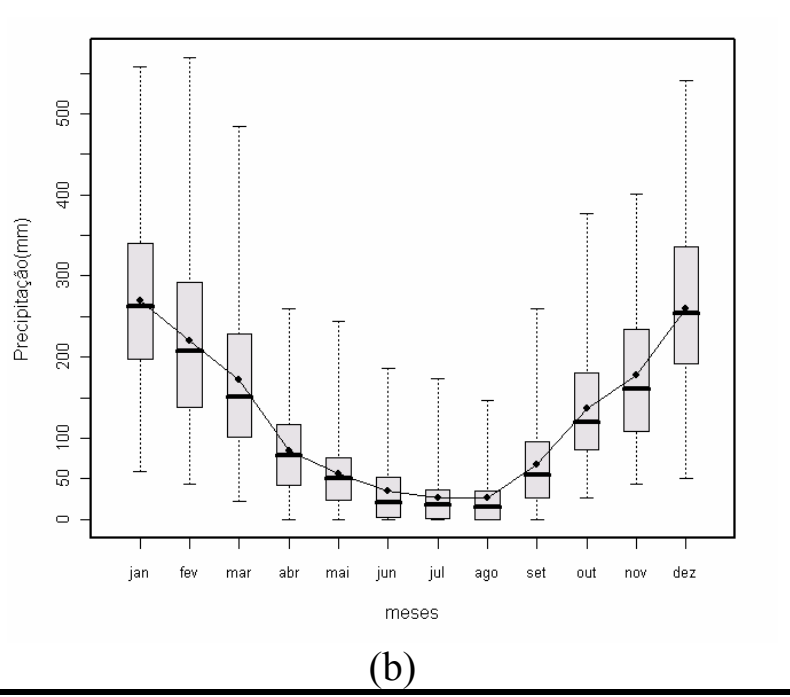

(b)

Figura B.1. (a) Distribuição das temperaturas mensais na estação C4-107 (Santa Rita do Passa Quatro). (b) Pluviograma mensal na região de Santa Rita do Passa Quatro, no período de 1961-2000 calculado com dados das estações meteorológicas listadas na Tabela B.1. A linha sólida unindo os pontos representa a média mensal das variáveis.

\section{CLIMATOLOGIA SAZONAL DA PRECIPITAÇÃO DE SP}

A partir de dados diários de precipitação disponibilizados pelo Departamento de Água e Energia Elétrica de SP (DAEE), determinou-se a climatologia da precipitação nas escalas de tempo anual e sazonal (estação seca e chuvosa). No total 1082 estações meteorológicas foram utilizadas. As séries de dados são referentes a um período de 40 anos (1961 - 2000), com poucos dados faltantes. Na Fig.B.2 a rede de estações meteorológicas utilizada é mostrada. Os dados foram tratados numa base mensal. Desta forma, para cada estação foram desconsiderados meses com falhas nos dados superiores a $30 \%$.

Para o cálculo da média climatológica da precipitação da estação chuvosa (ECh) considerou-se o período de transição entre dois anos, correspondente a Setembro-Abril (8 meses). Enquanto que para estação seca (ES) foi considerado o período Maio-Agosto (4 meses). Estes oito meses foram aqui sugeridos como representativos da ECh. Esta indicação foi baseada na contribuição mensal da chuva para a Região Sudeste do Brasil que entre outubro e abril corresponde a $85 \%$ do total anual (Marengo et al. 2005). Adicionalmente estudos antecedentes 
também encontraram que em média a estação chuvosa em SP inicia por meados de setembro e termina no final de Abril (Sugahara 1991; Kousky 1988).

A determinação das médias de precipitação foi baseada no seguinte cálculo:

$$
P_{E}=\sum_{1}^{m} P_{M} ; P_{N}=\frac{\sum_{1}^{i} P_{E}}{i}
$$

onde, $\mathrm{m}=$ número de meses (12 para média anual, 8 para média da ECh e 4 para a média da ES); $P_{M}=$ total de precipitação mensal; $i=40$ (número de anos, 1961-2000); $P_{E}=$ precipitação total anual, precipitação total sazonal ou mensal para cada ano; $P_{N}=$ média climatológica anual ou sazonal. Assim se obteve a média de precipitação nos diferentes períodos para cada estação meteorológica.

Os campos sazonais de precipitação mostram que a ECh teve um valor limiar de $800 \mathrm{~mm}$ (Fig. B.3.a), enquanto que a ES ficou definida por valores predominantemente menores que 600 mm (Fig. B.3.b). Estes campos realçam os picos pluviométricos do litoral e os baixos valores de precipitação ao longo do Vale do Paraíba, recorrentes em ambos os períodos. Na ES verificam-se baixos índices de precipitação $(<100 \mathrm{~mm})$ na maior parte do estado.

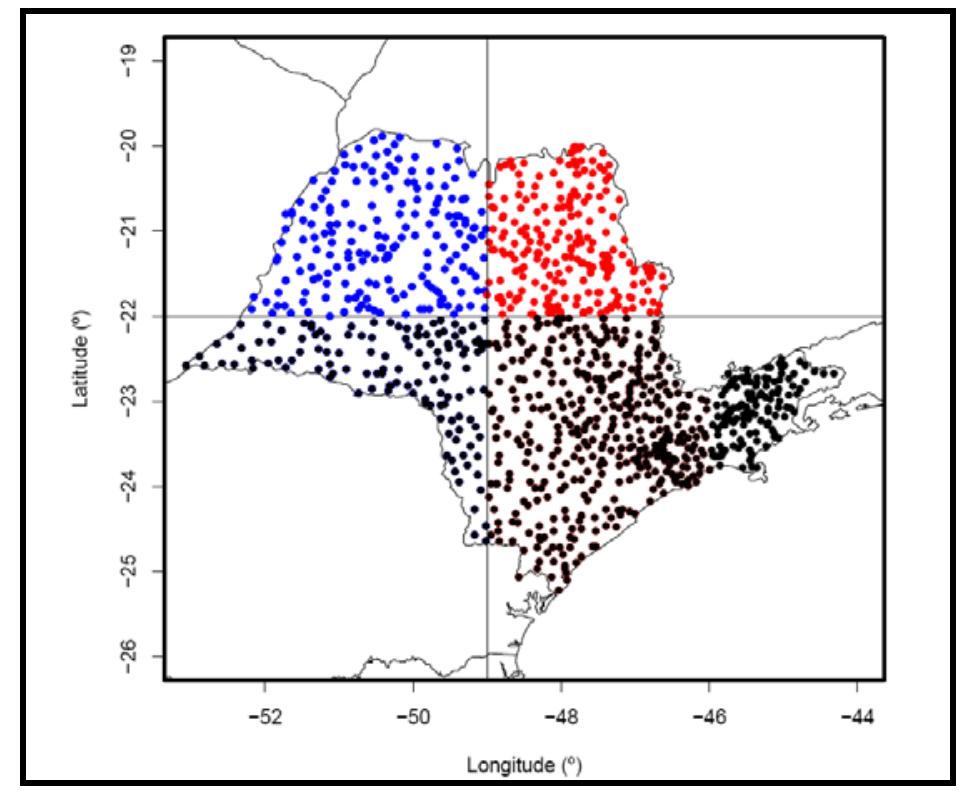

Figura B.2. Distribuição espacial das estações meteorológicas do DAEE em SP. Os pontos vermelhos e azuis representam as estações ao Norte de $22^{\circ} \mathrm{S}$, do setor Leste (entre $49^{\circ}$ e $46^{\circ} \mathrm{W}$ ) e Oeste (entre $49^{\circ}$ e $52^{\circ}$ W), respectivamente. 


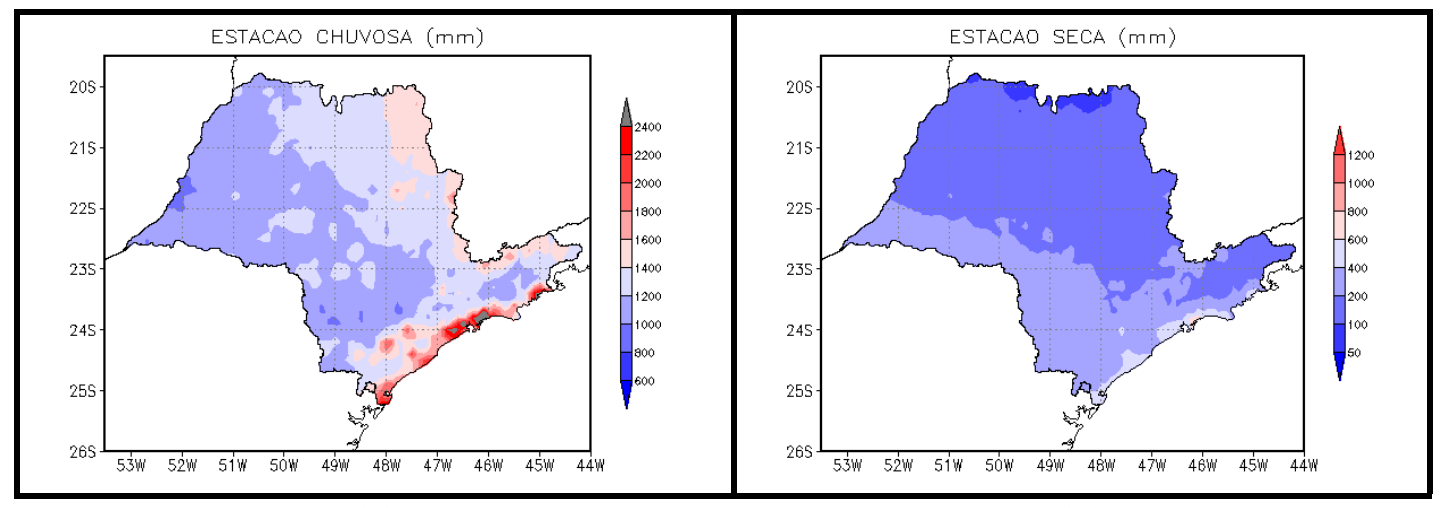

(a)

(b)

Figura B.3. (a) Climatologia da precipitação para estação chuvosa. (b) Climatologia da precipitação para estação seca. 
APÊNDICE C

FOTOGRAFIAS DAS ESTAÇOES DE RIBEIRÃO PRETO E CAMPINAS 


\section{RIBEIRÃO PRETO}

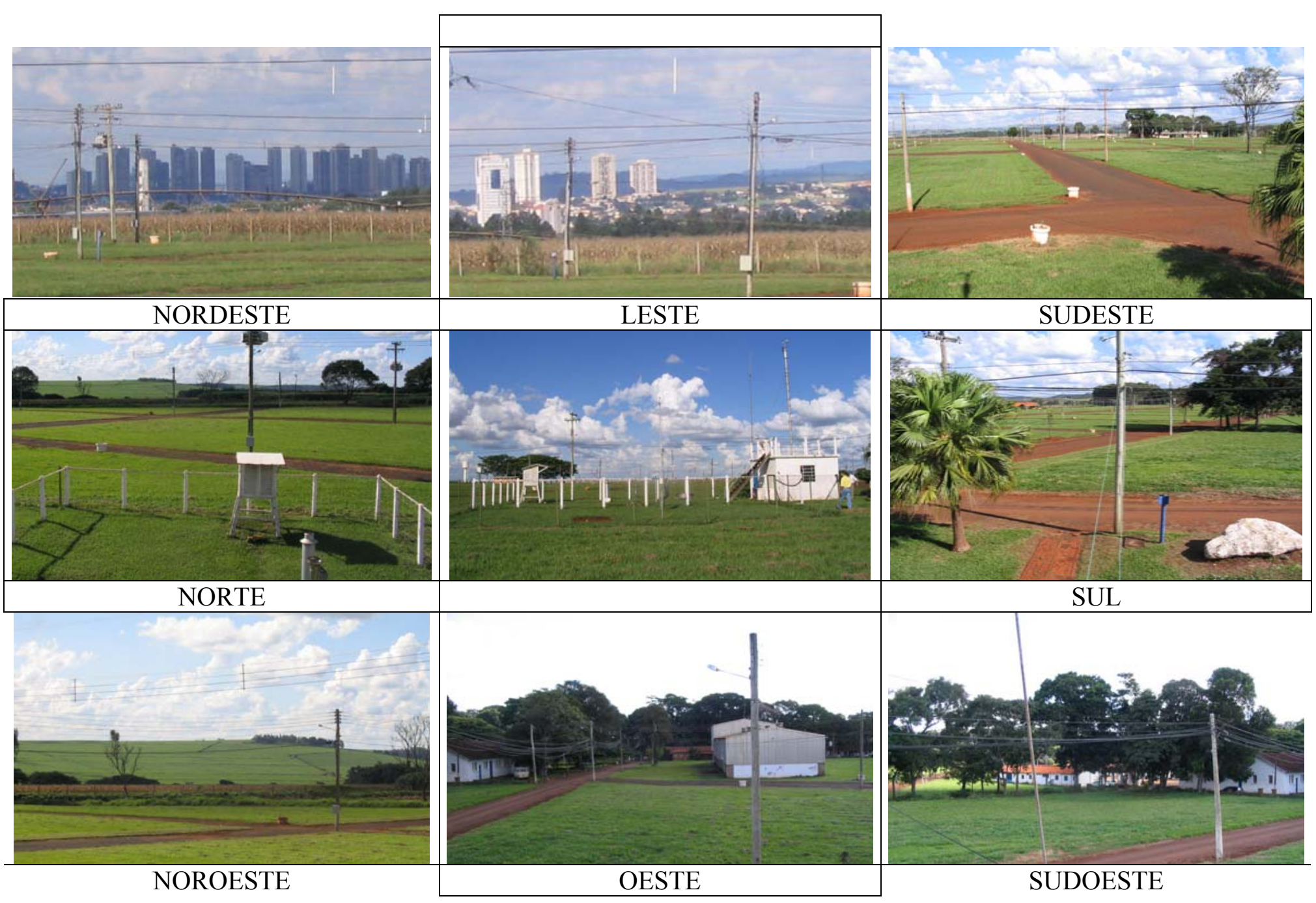

Figura C.1. Fotografias da estação meteorológica do IAC de Ribeirão preto tiradas em 10/04/2006 


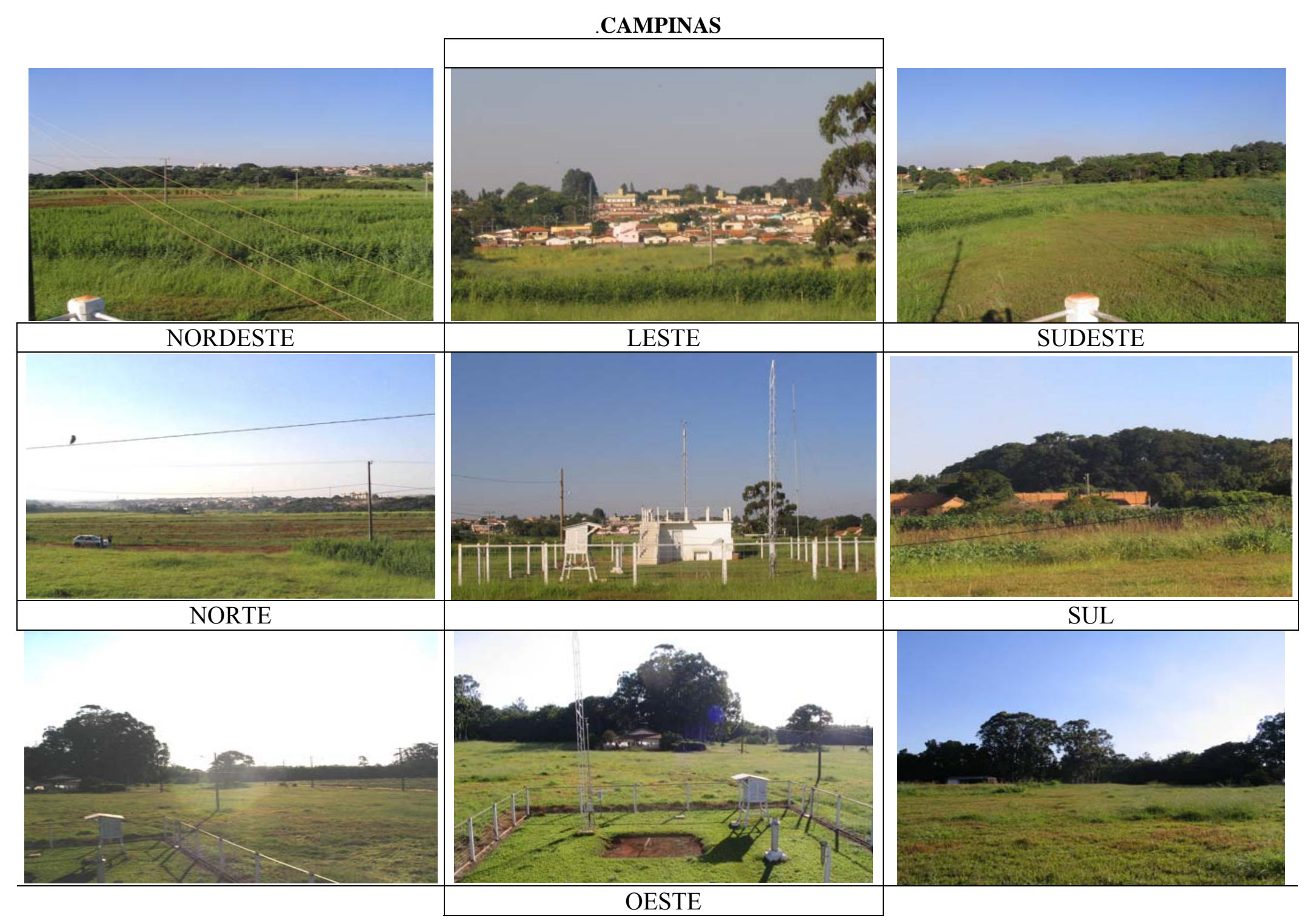

Figura C.2. Fotografias da estação meteorológica do IAC de Campinas tiradas em 03/05/2006. 


\section{APÊNDICE D}

\section{COMPARAÇÃO DOS TOTAIS DIÁRIOS DA IRRADIÂNCIA SOLAR INCIDENTE}

A radiação solar é a principal fonte de energia para os ecossistemas e por isso é importante quantificar se ocorrem diferenças entre as áreas experimentais. A Figura D.1.a,b apresenta a comparação entre os dados diários da irradiância solar incidente (Ki) medidos simultaneamente nas áreas experimentais. As relações encontradas indicam que Ki no cerrado foi menor que na cana, por menos de $4 \%$, e maior que no eucalipto, por menos de $1 \%$ (Fig. D.1). Para os dois casos as inclinações das retas não diferiram significativamente da unidade. Disto resulta que as diferenças no saldo de radiação ocorreram principalmente devido às propriedades radiativas de cada tipo de vegetação estudado. Uma aplicação importante deste resultado é que estas relações possibilitaram o preenchimento de falhas, quando pelo menos uma das áreas estivesse realizando as medidas.

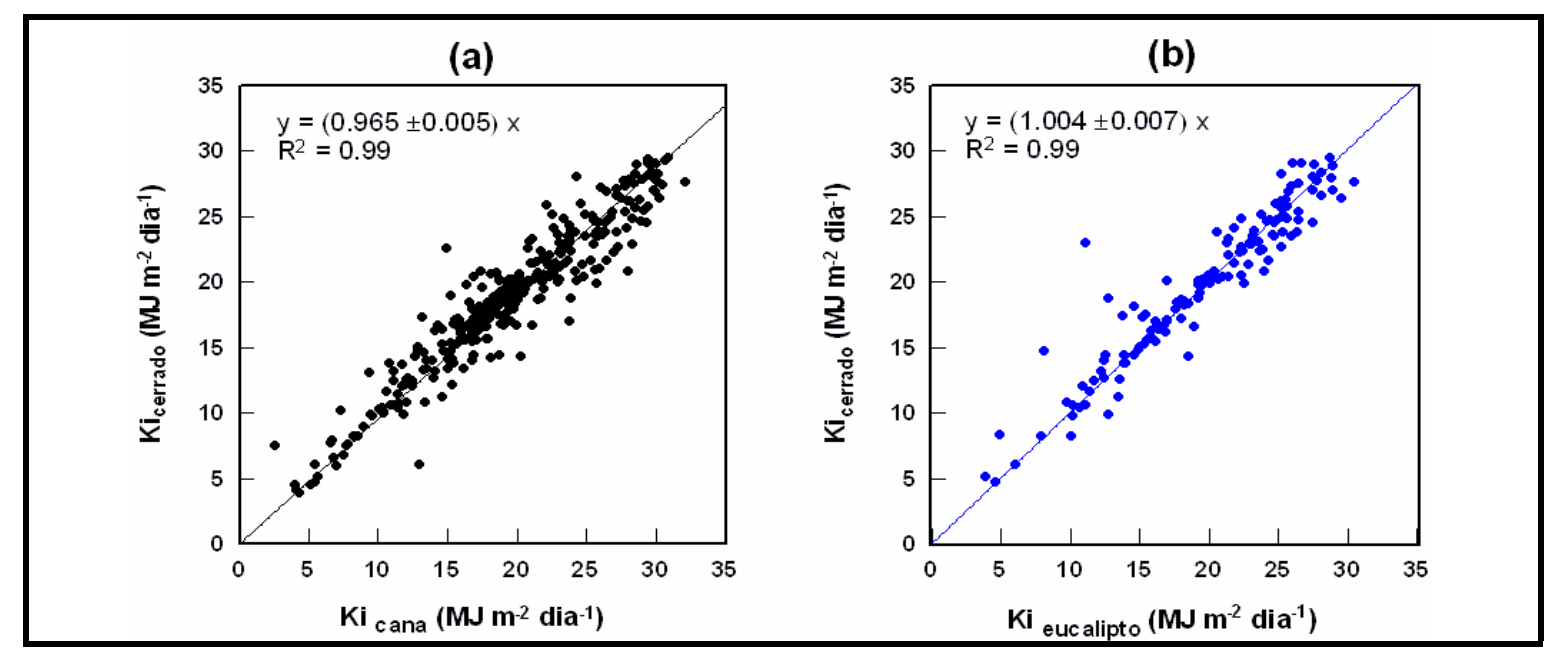

Figura D.1. Totais diários da irradiância solar global incidente (Ki), (a) no cerrado versus Ki na cana e (b) no eucalipto (todos em $\mathrm{MJ} \mathrm{m}^{-2} \mathrm{dia}^{-1}$ ). Os dados são mostrados para o período de 7/02/2005 a 6/02/2006 em (a) e de 22/07/2005 a 6/02/2006 em (b). 


\section{APÊNDICE E VARIAÇÃO SAZONAL DOS FLUXOS DE $\mathrm{CO}_{2}$}

O fluxo de $\mathrm{CO}_{2}(\mathrm{Fc})$ medido pelo método de EC representa o termo turbulento do fluxo através da interface entre atmosfera e o ecossistema. O ganho de $\mathrm{CO} 2$ pelo ecossistema representa perda de $\mathrm{CO} 2$ para atmosfera. Dessa forma, valores negativos de Fc referem-se à predominância da fotossíntese (dia) e positivos (noite) à respiração heterotrófica e autotrófica. Para os três ecossistemas, os picos negativos de Fc foram observados na estação chuvosa, quando funcionam como sumidores de carbono (Fig. E.1). No eucalipto e no cerrado, particularmente, verifica-se que no final da estação seca ambos apresentam taxas mínimas de absorção de carbono, um padrão coerente com os máximos do albedo RFA (seção 3, Fig. 3.1.5.b). A variabilidade sazonal de Fc apresentou um padrão bem distinto ao se comparar a cana com o cerrado (Fig. E.1.a,b). O período em que a cana e o cerrado funcionam como fonte de carbono é bem diferente para cada um. No cerrado ocorre uma gradativa redução da absorção de carbono, de $-25 \mathrm{~kg} \mathrm{C} \mathrm{ha}^{-1}$ dia $^{-1}$ em janeiro, até o período de transição da estação seca para chuvosa, quando se observa $-3 \mathrm{~kg}$ $\mathrm{C}$ ha ${ }^{-1}$ dia $^{-1}$ no início de setembro. Este padrão tem uma forte correlação com o padrão do albedo RFA (seção 3, Fig. 3.1.5.b), que aumenta concorrentemente neste período. Com as primeiras chuvas em setembro e a rebrota do cerrado, uma rápida recuperação da atividade fotossintética é verificada, passando Fc de $\sim-10 \mathrm{~kg} \mathrm{C} \mathrm{ha}^{-1} \mathrm{dia}^{-1}$ em setembro para $-35 \mathrm{~kg} \mathrm{C} \mathrm{ha}{ }^{-1} \mathrm{dia}^{-1} \mathrm{em}$ novembro.

No caso da cana a variabilidade de Fc (Fig. E.1.b) é bem marcada pelo evento da colheita e pelo período de crescimento. Durante o período de fevereiro a abril, a cana apresentou máximos de atividade fotossintética, com picos entre -45 e $-50 \mathrm{~kg} \mathrm{C} \mathrm{ha}^{-1} \mathrm{dia}^{-1}$. Estes máximos de produtividade são substancialmente superiores aos do cerrado, na mesma fase. Após a colheita, em meados de abril, a área transita durante $\sim 45$ dias como fonte de carbono, para sumidor de carbono posteriormente, já em junho. Enquanto se observa a fonte, predomina a respiração heterotrófica, como sugerem os picos positivos de $\sim 10 \mathrm{~kg} \mathrm{C} \mathrm{ha}^{-1} \mathrm{dia}^{-1}$. Com a rebrota da cana a atividade fotossintética domina os fluxos totais, observando-se picos de Fc em agosto de $-15 \mathrm{~kg} \mathrm{C}$ $\mathrm{ha}^{-1} \mathrm{dia}^{-1}$, até $-45 \mathrm{~kg} \mathrm{C} \mathrm{ha}^{-1} \mathrm{dia}^{-1}$ em dezembro e janeiro de 2006. De forma geral, as taxas de absorção de carbono durante o período diurno foram maiores para cana em comparação com o cerrado, e durante o período úmido. 
A área de eucalipto apresentou valores mínimos de absorção de $\mathrm{CO}_{2}$, de $\sim-10 \mathrm{~kg} \mathrm{C} \mathrm{ha}^{-1}$ $\mathrm{dia}^{-1}$, no final da estação seca e máximos na estação chuvosa com picos de $\sim-55 \mathrm{~kg} \mathrm{C}^{-1}$, os quais foram superiores a cana e ao cerrado (Fig. E.1.c). Apesar de o eucalipto ser uma espécie C3, e o cerrado conter espécies C4 (em princípio com maior eficiência fotossintética), o maior adensamento de indivíduos na plantação de eucalipto pode ter sido o fator preponderante para maior absorção de $\mathrm{CO}_{2}$.

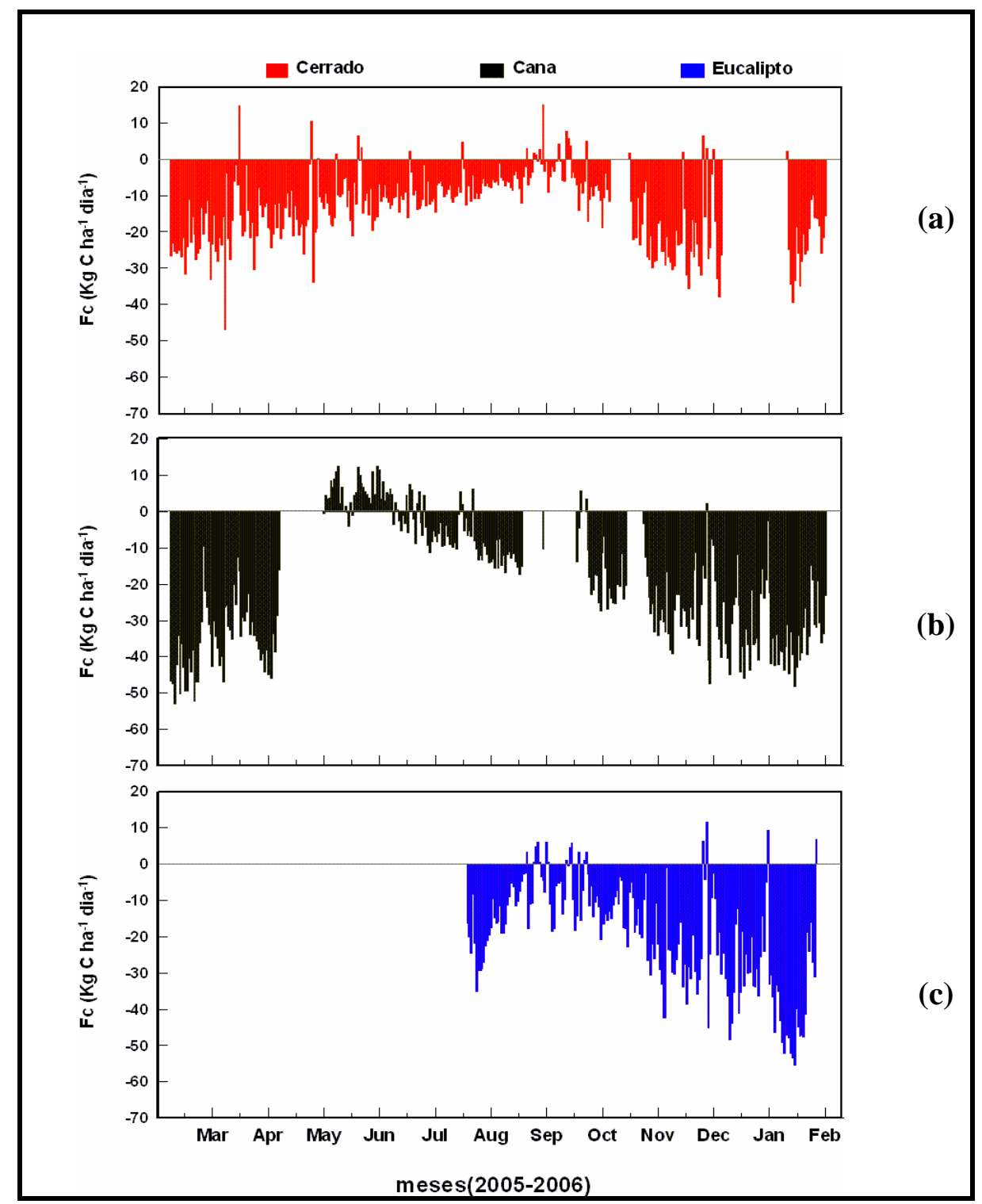

Figura E.1. Valores de Fc integrado diário em Kg C ha ${ }^{-1} \mathrm{dia}^{-1}$ para as áreas de (a) cerrado, (b) cana e (c) eucalipto. Os dados são mostrados para o período de 7/02/2005 a 6/02/2006 para a cana e o cerrado, e a partir de 22/07/2005 até 06/02/2006 para o eucalipto. 


\section{APÊNDICE F COMPARAÇÃO DOS FLUXOS MÉDIOS MENSAIS}

Apresentam-se aqui as mudanças microclimáticas e do balanço de energia por meio dos valores médios mensais das variáveis sobre a cana e o cerrado, onde as observações completaram um ano. Dessa forma, da comparação entre a cana e o cerrado (Fig. F.1), aponta-se:

$\Rightarrow$ Sobre a cana, a temperatura máxima foi consistentemente maior (Fig. F.1.a), na média por $1,7^{\circ} \mathrm{C}$, e a temperatura mínima foi menor ou aproximadamente igual (Fig. F.1.b) o que resultou em uma amplitude térmica superior (Fig. F.1.c).

$\Rightarrow$ Houve menor saldo radiação diurno $\left(\mathrm{Rn}_{\text {diurno}}\right)$ na cana (Fig. F.1.e), devido a dois fatores: o maior albedo (Fig. F.1.m) e a maior temperatura máxima (Fig. F.1.a). Na cana o ar foi um pouco mais úmido do que no cerrado (Fig. F.1.g) e a Tmin foi menor. Isto levou a um $\mathrm{Rn}_{\text {noturno }}$ (o qual é dominado pelo déficit de radiação de onda longa) maior sobre a cana (Fig. F.1.f). O Rn diário foi menor na cana (Fig. F.1.d), devido a maior influência do saldo de radiação de onda curta sobre a média diária de Rn.

$\Rightarrow$ A evapotranspiração é menor sobre a cana (Fig. F.1.k), e a razão de Bowen é maior (Fig. F.1.1). A primeira razão óbvia para este fato é que o dossel da cana não cobre totalmente o solo ao longo do ano e o crescimento foi lento até 160 dias após o corte. Assim as perdas por interceptação da precipitação podem ter contribuído para mais LE no cerrado. Além disso, com menos energia disponível e maior geração de calor sensível (Fig. F.1.j), explica-se a menor evapotranspiração da cana. 
(a)

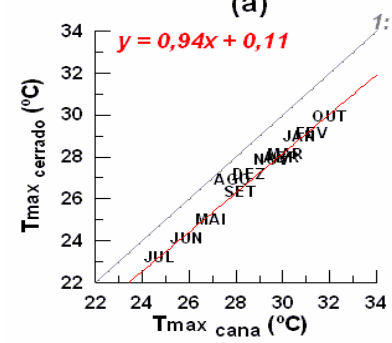

(d)

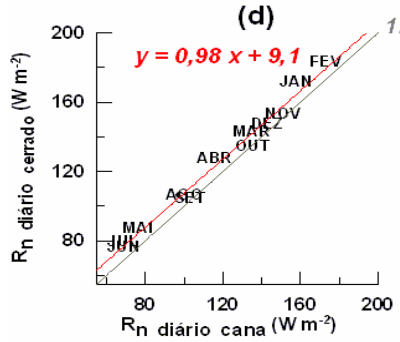

(g)

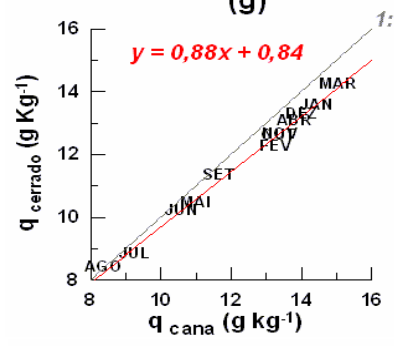

(j)

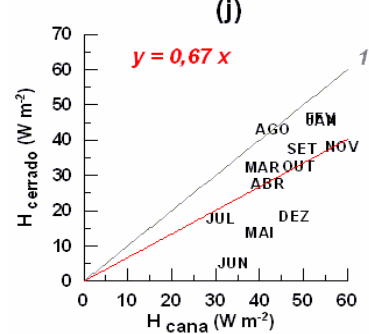

(b)

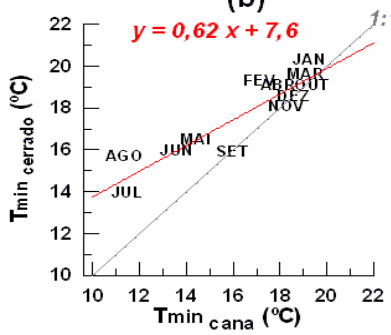

(e)

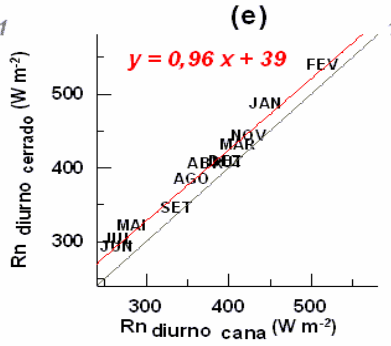

(h)

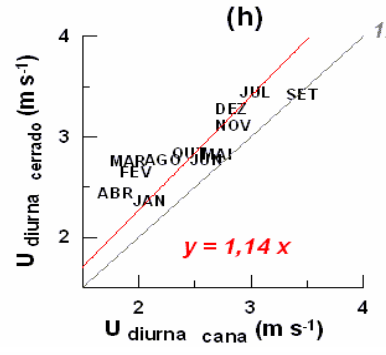

(k)

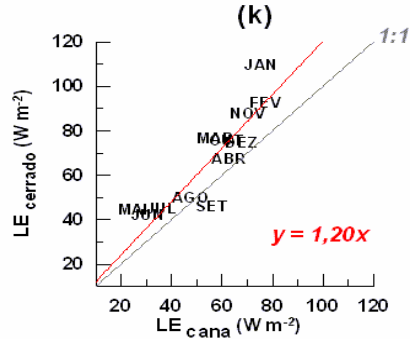

(m)

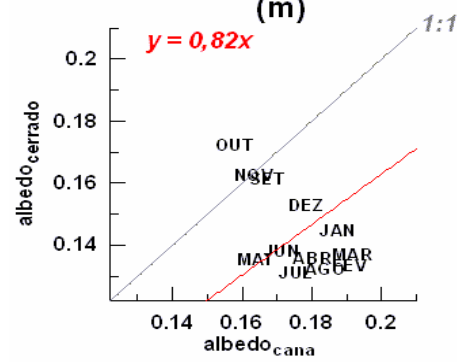

1:1 (c)

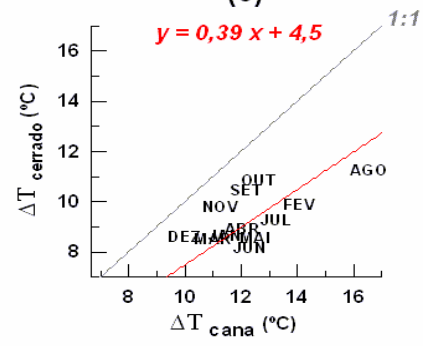

(f)

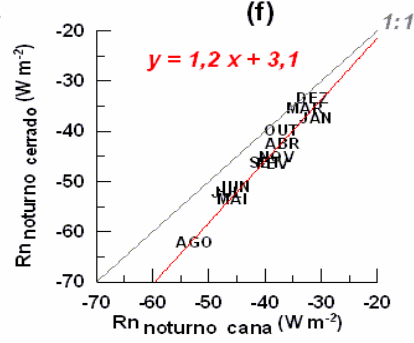

(i)

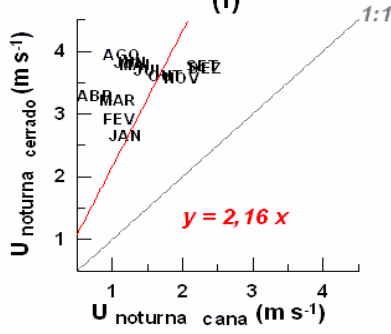

(I)

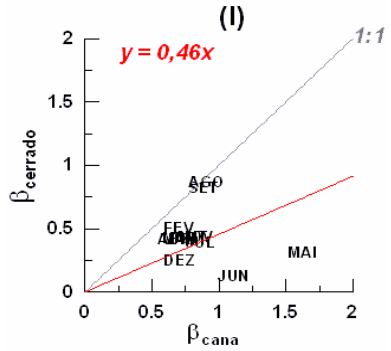

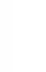




\section{APÊNDICE G CICLOS DIURNOS DOS FLUXOS DE ENERGIA}

A Figura G.1 apresenta a variação dos ciclos diurnos médios do saldo de radiação (Rn), fluxos de calor latente (LE) e sensível (H) e fluxo de calor no solo $(\mathrm{G})$, nos 5 períodos do ano, pré-definidos (seção 2.2), nas três áreas experimentais. No período úmido de 2005 e na transição do período úmido-seco, sobre a cana $\mathrm{Rn}$ foi distribuído quase que igualmente entre LE e $\mathrm{H}$ durante o dia, com máximos destes fluxos entre 150 e $250 \mathrm{Wm}^{-2}$, onde o termo $\mathrm{G}$ foi baixo, atingiu até $\sim 50 \mathrm{Wm}^{-2}$. Naqueles períodos, no cerrado, a radiação foi utilizada em maior parte para a evapotranspiração, que atingiu máximos entre $200 \mathrm{a} 300 \mathrm{Wm}^{-2}$. No período seco as observações de LE foram recorrentemente menores que $\mathrm{H}$, em pequena proporção, o qual atingiu máximos de $\sim 200 \mathrm{Wm}^{-2}$. Sobre a cana, as diferenças de $\mathrm{H}$ e LE foram mais evidentes. Além disso, G mostrou-se um termo importante no balanço de energia da cana, tendo em vista sua magnitude comparável a de $\mathrm{H}$, no período seco e de transição seco-úmido. Neste último período, para o cerrado e eucalipto, observa-se que LE supera os valores de $\mathrm{H}$ ao longo do dia. No período seguinte Rn foi utilizado predominantemente por LE no cerrado e eucalipto. Na cana ainda predominou um certo equilíbrio entre H e LE. Entretanto, as quantidades de energia foram notavelmente diferentes entre as três áreas: observa-se no período úmido de 2006, que LE no eucalipto $\left(\sim 500 \mathrm{Wm}^{-2}\right.$ de pico) supera o LE da cana por um fator de dois, e o LE do cerrado por cerca de $200 \mathrm{Wm}^{-2}$. O fluxo $\mathrm{Rn}$ no eucalipto é em sua quase totalidade disponibilizado para evapotranspiração neste período. Como conseqüência, nota-se uma diminuição das magnitudes de $\mathrm{H}$, maior na cana, decrescendo no cerrado, e reduzindo-se ainda mais no eucalipto. 


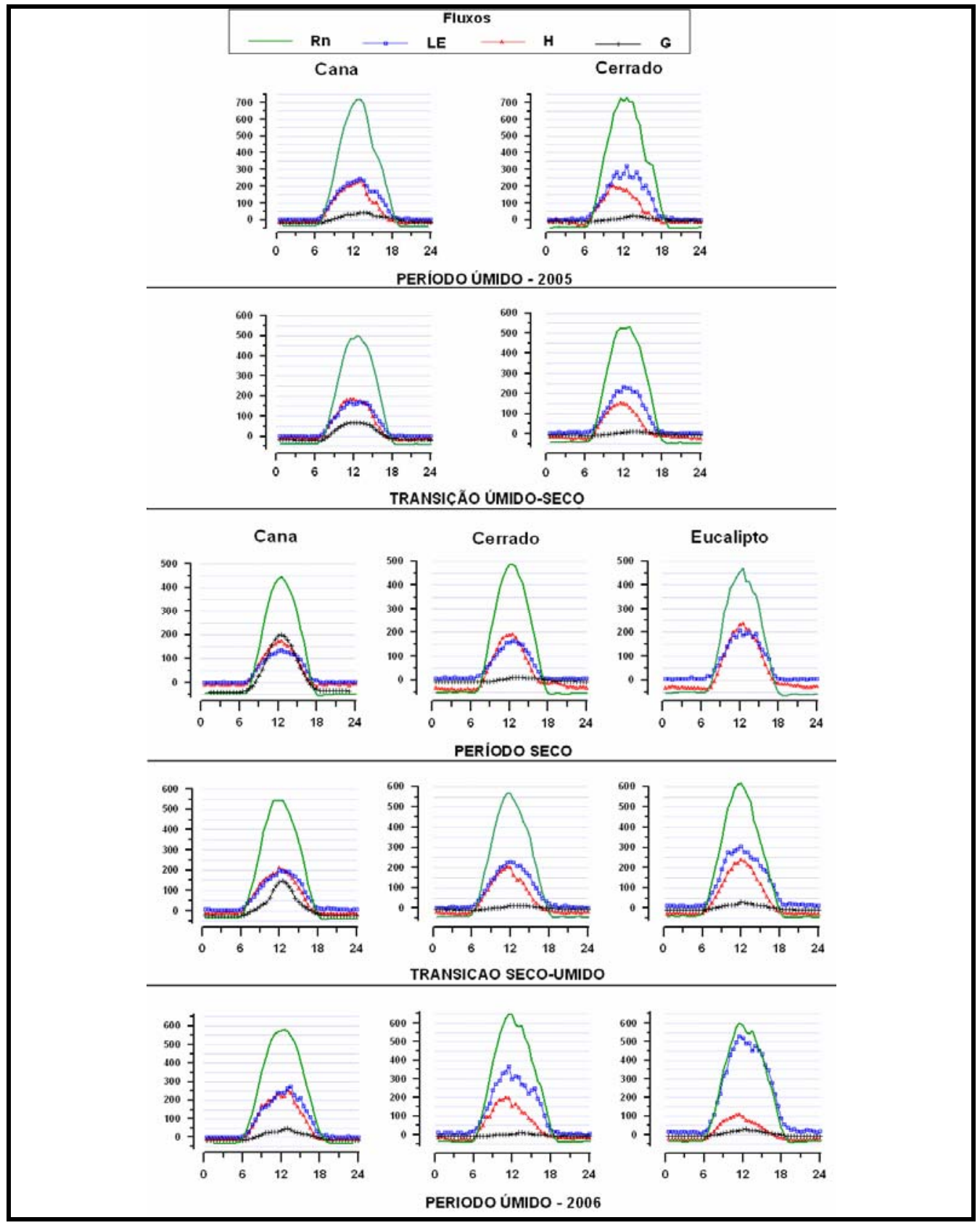

Figura G.1. Ciclos diurnos obtidos a partir dos valores médios de 30 minutos das componentes do balanço de energia (Rn, LE, H, G, todos em $\mathrm{Wm}^{-2}$ ) para o período úmido (Fev) de 2005, transição úmido-seco (Mar - Mai), período seco (Jun - Ago), transição seco-úmido (Set - Nov) e período úmido (Dez - Fev) de 2006. O eixo x corresponde à hora local. 